\title{
POLICY PREFERENCE FORMATION IN LEGISLATIVE POLITICS: STRUCTURES, ACTORS, AND FOCAL POINTS
}

\author{
by \\ Nils Ringe \\ B.A. in Politics and History, Brandeis University, 2001 \\ M.A. in Political Science, University of Pittsburgh, 2003
}

\begin{abstract}
Submitted to the Graduate Faculty of Arts and Sciences in partial fulfillment of the requirements for the degree of
\end{abstract} Ph.D. in Political Science

University of Pittsburgh 


\section{UNIVERSITY OF PITTSBURGH \\ GRADUATE SCHOOL OF ARTS AND SCIENCES}

This dissertation was presented

by

Nils Ringe

It was defended on

April 10, 2005

and approved by

B. Guy Peters, Ph.D., Professor, Political Science, University of Pittsburgh

Jennifer Victor, Ph.D., Assistant Professor, Political Science, University of Pittsburgh

Mark Hallerberg, Ph.D., Associate Professor, Political Science, Emory University

Thomas Bräuninger, Ph.D., Professor, Political Science, University of Konstanz (Germany)

Dissertation Advisor: Alberta Sbragia, Ph.D., Professor, Political Science, University of

Pittsburgh 
Copyright (C) by Nils Ringe

2006 


\title{
POLICY PREFERENCE FORMATION IN LEGISLATIVE POLITICS: STRUCTURES, ACTORS, AND FOCAL POINTS
}

\author{
Nils Ringe, Ph.D. \\ University of Pittsburgh, 2006
}

This dissertation introduces and tests a model of policy preference formation in legislative politics. Emphasizing a dynamic relationship between structure, agent, and decision-making process, it ties the question of policy choice to the dimensionality of the normative political space and the strategic actions of parliamentary agenda-setters. The model proposes that structural factors, such as ideology, shape policy preferences to the extent that legislative specialists successfully link them to specific policy proposals through the provision of informational focal points. These focal points shift attention toward particular aspects of a legislative proposal, thus shaping the dominant interpretation of its content and consequences and, in turn, individual-level policy preferences. The propositions of the focal point model are tested empirically with data from the European Parliament (EP), using both qualitative (interview data, content analyses of parliamentary debates) and quantitative methods (multinomial logit regression analyses of roll-call votes). The findings have implications for our understanding of politics and law-making in the European Union and for the study of legislative decision-making more generally. 


\section{TABLE OF CONTENTS}

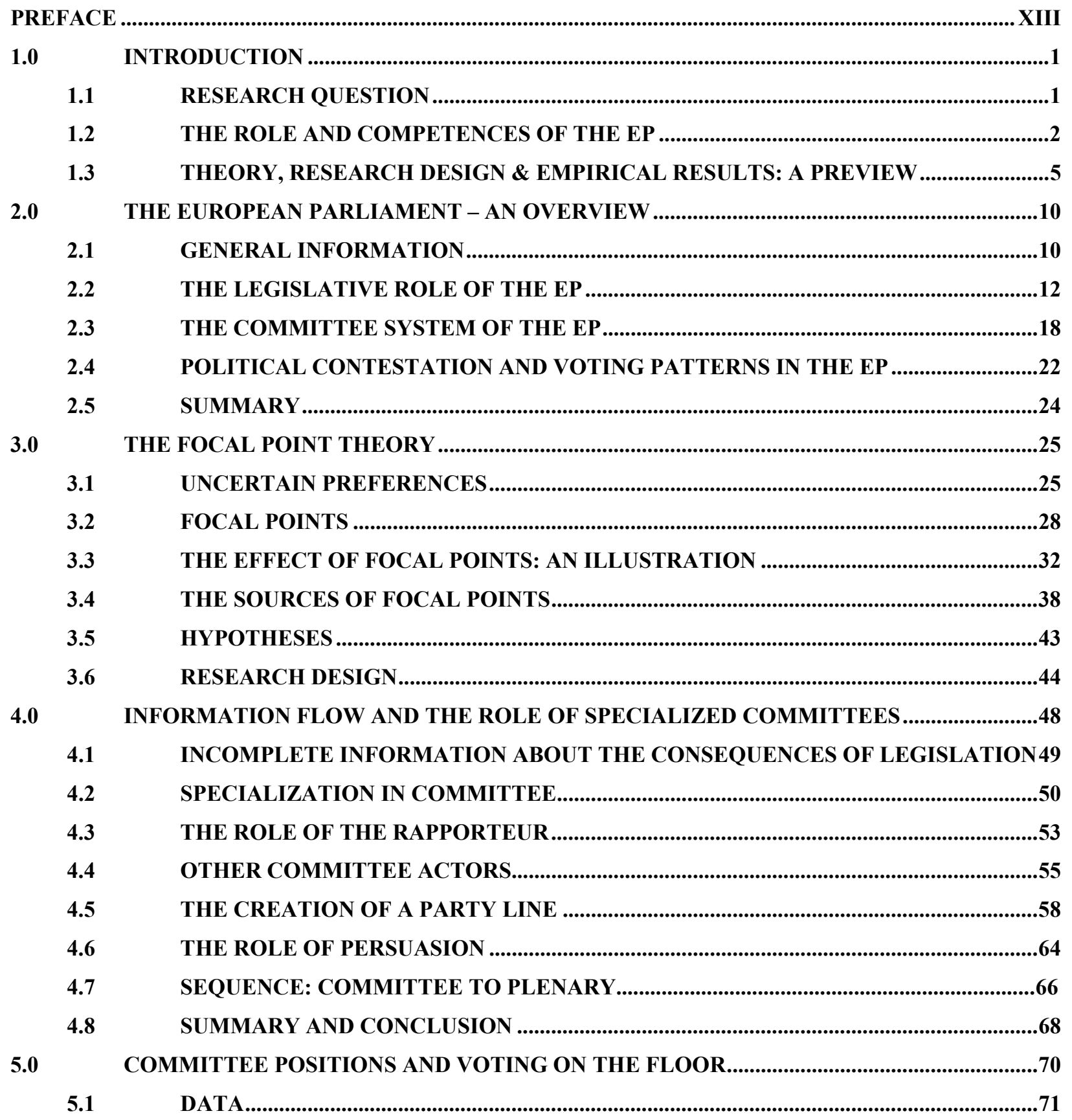




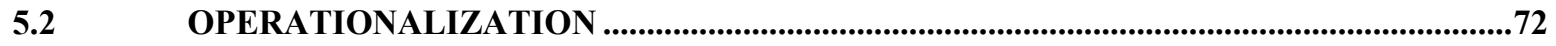

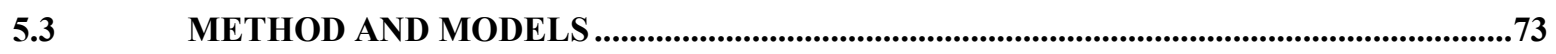

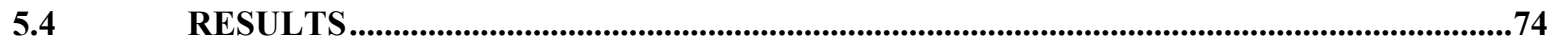

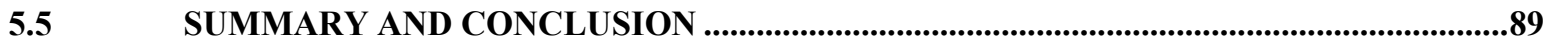

6.0 MECHANISMS OF PREFERENCE FORMATION: CASE STUDIES.........................................92

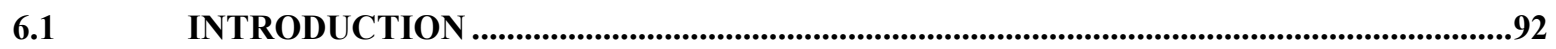

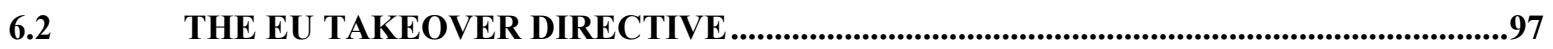

6.2.1 Qualitative Analysis: Focal Points and the Legislative Process..........................................99

6.2.2 Content Analysis...............................................................................................................104

6.2.3 Voting Patterns: The Impact of the Legislative Process on Voting Outcomes..............105

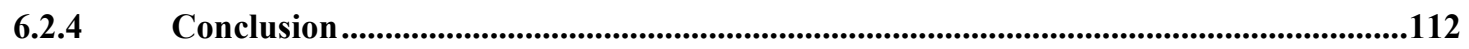

6.3 THE STATUTE AND FINANCING OF EU-LEVEL POLITICAL PARTIES ...................114

6.3.1 Qualitative Analysis: Focal Points and the Legislative Process........................................115

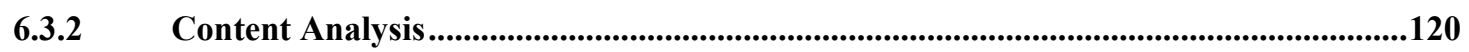

6.3.3 Voting Patterns: The Impact of the Legislative Process on Voting Outcomes..............121

6.3.4 Conclusion ....................................................................................................................................124

6.4 PROPOSALS ON FUEL QUALITY AND EMISSION STANDARDS FOR MOTOR

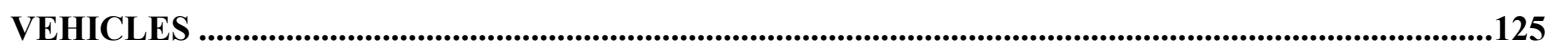

6.4.1 Qualitative Analysis: Focal Points and the Legislative Process......................................127

6.4.2 Content Analysis........................................................................................................................134

6.4.3 Voting Patterns: The Impact of the Legislative Process on Voting Outcomes..............135

6.4.4 Conclusion ...............................................................................................................................139

6IABILITY FOR ENVIRONMENTAL DAMAGE .....................................................140

6.5.1 Qualitative Analysis: Focal Points and the Legislative Process........................................142

6.5.2 Content Analysis.........................................................................................................154

6.5.3 Voting Patterns: The Impact of the Legislative Process on Voting Outcomes..............155

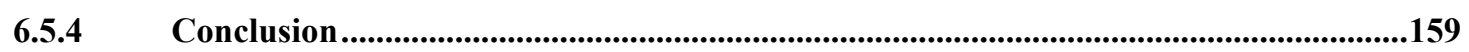

6.6 THE LIBERALIZATION OF PORT SERVICES IN THE EU .............................................161

6.6.1 Qualitative Analysis: Focal Points and the Legislative Process.........................................162

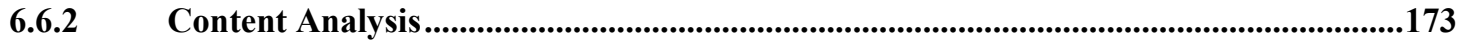

6.6.3 Voting Patterns: The Impact of the Legislative Process on Voting Outcomes..............174

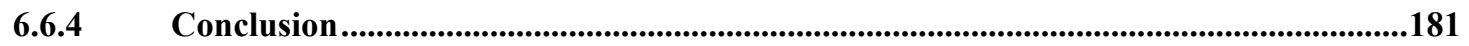

6.7 EUROPEAN UNION CITIZENSHIP AND THE FREE MOVEMENT OF PEOPLE ......183

6.7.1 Qualitative Analysis: Focal Points and the Legislative Process.........................................184

6.7.2 Content Analysis..........................................................................................................................192

6.7.3 Voting Patterns: The Impact of the Legislative Process on Voting Outcomes..............193

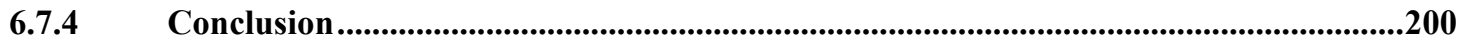




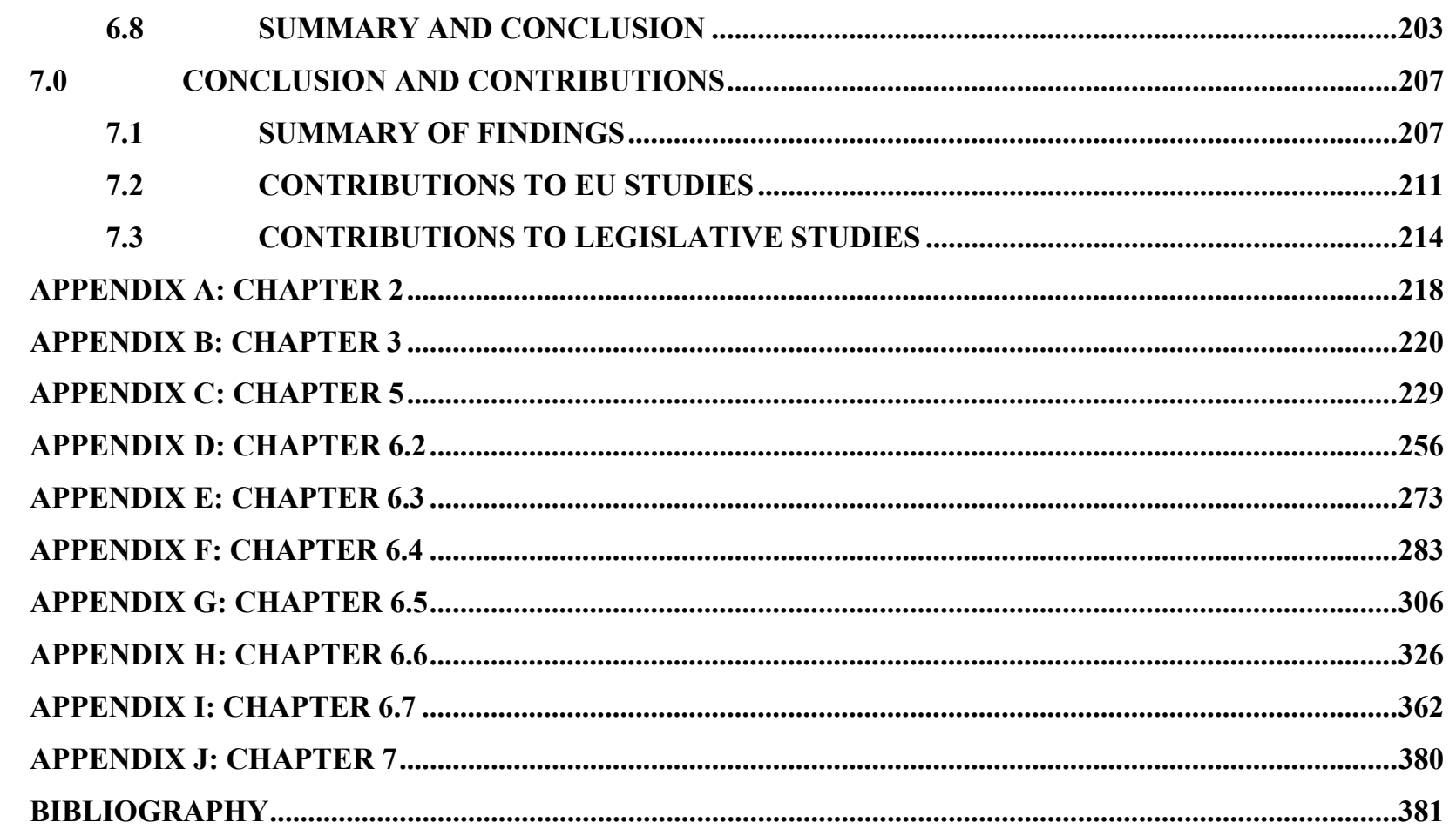




\section{LIST OF TABLES}

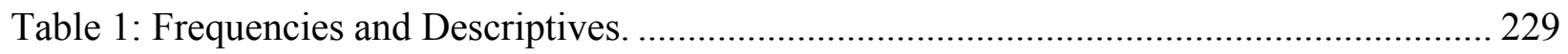

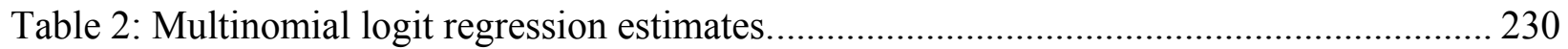

Table 3: Multinomial logit regression estimates excluding "National Party Delegation.”......... 235

Table 4:Multinomial logit regression estimates, Committee subsample 1............................... 248

Table 5: Multinomial logit regression estimates, Environment Committee............................... 249

Table 6: Multinomial logit regression estimates, Legal Affairs Committee. ……..................... 250

Table 7: Multinomial logit regression estimates, Transport Committee. .................................... 251

Table 8: Multinomial logit estimates excl. "Natl. Party Del.," Committee subsample 1.......... 252

Table 9: Multinomial logit estimates excl. "Natl. Party Del.," Environment Committee. ......... 253

Table 10: Multinomial logit estimates excl. "Natl. Party Del.," Legal Affairs Committee........ 254

Table 11: Multinomial logit estimates excl. "Natl. Party Del.," Transport Committee. ............. 255

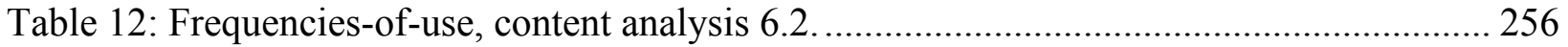

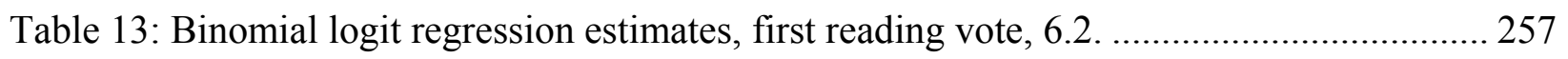

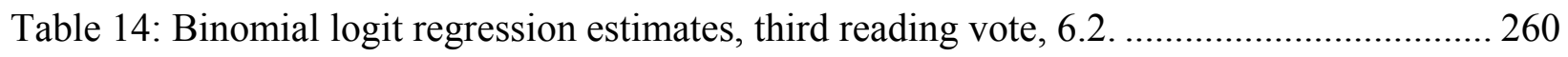

Table 15: Multinomial logit regression estimates, first reading vote, 6.2 ................................ 270

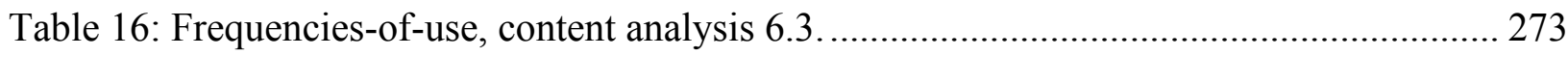

Table 17: Binomial logit regression estimates, first reading vote, 6.3 ................................... 274

Table 18: Multinomial logit regression estimates, first reading vote, 6.3 …………………..... 281

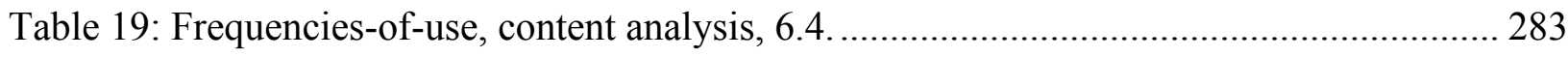

Table 20: Frequencies of vote outcomes by type of capitalism, multinomial logit, 6.4 ............ 283

Table 21: Frequencies of vote outcomes by type of capitalism, binary logit, 6.4 ..................... 284

Table 22: Binomial logit regression estimates, first reading vote, 6.4., 1996/163.................... 284

Table 23: Binomial logit regression estimates, first reading vote, 6.4., 1996/164a.................... 285 
Table 24: Multinomial logit regression estimates, first reading, 6.4. , 1996/163................... 304

Table 25: Multinomial logit regression estimates, first reading, 6.4. , 1996/164a. ................. 304

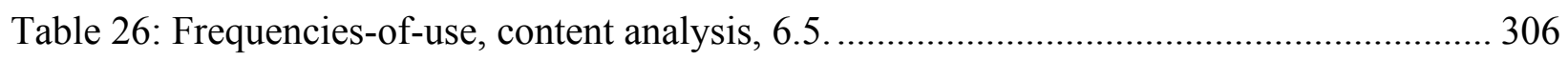

Table 27: Binomial logit regression estimates, first reading vote, 6.5 ................................. 307

Table 28: Multinomial logit regression estimates, first reading vote 6.5 ............................. 323

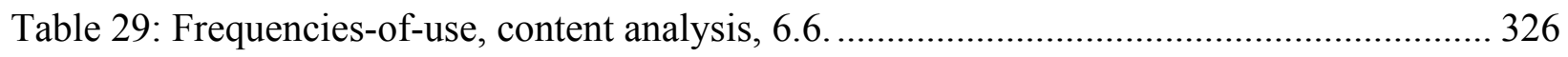

Table 30: Extreme Terminology content analysis, 6.6 ................................................ 326

Table 31: Binomial logit regression estimates, first reading vote, 6.6 ............................... 327

Table 32: Binomial logit regression estimates, third reading vote, 6.6 ................................ 329

Table 33: Multinomial logit regression estimates, first reading vote, 6.6........................... 359

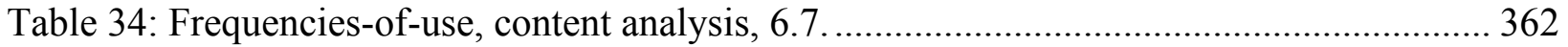

Table 35: Binomial logit regression estimates, first reading vote, 6.7 ................................. 363

Table 36: Binomial logit regression estimates, second reading vote, 6.7. Amend. 4............... 366

Table 37: Multinomial logit regression estimates, first reading vote, 6.7 ............................ 377

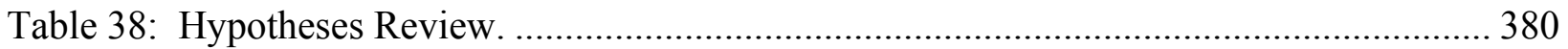




\section{LIST OF FIGURES}

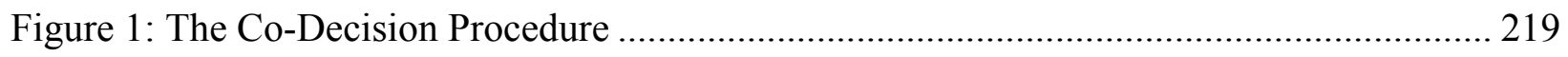

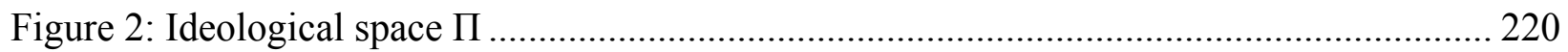

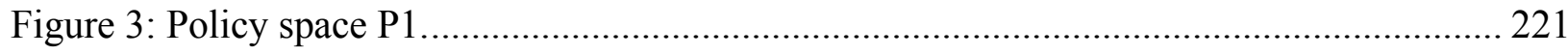

Figure 4: Policy space P1, with indifference curves...................................................... 222

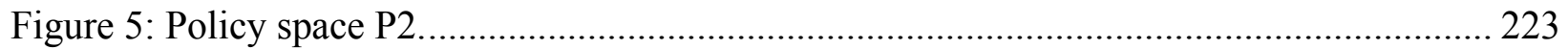

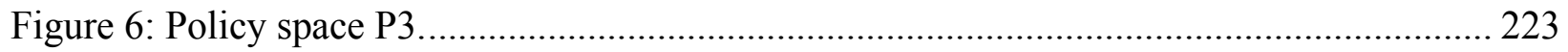

Figure 7: Policy space P1, greater salience of sovereignty-integration dimension, x2 ............ 224

Figure 8: Policy space P1, greater salience of sovereignty-integration dimension, x1, x2, x3. . 225

Figure 9: Policy space P1, greater salience of sovereignty-integration dimension, x1, x2, x3. . 226

Figure 10: Policy space P1, greater salience of Left-Right dimension, x1, x2, x3 ................ 227

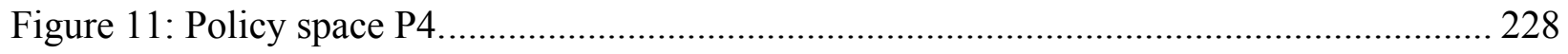

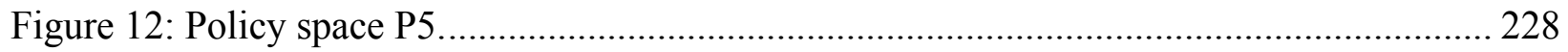

Figure 13: Probabilities of a YES vote, missing cases deleted listwise ................................. 231

Figure 14: Probabilities of a NO vote, missing cases deleted listwise ................................. 232

Figure 15: Probabilities of abstaining when others vote NO, missing cases deleted listwise... 233

Figure 16: Probabilities of abstaining when others vote YES, missing cases deleted listwise. . 234

Figure 17: Probabilities of a YES vote, excl. "National Party Delegation," listwise deletion. .. 236

Figure 18: Probabilities of a NO vote, excl. "National Party Delegation," listwise deletion.... 237

Figure 19: Prob. of abstain. when others vote NO, excl. "Natl. Party Del.," listwise deletion. . 238

Figure 20: Prob. of abstain. when others vote YES, excl. "Natl. Party Del.," listwise deletion. 239

Figure 21: Probabilities of YES vote, Committee subsample 1......................................... 240

Figure 22: Probabilities of YES vote, Environment Committee. ......................................... 241

Figure 23: Probabilities of YES vote, Legal Affairs Committee.......................................... 242 
Figure 24: Probabilities of YES vote, Transport Committee. 243

Figure 25: Probabilities of YES vote when excl. "Natl. Party Del.," Committee subsample 1. 244 Figure 26: Probabilities of YES vote when excl. "Natl. Party Del.," Environment Committee. 245

Figure 27: Probabilities of YES vote when excl. "Natl. Party Del.," Legal Affairs Committee.246 Figure 28: Probabilities of YES vote when excl. "Natl. Party Del.," Transport Committee...... 247

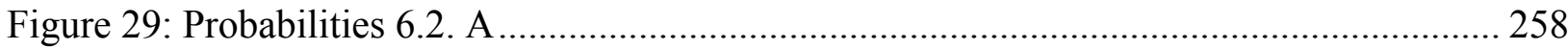

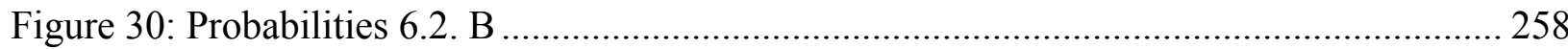

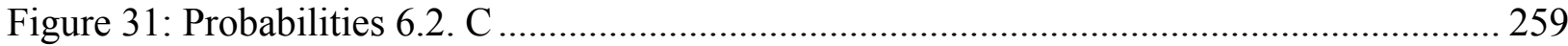

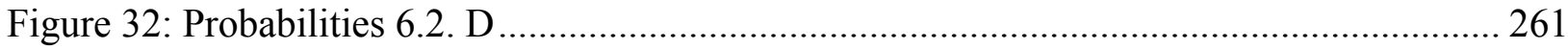

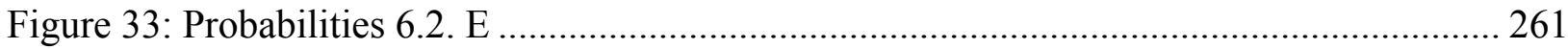

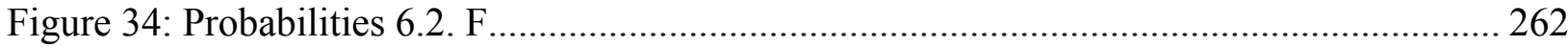

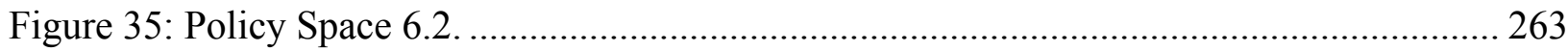

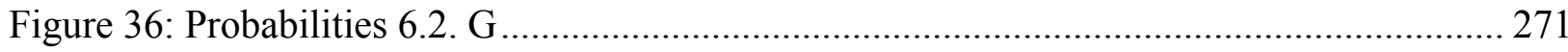

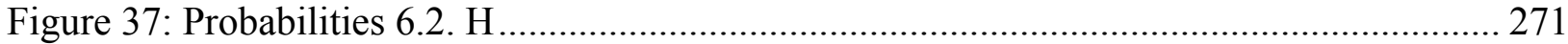

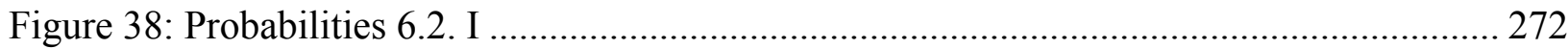

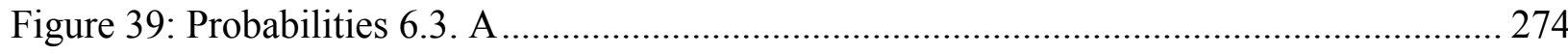

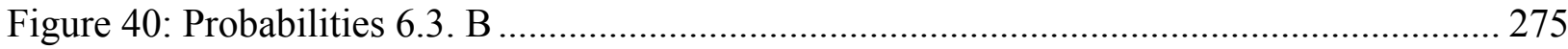

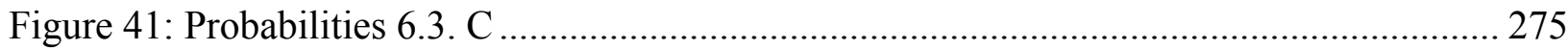

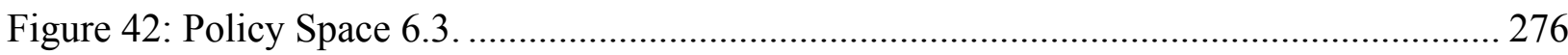

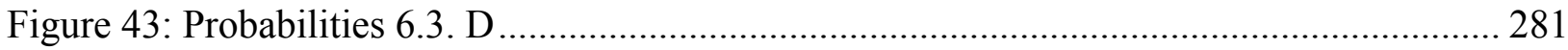

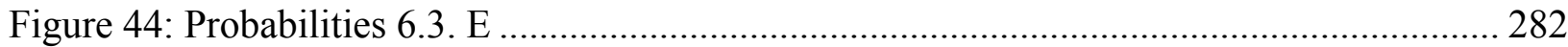

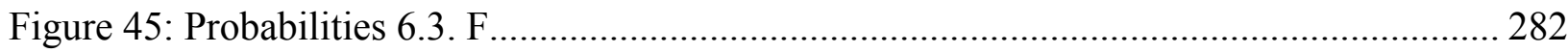

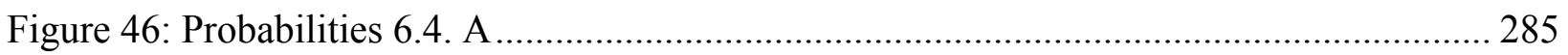

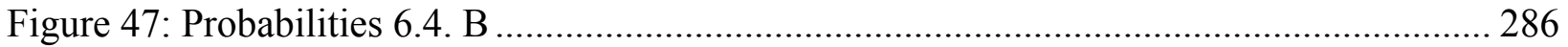

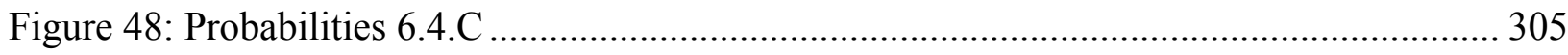

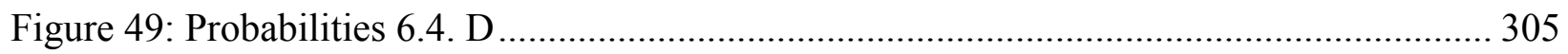

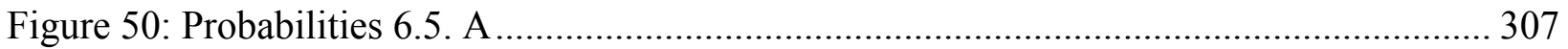

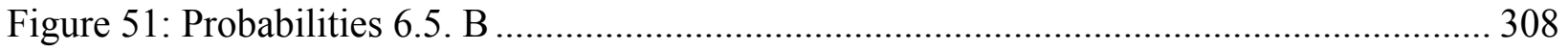

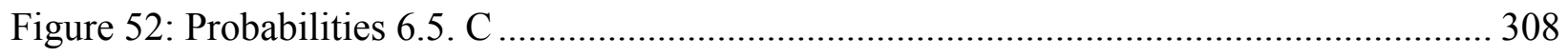

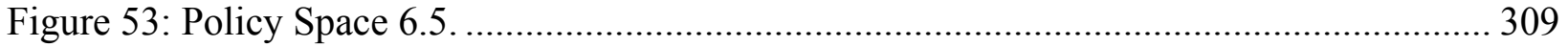

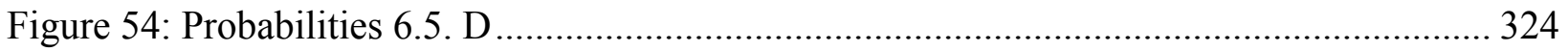




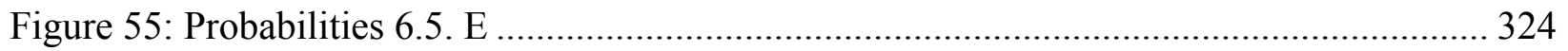

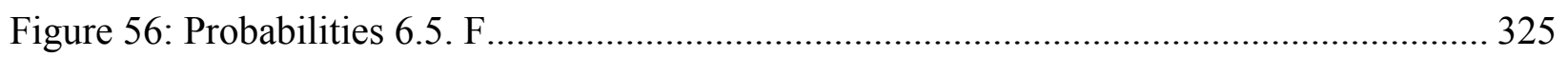

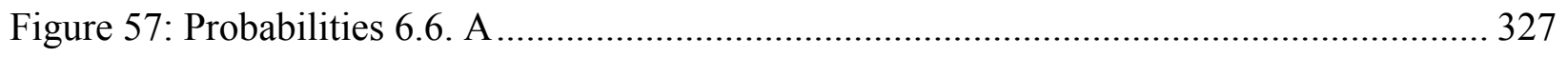

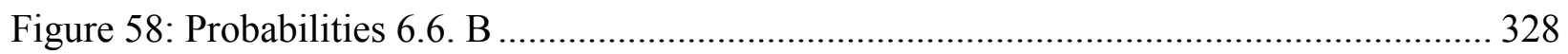

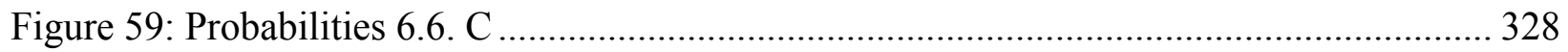

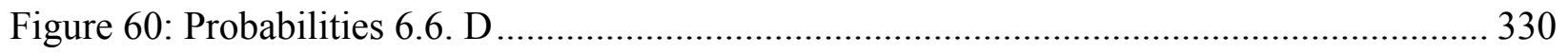

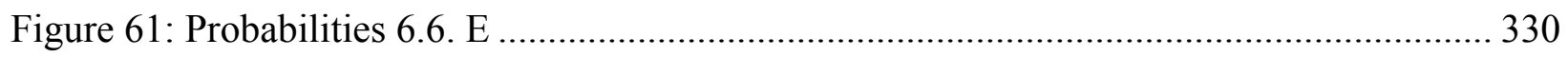

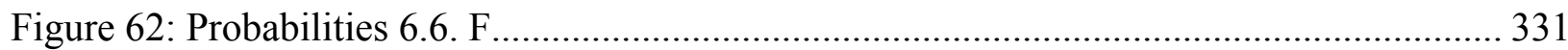

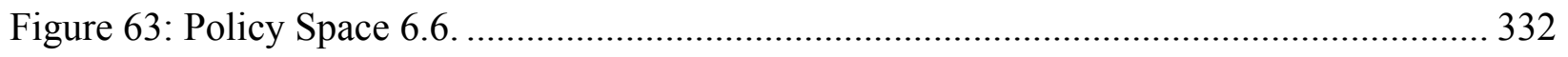

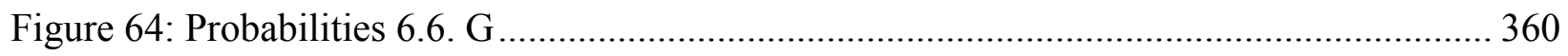

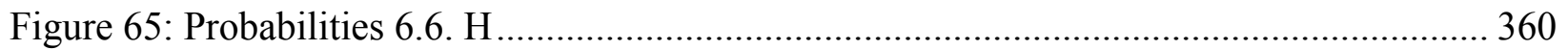

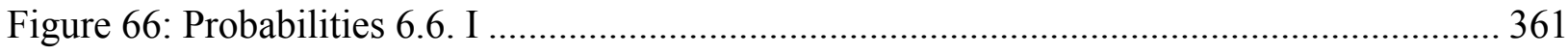

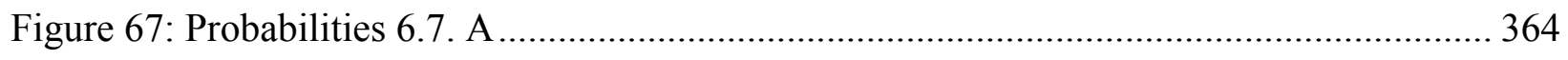

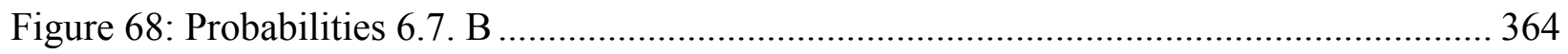

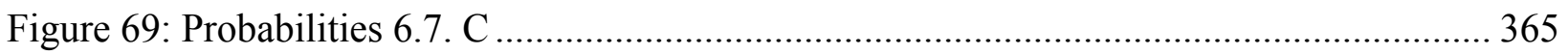

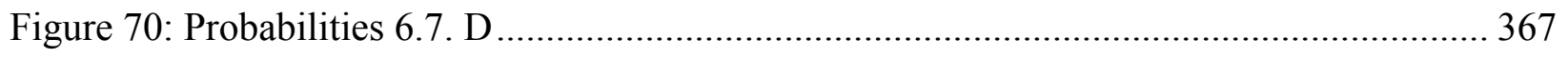

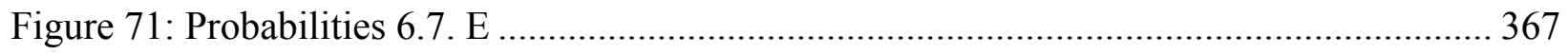

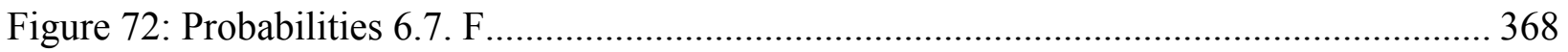

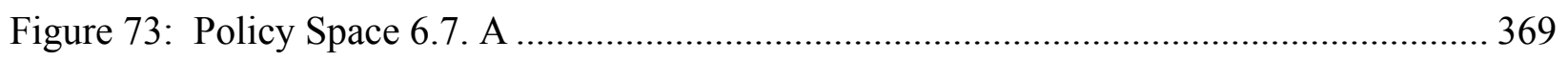

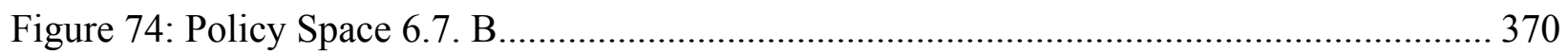

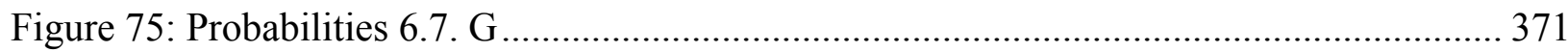

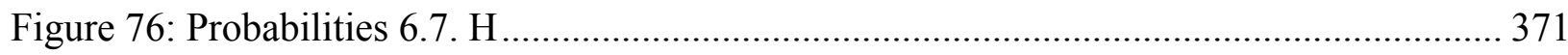

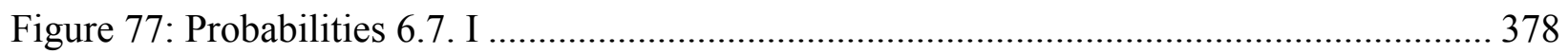

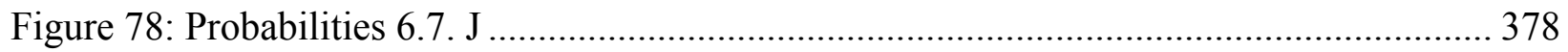

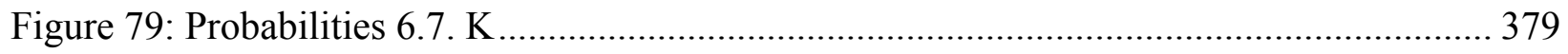




\section{PREFACE}

I am indebted to a great number of people who have contributed to the successful realization of this dissertation. First and foremost, I have to thank the members of my committee, Alberta Sbragia, Mark Hallerberg, Jennifer Victor, Thomas Bräuninger, and Guy Peters, who have provided substantive input without which this dissertation could not have been completed in this form.

In particular, I want to thank Alberta Sbragia and Mark Hallerberg. Their guidance has tremendously influenced my work and has been invaluable in shaping my development as a scholar.

A multitude of people have given me direction, raised concerns, and helped resolve questions along the way. I want to thank Chris Carman, Holger Döring, Steffen Ganghof, Michael Goodhart, Lothar Krempel, Amie Kreppel, Stanley Lemeshow, German Lodola, Juan Carlos Rodriguez-Raga, Sebastian Saiegh, Michael Shackleton, Daniel Thomas, Antoine Yoshinaka, three referees from the American Journal of Political Science, and the participants of the 2006 European Governance Conference at Emory University's Halle Institute for Global Learning. I want to especially thank Jason Koepke, who has read a number of drafts over time,

given important comments and suggestions, and provided much appreciated encouragement and friendship.

In addition, I would like to thank my respondents in the European Parliament, the European Commission, the Council of Ministers, and a number of Permanent Representations to the EU. I appreciate their time and generosity in meeting with me and providing captivating opinions and insights into the inner workings of the European legislative process. 
I received much appreciated funding and research support from the European Union Center at the University of Pittsburgh, the Max Planck Institute for the Study of Societies in Cologne, Germany, the National Science Foundation, and the Andrew Mellon Foundation.

I would like to acknowledge the help I have received from Tom Allen, Emily Boyle, Adina Lemeshow, Robert Victor, and the administrators in the Political Science Department at the University of Pittsburgh.

George Ross, Judy Hanley, and Carmen Sirianni have been most generous in providing me with a place to work during the summer and fall semesters 2005. Writing in a university environment, despite my absence from Pittsburgh, considerably increased my productivity and the quality of my work.

My graduate school experience at Pitt was enjoyable and rewarding thanks to the friendship and support I received from my fellow graduate students. We worked hard and had a good time-I hope it stays this way.

Sarah Halpern-Meekin's insights, critiques, and suggestions are challenging and absolutely indispensable. I look forward to a lifetime of exchanging ideas.

Finally, I want to express deep gratitude to my parents, who have always backed my endeavors both emotionally and financially. Their generosity and support cannot be overestimated, especially considering the genuine sacrifices they made for my pursuit of a firstclass education. For this reason, I dedicate this dissertation to them. 


\subsection{INTRODUCTION}

\subsection{RESEARCH QUESTION}

How do the general political preferences of legislative decision-makers translate into attitudes

toward specific policies? Despite the uncertain relationship between political intentions and consequences, much of the existing literature on policy choice in legislative politics assumes that the conversion of ideological and constituency interests into policy preferences is direct and automatic, i.e., that preferences are fixed and exogenous and simply constitute an "input" into the legislative decision-making process. This approach assumes, implicitly or explicitly, that some kind of "objective interest" underlies the choices of political decision-makers.

The problem with this conceptualization is that actors may have multiple "objective interests," and, as a result, might perceive different and potentially competing policy alternatives as desirable. The translation process of objective interests into actual policy choices may be complicated at two levels. First, a legislator can pursue several objectives simultaneously, which may be at odds with one another. For example, a pro-environmentalist might have to trade off some of his "greenness" in order to represent the interests of his constituents, or he might have concerns about the economic and social impact of environmental legislation in addition to his interest in conservation. Additionally, the legislator may lack "cause-and-effect knowledge" regarding the effects of the legislation: he might not have sufficient information to judge how his interests would be met upon the implementation of the policy. How does he assume a position 
toward the policy proposal under these circumstances? The translation of objective interests into actual policy choice may thus be anything but a straightforward process, as it often involves complex decisions under conditions of competing interests, substantive uncertainty, and asymmetric information.

This dissertation challenges the assumption of fixed and exogenous policy preferences. Instead, it seeks to determine how stable preferences concerning the outcomes of policy choice in legislative politics shape the positions individual legislators take toward particular policy proposals, especially under conditions of uncertainty and asymmetric information. Most importantly, the dissertation considers how individual-level ideal points on the primary dimensions of political contestation translate into actual legislation. It constitutes an effort to go beyond the question of what ought to be the positions of different political actors toward a specific policy proposal, and involves considering how legislators' own perceptions of their

political interests are translated and aggregated into policy choice. This approach ties the question of policy choice to the dimensionality of the normative and cognitive political space, while explicitly taking account of the strategic actions of parliamentary agenda-setters. Structure, actors, processes, and their interaction are thus taken seriously in explaining policy choice. The propositions of the decision-making model advanced here are tested empirically by analyzing policy choice in the European Parliament (EP).

\subsection{THE ROLE AND COMPETENCES OF THE EP}

The EP comprises the legislative branch of the European Union's (EU) institutions together with the Council of Ministers, which consists of ministers of the national governments of the EU 
member states. Since the most recent wave of enlargement, the EP has 732 members representing 455 million EU citizens from 25 member states. Members of the EP (MEPs) sit in transnational political groups, rather than national delegations. The two largest groups are the European People's Party (EPP, which is made up of conservative and Christian-Democratic parties), and the Party of the European Socialists (PES, comprising Europe's Social-Democrats).

Over the past two decades, the EP has evolved from a mere consultative institution into an authoritative and assertive actor in the political and institutional framework of the European Union. While it cannot initiate legislation, the EP has the power of amendment and veto in most policy areas. ${ }^{1}$ In addition to its legislative role, the EP approves the appointment of the European Commission, which it can also dismiss with a vote of censure, and it ratifies the EU budget, except on agricultural price supports and regional development spending.

While the right to initiate legislation lies with the European Commission, most proposals for EU law must receive the approval of both EP and Council. In this sense, the two institutions resemble the upper and lower houses in traditional bicameral legislatures. The legislative powers of the EP are restricted in some policy areas, but about three-quarters of EU legislation are covered by the co-decision procedure, under which the EP can reject legislation outright without the possibility of member state governments overturning this decision. This makes the EP an equal partner with the Council in most important areas of legislation, and the EP has proven very successful in shaping legislation: more than 80 percent of its amendments ultimately become law (Kreppel 2005: 4).

As the powers of the EP have increased over the course of the last twenty years and as the institution has grown increasingly assertive, the amount of literature on the politics of the

\footnotetext{
${ }^{1}$ In some high-profile areas, such as the Common Agricultural Policy, the EP still only possesses consultative powers.
} 
European Parliament has risen substantially. One of the most prevalent strands of this literature focuses on identifying the primary dimensions of political contestation in the European Parliament, i.e., the structure of the political space underlying policy choice. It examines whether political contestation in the EU is based on one, two, or more underlying dimensions (Hix and Lord 1997; Hooghe and Marks 1999, 2001; Hix 1999b; Marks and Wilson 2000; Marks and Steenbergen 2002; Gabel and Hix 2002; Hooghe, Marks and Wilson 2002). Analyses of roll-call votes in particular have found that policy conflict in the EP is principally characterized by two tangible and substantively important dimensions. ${ }^{2}$ The first is the traditional left-right ideological divide, which explains the vast majority of the votes (Noury 2002; Hix, Noury, and Roland 2005). ${ }^{3}$ A second dimension, evident to a lesser degree, is a sovereignty-integration dimension, ranging from less to more support for the European integration process (Hix 2001; Noury 2002; Noury and Roland 2002; Hix, Noury and Roland 2005). ${ }^{4}$

The existence and significance of these two dimensions has also been demonstrated in analyses of the European party federations' election manifestos (Hix, 1999; Gabel and Hix, 2002) and MEP surveys (Thomassen, Noury, and Voeten 2004). Most recently, Voeten (2005) compared roll-call voting behavior in the European Parliament with the preferences expressed by legislators in the 1996 Members of European Parliament Survey. The results of this analysis confirm the significant impact of low-dimensional ideological competition on the behavior of

\footnotetext{
${ }^{2}$ The existence of these two dimensions of EU politics has also been confirmed empirically in the positions national parties take toward Europe (Marks, Wilson and Ray 2001; Aspinwall 2002) and in the election manifestos of the European party federations (Hix 1999b; Gabel and Hix 2002).

${ }^{3}$ The Left-Right dimension is a summary of two socio-political or socio-economic value dimensions (Finer 1987; Hix 1999b; Inglehart and Flanagan 1987). First, it refers to the extent of desired intervention in individual social and political relations for a collective good; second, it refers to how far there should be intervention in individual economic relations.

${ }^{4}$ The sovereignty-integration dimension, sometimes labeled the integration-independence dimension, implies that the European integration process creates a center-periphery divide between those actors or groups who see their identity and interests as threatened by the integration process and those whose identity and interests are protected (Hix 1999b).
} 
MEPs. Voeten also fails to find support for the suggestion that gate-keeping institutions, such as party-group leaders, select issues strategically for roll-call votes, thus artificially reducing the dimensionality of the observed policy space. He does, however, suggest that the relevance of a third dimension may have been underestimated in previous studies, namely that of a libertariantraditional (Thomassen, Noury, and Voeten 2004) ${ }^{5}$ or "new politics" dimension (Hooghe, Marks and Wilson 2002). ${ }^{6}$ This importance of this dimension has not been demonstrated in statistical analyses, however, and it does not easily lend itself to the individual-level quantification necessary for the analyses below. The dimension is also highly correlated with the Left-Right dimension (Hooghe, Marks and Wilson 2002). Finally, a recent analysis on the basis of expert surveys identifies two orthogonal dimensions as the basis of party group positions: one consisting of the classic left-right social and economic issues, and the other related to the powers and scope of EU institutions (McElroy and Benoit 2005). For these reasons, this analysis assumes the importance of two primary dimensions of conflict. ${ }^{7}$

\subsection{THEORY, RESEARCH DESIGN \& EMPIRICAL RESULTS: A PREVIEW}

One serious shortcoming of the literature on the dimensions of conflict in the EP is its static nature. While providing important insights into the underlying structure of political competition in the EP, it fails to take account of the dynamic character of decision-making processes. Most importantly, the existing literature assumes (at least implicitly) that the policy choices made on

\footnotetext{
${ }^{5}$ This libertarian-traditional dimension consists of moral issues (e.g. abortion), the issue of immigration, and issues in the domain of law and order (Thomassen, Noury and Voeten 2004).

${ }^{6}$ This new politics dimension ranges from "green/alternative/libertarian" (GAL) to "traditional/authoritarian/nationalist" (TAN) (Hooghe, Marks and Wilson 2002).

${ }^{7}$ The theoretical model advanced and tested in this dissertation could accommodate a new two-dimensional spatial structure as well one or more additional ideological dimensions, however. For details, see Chapter 3 below.
} 
the basis of the dimensional positions of individual parliamentarians are predetermined: their positions translate automatically and directly into choices and outcomes. Seeking to qualify this overly parsimonious explanation of policy choice, this dissertation attempts to specify the conditions under which ideology shapes decision-making processes and outcomes.

Focusing on the interaction of structure, process, and actors in shaping policy choice, this dissertation presents a model of decision-making that views the translation of general interests into policy preferences as an indirect process: it is mediated by the degree to which strategic legislative specialists on the responsible EP committees successfully link normative and ideological preferences to specific policy proposals through the provision of focal points. These focal points are short-hand devices for communicating information. They shift attention toward particular aspects of a legislative proposal, thus helping to classify and evaluate its perceived content and consequences. By shaping the process of deliberation, focal points may serve as a means to establish mutually acceptable general positions toward a policy proposal, thus providing a common theme around which policy coalitions can form. As the basis for the aggregation of individual-level positions toward the proposal, focal points critically influence policy choice.

To test the applicability of the focal point model, the study relies on roll-call vote data that is analyzed in a multinomial logit regression framework, a simple content analysis of parliamentary debates, and a series of 80 interviews with members of the European Parliament and parliamentary officials, as well as a small number of representatives from other EU institutions. This data provides solid support for the propositions of the model. The interview data demonstrates that specialized committee members constitute the primary providers of 
information to EP legislators not directly involved with a given legislative proposal. ${ }^{8}$ These "backbenchers" often lack detailed information about the content and consequences of the proposal, meaning that they have to rely on a handful of committee experts whose judgment they trust. ${ }^{9}$ The positions of these committee experts thus serve as the basis for the positions of the EP backbenchers. Much depends, however, on the configuration of involved actors, their reputations, and their interaction. Consequently, processes and outcomes are uncertain and cannot be predicted a priori.

The analysis of the roll-call vote data shows that backbenchers indeed follow their committee representatives when voting in plenary. Specifically, the analysis reveals that MEPs are most likely to follow their national party colleagues, if they actually have a national party representative in the responsible committee. This is not the case more than 40 percent of the time, however, meaning that in the majority of cases, MEPs follow the representatives of their EP party group when voting on the EP floor. National affiliation, in contrast, barely matters when predicting plenary votes on the basis of the preceding committee vote.

The results also demonstrate that MEPs compare the positions of their different representatives on the committee, that is, committee members who share their national affiliation, transnational party group affiliation, or national party affiliation. When choosing their own positions toward a policy proposal, members "triangulate" the information they receive, in particular from their party group and national delegation representatives. When these positions

\footnotetext{
${ }^{8}$ This study distinguishes between policy experts who possess the specialized knowledge and information to objectively judge the content and consequences of specific legislative proposals and the majority of MEPs who do not possess this profienciency. It is concerned with the determination of policy preferences of this latter group.

${ }^{9}$ Note that the term "backbencher" is used throughout to describe those members of the EP not directly involved in the deliberation and negotation concerning a particular policy proposal. This term is not meant to imply a lack of proficiency, but rather describes those MEPs who are making decisions on legislation which is outside the realm of their legislative specialization.
} 
diverge, the resulting vote in plenary is quite uncertain, while a shared common position means that the probability of a backbencher voting accordingly in plenary is almost assured.

The detailed investigation of a series of legislative proposals from different policy areas demonstrates that political processes and outcomes differ depending on how a legislative proposal is presented by committee specialists in relation to the two dominant ideological dimensions in the EP, the left-right divide and the sovereignty-integration dimension. Strategically deployed focal points influence the variable interpretation of what the issue at hand is "all about," thus shifting policy preferences during the process of parliamentary deliberation. When an issue is presented as a left-right issue, for example, the outcome of a given policy making process can be fundamentally different than if the same issue is explicitly linked to the process of European integration. This can make or break a legislative proposal, with important consequences across the EU member states.

This dissertation contributes to three strands of literature. In the realm of European Union studies, it adds to our knowledge of law-making in the EU and advances our understanding of political contestation and voting behavior in the European Parliament. It also makes a more general contribution to the study of legislative decision-making by specifying the conditions under which ideology structures policy choice. It emphasizes the importance of normative dimensions of collective action, while stressing the conscious interaction of these structural elements with distinctly strategic considerations in the legislative process: the strategic provision of focal points is constrained by the normative and political context within which the decisionmaking process takes place. Within these constraints, however, focal points serve as intervening variables linking general ideological predispositions with specific policy proposals. Finally, at the most general level, this research contributes to the study of preferences and preference 
formation, which have been examined widely in the research on policy choice, by questioning the conceptualization of preferences as exogenous inputs into decision-making processes. 


\subsection{THE EUROPEAN PARLIAMENT - AN OVERVIEW}

\subsection{GENERAL INFORMATION}

The European Parliament (EP) plays a critical role in European Union (EU) politics. During the course of the past twenty years, the previously consultative "talking-shop" has gained extensive authority, not least in terms of legislative power, which has increased dramatically over time. Today, the EP is an equal partner of the Council of Ministers, where the EU member states are directly represented by ministers of the national governments, in most important areas of legislation.

Members of the European Parliament (MEPs) have been elected every five years since 1979. ${ }^{10}$ A large number of MEPs have extensive political experience. For example, 28 percent of MEPs in the $1999-2004$ parliamentary term (the $5^{\text {th }}$ EP) had national parliamentary experience, a number that increased to 37 percent in the current legislature (the $6^{\text {th }}$ EP). Often, these MEPs held important posts, such as Speaker or Deputy Speaker. 10.2 percent in the $5^{\text {th }}$ EP and 16 percent in the $6^{\text {th }}$ EP have national ministerial experience, and many MEPs hold leadership positions in their national parties. Six MEPs in the $5^{\text {th }}$ EP and eleven in the $6^{\text {th }}$ EP are former heads of state or prime ministers, and numerous members have previously served as regional

\footnotetext{
${ }^{10}$ This chapter relies heavily on Corbett et al. (2005) for descriptive information of the EP and its members, committees, and procedures.
} 
presidents, state or regional prime ministers, members of the European Commission, or held other posts in regional and municipal government (Corbett et al. 2005: 48-54).

MEPs sit in transnational party groups that correspond to the traditional European "party families." Currently, there are seven such party groups uniting the existing national parties along the lines of the traditional party "families." The two largest party groups are the center-right European People's Party (EPP-ED, consisting of Conservatives and Christian-Democrats) and the center-left Party of the European Socialists (PES, comprising Europe's Social-Democrats). Smaller groups are the Alliance of Liberals and Democrats for Europe (ALDE, previously ELDR), The Greens/European Free Alliance (Greens/EFA), the Group of the United European Left/Nordic Green Left (GUE/NGL), the Independence/Democracy Group (Ind/Dem), and the Union for Europe of the Nations (UEN).

Most members tend to follow the collective position, or "party line," of their party groups, but party discipline is less pronounced in the EP than in most national parliaments. A primary reason for this reality is the absence of a stable government-opposition dynamic, since there is no European-level government based on the partisan majorities in the EP. Hence, there is no traditional executive reliant on the support of a cohesive parliamentary majority. Secondly, party groups lack the sanctions available to national parliamentary parties against members deviating from the party line. They may be able to use the carrot-and-stick approach of granting or refusing committee membership or the responsibility for drafting legislative reports (see McElroy 2003, Kreppel 2002: 198-202), but these enforcement mechanisms are relatively weak. Most importantly, the ultimate sanction of excluding dissenting members from the party list in the next election is not available to EP party groups, as the power of nomination lies with the national parties. A third and final reason for a lower level of party discipline in the EP lies in the 
diverse makeup of the party groups, which consists of national party delegations representing a distinct degree of national, regional, or sectoral interests (Corbett et al. 2005: 104). While not frequent, it is not uncommon for national delegations or other subsets of MEPs to opt out of the party line with regard to particular votes.

National delegations play an important part in the structure of the EP party group, and most of them even have their own officers and staff (which tend to be quite small, however). National party delegations constitute the direct link between national parties and EP party groups, meet collectively as subsets of the party group, and often assume a common position and act as a cohesive bloc in party group discussions. Moreover, positions within the party groups are distributed on the basis of the sizes of the national party delegations that comprise them, and as explained above, it is the national parties that draw up electoral lists in EP elections. As a result, especially larger national delegations are in a very potent bargaining position within their EP

party groups (Raunio 1996: 72). In rare instances, national party delegations receive specific voting instructions from their national leadership, but most of the time they act as their own principals while engaging in a continuous exchange of views and information with their national party leaderships. In general, however, there is no single leadership group that fully controls the activities and vote choices of individual MEPs (Kreppel 2005: 12).

\subsection{THE LEGISLATIVE ROLE OF THE EP}

While the right to initiate legislation lies with the Commission, most proposals for EU law must receive the approval of both the EP and Council. In fact, a "draft directive" introduced by the Commission is indeed a draft (Corbett et al. 2005: 9), with MEPs and members of the Council 
going through the proposal sentence by sentence. After much rewriting and amending, the positions of the two institutions must be reconciled. In practice, this means that a large numbermore than 80 percent (Kreppel 2005: 4)—of amendments tabled by MEPs ultimately become law. Hence, individual MEPs play a substantial role in creating legislation, "a classical parliamentary function almost forgotten by some national parliaments" (Corbett et al. 2005).

The extent of the EP's legislative powers depends on the decision-making procedure applicable to particular pieces of legislation, and only with the recent introduction of the "codecision procedure" through the Treaties of Maastricht, Amsterdam, and Nice, has the EP become a genuine co-legislator. Co-decision now covers the majority of policy areas and has become the de facto "normal" decision-making procedure.

Co-decision is one of four decision-making procedures governing the EP's legislative role, depending on the policy area of the proposal in question. The other three are the consultation procedure, the cooperation procedure, and the assent procedure. The consultation procedure was the EU's main legislative procedure historically. It is used much less today, but remains applicable to important institutional and budgetary matters, as well as certain aspects of citizens' rights and justice and home affairs. ${ }^{11}$ Under this procedure, the EP gives its consultative opinion on a Commission proposal, but the Council is not bound by the EP's position.

While the EP provides its opinion only once under the consultation procedure, the cooperation procedure provides for two parliamentary readings. That is, after consideration by the Council, the text is referred back to the EP for a second reading at which the EP may approve the text, reject the text, or propose amendments. The Commission may incorporate any additional amendments into the text, which can then only be modified by unanimity in the

\footnotetext{
${ }^{11}$ For more details on all four procedures, please refer to Corbett et al. 2005:196-239.
} 
Council. Amendments not supported by the Commission also require unanimous support to be adopted in the Council. Hence, under the cooperation procedure the EP's role is no longer merely consultative.

Under the assent procedure, the Council must attain the EP's assent before certain important decisions can be taken. While the EP thus has the power to accept or reject a proposal, with a rejection being final, it does not have the power of amendment. The assent procedure applies today to very few issue areas, including decisions with regard to sanctions against EU member states in the case of "serious and persistent breach of fundamental rights" (Article 7), aspects of EU central banking, structural and cohesion funds, ${ }^{12}$ and international agreements.

Finally, the co-decision procedure is the primary legislative procedure by which European laws are created today. ${ }^{13}$ Co-decision provides the EP with the power to adopt legislation jointly with the Council of Ministers. It makes the two institutions equal partners in the legislative process by requiring them to agree on an identical text before a proposal becomes law. A conciliation committee featuring an equal number of members from $\mathrm{EP}$ and Council is set up when the two bodies cannot reach agreement after two parliamentary readings. This committee seeks to negotiate a compromise text subject to approval by both institutions. Under co-decision, EP and Council have the power to reject a proposal either at second reading or following conciliation, causing the entire procedure to lapse and the proposal to fall. The Commission may also withdraw its proposal at any time. Co-decision was introduced in the 1993 Maastricht Treaty, but its scope was expanded considerably by the Treaties of Amsterdam (1997)

\footnotetext{
12 These funds are allocated by the EU to support the poorer regions of Europe and to integrate European infrastructure, especially in the transport sector.

${ }^{13}$ The volume of co-decision dossiers has increased dramatically just during the last few years. While only 166 codecision acts were adopted during the 1994-1999 legislative term, this number increased to 403 during the 19992004 term, after the Treaty of Amsterdam increased the number of areas covered by the procedure from fifteen to 34 (Rasmussen and Shackleton 2005: 1).
} 
and Nice (2001). Today, about 80 percent of legislation is decided under the co-decision procedure.

This study focuses on EP decision-making under the co-decision procedure, which is illustrated in Figure 1.

[Figure 1 here]

This warrants a more detailed description of this process, which begins with a legislative proposal being drafted and introduced by the Commission and considered independently by both EP and Council. The EP appoints a member of the responsible EP committee (see below) as the "rapporteur," who is usually an MEP with expert knowledge in the issue area in question. ${ }^{14}$ The rapporteur has three primary responsibilities:

- incorporating the EP's amendments into the draft proposal (containing suggested amendments as well as statement of reasons behind these amendments),

- steering the proposal through the different stages of the legislative process, - negotiating compromise both within the EP and with the other two institutions.

The rapporteur's report is discussed and voted on in the responsible committee, where a first set of amendments is tabled. Other committees may also be asked for an opinion report if the legislation touches upon their competencies, but their amendments are subject to a vote in the responsible committee before the report is submitted to the plenary. After this, the report is referred to the EP plenary for debate and a vote during the first parliamentary reading. The

\footnotetext{
${ }^{14}$ Corbett et al. (2000: 117-18) maintain that "if the suggested rapporteur is recognized as a specialist on the issue it is easier to get an agreement on his or her nomination. Certain technical issues on which there is little political controversy but on which a committee member is a specialist are again and again referred to the same specialist."
} 
finished report is voted on in full plenary, where further amendments may be introduced to the existing text by EP groups or at least 37 MEPs. The report must be adopted by a simple majority, i.e., the majority of MEPs taking part in the vote. There is no formal time limit on the first parliamentary reading.

Before the proposal is forwarded to the Council of Ministers, the Commission may alter its initial legislative proposal to incorporate EP amendments which, in its view, improve the initial proposal and/or are likely to facilitate an agreement. The Council can do one of two things in its first reading. First, it may accept the text as adopted in Parliament, which ends the legislative process with the proposal coming into effect as amended by the EP. This event does occur at times, either when there is a broad existing consensus in favor of the policy proposal, or due to time pressure. Alternatively, the Council may reject the text as it is and formulate a common position among the member state governments. This common position usually accepts some of the amendments of the EP in order to facilitate a compromise with Parliament in subsequent stages of the decision-making process, but may reject all EP amendments.

Within three months of the Council's common position, Parliament must conduct its second reading or formally extend the time table by one month. Otherwise, the common position enters into force. In second reading, the EP can either adopt changes to the common position or reject it entirely, which would end the co-decision procedure at this point in time. For both options, an absolute majority of MEPs is needed, that is, more than 50 percent of the total number of members, and strict rules govern the introduction of amendments in second reading. ${ }^{15}$ Most importantly:

\footnotetext{
${ }^{15}$ Key negotiators in the EP are well aware of the implications of the absolute majority requirement in second reading and plan their strategy accordingly (Rasmussen and Shackleton 2005: 17).
} 
- amendments adopted in first reading may be re-tabled if they were not accepted by the Council,

- amendments may be concerned with a part of the common position which did not appear in, or is substantially different from, the Commission's initial proposal,

- amendments may be introduced as a compromise between the positions of the colegislators.

The text is first discussed in the responsible committee, following the same rules and practices in first reading. The only difference is that the text to be amended is the Council's common position and not the Commission's initial proposal. Also, the parliamentary committees which were asked for an opinion in first reading are not consulted again. While the committee adopts the report in second reading by simple majority, the text must be approved by an absolute majority of MEPs. The EP may also reject the common position in second reading, which ends the legislative procedure, but has never exercised this prerogative to this date.

Usually, the text is amended and referred back to the Council. At this point, one of three things will happen. First, Council may adopt the proposal including the changes proposed by the EP. Second, it may reject the text completely, causing the proposal to fall. Third, the two institutions may enter conciliation.

The conciliation committee is composed of an equal number of MEPs and representatives of the Council and tries to forge a compromise text acceptable to both institutions. Negotiations are conducted during informal trialogue meetings involving small teams of negotiators for each institution, with the Commission playing a mediating role (hence the name "trialogue"). The participants in these trialogues report to their respective delegations, which must approve the results of their negotiations. 
In the end, conciliation has two possible outcomes. If the committee fails to come up with an agreement, the proposal is withdrawn and the procedure lapses. If the conciliation committee does succeed in agreeing on a compromise text, however, this text goes into third reading, in which either EP or Council may reject the proposal. In this case, the text is withdrawn and the proposal falls. If, on the other hand, the text is adopted by both institutions, the proposal enters into force.

In sum, the EP is truly a co-legislator with the Council under co-decision. This conclusion is inevitable both in terms of the number of successful amendments and the substantive impact on proposed legislation (Judge and Earnshaw 2003: 291). Accordingly, it is increasingly inappropriate to view the EP, as once was the norm and remains popular, as a “powerless, money-wasting “talking shop"”' (Peterson and Bomberg 1999: 43).

\subsection{THE COMMITTEE SYSTEM OF THE EP}

The EP's permanent committee structure has been described as its "legislative backbone" (Westlake 1994: 191). In effect, most of the detailed parliamentary work is conducted in and by committees, the majority of substantive changes and compromises are constructed inside the committee, and committee work is the most time-consuming activity for parliamentarians and defines the focus of their work (Kreppel 2005; Corbett et al. 2005; Neuhold 2001). As the powers of the EP have increased over time, so has the role of its committees in shaping legislation, especially as they have progressively acquired policy-specific expertise (Mamadouh 
and Raunio 2003). As a result, EP committees are more active and influential than their counterparts in national European parliaments. ${ }^{16}$

The number, sizes, and responsibilities of the committees are decided in the early days of a newly elected parliament. They are confirmed after two and a half years, at the mid-point of the parliamentary term. The current 2004-2009 EP has a total of 20 committees. This number is up from 17 during the previous parliamentary term. ${ }^{17}$ Committees vary substantially in size; during the 1999-2004 parliamentary term, for example, the Environment Committee had 56 members and the Legal Affairs Committee only 30. Membership is effectively decided by the EP party groups through the use of proportional representation of both party groups and nationalities, meaning in such a way that the composition of each committee reflects the balance between the party groups in plenary. As a result, their composition broadly reflects that of the EP as a whole (Shackleton 2002: 101). The majority of MEPs serve on one committee each as a full member and a substitute.

Committees act as largely autonomous entities within the EP. All legislative proposals are referred directly and without debate to the responsible committee, which examines and deliberates the proposed legislation before returning it to the plenary in the form of a draft report. Committees have gate-keeping powers within their areas of jurisdiction and a "relative monopoly on information and expertise" (Kreppel 2005: 5).

\footnotetext{
${ }^{16}$ For a comparison between EP committees and those in other European national legislatures, see Mamadouh and Raunio (2003). For a comparison between the EP and the U.S. Congress, see Kreppel (2005).

${ }^{17}$ Subsequent analyses are based on data from the previous parliamentary term (1999-2004), when the EP had the following 17 standing committees: Committee on Agriculture and Rural Development; Committee on Budgetary Control; Committee on Budgets; Committee on Citizens' Freedoms and Rights, Justice and Home Affairs; Committee on Constitutional Affairs; Committee on Culture, Youth, Education, the Media and Sport; Committee on Development and Cooperation; Committee on Economic and Monetary Affairs; Committee on Employment and Social Affairs; Committee on Fisheries; Committee on Foreign Affairs, Human Rights, Common Security and Defence Policy; Committee on Industry, External Trade, Research and Energy; Committee on Legal Affairs and the Internal Market; Committee on Petitions; Committee on Regional Policy, Transport, and Tourism; Committee on the Environment, Public Health, and Consumer Policy; Committee on Women's Rights and Equal Opportunities.
} 
Each committee has one chair and three vice-chairs, who are elected by the committee members. In practice, however, these positions are carefully distributed by agreement among the party groups based on their number of members. Seniority does not play any role in this process. The chairs preside over the meetings of the committee, speak on its behalf at plenary sessions, and represent it at the regular meetings of committee chairs. Yet, the rapporteur system means that individual members, and not committee chairs, are the key actors negotiating individual pieces of legislation (Mamadouh and Raunio 2002: 13).

Another important committee position is that of the group coordinator, who is the main spokesperson of his or her party group in each committee. In fact, previous research suggests that MEPs generally view coordinators as the most dominant force in EP committees, but that their influence is subject to their personalities (Whitaker 2002: 78-80). The coordinator also distributes tasks among the member of her party group. Most importantly, once a report has been allocated to a party group in a committee, it is usually the coordinator who picks the rapporteur among his party colleagues. The coordinators also convene the meetings of committee members from their party group and often act as party whips in committee (Whitaker 2001: 68, Corbett et al. 2005: 127). Jointly, the coordinators of the party groups set the committee's future agenda, discuss forthcoming votes, and distribute rapporteurships.

Rapporteurs are chosen by a system whereby each party group receives a quota of points according to its size. Reports to be allocated are discussed by the group coordinators who decide on the number of points an individual report is "worth." They then make bids on different reports on behalf of their party group until they have used up their quota.

Existing research concerning the distribution of rapporteurships has produced contradictory results. While Raunio and Mamadouh (2002) and Benedetto (2005) argue that the 
division of rapporteurships between party groups is largely representative of their size, other research indicates that the distribution is hardly proportional among party groups and national delegations within the committee (Kaeding 2004, 2005). Hoyland (2006) maintains that MEPs from parties represented in the Council of Ministers are more active on co-decision dossiers than those not represented, while Kaeding (2004) points to differences related to background, expertise, and constituency interests as factors accounting for the active involvement of MEPs in the legislative decision-making process as rapporteurs.

The groups who do not receive the rapporteurship for a specific report appoint a "shadow rapporteur" responsible for preparing the group's position and monitoring the work of the rapporteur. This position has become increasingly important in the recent past. Shadow rapporteurs (often referred to simply as "shadows") inform the other members of their political groups of the progress of the deliberation and negotiation process, give them recommendations, draw up amendments, lead the discussion and rally the troops when "their" issue is discussed in committee or plenary, or within their group. This position has become necessary because many dossiers discussed in the EP today are so highly technical that MEPs not dealing with the proposal directly are unfamiliar with the details of the proposal under consideration (Neuhold 2001).

It is also increasingly common for rapporteurs dealing with important reports to have separate meetings with the shadows, who may even be invited to participate in meetings with Commission and Council. ${ }^{18}$

\footnotetext{
${ }^{18}$ Different studies have shown that the Council is quite interested in informal contacts and negotiations with rapporteurs and shadow rapporteurs from big political groups to ensure that deals are backed by a large range of opinion in the Parliament and are therefore more likely to be acceptable (Rasmussen and Shackleton 2005: 10; Farrell and Heritier 2003b: 592; Raunio and Shackleton 2003: 178).
} 
Committees have a small staff, especially compared to the U.S. Congress, for example. They usually have only between two and eight administrators, one or two committee assistants, and a number of secretaries. Committees are also assisted by the EP's Legal Service. Finally, the party groups have up to three people in charge of following a specific committee who, together with the personal assistants of individual members, assist the committee and its members.

The existing scholarship on the EP committees remains sparse, despite some recent research on committee assignment and party control of EP committees (Kreppel 2005; Mamadouh and Raunio 2002, 2003; McElroy 2002, 2006; Whitaker 2001; Kaeding 2004, 2005; Hausemer 2005). Our understanding of committees in the EP is thus quite limited.

\subsection{POLITICAL CONTESTATION AND VOTING PATTERNS IN THE EP}

As a direct result of the increase in EP powers over time, academic interest in the EP has increased substantially during the last decade, with a group of young scholars taking the lead. ${ }^{19}$ Deductive, quantitative and/or rational choice studies have been particularly influential, and our understanding of the institution has been expanded in a great number of ways. These studies establish that policy conflict in the EP is principally characterized by two substantively important dimensions, namely the traditional Left-Right ideological divide and a pro-/anti-EU dimension ranging from less to more support for the European integration process. ${ }^{20}$

Analyses of EP voting patterns highlight the increase in party group cohesion and ideology-based party competition in the EP on the basis of these dimensions. While previous

\footnotetext{
${ }^{19}$ The research of Simon Hix, Amie Kreppel, Abdul Noury, Gerard Roland, Tapio Raunio, and other members of the European Parliament Research Group (EPRG) deserve special mention.

${ }^{20}$ For additional details and bibliographical information, please refer back to section 1.2. in the Introduction.
} 
research already suggested that MEPs are more likely to vote along transnational party lines than national lines (Attinà 1990; Brzinski 1995; Raunio 1997; Hix and Lord 1997), recent and more comprehensive roll-call vote analyses demonstrate that MEPs vote in accordance with their party affiliations, rather than their national affiliations (Noury 2002), and that the distance between parties on the Left-Right dimension is the strongest predictor of coalition patterns (Hix, Noury, and Roland 2005). This tendency was also confirmed in analyses of party competition between the two main EP party groups (PES and EPP), which show that the party system in the EP has become more consolidated and more competitive as the powers of the EP have increased over time (Hix, Kreppel, and Noury 2003). At the same time, party group cohesion in the EP has been shown to be quite high. Analyses on the basis of roll-call votes by Hix, Noury, and Roland (2005: 216) have confirmed past findings of significant levels of party cohesion (Attinà 1990; Raunio 1997; Kreppel and Tsebelis 1999; Kreppel 2002; Hix 2001; Hix 2002; Noury 2002; Thomassen, Noury, and Voeten 2004), showing "that the six main political forces in the European Parliament are remarkably cohesive party organizations." In sum, the power of transnational parties in the EP has risen "via increased internal party cohesion and inter-party competition" (Hix, Noury, and Roland 2005). ${ }^{21}$

This new literature on the EP has also confirmed that the EP, like the EU as a whole, can be fruitfully studied in a comparative framework, rather than being treated as a unique phenomenon. The most useful comparisons, in this regard, focus on the parliamentary (Westminster) system and on the US Congress. Both have yielded important insights into the regularities and singularities of the EP. While the comparison with "normal" parliamentary

\footnotetext{
${ }^{21}$ A recent article on selection bias in the use of roll-call vote analyses by Carrubba et al. (2004) sheds some doubt on these conclusions, however. While instructive and pointing out very real potential problems associated with analyzing roll-call votes, a number of issues cast doubt on the validity of Carrubba et al.'s claims, which require and deserve further examination in the future. The issue of selection bias in the use of roll-call votes is addressed in more detail in Chapter 5.
} 
systems demonstrates the importance of party politics and the EP party groups, comparisons with Congress emphasize the critical role of specialized parliamentary committees in EP decisionmaking.

\subsection{SUMMARY}

The EP plays a critical role in EU politics today and has evolved from a mere consultative "talking-shop" into an assertive and powerful actor in the Union's political and institutional framework, particularly over the past two decades. The attention it has received in academic circles during the last few years is thus well-warranted. Much remains to be learned, however, about this institution that is still in many regards a "new" legislature. While recent cumulative research efforts have produced invaluable insights into the broad patterns of behavior of European parliamentarians and the structural characteristics of the EP as an institution, each

piece of newly acquired knowledge raises new questions. It is particularly evident that we have to start paying more detailed attention to the behavioral patterns of MEPs and the institutional setup and evolution of the EP. 


\subsection{THE FOCAL POINT THEORY}

\subsection{UNCERTAIN PREFERENCES}

This dissertation seeks to establish how the general political preferences of legislative decisionmakers translate into their positions toward specific policies. To identify this translation process, the decision-making model advanced in this project distinguishes among ideological preferences, the positions decision-makers take toward specific policy proposals, and the strategies they choose to achieve their goals. ${ }^{22}$ It assumes that decision-makers' outcome preferences are fixed, while their policy preferences and strategies are latent. Outcome preferences are defined as structural variables that are stable, exogenously determined preferences over outcomes, that is, preferences concerning the (uncertain) effects or consequences of policy choices upon their implementation (Krehbiel 1991: 66-67). Most importantly, outcome preferences can be policyoriented (decision-makers care about the content and consequences of the policies they choose) or office-oriented (decision-makers care about being re-elected).

Policy preferences, in contrast, are derived from outcome preferences (Krehbiel 1991: 66-67). They are the positions decision-makers assume toward particular policy issues or proposals, based on their beliefs about how a given policy action relates to their most preferred

\footnotetext{
${ }^{22}$ There is no single definition of the term "preference." Here, a preference is considered to be a comparative ranking of a set of objectives (Druckman and Lupia 2000), while preference formation refers to processes by which social actors decide what they want and what to pursue (Hall 2003). For a very useful discussion of preferences and preference formation, see Druckman and Lupia 2000.
} 
outcome. Policy preferences are potentially changeable and inconsistent, since the link between policies (i.e., the objects of legislative choice, such as proposals, bills, legislation, or laws) and outcomes (i.e., the consequences of a policy upon its implementation) is often uncertain. Accordingly, a decision-maker's utility function over policies is based on preferences over outcomes, while she can only take action on policies (Krehbiel 1991: 68).

Finally, actors choose strategies to achieve the goals defined by their policy preference. This strategy is highly context-related, however; it is bound by the macro-political context, structural and institutional variation, and opportunity structures (Woll 2005). In the context of legislative decision-making, the most basic and common strategy choice is between voting for or against a policy proposal.

This project approaches the question of preferences and outcomes by relying on the intuition of spatial theory, which originated in economics (Hotelling 1929; Smithies 1941), but has a long history of application in political science (Downs 1957; Black 1958; Arrow 1963; Duverger 1951; Shepsle 1979, 1991; Riker 1982; Enelow and Hinich 1984; Hinich and Munger 1994, 1997; Ordeshook 1986; Shepsle and Bonchek 1997). Spatial theory is a simple model of political choice that conceives of preferences as points in a "space" consisting of one or several dimensions. These dimensions are ordered sets of alternatives, and rational political actors choose the alternative "closest" to their own ideal points.

I identify a low-dimensional ideological space as the critical context structuring choices in legislative politics (Hinich and Munger 1994, 1997). This ideological space is comprised of the dominant ideological dimensions, meaning that its dimensionality is much lower than classical policy- or issue-spaces. Moreover, dimensions of the space are determined by the way issues cluster in actors' believes or rhetoric (Hinich and Munger 1997: 191). In the ideological 
space, actors are assumed to choose policy alternatives that are closest to their ideological ideal points. These ideal points are stable normative and cognitive positions on the ideological dimensions, representing long-standing and durable norms and values that are exogenous to the decision-making process (Marks and Wilson 2000; Scott 2001). Ideal points on the ideological dimensions correspond to ideological outcome preferences, and thus the policy-orientation of legislative decision-makers. For the case of the EU, I assume this ideological space to be essentially two-dimensional, ${ }^{23}$ consisting of the Left-Right and sovereignty-integration dimensions. $^{24}$

Attaining a policy preference involves the process of balancing potentially conflicting ideological preferences, since most political issues are multidimensional in nature (Baumgartner, Jones and MacLeod 2000: 325). Legislators may thus be confronted with circumstances in which they face trade-offs between competing ideological preferences (Hinich and Munger 1997: 200), or between ideological preferences and constituency interests (Aldrich and Rohde 1997-98, $1998,2000,2001)$. Hence, the translation of outcome into policy preferences is a matter of causal and normative beliefs. Policy makers must somehow relate a policy proposal to the existing ideological space by interpreting the content and consequences of a proposal in reference to its dominant dimensions. This, however, is hindered by the frequent absence of "cause-and-effect knowledge" regarding the effects of implemented legislation (Cooper 1977: 148; Austen-Smith and Riker 1987: 897; Gilligan and Krehbiel 1990: 533).

\footnotetext{
${ }^{23}$ As the discourse below will show, the model advanced here could easily be extended to either accommodate a new two-dimensional space consisting of a different set of dimension, if empirical findings were to demonstrate this structure, as well as one or more additional ideological dimensions. I limit the analysis to two dimensions for three reasons: first, the current state of knowledge about the dimensions of conflict in the EP supports this choice; second, the model will be more intuitive when discussed in the context of two dimensions only; and third, the ideological space is, by definition, considered to be low-dimensional.

${ }^{24}$ While some analyses suggest that additional dimensions of conflict may also structure policy conflict in the EP, such as a libertarian-traditional dimension (Thomassen, Noury, and Voeten 2004) or a "new politics" dimension (Hooghe, Marks and Wilson 2002), their impact on legislative outcomes, i.e., MEP voting patterns, has yet to be demonstrated.
} 


\subsection{FOCAL POINTS}

Under conditions of uncertainty about what ideological dimension is relevant to a particular policy decision, that is, which ideal point should become pertinent for the individual legislator, the ideological space provides for an infinite number of possible equilibria. The decision-making process thus resembles a coordination game that provides no way of distinguishing one equilibrium from another, even when the players have a shared interest in finding common ground for a policy outcome. Under these circumstances, where there is no one "natural" policy solution, or outcome-equilibrium, but a set of different potential solutions, it is difficult for political actors choose one over another. They have to rely on some feature external to the game to facilitate the selection of an equilibrium. For a two-person "pure coordination game," Schelling (1960) and Mehta, Starmer and Sudgen (1994) show that people can use different "labels" to coordinate their behavior, resulting in the selection of one single equilibrium. Similarly, Garrett and Weingast (1993) suggest that "ideas, social norms, institutions, or shared expectations" can facilitate the realization of potential gains between actors facing multiple possible equilibria. ${ }^{25}$

This proposition constitutes the starting point of my theory, which acknowledges that outcome preferences structure legislative decision-making, but suggests that this process is indirect and mediated by factors endogenous to the policy process. It maintains that structure, such as the ideological space or constituency interest, impacts decision-making to the extent that

\footnotetext{
25 In the example Garrett and Weingast (1993) provide, the member states of the European Community acknowledged the principle of "mutual recognition" to constitute an acceptable basis of an agreement that led to the creation of the European single market in the 1986 Single European Act. This principle was well-established in EC politics, had been used by the European Court of Justice to settle disputes in the economic policy realm, and could serve as a universally recognized keystone for the single market. In the game theoretic literature, the link between beliefs and equilibria has been emphasized in the context of signaling games. Kreps and Wilson (1982), for example, elevate beliefs to the level of importance of strategies in the definition of equilibrium.
} 
legislative entrepreneurs link outcome preferences to specific policy issues through the provision of focal points that link ideological ideal points with particular policies. They connect outcome preferences to specific policy issues by supplying simplifying ideas or images about the consequences of a policy proposal to legislators faced with a large number of decisions on highly specialized and varied subjects. These focal points help resolve conflict between potentially contradictory normative and political considerations by emphasizing, classifying, and evaluating specific aspects of the proposal. Legislators acting under conditions of uncertainty about the consequences of a policy choice rely on focal points to help them link their latent ideal points on the ideological dimensions with specific policy proposals, making them pertinent to the decision at hand. Focal points thus serve as short-hand devices for communicating information that emphasizes the respective salience of the ideological dimensions by shifting attention toward specific perceived outcomes of a given policy proposal. Simply put, they affect the receivers' perceptions of which outcome preference matters with regard to a policy proposal, and how intensely it matters. These perceptions are then aggregated through the formation of policycoalitions. $^{26}$

While the game theoretic literature conceives of focal points as the equilibria resulting from players in pure coordination games following the coordinating "label" they consider to be most salient (Schelling 1960; Metha, Starmer and Sugden 1994), that is, as the outcome of the game, the term is used more broadly in the less formal literature. Garrett and Weingast (1993: 176), for example, maintain that focal points do not always emerge without conscious effort on the part of interested actors, but that they must often be "constructed." Hence, focal points are

\footnotetext{
${ }^{26}$ It is important to note that focal points are targeted at those MEPs not directly involved in the decision-making process either for a lack of time and resources, or because they do not possess the necessary expertise to genuinly evaluate the content and implications of the proposed legislation, or both. It is the preferences and positions of these MEPs that this study seeks to account for. MEPs who do not fall into this category do not have to rely on focal points for the determination of their policy preferences and positions.
} 
less the outcome of process, but a tool facilitating this outcome. In this sense, the provision of focal points constitutes an example of what William Riker has termed "heresthetic," which describes the attempt to structure the political context in such a way as to move the process of contestation from one to another dimension (Riker 1986, 1990). According to Riker, actors can introduce new issue dimensions, or dismiss or reinterpret existing ones by "displaying the relevance of a dimension, recalling it from latent storage to the center of psychic attention" (Riker 1990: 54). However, while the concept of heresthetic is quite broad and includes various forms of strategic voting and agenda manipulation (Riker 1990: 50-54), the provision of focal points should be conceived of as a very specific mechanism of heresthetic: by shifting attention toward particular aspects of a policy proposal, focal points influence policy-makers' perceptions of the relevance and salience of the dominant ideological dimensions. Hence, their introduction structures the political context by affecting the dimensional location of political deliberation and contestation.

Riker argues that heresthetic is a process that restructures the political space from a model where equilibrium is likely to exist to one where it is not (Riker 1990: 51). Focal points, however, work the other way around by transforming a model with multiple possible equilibria into one where certain equilibria are more likely. This is exactly the purpose of a focal point: to increase the likelihood of legislators choosing one equilibrium over another, thus providing the basis for a policy coalition to either push through or defeat a policy proposal. Focal points achieve this result by linking a policy proposal with the dominant ideological dimensions, i.e., by tying the decision-making process to the lower-dimensional ideological space. This decreases the number of dimensions considered to be salient for the decision at hand and decreases the number of possible equilibria; it thus puts a distinct limit on the ability of strategic actors to manipulate 
the dimensional placement of an issue. However, focal points must supply information about the potential consequences of a legislative proposal in reference to the other legislators' ideological ideal points or outcome preferences. If this link fails to be established, meaning if the focal point fails to appeal the other legislators' exogenous sets of norms and values, it will be rejected by the "receiver." ${ }^{27}$ In this sense, the provision of focal points reflects and is constrained by the existing ideological space: focal points are not "free-floating."

In the context of the EP, focal points are likely to fall into three broad categories based on the outcome preferences they "target." Focal points relating to the sovereignty-integration dimension should address the trade-off between the objective to build an "ever closer Union" and the desire to retain national sovereignty. This emphasis should prompt decision-makers to act based on their positions on the sovereignty-integration dimension. Examples for such focal points would be the emphasis on the necessity for completing specific European projects on the one hand (such as the single market, Economic and Monetary Union, EU enlargements, a common foreign and security policy, etc.), or the emphasis on the singularity and desirability of national cultures, identities, institutions, or decision-making authority on the other.

In contrast, focal points relating to the Left-Right divide should emphasize traditional Left-Right issues and induce European decision-makers to act based on their positions on the Left-Right divide. These focal points would, for example, stress the conflict between economic regulation and liberalization, or the tradeoff between employee protection and business promotion.

\footnotetext{
${ }^{27}$ This is also important with regard to Riker's concept of heresthetics, which has been criticized for failing to identify the constraints on the introduction of new issue dimensions. If each actor has to simply introduce an additional dimension in order to "win," then why do we not observe the introduction of an infinite number of dimensions on any given issue (Mackie 2003)? Placing the manipulation process in a low-dimensional ideological space puts a distinct limit on actors' ability to manipulate the dimensional placement of an issue.
} 
Finally, focal points may stress the need to protect distinct constituency interests. In the case of the EU, these are most likely nationally-based, such as national economic interests. By emphasizing the positive or negative impact of a proposal for national constituencies, constituency-centered focal points should prompt decision-makers to vote in ideologically diverse coalitions, for example as national blocs.

The basic argument advanced here is that depending on which focal point (or focal points) dominates the deliberation process concerning a particular legislative proposal, legislators not directly involved in the deliberation process will perceive of the issue in different ways. For example, a legislative proposal regulating economic policy at the EU level could be presented by the people directly involved in the dossier as a matter of harmonization toward the completion of the EU single market. As a result, pro-EU legislator without complete information about the content and consequences of the legislation would be likely to support the legislation. If, however, the issue were presented as one of liberalization, members of parliament on the left side of the political spectrum would likely oppose the measure.

\subsection{THE EFFECT OF FOCAL POINTS: AN ILLUSTRATION}

To illustrate the impact of focal points on the preference functions of legislators, consider first the ideological space below, which consists of the Left-Right divide and the sovereigntyintegration dimension. Also assume that there are three individual MEPs $\left(\mathrm{x}_{1}, \mathrm{x}_{2}, \mathrm{x}_{3}\right)$, who each have ideal points on these dimensions. ${ }^{28}$

\footnotetext{
${ }^{28}$ Note that for ideal points, subscripts are used to identify people, so $\mathrm{x}_{1}$ is MEP 1's ideal point, and $\mathrm{x}_{\mathrm{i}}$ is MEP $\mathrm{i}$ 's ideal point. I use italics to indicate ideal points in the ideological space.
} 
[Figure 2 here]

The ideological space is not actually divorced from issues, because ideologies provide a set of "linkages" with the n-dimensional space of policies; these linkages are highly uncertain, however (Hinich and Munger 1997: 191). Hence, the process of relating a policy proposal to the existing ideological space by interpreting its content and consequences in reference to the dominant ideological dimensions consists of a complete or partial transposition of the ideological space into the relevant policy space in which decision-making takes place. In the case where there are no variables, such as focal points, intervening in the transposition of the ideological space into a given policy space, the relevant policy space looks exactly like the ideological space above. In this space, let SQ (status quo) and NP (new policy) be two competing policy options.

[Figure 3 here]

If ideological ideal points and the two policy options are thus distributed in the policy space, and if the salience of the two dimensions is equal (when the legislators perceive neither dimension to be more important than the other), the status quo will be retained. As represented in the graphic below, equal salience of the two dimensions means that the legislators' indifference curves (the sets of points that give them the same level of satisfaction) are of circular form. These circles have the property that all points along the indifference curves are equally far from the ideal points of the legislators $\mathrm{x}_{1}, \mathrm{x}_{2}$ and $\mathrm{x}_{3}$. The legislators compare policy proposals on the basis of the distance from their ideal points, meaning that if the radius of the circle circumscribing their indifference curves is the distance from their ideal points to the status quo 
point (here: SQ), any new policy that falls inside the indifference curve constitutes a preferred alternative to the status quo. In Figure 4, voting for the status quo is the preferred alternative for $\mathrm{x}_{1}$ and $\mathrm{x}_{2}$, since the new policy (NP) lies outside their indifference curves. $\mathrm{x}_{3}$ would prefer NP, however, which is closer to her ideal point than SQ. Accordingly, under majority rule, NP would be defeated 2-1.

[Figure 4 here]

As defined above, focal points emphasize the respective salience of the ideological dimensions by shifting attention toward the (perceived) consequences of a given policy proposal. In doing so, they affect the prevalent perceptions of which outcome preference matters with regard to the proposal, and how intensely it matters. In other words, focal points affect the salience attached to the ideological dimension when they are transposed into the policy space. The most extreme versions of this transposition would be if one of the two ideological dimensions were to become completely irrelevant, i.e. if its salience were zero. In this case, the relevant policy space is one-dimensional, reflecting only the dominant ideological dimension. If the Left-Right divide were this dominant dimension, SQ would be the preferred policy option for $\mathrm{x}_{1}$ and $\mathrm{x}_{2}$, whose ideal points are closer to SQ than to NP. NP lies inside $\mathrm{x}_{3}$ 's indifference curve, however, and would thus be her preferred alternative. Therefore, NP would again be defeated 21.

[Figure 5 here] 
In contrast, if the sovereignty-integration dimension were dominant to the degree that the Left-Right divide was irrelevant, NP would narrowly prevail. As the figure below demonstrates, both $\mathrm{x}_{2}$ and $\mathrm{x}_{3}$ prefer the new policy NP over the status quo SQ, as it lies inside their indifference curves. $x_{1}$ still prefers the SQ, however, meaning that NP would defeat SQ in a 2-1 vote.

[Figure 6 here]

Yet, it might also be the case that neither dimension is utterly irrelevant, but that one is perceived to be more salient than the other. In this case, indifference curves are no longer circular, but have an elliptical shape. Specifically, if the horizontal dimension is more salient, the indifference curves are "squeezed" from the sides, because the more important a dimension is to an actor, the more small changes in the policy affect her satisfaction. In contrast, if the vertical dimension is more salient, the indifference curves are "squeezed" from above and below. Hence, if focal points affect the perceived salience of the ideological dimensions with regard to a particular policy proposal, they change the shape of the indifference curves of the decisionmakers.

For example, if the provider of focal points could convince MEP $\mathrm{x}_{2}$ that the sovereigntyintegration dimension is only a bit more salient than the Left-Right divide when deciding between SQ and NP, $\mathrm{x}_{2}{ }^{\text {s }} \mathrm{s}$ indifference curve would change in such a way that voting for NP now becomes his preferred alternative (still assuming equal perceived salience of the ideological dimensions for $\mathrm{x}_{1}$ and $\mathrm{x}_{3}$ ). As we can see in the figure below, the new policy NP, which was previously outside $x_{2}$ 's indifference curve (see Figure 4), now lies inside his new, elliptical indifference curve. 
[Figure 7 here]

This result would be the same if the focal point affected not just $\mathrm{x}_{2}$ 's perception of the salience of the ideological dimensions, but $\mathrm{x}_{1}$ 's and $\mathrm{x}_{3}$ 's as well.

[Figure 8 here]

An even greater salience of the sovereignty-integration dimension over the Left-Right divide, however, would entail that $\mathrm{x}_{3}$ 's policy preference changed, and that SQ would actually defeat NP by a vote of 2-1. As we can see below, NP no longer lies inside $x_{3}$ 's indifference curve, meaning that if $\mathrm{x}_{3}$ perceived the sovereignty-integration to be very salient, she would consider the status quo to be her preferred alternative.

[Figure 9 here]

Finally, consider the case where a focal point aims to emphasize the salience of the LeftRight over the sovereignty-integration dimension (where the indifference curves are "squeezed" from the sides). Here, the status quo would again prevail as the preferred policy preference for $\mathrm{x}_{1}$ and $\mathrm{x}_{2}$, as NP lies outside their indifference curves.

[Figure 10 here] 
This series of examples shows how focal points could impact policy decisions by influencing the respective salience of ideological ideal points when the two-dimensional ideological space is transposed into an N-dimensional policy space. These examples, however, assume that actors are policy-oriented. This leaves us to consider the case of office-driven politicians, who may be willing to deviate from their ideological ideal points in order to better represent or "serve" their constituents (and to get re-elected). If this were the case, their indifference curves would change based on the degree to which the ideological dimensions' salience diminishes.

The most extreme example of this incidence would be if the ideological dimensions became completely irrelevant and their salience were zero, and were replaced by a constituency dimension where actors are aligned on the basis of the (perceived) respective gains of their constituents. In the case of the EU, this constituency element would most likely be national interest, where the comparative advantage of each member state is the most salient variable in the decision-making process. The graphic below provides one possible example where NP would pass with the votes of $\mathrm{x}_{1}$ and $\mathrm{x}_{3}$, for whom NP lies inside their indifference curves.

[Figure 11 here]

Another possibility would be that the constituency element affected the salience of each ideological dimension asymmetrically. If, for example, the sovereignty-integration divide became irrelevant, while the Left-Right dimension retained at least some of its salience, a policy proposal would be evaluated in a two-dimensional policy space such as the one below. In this case, NP would be $x_{1}$ 's and $x_{3}$ 's policy preference, and both would vote to defeat SQ. 
[Figure 12 here]

\subsection{THE SOURCES OF FOCAL POINTS}

All of this leaves one crucial question: Where do focal points come from? I argue that they are provided by legislative entrepreneurs with private information about the expected consequences of a policy proposal. These legislators are policy specialists to whom less-informed, and lessinvolved, members have delegated the task of providing information relevant to the policy decision. ${ }^{29}$ Hence, the focal point model includes a distinctly strategic element, despite its emphasis on the constraints imposed by the structure of the ideological space. After all, shifting attention means emphasizing and evaluating particular aspects of a legislative proposal, even within certain constraints, and the providers of focal points should thus have a great deal of influence over decision-making processes and outcomes.

Within a context of incomplete and asymmetric information, however, the institutional structure of a legislative arena is critical in positioning some actors in advantageous positions as providers of focal points. The important question is who this structure favors as the supplier of information and expertise, and the likely sources of focal points in legislative decision-making processes are either strong parties or strong legislative committees.

While the literature on the development of the EP and its party groups has generally found their authority to be increasing, party groups in the EP remain weak compared to their

\footnotetext{
${ }^{29}$ In the U.S. context, voting choice studies have frequently shown that legislators rely heavily on information from "specialist" legislators or "trusted colleagues" who are knowledgeable on the particular issue under consideration (Zwier 1979; Matthews and Stimson 1975; Kingdon 1981; Sabatier and Whiteman 1985).
} 
counterparts in national parliamentary systems. Most importantly, EP groups are themselves made up of full, sovereign political parties, making it more difficult for the party groups to "bind the parts" (Lord 1998: 205). This makes them different from the internally hierarchical, strong parties in West European parliamentary systems. Moreover, the EP party groups have no direct influence over the selection of their members, since the authority to draw up party lists for European elections lies with the national parties. Finally, EP party groups have more limited resources and staff than parties in national parliaments, thus further undermining their role as information providers.

The EP's permanent committee structure, on the other hand, has been described as its "legislative backbone" (Westlake 1994: 191). The role of EP committees is more active and powerful than that of their counterparts in other national parliaments: they propose amendments to legislation in the form of a report and a draft resolution, which are then submitted to the EP plenary in an almost "take-it-or-leave-it" form (Hix 1999a: 78). The EP is more like the U.S. Congress than most European parliaments in this regard.

The EP's committee system provides members with the opportunity to acquire expertise in specific policy areas, meaning they should be expected to serve as the primary providers of focal points. As a result, committees in the EP can fulfill their role as formal mechanisms of establishing a division of labor among legislators of (nominally) equal status (Judge and Earnshaw 2003) and facilitate legislative decision-making by providing "economics of operation" (Mattson and Strøm 1995). This leads to efficiency gains, as legislation is processed more quickly than if the plenary as a whole were involved collectively, and promotes specialization and expertise to deal with "problems of complexity, technicality and information overload" (Judge and Earnshaw 2003). 
Much like the permanent committees with fixed jurisdictions in the U.S. Congress, the jurisdictional organization of EP committees is based on the need to specialize, and its committees have considerable influence on the legislative agenda. This warrants a closer examination of the literature on committees in Congress. Within the branch of rational choice work grounded in the "new institutionalism," two prevalent analytical perspectives have sought to explain the roles of committees. First, the "distributive perspective" is tied to the names of Kenneth Shepsle and Barry Weingast (Shepsle 1979, Shepsle and Weingast 1981). It focuses on members' gains from trade, where legislatures are "a collective choice body whose principal task is to allocate policy benefits" (Krehbiel 1991: 3). Legislators' primary role is to secure a favorable distribution of direct benefits to their constituents. In this perspective, committees serve as instruments to fulfill this goal and are composed of high-demanders (members with a high demand for the policies in their jurisdiction). Congressional rules and procedures give such committees control over policy making within their domain, so that the committee system serves as a mechanism for a intra-institutional "logroll": members gain influence in the policy areas they care most about, while sacrificing the ability to determine policy in areas less salient to them (Weingast and Marshall 1988). In effect, they trade influence with one another.

The second, "informational", perspective conceives of committees as more than distributional devices. Instead, they are also designed to help members reap gains from specialization. The informational approach emerged from a series of papers by Keith Krehbiel and Thomas Gilligan (1987, 1989, 1990), as well as Krehbiel's 1991 book Information and Legislative Organization. In their view, institutional arrangements reflect the need to acquire and disseminate information, and committees provide the necessary incentives for legislators to specialize to achieve their political goals. Specialization is thus a potential collective good 
(Krehbiel 1991: 5) realized through institutional organization. Rather than consisting of highdemanders, as the distributive approach suggests, the informational perspective suggests that individual committees reflect the heterogeneity of the whole house, so that legislators can secure the gains from specialization while ensuring that the policy outcome does not deviate from the majority preference. Empirical tests of the distributive and informational perspectives have thus focused on the composition of legislative committees: do they consist of preference outliers, as the distributive perspective suggests, or are they representative of legislature as a whole, as the informational perspective maintains?

Analyses of EP committee composition suggest that they are heterogeneous in terms of both nationality and party affiliation and thus generally representative of the parent chamber (Bowler and Farrell 1995; McElroy 2003). Moreover, the evidence points toward a high degree of specialization among committee members who tend to self-select into the committees of their choice based on policy interest (McElroy 2003; Whitaker 2001), rather than constituency concerns (Whitaker 2001; Mamadouh and Raunio 2003). Therefore, empirical evidence suggests that EP committees assume an informational role by supplying information that reduces individual legislators' uncertainty about the consequences of diverse legislative proposals (Krehbiel 1991). This is also the role that the focal point theory assigns to individual committee members, meaning that the focal point theory falls squarely into the informational camp. Using the general propositions of the informational perspective as a starting point, the focal point model specifies the mechanism of information distribution by emphasizing that focal points situate specific policy proposals in reference to the ideology space, thus summarizing and 
simplifying the issue under consideration for those legislators not directly involved in the deliberation process. ${ }^{30}$

One important question this discussion raises, however, is whether reliance on specialized sub-units for information about policy proposals equals the abdication of policy making authority by the less-informed and less-involved backbenchers. ${ }^{31}$ Lupia and McCubbins (1994: 370) argue one way to avoid this loss of control by the principal is an institutional structure where "the likelihood that there will be informed adversaries is high," i.e., that there is "competition between information providers." According to Bowler and Farrell (1995), this is indeed the case in EP committees, which feature internal deliberative processes with opposing sets of interests. While this is probably, at least in part, because EP committees are not composed of homogeneous high-demanders in comparison to the parent chamber (McElroy 2003: 129), the structure of EP politics provides members with an additional, distinct way of checking the information they receive from their committee representatives. After all, MEPs are not just represented by members of their EP party groups, but also by representatives of their country of origin, and often by members of their national party delegations. This reality means that MEPs who delegate the role of information provider to specialized committee members can "triangulate" the information they receive. For example, a German Social Democrat can compare the positions assumed by the committee representatives of the Party of the European Socialists (PES), the German Social Democrats (SPD), and all the other Germans on the responsible

\footnotetext{
${ }^{30}$ It is important to note that this analysis does not follow the traditional path of weighing distributive against informational arguments in analyzing the composition of EP committees. Instead, it considers how information passes from committees, which have already been shown to be representative of the parent chamber, to the EP floor. ${ }_{31}$ As claimed, for example, by Blondel 1968; Meny 1990; Laver and Schofield 1990; Lowi 1979; Smith 1988; Wattenberg 1990.
} 
committee when deciding on a policy position. ${ }^{32}$ As a result, MEPs can feel assured that delegating to specialized committees still results in "good" policy.

\subsection{HYPOTHESES}

I evaluate the applicability of the focal point model vis-à-vis two alternative theoretical accounts of the conversion of outcome preferences into policy preferences. The first is an "exogenous preferences" model that perceives of policy preferences as a predetermined and fixed input into the policy making process. In this perspective, outcome preferences translate directly into policy preferences, and decision-making processes do not shape policy preferences and policy choice. In other words, both policy preferences and outcome-equilibria are predetermined.

H1a: Policy preferences are exogenous to the decision-making process. H1b: Outcome-equilibria are predetermined.

The second model follows the logic of the new-institutionalist "garbage-can" (Cohen, March, and Olsen 1972), where policy outcomes are the result of an unpredictable confluence of problems, solutions, participants, (problematic) preferences, and choice opportunities. These elements flow in and out of a garbage-can, and which problem gets matched with what solution is largely due to chance. According to the garbage-can approach, policy preferences and policy choice are the random outcome of the decision-making process.

\footnotetext{
${ }^{32}$ Naturally, MEPs may receive additional information from sources outside the parliament, such as national governments, national party leaderships, or lobbyists. The effect of these external sources of information will be discussed in the empirical sections below.
} 
H2a: Policy preferences are endogenous to the decision-making process.

H2b: Outcome-equilibria are random.

The focal point model, in contrast, views policy preferences as neither exogenous nor random. While they are considered to be the outcome of a dynamic process, rather than merely an input into this process, the translation of outcome preferences into policy preferences is not coincidental. Most importantly, there is one subset of actors (committee specialists) that steers the process of conversion for the entire population, and thus creates opportunities for policy choice. That is, committee specialists provide a common theme around which policy coalitions can form and thus make certain outcome-equilibria more likely than others.

H3a (= H2a): Policy preferences are endogenous to the decision-making process.

H3b: Outcome-equilibria are neither predetermined nor random, but can be predicted on the basis of the prevailing focal points.

\subsection{RESEARCH DESIGN}

The focal point theory entails predictions about decision-making processes as well as their outcomes. Hence, the empirical analysis is based on detailed qualitative data about the process of policy making in the EP and quantitative analyses of their outcomes, namely voting patterns in the EP plenary. The analysis proceeds in three steps. First, it examines the roles of committees in the European Parliament on a general level to determine if committee members serve as sources of information for legislative backbenchers. Second, it investigates to what extent legislators follow the lead of their committee members when voting on the floor. Third, it examines a series 
of six legislative proposals in detail to establish the mechanism and patterns of information provision.

These analyses are based on three sets of data: in-depth interviews, records of debates in the EP plenary, and roll-call vote data. The roll-call vote data is analyzed using multinomial logit regression and falls into two categories. First, I created a large-N dataset to compare the voting patterns in the committee responsible for a legislative dossier. This dataset includes 95 roll-call vote and 40,574 individual-level observations. Second, I analyze specific roll-call votes from my six case studies in each of the case study chapters. Specific details about these analyses are provided in the respective chapters.

The EP plenary debates are analyzed in a content analysis framework, utilizing a computer text analysis software package called Textpack to establish frequency-of-use lists and to identify keywords in context. This analysis serves to determine the extent to which different focal points dominated the deliberation processes concerning the legislative proposals serving as case studies. Once again, details about coding and analysis will be found below.

Finally, I rely on the responses of my interview partners from a series of 80 in-depth interviews with members of the European Parliament and EP officials, as well as a small number of representatives from the European Commission and the Council of Ministers. The interviews were conducted between June 2003 and March 2005 in a semi-structured format, consisting of a series of core questions supplemented by follow-up and in-depth discussion about different subjects the respondent was willing to provide further detail about. Each interview focused on one particular legislative proposal to be evaluated in a case study format, yet went beyond issues particular to the policy at hand to address broader questions about decision-making processes in the EP. 
While these interviews do not generate quantifiable data, this was not their purpose. Instead, they are supposed to provide in-depth understanding based on detailed observation about the processes and mechanisms of decision-making, which quantitative data alone could not provide. The result is a rich set of qualitative data providing general lessons and case-specific insights. It is important to note, however, that the interviews go beyond mere description and were conducted with the aim of testing theory, as they provide the basis for assessing deductively derived predictions about the sources and mechanisms of information provision. I thus seek to evaluate the overall consistency of the qualitative data with the predictions of the theory.

Unfortunately, judging the validity and the reliability of the data is difficult with this kind of approach. I seek to overcome this limitation through three means. First, I conducted a large number of interviews, allowing for a search for consistency across the answers provided. For each case study, I conducted between nine and 13 interviews for a total of 80 , reaching a point of saturation both with regard to the specific policy proposal and the general questions relating to processes of policy choice in the EP. Second, I conducted interviews not just with politicians: while 44 of the 80 respondents are MEPs (two of whom were interviewed twice, once in 2003 and again in 2005), 27 are EP officials, three are Commission officials, and four are Council officials. Once again, consistency of responses across this diverse range of respondents enhanced their credibility. Finally, I sought to interview a sample of respondents representative of the EP population, which was particularly successful with regard to political affiliation. The interviews involved representatives from all seven major party groups in the EP and are distributed across these party groups proportionately by party strength (measured as total number of MEPs). In this regard, the sample of respondents does represent a "microcosm" of the Parliament. Concerning the countries of origin of my respondents, however, the interviews are not distributed as 
proportionally, partially due to linguistic constraints, but also to availability and willingness to be interviewed. Specifically, Austria, Finland, Ireland, the Netherlands, and Sweden are overrepresented, while France, Italy, and Spain are underrepresented. Respondents from Belgium, Denmark, Germany, Greece, Luxembourg, Portugal, and the UK are represented more or less proportionally. It is important to note, however, that my sample does include respondents from all the (then) $15 \mathrm{EU}$ member states.

The interviews focus on six legislative proposals serving as case studies. These proposals concern:

- EU takeover legislation (legislative reference number: COD/1995/0341).

- Union Citizenship: free movement and residence (COD/2001/0111).

- Liberalization of port services in the EU (COD/2001/0047)

- Liability for environmental damage (COD/2002/0021)

- Statutes and financing of EU-level political parties (COD/2003/0039).

- A package of proposals on fuel quality and emissions from motor vehicles (COD/1996/164a, COD/1996/164b, COD/1996/163)

In selecting these cases, I limited the pool of possible choices to recently concluded dossiers that were decided under the co-decision procedure. I excluded cases where the controversy was of a technical or definitional nature, rather than content-driven. Among the remaining legislative proposals, I sought to assure variance in critical case characteristics, such as issue area, committee jurisdiction, party membership of the rapporteur, number of parliamentary readings, and level of initial controversy. This case selection is non-random, but does not constitute a selection on the dependent variable, as details about the proposals were entirely unknown at the outset of the research project. 


\subsection{INFORMATION FLOW AND THE ROLE OF SPECIALIZED COMMITTEES}

This chapter investigates how legislators receive the information they need to make informed decisions about specific policy proposals. In this effort, it considers the extent to which their positions are shaped by decision-making processes, and the impact of institutional structures on information provision and transmission.

Drawing from the interview data, the chapter demonstrates that MEPs often lack detailed information about the content and consequences of any given legislative proposal; that specialization in the EP committees serves as a way to alleviate this shortcoming; that specialized committee members constitute the primary providers of information to EP backbenchers; that a handful of committee experts creates their party groups' official positions toward each policy proposal; that committee members lobby for their positions among their colleagues; and that, ultimately, these positions are likely to be adopted.

Accordingly, this chapter demonstrates that policy preferences are hardly exogenous factors determining policy choice, a finding that contradicts hypothesis H1a, one of the propositions of the exogenous preference model. Instead, it lends support to the contention of the garbage-can and focal point models that policy preferences are endogenous to the decisionmaking process ( $\mathrm{H} 2 \mathrm{a}$ and $\mathrm{H} 3 \mathrm{a})$. 


\subsection{INCOMPLETE INFORMATION ABOUT THE CONSEQUENCES OF LEGISLATION}

One critical reason for the need for specialization in legislative decision-making is the informational constraints imposed on legislators by a lack of time and resources. This reality, and how it affects decision-making, was emphasized by numerous respondents in the interviews performed for this analysis. As one MEP noted:

"So many things happen in the EP, so many different subjects are being debated in different committees, that none of us follows everything with much detail ... You don't have the time to look at everything yourself ... We are always under time pressure here. ${ }^{33}$

This sentiment is widespread among MEPs, with time identified as the most important constraint. ${ }^{34}$ Closely related, however, are the limited resources available to MEPs in terms of personal and professional assistance. ${ }^{35}$ MEPs do not have the luxury of many advisors, ${ }^{36}$ and unless an assistant happens to be aware of a potential problem with a particular piece of legislation, for example, the MEP might very likely not be aware of it personally. ${ }^{37}$ As in other legislatures, such as the U.S. Congress (Hall 1996), individual legislators' choices about participation in the active treatment of different policy proposals is a function of their willingness to invest scarce time, energy, and resources.

\footnotetext{
${ }^{33}$ Respondent \#48.

${ }^{34}$ Respondent \#6, Respondent \#68, Respondent \#19, Respondent \#9, Respondent \#72, Respondent \#18, Respondent \#51, Respondent \#38; see also Corbett et al. (2005: 57-8).

${ }^{35}$ For details on members' assistants, see Corbett et al. (2005: 67-9)

${ }^{36}$ Respondent \#18. Members are provided with a secretarial allowance to employ personal assistants and have considerable freedom in using these funds. They may choose to employ two well-paid assistants or several less-well paid or part-time employees (Corbett et. al 2005: 67). The total number of assistants per MEP is rarely more than three or four, however.

${ }^{37}$ Respondent \#9.
} 
As a result, it is quite common for members not to know very much substantive detail about the issues under consideration. A number of respondents readily acknowledged that most members generally do not know the majority of what they are voting on. ${ }^{38}$ One explains that she knows what an issue is "basically about" from the discussion in the party group meeting, but when an issue is divided into " 75 votes, I really don't know each time what I vote ... If there is something that I don't care about, it must be handled by somebody who has more knowledge and interest in it." 39 Another MEP, from the transport committee, describes that he cannot follow what is going on in the environment committee with regard to animal testing "from A to Z." He relies on his party's specialists to scrutinize those issues for him so that he knows what the basic issues and divisions are. He is provided the essential information he needs to "make up his mind" by his party colleagues, but he cannot "pay attention to Paragraph 7, Part 8, of some dossier" he is not directly involved in. ${ }^{40}$

\subsection{SPECIALIZATION IN COMMITTEE}

This results in the delegation of decision-making authority to a number MEPs in the responsible legislative committee who are experts in the particular policy area under consideration. It is these few informed legislators who guide the parliament as a whole through a given legislative process and set the parameters for action. Following a natural division of labor between specialists on

\footnotetext{
${ }^{38}$ Respondent \#35, Respondent \#68, Respondent \#19, Respondent \#9, Respondent \#7, Respondent \#2. See also Rasmussen and Shackleton $(2005: 3,16)$, who maintain that the "vast majority" of MEPs are only able to "follow with difficulty the progress of negotiations before they are invited to vote at first or second reading" and that "the time available to verify an agreement is normally shortest at second reading, with the vote often taking place only a matter of days after the conclusion of negotiations. Necessarily this reduces the scope for challenges to an agreement, with other members obliged to accept on trust that they should vote in favor."

${ }^{39}$ Respondent \#7.

${ }^{40}$ Respondent \#19.
} 
different issues, legislators tend to follow the information and advise they receive from their colleagues. As the informational perspective on the role of committees suggests (Krehbiel 1991), MEPs essentially "leave it to the experts" and follow their lead, allowing them to reap the gains from specialization.

In this context, it was striking that a large number of respondents used the word "trust" unprompted during the interviews, ${ }^{41}$ while others used similar terms such as "relying on" ${ }^{42}$ or "following" committee experts. ${ }^{43}$ This finding matches what we know about the U.S. Congress, where analyses of vote choice have found that legislators rely on information from legislative specialists or "trusted colleagues" knowledgeable about the particular issue at hand (Zwier 1979; Matthews and Stimson 1975; Kingdon 1981; Sabatier and Whiteman 1985). As one senior MEP from the environment committee describes, when a social policy expert who he has known for many years approaches him and suggests a position on a social policy issue, then he will, under most circumstances, follow this advice. ${ }^{44}$ Another MEP explains that:

"You don't even read the report. You go to plenary, you have some general knowledge what is in that report, but you just trust your colleagues from your party in that committee. You trust that they are the experts, and that they have gone through the issue details. It is based on mutual trust." ${ }^{45}$

Others maintained that:

\footnotetext{
${ }^{41}$ Respondent \#4, Respondent \#6, Respondent \#7, Respondent \#11, Respondent \#19, Respondent \#22, Respondent \#35, Respondent \#38, Respondent \#42, Respondent \#42, Respondent \#44, Respondent \#47, Respondent \#47, Respondent \#48, Respondent \#68, Respondent \#72.

${ }^{42}$ Respondent \#14, Respondent \#34.

${ }^{43}$ Respondent \#1, Respondent \#8, Respondent \#69, Respondent \#18, Respondent \#55, Respondent \#51.

${ }^{44}$ Respondent \#22.

${ }^{45}$ Respondent \#35.
} 
"If you are a specialist [and] you don't know anything about some other issue ... then you are going to trust your colleagues." 46

"I trust my friends in the committee, and they trust me.",47

"You rely on your colleagues, especially on technical issues."

"[In each party group] you only really have three specialists, or four; the rest is [sic] just following the specialists." 49

As this last quote indicates, not everyone is a specialist on a given issue even within the responsible committee, especially in those with broad jurisdictions. ${ }^{50}$ The complex nature of many proposals effectively excludes most members from the detailed negotiations and deliberations even if they possess general expertise in the substantive issue areas covered by the committee. ${ }^{51}$ For example, an expert on environmental policy might be a specialist dealing with biodiversity and be relatively uninformed on the nitty-gritty aspects of carbon dioxide emissions; it is "double-Dutch, even for someone who is living with it every day," as one EP official maintained. $^{52}$

As a result, there are usually only a small number of people who assume the leadership among their party colleagues, ${ }^{53}$ who try to inform the committee about the breadth of the repercussions of what is going on, ${ }^{54}$ and who delineate the voting patterns of the party group as a

\footnotetext{
${ }^{46}$ Respondent \#72.

${ }^{47}$ Respondent \#11.

${ }^{48}$ Respondent \#14.

49 Respondent \#18.

${ }^{50}$ Respondent \#17, Respondent \#77, Respondent \#19, Respondent \#38, Respondent \#18.

${ }^{51}$ Respondent \#45, Respondent \#72, Respondent \#51, Respondent \#49.

52 Respondent \#51.

${ }^{53}$ Respondent \#18, Respondent \#19, Respondent \#38, Respondent \#45, Respondent \#48, Respondent \#49, Respondent \#6, Respondent \#32, Respondent \#68, Respondent \#33.

${ }^{54}$ Respondent \#38.
} 
whole. ${ }^{55}$ Moreover, time and resource constraints also affect committee members, with the result that even within the committee, responsibility for handling a certain dossier is delegated to a select few. The most important official position, in this regard, is that of the rapporteur, who handles a dossier on behalf of the committee and the parliament as a whole.

\subsection{THE ROLE OF THE RAPPORTEUR}

The question of who is the rapporteur is quite important, according to my respondents. One parliamentary official maintained that whenever a party group gets a dossier, the question is "Who will be the rapporteur?"56 The individual aspect is almost as important as what party group the rapporteur is from, as a number of respondents explain, because it matters whether she is a moderate or center person from the left or right, how she presents her report, and if she is looking to capture the middle ground. ${ }^{57}$ One official goes as far as suggesting that it does not matter at all what country or party group a rapporteur is from, but that it depends on personality alone. ${ }^{58}$ Whether the rapporteur establishes a wording of his report that is "as inclusive as possible, or [...] as narrow as possible" is of great importance for the decision-making process. ${ }^{59}$ The rapporteur has the ability to steer subsequent stages of the decision-making process through her initial report and her behavior throughout the process. ${ }^{60}$

\footnotetext{
${ }^{55}$ Respondent \#19, Respondent \#47.

${ }^{56}$ Respondent \#38, Respondent \#9, Respondent \#14.

${ }^{57}$ Respondent \#21, Respondent \#4, Respondent \#18.

58 Respondent \#33.

${ }^{59}$ Respondent \#38.

${ }^{60}$ Respondent \#14, Respondent \#48, Respondent \#34, Respondent \#30, Respondent \#37, Respondent \#35.
} 
An important question is which way a rapporteur is likely to be arguing her case. ${ }^{61}$ One MEP provided the example that "if you are doing stuff that concerns terrorism and the rapporteur is a UK conservative, you are going to get a very different take on the report than if you have got a Greek communist." 62 This is partially a substantive issue, but also relates to the "tone of language" of the rapporteur; if "just the style of presentation is highly confrontational," according to one MEP, it affects the process of deliberation. ${ }^{63}$

Accordingly, the importance of the personal reputation of the rapporteur was emphasized by a broad group of respondents. ${ }^{64}$ Here, the key question seems to be to what extent a rapporteur is willing to take on the role of the rapporteur on behalf of the whole EP or attempts to promote her national or individual position. ${ }^{65}$ Her approach is usually already apparent in the first preparatory stages in the treatment of a dossier, where she assumes the leading role. ${ }^{66}$ She could, for example, follow a strategy of creating a working document that reflects her own personal convictions and positions more than those of the EP as a whole, or even her own party group. Alternatively, she can immediately seek to incorporate the positions of others into her initial working document, including actual preliminary negotiations with representatives from the other party groups. ${ }^{67}$ This makes a significant difference not just in terms of cooperation among the key actors and the atmosphere within which deliberation and negotiation take place,

\footnotetext{
${ }^{61}$ Respondent \#37, Respondent \#14, Respondent \#38.

62 Respondent \#38.

${ }^{63}$ Respondent \#38.

${ }^{64}$ Respondent \#33, Respondent \#51, Respondent \#9, Respondent \#38, Respondent \#17, Respondent \#42, Respondent \#47.

${ }^{65}$ Respondent \#38.

${ }^{66}$ Respondent \#17.

${ }^{67}$ Respondent \#56.
} 
but also, and perhaps more importantly, impacts the outcome of the first reading, ${ }^{68}$ which sets the stage for successive readings by significantly constraining the room for maneuver.

These different styles affect how other MEPs perceive the rapporteur not just for the case at hand, but also in the future. If the rapporteur has the reputation of seeking cooperation and compromise, this will positively affect how she and her report are received in committee as well as in the plenary. ${ }^{69}$ This willingness and ability to compromise and go beyond national, partisan, or personal convictions is, in fact, what respondents identified as a primary factor of what makes a strong rapporteur, together with expertise and networks and contacts across party lines. ${ }^{70}$ One illustrative example for the importance of reputation was provided by a parliamentary official, who describes the reputation of Bernd Lange, a Socialist former MEP from Germany, as follows:

"If you were to do a study of all the reports done by Mr. Lange, you would find that 99 times out of 100, his proposals are adopted unanimously. In the past 5 years, the time I spent here, anything that he ever did, he was just blindly followed. [...] Everybody thought that he was not going to pull a fast one. Even the EPP went along with him on lots of stuff, on nearly everything.",71

\subsection{OTHER COMMITTEE ACTORS}

Since there is only one rapporteur for each legislative proposal, this position is allocated between the party groups, sometimes amidst considerable controversy. The party groups who do not end up holding a rapporteurship then appoint a shadow rapporteur, whose responsibility it is to

\footnotetext{
${ }^{68}$ Respondent \#4.

${ }^{69}$ Respondent \#17, Respondent \#33, Respondent \#47.

${ }^{70}$ Respondent \#4, Respondent \#17, Respondent \#9, Respondent \#33, Respondent \#18, Respondent \#42, Respondent \#47, Respondent \#25, Respondent \#70.

${ }^{71}$ Respondent $\# 9$.
} 
monitor the dossier on behalf of his party group. These shadow rapporteurs are very influential in that they are the primary negotiation partners of the rapporteur within the committee, as well as the primary sources of information for his or her party colleagues.

Each party group also has a group coordinator in each committee. The responsibilities of the coordinators are much more broadly defined that those of the rapporteurs or shadows, however, in that they do not focus on a single issue or proposal, but seek to establish a coherent approach to the entire universe of proposals under consideration in the committee. For example, they generally have a file listing the different legislative proposals that come to the committee, including a brief description prepared by the EP secretariat as to what they concern. ${ }^{72}$ Accordingly, their outlook is more universal than that of the shadow rapporteurs. Coordinators are, in essence, their party groups' leaders within the domains of the committee, and they are superior to the rapporteur or shadow rapporteur. In reality, however, rapporteur and coordinator tend to work in tandem and jointly lead their party groups through the decision-making process. As a result, they possess considerable discretion, including being able to "put a lid" on issues they prefer to leave out of a report. ${ }^{73}$

Finally, there is also an element of self-selected participation among committee members. If an MEP gets actively involved in a given issue based on personal interest or motivation, "you have to count him in," as one MEP put it. ${ }^{74}$ All together, then, the actual group of participants remains relatively small. Specifically, my respondents suggested that it is usually only a handful of experts from each party who really treat a legislative proposal in detail and bargain amongst

\footnotetext{
${ }^{72}$ Respondent \#29.

${ }^{73}$ Respondent \#38.

${ }^{74}$ Respondent \#45, also: Respondent \#18.
} 
themselves with regard to matters of public policy, ${ }^{75}$ and that the set of active participants shifts across bills (see also Hall 1996: 8). ${ }^{76}$ Only when an issue is especially controversial does this number increase. In the words of one official, the rest of the committee members, just as the remaining MEPs outside the committee, "are following what their leaders are telling them."77

This reality is also important in formal terms, since it leaves committee members who participate actively in the deliberation process of a specific legislative proposal with a great deal of influence, especially if they also happen to play official roles, such as rapporteur or shadow rapporteur. The impact that a single MEP can have on a policy outcome appears to greatly outweigh that of his counterpart in an EU member state. ${ }^{78}$ Therefore, it is not only a question of who is actually involved in the deliberation process, but also of the configuration of those involved. These factors can have a significant impact on the level of contestation or cooperation within the committee, the substantive content of deliberation and negotiation, and thus on the outcome of the decision-making process. ${ }^{79}$

The important role that particular individuals play in the decision-making process means that it depends to a significant degree on who is involved, how they interact with their colleagues, and their level of influence in their respective party groups. Different respondents described this element as follows:

"Each process is different depending on the people participating in it."

\footnotetext{
${ }^{75}$ Respondent \#45, Respondent \#48, Respondent \#49, Respondent \#6, Respondent \#18, Respondent \#19, Respondent \#38, Respondent \#32, Respondent \#68, Respondent \#33.

${ }^{76}$ Rasmussen and Shackleton (2005: 4) argue that MEPs have little informal control over the work of key negotiators, while Farrell and Heritier (2003a: 8) argue that "it is often extremely difficult for others within the Parliament ... to have any idea of what exactly is going on."

${ }^{77}$ Respondent \#18.

${ }^{78}$ Respondent \#6, Respondent \#44, Respondent \#37, Respondent \#72, Respondent \#45, Respondent \#48; see also Corbett et al. (2005: 9, 56-7).

${ }^{79}$ Respondent \#28, Respondent \#78, Respondent \#29, Respondent \#33, Respondent \#77, Respondent \#51.

${ }^{80}$ Respondent \#28.
} 
"You have to be aware of the intraparliamentary element as well, between groups and personalities in committee." 81

"It is an issue of how many people are worried, and how powerful they are." 82

"It certainly matters who is in charge of a report: who are the rapporteur, shadows, coordinators?"

\subsection{THE CREATION OF A PARTY LINE}

The informational structure of the party groups resembles a series of information filters, originating from the rapporteur and coordinator to the committee working groups, the coordinator meetings, the party working groups, and finally the party plenary. At each of these stages (which are explained and discussed below), information is made available and distributed, but within the constraints of time management and, to some extent, the strategic interests of the key players. The (more or less cohesive) official party line concerning a given proposal is the end result of this information distribution process, rather than an exogenous input preceding the decision-making process. ${ }^{84}$ Parties have, in the words of one MEP, "very broad lines, but there is no particular position on particular issues or particular directives. That is usually built up." 85 There is no party line dictated by the party leaderships, but rather one that is defined,

\footnotetext{
${ }^{81}$ Respondent \#78.

${ }^{82}$ Respondent \#29.

${ }^{83}$ Respondent \#77.

${ }^{84}$ Respondent \#47, Respondent \#34, Respondent \#2, Respondent \#72, Respondent \#45, Respondent \#17.

${ }^{85}$ Respondent \#45.
} 
represented, and propagated by the key actors. ${ }^{86}$ In a sense, what constitutes the party's "leadership" shifts with each legislative proposal and centers around the responsible rapporteur or shadow rapporteur and the party coordinators in the responsible committee. Rather than acting as representatives of an existing party line, those handling a dossier are its architects, as a large number of respondents maintained. ${ }^{87}$

The cooperation among the critical players is a crucial element in this regard, as it constitutes a back and forth between positions that is ultimately carried into the party groups and the plenary. The central role of individuals and the significance of their interaction are further enhanced by the importance of informal channels in the decision-making process, described by one EP official as follows:

"A lot of what goes on this parliament goes on in the lift, for example. The rapporteur bumps into the shadow from another group, and they have a bit of a chat, and maybe they will have a cup of coffee." ${ }^{88}$

Deliberation is thus not limited to formal settings, but proceeds (critically) in informal settings as well. ${ }^{89}$

Once the key players in the committee have established their positions, often already targeted at a compromise with the other shadows, they establish a common position with their party colleagues in committee during the meetings of the committee working groups, which consist of all members of a party group sitting on the committee. Of course, these committee

\footnotetext{
${ }^{86}$ Rasmussen and Shackleton (2005: 12) also argue that the grounds for deliberation and negotiation of particular legislative proposals is determined by the rapporteur and other key negotiators in first reading, when the formal positions of EP and Council are yet to be determined.

${ }^{87}$ Respondent \#16, Respondent \#22, Respondent \#1, Respondent \#2, Respondent \#72, Respondent \#9, Respondent \#18, Respondent \#45, Respondent \#48, Respondent \#56, Respondent \#19, Respondent \#44, Respondent \#33,

Respondent \#69.

${ }_{88}^{88}$ Respondent \#9.

${ }^{89}$ Respondent \#22, Respondent \#29, Respondent \#9.
} 
working group meetings are often preceded by informal or formal meetings between members of the same national delegations, who then promote their positions in the committee working group meeting.

Once a common position has been established among committee members from the same party, this position is presented either directly to the party plenary or, increasingly, to another set of intermediaries, namely within the coordinator meetings (where the coordinators from different committees exchange information) ${ }^{90}$ and (in the larger party groups, such as EPP, PES, and Liberals) the party working groups, which coordinate the parliamentary work of the party group members across different committees with overlapping policy competences. ${ }^{91}$ These steps are very important, as potential controversies are detected and discussed with members of the other committees who may have a stake in the issue. The party working groups in particular are designed to reduce and relieve the work-load of the party groups. In the words of one Socialist MEP, they "filter out"92 the most important aspects of a proposal and, if possible, are supposed to come to solidify a common party group position. ${ }^{93}$

It is at this step of the decision-making process, however, that a number of secondary sources of information and expertise can give their input into the evolution of a policy proposal. First, the lead committee is often not the only committee dealing with a particular piece of

\footnotetext{
${ }^{90}$ Respondent \#14.

${ }^{91}$ The EPP, for example, has five working groups: Working Group "A" (responsible for: Committee on Foreign Affairs, Human Rights, Common Security and Defence Policy; Committee on Development and Cooperation); Working Group "B" (Committee on Industry, External Trade, Research and Energy; Committee on Employment and Social Affairs, Committee on Culture, Youth, Education, the Media and Sport; Committee on Women's Rights and Equal Opportunities); Working Group "C" (Committee on Budgets; Committee on Budgetary Control; Committee on Agriculture and Rural Development; Committee on Fisheries); Working Group "D" (Committee on Legal Affairs and the Internal Market; Committee on Citizens' Freedoms and Rights, Justice and Home Affairs; Committee on Constitutional Affairs; Committee on Petitions); Working Group "E" (Committee on the Environment, Public Health and Consumer Policy; Committee on Regional Policy, Transport and Tourism; Committee on Economic and Monetary Affairs).

${ }_{92}$ Respondent \#56.

${ }^{93}$ Respondent \#2, Respondent \#72.
} 
legislation, as other committees can request to serve as opinion-giving committees. These committees also appoint their own rapporteurs, who draft reports on their behalf. These opinions are not binding, however, meaning that they do not have to be incorporated by the lead committee. As a result, the impact of opinion-giving committees is generally weak.

Furthermore, the EP party groups have their own political advisors who treat different dossiers on behalf of the party bureau. ${ }^{94}$ These advisors often work closely with the coordinators and rapporteurs of their party groups in the committees for which they are responsible. The party advisors can play important roles, especially in terms of coordinating various positions among party members; yet, the actual political responsibilities lie with the actors in the lead committee.

Finally, the EP has become one of the central hubs for lobbying activities as its legislative powers have increased over time. Lobbyists come to play a role particularly when issues are highly controversial, either a priori or in the process of deliberation. For them to be successful in affecting the positions of large numbers of MEPs, however, they still have to rely on the right "players" in the lead committees.

If a common position comes out of the party working group, it is unlikely to be questioned by the party plenary and stands as the official party line, including voting instructions for the plenary vote called "voting lists." ${ }^{" 95}$ In the words of one long-serving EP official:

"Sometimes the plenary of the group can depart from what is proposed by the working party people, the coordinator on the issue, or the shadow, but that is uncommon. Very, very uncommon." 96

\footnotetext{
${ }^{94}$ The party bureau is the leadership of the actual EU level party organization, rather than the parliamentary party group.

${ }_{95}$ Respondent \#34, Respondent \#2, Respondent \#43, Respondent \#33, Respondent \#72, Respondent \#45, Respondent \#58.

${ }^{96}$ Respondent \#72.
} 
Only if it is a very important issue for a national constituency or of conscience will national party delegations or individual actors deviate from the party line, following the so-called "conscience clause." In this rare case, a separate voting list is supplied by the national party delegation, allowing the individual MEP uninformed about the details of a proposal to compare and contrast positions.

In sum, the decision-making process in the EP strongly relies on extensive structuring of the matter under consideration before it reaches either the party group as a whole or the EP plenary. This is, in fact, the very purpose of the decision-making process being led by specialists: to avoid lengthy discussion of technical details in party group or EP plenary. ${ }^{97}$ Controversies are supposed to be settled amongst the specialists, while it is the broader political aspects of the proposed legislation that extend into the wider arena of party or EP plenary. Different, and more technical, aspects of a dossier might make it into the broader setting if they cannot be settled in committee, but is not very likely, especially with highly technical dossiers. ${ }^{98}$

One German MEP explicitly distinguished this system from the German Bundestag, explaining that committee members in the EP are not merely representatives of their party organizations. ${ }^{99}$ Decision-making in the EP committees is not based on predetermined positions, but the reverse: positions toward a legislative proposal are the product of committee deliberation and negotiation. The party plenary as a whole enters the picture only toward the end of the negotiation process, when committee deliberation is almost complete. The party plenary then determines if there is need for adjustment of the committee position, but in the words of one

\footnotetext{
${ }^{97}$ Respondent \#38, Respondent \#33.

${ }^{98}$ Respondent \#33, Respondent \#45

${ }^{99}$ Respondent \#37.
} 
British MEP, "it is rare for enough people in the full EP to study the question who are not on the committee, who actually want to change the whole thing."100

This system allows for a significant amount of individual leadership, yet with a series of checks and balances to the extent that it is hardly a "one-way street." respondents maintained, it would be very difficult to "sneak" something of substantial controversy through the different screening stages without somebody noticing along the way; ${ }^{102}$ hence, the party line proposed by the committee members has to be acceptable to the group. At the same time, all intermediary forums for deliberation falling in between the committee and plenary stage operate under significant time constraints, ${ }^{103}$ meaning that real controversy will only erupt if the issue contains provisions that are simply unacceptable to some. In most cases, according to my respondents, a majority position from the committee working group is likely to prevail in the party working group, which will then also succeed as the official party line in the party plenary. As a result, the transmission mechanism from key players in committee to the committee as a whole, and then further into the party groups and the EP plenary, functions quite smoothly, unless a player with the necessary stature intervenes in the process to raise additional concerns. In fact, this transmission from specialist to regular legislator appears to be the default option. This is partially for practical reasons. As one respondent explains:

"If we [in the committee] were to go to the full group with very sensitive issues that we could not agree on among ourselves, all hell would break lose. Because then you know what happens? Members actually read the amendments! And this is not good."104

\footnotetext{
${ }^{100}$ Respondent \#48.

101 Respondent \#47.

${ }^{102}$ Respondent \#48, Respondent \#14.

103 Respondent \#48.

104 Respondent \#9.
} 


\subsection{THE ROLE OF PERSUASION}

The rapporteur and shadow rapporteurs serve as the architects of the party line regarding a given legislative proposal, meaning that they are not assured the support of their parties a priori. ${ }^{105}$ Naturally, they have little coercive powers to actually "whip" their party colleagues into following this line. Therefore, discussion and persuasion play especially important roles in the internal party group deliberations, ${ }^{106}$ and the presentation of issues by the key players impacts to a significant extent how an issue is perceived by the less-involved party members. ${ }^{107}$ Rather than "whipping" their fellow colleagues into accepting their line, key committee actors have to "sell" it convincingly. The basic process consists of specialists seeking the necessary majorities for each individual dossier, rather than relying on an existing and predetermined configuration of party strengths. $^{108}$

Especially when there are competing views amongst different groupings in the EP, the "real battle begins before the plenary," according to one MEP. ${ }^{109}$ The active members from each group - the rapporteur, the shadows, and the coordinators in particular - lobby for their amendments, and "you can really influence your colleagues by doing a lot of work after the committee vote and before the plenary." Formally, it is the responsibility of shadow and coordinator to explain a common position to their party group and to convince them of its merit. One MEP describes this effort as "persuasion, or bringing to light the facts they [the other party group members] are not aware of."110 Active committee members thus act as internal pressure

\footnotetext{
105 Respondent \#4.

${ }^{106}$ Respondent \#45, Respondent \#56, Respondent \#22.

${ }^{107}$ Respondent \#59, Respondent \#16, Respondent \#25.

${ }^{108}$ Respondent \#2, Respondent \#40, Respondent \#37.

${ }^{109}$ Respondent \#35.

${ }^{110}$ Respondent \#58.
} 
groups among their party colleagues: they identify the key points of a legislative proposal to provide a general common understanding of why a position is taken. ${ }^{111}$

Discussions in the party group meeting tend to be short, especially when an issue has not been previously identified as controversial. Much depends on the presentation and substantive foci of the committee members, however: what features of the proposal do they emphasize? According to a number of respondents, particular issues or specific aspects of an issue are often simplified and emphasized to make them comprehensible to all, and to fit within the timeframe of the party group meeting. ${ }^{12}$ As a result, certain (potentially important) nuances are sometimes neglected. Instead, certain value-laden keywords may prevail in the debate, at the expense of a more differentiated discussion. Another MEP put it more bluntly: final plenary votes are not votes on the issue, but "on the issue as it is presented!"113 As there are "a number of bases on which to judge what legislation is going to do, or not going to do, and what it is about," it is often the particular focus created by those actively involved that informs vote choice. ${ }^{114}$

Finally, shadows have the additional argument that if they lack backing among their party colleagues, their negotiating position in committee will be severely undermined, and that what they are presenting is usually the product of extensive negotiations. ${ }^{115}$ Hence, when a compromise between different shadows and the rapporteur stands, the shadows will likely fight hard to have their positions accepted in their respective party groups, ${ }^{116}$ and the expectation is that they should, and indeed will. ${ }^{117}$ Any other result would be quite an embarrassment; the usual assumption among negotiators in the responsible committee is that shadows do have a mandate

\footnotetext{
111 Respondent \#38.

112 Respondent \#25.

113 Respondent \#16.

${ }^{114}$ Respondent \#16, Respondent \#59.

${ }^{115}$ Respondent \#7, Respondent \#48, Respondent \#33.

${ }^{116}$ Respondent \#33.

${ }^{117}$ Respondent \#7, Respondent \#58.
} 
from their groups. ${ }^{118}$ They might have to "go back and ask for a mandate" occasionally, especially when it comes to controversial points, but the sentiment, by and large, is summarized by a statement from one shadow rapporteur: "In the end, when I have done the negotiations, they better follow me!" ${ }^{119}$ Accordingly, the most common result is that after a short presentation by the coordinator or shadow the group will accept their positions relatively easily. The authority and standing of the shadow rapporteur are very important, however, and not all are equal. ${ }^{120} \mathrm{~A}$ lot, one MEP explains, depends on the image a shadow has in his group. The example she provides is that, given her own reputation and area of expertise, her party colleagues "probably" believe her when she argues that something "is good for small- and medium-sized businesses."121

\subsection{SEQUENCE: COMMITTEE TO PLENARY}

As a result of this process, what comes out of committee sets the stage for what is to come in plenary. ${ }^{122}$ While it is not a foregone conclusion that a majority in committee will automatically translate into a majority on the floor, ${ }^{123}$ especially when the committee vote was decided by a small margin, the majority of respondents suggested that the plenary will follow the committee.

"At the end of the day, the plenary always reproduces what has been done at the committee level ... Most of the time, the work that is done at the committee level is accepted by the plenary." 124

\footnotetext{
${ }^{118}$ Respondent \#68, Respondent \#33.

119 Respondent \#7.

${ }^{120}$ Respondent \#25.

121 Respondent \#35.

122 Respondent \#2, Respondent \#37.

${ }^{123}$ Respondent \#44, Respondent \#2, Respondent \#38.

124 Respondent \#72.
} 
"It is often the case that the configuration of the committee translates into plenary.", 125

"It is usually the case that the configuration in the committee is reflected in the plenary vote. $" 126$

"We have a sort of saying that the full EP results tend to follow the results of the committee.",127

"The consensus that arises from the committee is hoisted on the plenary as a whole ... The majorities in the committee are the same as the majorities in plenary. Parliament rarely goes against what the committee says ... Once an issue goes through the committee, it is going to invariably also make it through parliament.",128

"Once you have something approved by a committee, usually that committee manages to get this approved by their political groups." 129

This finding confirms what one would expect from an informational committee that is generally representative of the parent chamber (Bowler and Farrell 1995; McElroy 2003), namely that gains from specialization are ensured while committee outcomes appear not to be too detached from the majority preference (Krehbiel 1991).

\footnotetext{
${ }^{125}$ Respondent \#14.

${ }^{126}$ Respondent \#55.

${ }^{127}$ Respondent \#48.

${ }^{128}$ Respondent \#16.

${ }^{129}$ Respondent \#45.
} 


\subsection{SUMMARY AND CONCLUSION}

In sum, this chapter finds that MEPs rely on their specialized colleagues in the responsible committee for information about a legislative proposal. Moreover, it demonstrates that positions toward specific proposals are far from predetermined, since party positions are the product of the committee decision-making process, rather than an exogenous input. This confirms hypotheses $\mathrm{H} 2 \mathrm{a}$ and $\mathrm{H} 3 \mathrm{a}$ of the garbage-can and focal point models, which stated that policy preferences are endogenous to the decision-making process, and undermined the rival proposition of the exogenous preference model (H1a).

This chapter establishes that it is indeed the standing committees and their specialized members who serve as the principal providers of information to MEPs in the EP plenary, and that the positions assumed by committee members serve as the basis for the positions of the EP backbenchers. Much depends, however, on the configuration of actors involved, their reputations, and their interaction; as a result, processes and outcomes are uncertain.

One question this chapter raises concerns the link between parties and committees (Cox and McCubbins 1993). While the evidence highlights the informational role of committees in EP politics, it also emphasizes how party structures transmit positions toward policy proposals from the committee level to the EP plenary. Should we conceive of committees as informational bodies enhancing the possibility of making "good policy," as the informational perspective maintains, or are committees instruments facilitating the creation of a cohesive party line?

Since the informational and party control perspectives are not actually mutually exclusive or inherently contradictory, the answer to both questions is a conditional yes. On the one hand, information and the competitive exchange of information serve as tools for EP backbenchers to assure the representation of their interests even when they are not participating actively in the 
deliberation of a policy proposal. They can select who they "trust." On the other hand, the smaller number of actual participants who deliberate and negotiate on behalf of their uninvolved colleagues makes the formation of a common party position much easier, since the structure of the EP party groups ensures a smooth transmission of this position from the committee to the floor, at least most of the time. It is important to emphasize, however, that any party line is not imposed from above by the party group leaderships, but is endogenous to the deliberation process, which contradicts the notion of the cartel party proposed by Cox and McCubbins (1993). Instead, it appears that the party's leadership is a fluid concept, as those members actively participating in the decision-making process regarding a legislative proposal are the de facto leaders of their parties. 


\subsection{COMMITTEE POSITIONS AND VOTING ON THE FLOOR}

One of the principal findings of the previous chapter is that it is members of the standing EP committees who are the architects of a party group's position toward specific policy proposals. Unlike traditional parliamentary systems, where party positions are largely determined by strong party leaderships and based on a distinct government-opposition cleavage, a party line in the EP is not established prior to the deliberation in the first reading phase of the legislative decisionmaking process. Rather, it is the result of this deliberation process, with committee members establishing and proposing the positions their parties are to assume toward a policy proposal. As a result, it is commonly suggested that the position of the party group delegation in a given committee translates more or less directly into the plenary, i.e. that the configuration of intracommittee votes should be largely mirrored in the subsequent plenary vote. This proposition has not been empirically tested, however, a shortcoming this chapter seeks to rectify. It constitutes a first systematic comparison of votes on legislative resolutions in the responsible committees with the successive plenary vote.

The results show that the positions of committee members constitute significant predictors of voting patterns in the EP plenary. Specifically, they indicate that MEPs primarily follow their national party delegation colleagues in the committee responsible for a piece of legislation when voting in the EP plenary, but only when they actually have a colleague from their national party delegation in the committee. This is not the case most of the time, however. 
When not represented by a national party colleague, MEPs follow their party group representatives. Yet, they do not rely solely on the national party delegation or EP party group committee positions. Instead, they seem to compare the positions of their subsets of colleagues in the committee when making a vote choice: they "triangulate" the information they receive. As a result, an individual-level plenary vote is quite uncertain when the positions of committee representatives of the national party delegation and the EP party group representatives diverge, while MEPs are almost certain to follow the committee lead when there is a common position among national party and party group representatives.

Therefore, the evidence presented in this and the previous chapter disconfirms the contention of the exogenous preference model ( $\mathrm{H} 1 \mathrm{~b})$, which stated that outcome-equilibria are predetermined, since voting patterns in plenary are actually quite uncertain. Depending on the combination of actors in committee and the configuration of who is represented by whom, individual-level positions are more or less secure, and voting patterns on the EP floor will vary substantially.

\subsection{DATA}

This analysis is based on the entire population of plenary roll-call votes on legislative resolutions taken during the 1999-2004 parliamentary term under the co-decision procedure where the final votes in either the first or third reading stages were recorded by name. Excluded are those cases for which there was no preceding vote in committee, or when the committee vote did not take place in the same legislative term. I also excluded all cases where the votes of committee 
members were unanimous, as there would be no variation in the predictor variables. This yields a total of 95 roll-call votes and 40,574 individual-level observations.

\subsection{OPERATIONALIZATION}

For each roll-call vote, I identified how all members of the responsible EP committee voted based on their subsequent vote in plenary. I then treated these individual-level votes as predictors of plenary voting behavior. In light of the findings in the previous chapter, which showed that MEPs determine how to vote based on the positions of committee experts, there are three possible groups of experts who could serve in this position-setting role: first, the general population of MEPs may follow the vote recommendations of their party group colleagues in the committee. Second, they may follow the representatives of their national colleagues, rather than party group colleagues, when voting in plenary. Finally, they may focus specifically on the members of their national party delegations when considering how to vote.

To operationalize these variables, I determined three types of "majority positions." First, the majority position among committee members from the same EP party group. Second, the majority position of each national group. Finally, the majority position of each national party delegation. I defined majority position as a qualified majority of 60 percent. ${ }^{130}$ I then created variables for these common committee level positions of the EP Party Group, National Group,

\footnotetext{
${ }^{130}$ This threshold is chosen based on the following reasoning: using the common majoritarian threshold of 50 percent would entail that we identify a "common position" even when a grouping is, in fact, dramatically divided. For example, we would code a 100-99 majority in one of the large party groups as a common party position on an issue. At the same time, a threshold of two-thirds would be quite restrictive. We would, for instance, fail to recognize as a common position when five of eight members of a small party group vote together. The threshold of three-fifth, or 60 percent, was chosen to capture the middle ground. It is important to note, however, that most majority positions were quite robust; hence, it is unlikely that a different threshold would severely change the results of the analysis. The general patterns found below would likely be observed with different threshold specifications as well, while some of the actual values might vary somewhat.
} 
and National Party Delegation as predictors for the votes of all party group, nationality, and national delegation members in plenary, respectively. If there was no majority position, or if an individual MEP did not have a representative of his party group, national group, or national party delegation in the committee, it was coded as a missing value. ${ }^{131}$

Just like the dependent variable, which is simply the votes cast by the individual MEPs in the plenary, the three predictors can take three values: 0 for a No vote, 1 for a Yes vote, and 2 for an abstention. Descriptive statistics for all variables are provided in Table 1.

[Table 1 here]

\subsection{METHOD AND MODELS}

I analyze the data in a multinomial logit analysis framework. In formal terms, the primary regression model is expressed as:

(1) Vote $=a+\beta_{1}$ EP Party Group $+\beta_{2}$ National Group $+\beta_{3}$ National Party Delegation

To determine if the positions of committee members constitute potent predictors of voting patterns on the EP floor, that is, to establish the increase in the variance explained resulting from the inclusion of these predictors, I compare the model from above against a baseline model comprised simply of ideology variables for the sovereignty-integration and the

\footnotetext{
${ }^{131}$ Since it was not possible to establish the EP Party Group predictor for non-attached MEPs, they are excluded from the analysis.
} 
Left-Right dimensions. To account for individual-level positions on these dimensions, I use MEP NOMINATE coordinates on the classic economic Left-Right dimension and pro-/anti-integration divisions in the European Parliament (Hix, Noury, and Roland 2005). The variables range from 1 to 1 , where -1 indicates an extreme leftist position on the Left-Right dimension and an anti-EU position on the sovereignty-integration dimension. I also compare the variance explained of the original model to an additional model that includes both committee position predictors and ideology variables. These models are expressed as:

(2) Vote $=a+\beta_{1}$ Left-Right Position $+\beta_{2}$ Sovereignty-Integration Position

(3) Vote $=a+\beta_{1}$ EP Party Group $+\beta_{2}$ National Group $+\beta_{3}$ National Party Delegation $+\beta_{4}$ Left-Right Position $+\beta_{5}$ Sovereignty-Integration Position.

\subsection{RESULTS}

The first noteworthy result from the analysis of the voting data is that the positions of committee members are indeed very potent predictors of the voting patterns in the EP plenary. The pseudo-

$\mathrm{R}^{2}$ of model (1) increases by .51 in comparison to the baseline model (2), while the pseudo- $\mathrm{R}^{2}$ of model (3), which includes both committee predictors and ideology variables, is equivalent to that of Model (1):

Model (1): Pseudo- $\mathrm{R}^{2}=.57$

Model (2): Pseudo- $\mathrm{R}^{2}=.06$

Model (3): Pseudo- $\mathrm{R}^{2}=.57$ 
These results are strongly supportive of proposition that MEPs rely on their specialized colleagues in the responsible committee for information about a legislative proposal.

[Table 2 here]

Table 2 displays the multinomial logit regression estimates for Model (1), with "Abstention" as the omitted baseline choice. ${ }^{132}$ It shows that the coefficients representing the common positions of the EP party group and the national party delegation are highly statistically significant, meaning that both common positions are potent predictors of Yes and No votes in the EP plenary. The coefficient for the national party position, however, is quite a bit larger than that of the EP party group, meaning that MEPs are most likely to follow their national delegation members. A common position of the national group, in contrast, fails to achieve statistical significance. $^{133}$

Since these coefficients are substantively difficult to interpret, the program CLARIFY is used to calculate conditional predicted probabilities. Clarify, which is compatible with the STATA statistical analysis package, is a computer program that uses Monte Carlo simulation to convert the raw output of statistical procedures into results that are intuitive and of direct interest to the researcher, including predicted probabilities, without changing statistical assumptions or requiring new statistical models (King, Tomz, and Wittenberg 2000). For example, it allows for the calculation of predicted probabilities at different values of all independent variables, chosen by the researcher.

\footnotetext{
${ }^{132}$ Note that due to listwise deletion of missing values, the individual analyses conducted in what follows do not add up to the original $\mathrm{N}$ of 40,574 .

${ }^{133}$ Note that the statistical significance of the coefficients does not change if the standard errors in the clustered rollcall votes are adjusted for (making the standard errors slightly larger).
} 
The columns in Figure 13 display the predicted probabilities of MEPs voting in favor of a legislative proposal on the EP floor as a function of different configurations of positions among committee actors, meaning the predicted probabilities of a Yes vote in the plenary vote at different values of the other independent variables.

[Figure 13 here]

Column 1 presents the probability of an MEP voting in favor of a proposal in plenary when her party group, national group, and national delegation representatives in the responsible committee voted against (when the value of all three independent variables is 0 ). This probability is negligibly small at only two percent. Columns 2-4 show the probabilities of voting Yes when the national group (column 2), the national delegation (column 3) and the EP party group (column 4) support a proposal, while the other two respective groupings vote against. Column 2 demonstrates that the national group position is irrelevant in influencing vote choice: the probability of voting in favor of the proposal remains stable at two percent when the value of the national group variable is 1 and the values of the EP party group and national party delegation variables are 0 . In contrast, if the committee members from the MEP's party group vote in favor (column 4), the probability of a Yes vote increases by 31 percent to a total of 33 percent even if national group and the national party delegation vote against. The most powerful predictor, however, is the common position of the national party delegation (column 3): even if the party group and national group members in the responsible committee oppose a proposal, the probability of the MEP following the common position of her national party colleagues is 64 percent. 
Columns 5-7 show the additional increases in the probability of a Yes vote on the EP floor when different configurations of two of the committee groupings support a proposal. The pattern from above is also apparent in these columns. The probability of a Yes vote when national group and national delegation assume a common position in favor of a proposal while the party group opposes is 69 percent (column 5), while party group and national group sharing a common position in favor entails a probability of a Yes vote of only 38 percent (column 6). A vote in favor is all but assured, however, when party group and national delegation support a proposal together against the position of the national group; in this case, the probability of a Yes vote is 97 percent (column 7). This is equivalent to the probability of a Yes vote when all three groupings support the proposal (column 8), once again demonstrating the marginal impact of the national group position on voting patterns in the EP plenary.

These results also show that MEPs "triangulate" the information they receive from their party group and national delegation representatives. If these positions are contradictory, they are considerably less likely to follow one or the other, while a consistent position across both groups of representatives yields a very high probability of the MEP following the committee position.

[Figure 14 here]

Figure 14 shows the predicted probabilities of a No vote in plenary and confirms the pattern from above. ${ }^{134}$ Starting from a baseline probability of voting against a proposal of one percent when party group, national group, and national delegation support a directive (column 1), the pattern of increases in probability is almost exactly the same as in Figure 13.

\footnotetext{
${ }^{134}$ Note that since there are three outcome categories (Yes, No, Abstention), the probability of a No vote is not simply the opposite of the probability of a Yes vote.
} 
The probability of a No vote is two percent when both party group and national delegation representatives vote in favor, with the national group voting against (column 2). Party group members opposing the proposal raises the probability to 31 percent (column 4), while a common national delegation position against the proposal yields a 62 percent probability of MEPs opposing a proposal on the floor (column 3).

Once again, a joint common position of party group and national delegation members in opposition to a proposal entails a very high probability of MEPs voting No in plenary; as column 7 shows, this probability is 98 percent, thus supporting the triangulation thesis. In contrast, the probabilities resulting from joint positions of national group and national delegation (column 5: 67 percent) and between party group and national group (column 6: 36 percent) are considerably lower.

The results indicating the predicted probabilities of abstaining are presented here in two categories: the probability of abstaining when some group of committee representatives opposes a proposal, and the probability of abstaining when it supports a proposal. ${ }^{135}$ As the figures below demonstrate, this differentiation does show some alternative patterns. First, Figure 15 shows the probability of abstaining when other committee members vote against a proposal.

[Figure 15 here]

\footnotetext{
${ }^{135}$ Abstentions are often the result of individual MEPs or entire national delegations deviating from the party line on the basis of the "conscience clause," when a particular vote is perceived to have a special impact on their constituencies. To provide one example, a Belgian Christian-Democrat (Respondent \#25) interviewed in the context of the Port Services directive gave the following reasoning for abstaining in the final vote on the EP floor: "I did not want to change my mind or my vote, but also did not want to punish my Belgian colleagues with a No vote. Abstaining hurt neither the Belgians nor Mr. Jarzembowski [the rapporteur and party colleague].”
} 
The most obvious finding is that when it comes to abstentions, the position of the national party delegation members is the only potent predictor of MEPs abstaining on the EP floor. It entails a mere 10 percent probability of abstention, however, when party group and national group oppose a proposal (column 3, when the values of the party group and national group variables are 0 and the value of the national party delegation variable is 2). In contrast, neither party nor national group members abstaining in committee has any impact on the probability of MEPs abstaining in plenary, as columns 2, 4, and 6 demonstrate.

Column 5 shows that the probability of MEPs choosing to abstain on the floor is eleven percent when national group and national delegation representatives abstain in committee. This number increases substantially to 80 percent, however, when party group and national delegation abstain collectively in committee (column 7).

Next, Figure 16 illustrates the probability of abstaining when certain groupings of committee members support, rather than oppose, a proposal.

[Figure 16 here]

Once again, the probability of abstaining hinges primarily on the position of committee members from the national party delegation. This probability is higher, however, when party group and national group members support the proposal than when they oppose it (41 percent [column 3] versus ten percent [column 3 in Figure 15]). The probability of following party group members in abstaining is also slightly higher at nine percent (column 4), while the position of national group members is once again irrelevant (column 2). As in Figure 15, the probability of 
abstaining is most pronounced when party group and national party delegation members abstain together in committee (81 percent, column 7).

STATA's default way of dealing with missing values is listwise deletion, where any cases with missing data on one or more of the variables are eliminated from the analysis. In this analysis, listwise deletion of missing values means that only those cases are included when MEPs are represented by colleagues from their party groups, national groups, and national delegations in the responsible committee. This, however, is often not the case. Most importantly, in the majority of cases MEPs are not represented by members of their national party delegation: of the total $\mathrm{N}$ of 40,574 valid individual votes, 17,306 (or 43 percent) are missing because MEPs do not have a member of their national delegation taking part in the committee vote. So the question is: who do MEPs follow when they do not have a national delegation representative in the committee? The analysis above suggests strongly that they would follow their party group representatives. To ascertain this pattern, I run an additional analysis excluding those cases where MEPs are represented by national delegation colleagues in the committee.

[Table 3 here]

Table 3 displays the multinomial logit regression estimates for those votes where legislators do not have a national party representative on the responsible committee. Again, "Abstention" is the omitted baseline choice. The table shows that only the coefficient representing the common positions of the EP party group is statistically significant. This result indicates that a common party group position in committee is a more potent predictor of both Yes and No votes in the EP plenary. Hence, MEPs are far more likely to follow their party group 
colleagues on the responsible committee when they lack representation by members of their own national delegation.

Figure 17 makes the substantive impact of these coefficients more accessible by presenting predicted probabilities of a Yes vote on the EP floor. It shows that a common position in favor of a proposal on the part of the national group representatives yields only a 27 percent probability of an MEP voting in favor on the floor (column 2), while the probability is 81 percent when party group members vote in favor.

[Figure 17 here]

This pattern also applies in the case of No votes. Figure 18 shows that a common EP party group position in opposition to a proposal in committee entails a 73 percent probability of members voting against the proposal in the subsequent plenary vote (column 3 ), while this number is only 13 percent for a common national group position (column 2).

[Figure 18 here]

Finally, the EP party group position also constitutes the most potent predictor of abstentions in plenary. Figure 19 and Figure 20 demonstrate the probability of abstaining when the EP party group members in the responsible committee abstain collectively: it is 39 percent when the party group members vote against the proposal (Figure 19, column 3) and 38 percent when they support it (Figure 20, column 3). In contrast, national group members abstaining 
together in committee does not increase the probability of MEPs abstaining in plenary, as columns 2 in Figure 19 and Figure 20 show.

[Figure 19 here]

[Figure 20 here]

Committee Subsamples: One of the questions that remain is whether there are variations in the patterns from above as a function of issue area, i.e., the committee responsible for legislative proposals. I consider this by examining the probabilities of Yes votes in plenary by committee subsample.

For some committees (Environment, Legal Affairs, Regional Policy and Transport) the data provides a substantial amount of roll-call votes, while the number of roll-call votes from other committees is more limited. Therefore, I consider three subsamples based on the responsible committee:

- Environment Committee.

- Legal Affairs Committee.

- Regional Policy and Transport Committee.

- A subsample combining all remaining roll-call votes from those committees where ten or less roll-call votes were taken. ${ }^{136}$

${ }^{136}$ Votes from the following committees are included in this subsample: Committee on Citizens' Freedoms and Rights, Justice and Home Affairs; Committee on Constitutional Affairs; Committee on Culture, Youth, Education, the Media and Sport; Committee on Development and Cooperation; Committee on Economic and Monetary Affairs; Committee on Employment and Social Affairs; Committee on Industry, External Trade, Research and Energy; Committee on Women's Rights and Equal Opportunities. 
The results of these additional analyses suggest that there may be slight variations in voting patterns depending on the committee in charge of the legislation. Most importantly, the analysis of the subsample of different responsible committees suggests that national delegation representatives in the responsible committee are not necessarily the primary providers of information to their less-specialized colleagues in plenary. ${ }^{137}$ Figure 21, which includes the same substantive information as Figure 13, illustrates this variation. It shows that for the subsample of different committees with a small number of roll-call votes, it is the common position of party group members in committee that constitutes the primary predictor of voting patterns in plenary (column 4). The other predictors by themselves have little impact on the probability of MEPs supporting the legislation in plenary. It is noteworthy, however, that one important pattern from the analysis of the entire sample is confirmed here: when committee representatives from party group and national party delegation share a common position in committee, it is almost assured that a given MEP from this party group and national delegation will adopt this position in plenary. This probability of 97 percent is equivalent to that in Figure 13 (compare columns 7 in Figure 13 and Figure 21).

[Figure 21 here]

The other three subsamples of individual committees (Environment, Legal Affairs, Regional Policy and Transport) confirm the voting pattern from the whole sample of votes, as Figure 22, Figure 23, and Figure 24 demonstrate.

\footnotetext{
${ }^{137}$ To keep this discussion short, I explicitly discuss the predicted probability results only. The pure regression tables (Table 4 - Table 11) are attached in the Appendix of Chapter 5. I also focus here only on the probabilities of MEPs voting in favor of the legislation.
} 
[Figure 22 here]

[Figure 23 here]

[Figure 24 here]

In each case, the common position of national party delegation members in committee constitutes the most potent predictor of votes on the EP floor (see columns 3). This trend is especially pronounced in the Legal Affairs Committee (Figure 23), where the probability of a given MEP voting in favor of a legislative proposal is 97 percent when her national delegation representatives support the proposal in committee, even when there is a common position against the legislation among party group and national group representatives in the responsible committee.

The second most potent predictor of voting behavior in the EP plenary is a common position among party group representatives in committee (see columns 4 in Figure 22, Figure 23, and Figure 24), while the common position of MEPs from a member state is all but irrelevant.

Once again, one important voting pattern is confirmed in these analyses: a shared common position among party group and national party delegation representatives in the responsible committee entails that MEPs are almost certain to follow their lead. Columns 7 in Figure 22 (91 percent), Figure 23 (99 percent), and Figure 24 (96 percent) illustrate this trend.

As above, I also examine voting patterns based on these subsamples for the cases where MEPs do not have at least one national delegation colleague in the responsible committee. The 
following figures (Figure 25, Figure 26, Figure 27, Figure 28) display the same substantive information as Figure 17 and confirm the finding that when lacking representation from a national party group member on the responsible committee, MEPs are most likely to follow the common position of their party group colleagues. The probability of following party group committee members in supporting a legislative proposal thus ranges from 73 percent to 84 percent (columns 3 in Figure 17, Figure 25, Figure 26, Figure 27, Figure 28), even when national group representatives oppose the legislation. When the situation is reversed, on the other hand, this probability is significantly lower (between 17 and 35 percent, columns 2).

[Figure 25 here]

[Figure 26 here]

[Figure 27 here]

[Figure 28 here]

To sum up the results from the subsample analyses: if committee members from a party group and national party delegation share a common position in favor of a piece of legislation, MEPs on the EP floor are almost certain to support the legislation as well. In contrast, the positions of national representatives are all but irrelevant. These patterns confirm the results from the whole sample of roll-call votes analyzed above. The results presented in Figure 21, on the other hand, suggest that there may be variation in the relative predictive power of the party group 
and national party delegation variables. While the analyses of the whole sample of votes and three committee subsamples (Environment, Legal Affairs, Regional Policy and Transport) identify the common position of the national party group representatives in committee as the most potent predictor of voting patterns on the floor, the findings from the subsample consisting of votes from a variety of different committees suggest that the common position of party group representatives may be relatively more potent. Future analyses of larger number of votes from these committees may shed light on this issue.

The Question of Selection Bias: My data raises some questions with regard to selection bias arising from the use of roll-call vote data. As discussed mentioned above, Carrubba et al. (2004) show that the recorded votes in the EP differ along several dimensions from the remaining votes in the EP (for example, by requesting party group and substantive issue area), indicating that the roll-call vote sample in the case of the EP may be severely biased. They also show that this bias touches directly on the issues of party group cohesion and the dimensionality of policy conflict. First, the analysis of the roll-call vote sample illustrates that the votes appear to be requested disproportionately by the party groups, meaning that these requests are likely selective and strategic either for contentious decisions or to discipline the party rank-and-file. As a result, findings of party cohesion must be regarded with skepticism, and results about the dimensionality of the political space are questionable since not all party groups all have identical policy agendas. Second, studies using roll-call votes have likely misrepresented the policy space because the sample of votes is not representative by issue area, either; as a result, dimensions of 
conflict from issue areas under-sampled might be disregarded, while those over-sampled would be exaggerated. ${ }^{138}$

While instructive and pointing out very real potential problems associated with analyzing roll-call votes, a number of issues cast doubt on the validity of Carrubba et al.'s claims. First, the authors draw conclusions concerning the biasedness of roll-call votes on a sample of votes that is likely biased itself. They are relying on a dataset that includes all votes in the EP plenary sessions from July 1999 to June 2000 without taking into account that during the first year of a new legislative term, the number of roll-call votes taken may be significantly lower than in succeeding years, since the amount of legislative activity may be lower during the first months in office. Much time is spent on the allocation of official positions and the determination of committee responsibilities, size, and membership, for example. My own set of data used in the analyses above also suggests that the number of roll-call votes taken between July 1999 and June 2000 may indeed be much lower than in later years. Of the total number of 122 votes on legislative reports collected for the 1999-2004 term, only 17 fall into the time period examined by Carrubba et al., while the average number of roll-call votes is 26.25 for the other four years of the fifth EP. It is thus questionable if the set of votes included in their analysis is, in fact, a representative sample of the total universe of roll-call votes. Instead, it appears that the time period covered is an "outlier" in its distribution of roll-call versus unrecorded votes.

More importantly, Carrubba et al. are also not asking the right counterfactual question to truly make a causal statement about the biasedness of roll-call vote samples. If they want to claim that the outcomes we witness when analyzing roll-call votes are contaminated by the bias

\footnotetext{
${ }^{138}$ Simon Hug (2005) presents evidence for selection bias in recorded vote in the Swiss lower house, illustrating to what extent commonly used figures on party discipline are biased because of the selective nature of roll call votes. James M. Snyder (1992) examines similar issues of selection bias for the U.S. Congress.
} 
of the sample used, they need to demonstrate that in a world in which all roll-call votes were unrecorded, people would actually be voting differently (at least by and large) than they are now. This assumption is merely implicit in their argument, however, which exaggerates the importance of party control in that it emphasizes that party leaders strategically request roll-call votes to enforce party discipline. The authors thus assume that MEPs would vote differently if a given vote was unrecorded. My own research shows that this counterfactual is, in fact, unlikely.

I argue that MEPs rely on trusted specialists when taking positions on issues that fall outside their own realms of expertise. In search for reliable information, they are most likely to turn to their party colleagues who happen to be experts in a given policy area. If this is true, which my research strongly suggests is the case, then the counterfactual Carrubba et al.'s propositions are based on is incorrect, because party cohesion is not a function of party control but of policy expertise, information, shared ideology, and interpersonal trust. In this scenario, MEPs are no more or less likely to follow their party experts in roll-call votes than in unrecorded ones. In counterfactual terms, then, what Carrubba et al. need to show to make their case is that legislators would — to a significant degree and in substantial numbers—vote differently if a given vote is a roll-call vote versus an unrecorded vote. The evidence presented here critically undermines this proposition, however.

Unfortunately, the next step in adjusting for potential biases in roll-call vote analyses by incorporating an explicit model of roll-call vote requests, for example in a Heckman selection bias model, has not yet been taken. Therefore, the question of selection bias in using EP roll-call vote data remains unanswered in both theoretical and empirical terms. Future research in this direction holds much promise, and it will be instructive to re-run the analyses presented here with an adjustment for potential bias in roll-call votes. 


\subsection{SUMMARY AND CONCLUSION}

These results show that the positions of EP committee members are significant predictors of MEP voting patterns in the plenary. MEPs rely primarily on their national party delegation colleagues in the committee responsible for a piece of legislation when making their vote choices on the EP floor, if they have national party representatives sitting in the committee. When this is not the case, that is, more than 40 percent of the time, they follow their party group representatives. This pattern is evident with regard to votes in favor of and opposition to a proposal, as well as abstentions.

The results also suggest that MEPs "triangulate" the information they receive by comparing the positions of their different representatives in the committee. Most importantly, they evidently compare the positions of party group and national delegation members. When these positions diverge, the resulting vote in plenary is quite uncertain. When both share a common position, however, the probability of a backbencher voting accordingly in plenary is very high indeed: as columns 7 in Figure 13, Figure 14, Figure 15, and Figure 16 demonstrate, this probability is 97 percent for a Yes vote, 98 percent for a No vote, and 80 percent or 81 percent in the case of an abstention.

These results mirror one of the key findings of Hix (2002), who argued with regard to voting patterns in the EP that when the national parties in the same parliamentary group decide to vote together, the EP parties look highly cohesive, but that this cohesion breaks down when national party delegations take opposing policy positions. Here, I find that when the committee members of the national party delegations share the common position of their EP party groups, their national party colleagues are almost certain to follow their lead. However, while Hix makes a principal-agent argument and maintains that MEPs respond to the principals who control their 
election (the national parties) rather than the principals who control their influence in the EP (the EP party groups), this and the previous chapter suggest that the key to these patterns of behavior is information. MEPs are more likely to follow their national party colleagues because they trust the information they receive from their national party experts on specific policy issues more than that of their party group experts from different national party delegations. Only if they are not represented by "one of their own" do they rely more heavily on party group experts. When both national party and EP party group experts agree, however, and provide a common set of information, these two bases of trust combine and make it almost certain that the individual MEP will follow their lead.

Thus far, the empirical analyses have focused on the broader patterns of information provision in the EP, linking individual level voting patterns in the EP plenary to the parliament's standing committees. These analyses show that EP backbenchers rely primarily on their committee representatives for information about particular legislative proposals, and that the positions of committee members constitute a highly statistically and substantively significant predictor of voting patterns on the EP floor. This evidence disconfirms the proposition of the exogenous preference model (H1b), since outcome-equilibria in EP decision-making are far from predetermined.

The question that remains, however, is to what extent outcome-equilibria are the random results of decision-making processes. While the garbage-can model suggests that particular outcomes are largely due to chance, as problems, actors, and opportunities converge (H2b), the focal point model considers this process to be much more structured. Outcomes may not be predetermined, but they are not random either $(\mathrm{H} 3 \mathrm{~b})$. The model maintains that focal points provided by committee specialists constitute the basis of policy preferences and thus create 
opportunities for policy choice by making certain outcome equilibria more likely than others. To test this proposition and to examine the role of focal points as the mechanism translating outcome preferences into policy preferences, the following chapter examines a series of six legislative proposals from different policy areas as case studies. 


\subsection{MECHANISMS OF PREFERENCE FORMATION: CASE STUDIES}

\subsection{INTRODUCTION}

The previous two chapters provided two critical insights into EP decision-making. First, they established that the policy preferences of MEPs are endogenous to legislative decision-making processes, as legislative backbenchers rely on their specialized colleagues for information about a given legislative proposal prior to taking a position on the issue. Second, the chapters demonstrated that outcome-equilibria in the EP are a function of the decision-making process, and thus far from predetermined. Hence, both propositions of the exogenous preference model (H1a and $\mathrm{H} 1 \mathrm{~b}$ ) are disconfirmed at this point.

This chapter considers if decision-making outcomes in the EP are the random results of decision-making processes $(\mathrm{H} 2 \mathrm{~b})$, as the garbage-can model suggests, or the result of more structured decision-making processes where committee specialists create opportunities for policy choice by providing informational focal points that serve as the bases of policy coalitions. If this latter scenario were true, outcome equilibria would be neither predetermined nor random, but predictable on the basis of the prevailing focal points $(\mathrm{H} 3 \mathrm{~b})$. This hypothesis is based on the following logic: a focal point affects how actors in plenary perceive a specific policy proposal, which, in turn, affects their policy preferences. These policy preferences provide the basis of multi-actor policy coalitions, the constellation of which determines plenary voting patterns and 
thus policy outcomes. Hence, the identification of the dominant focal point(s) in the deliberation of individual policy proposals allows for predictions concerning the expected policy outcomes.

Moreover, the characteristics of focal points provide the basis for a set of specific expectations concerning the way in which their provision by specialized committee members impacts the policy preferences of other legislators. If the focal point model were correct, the analyses of the individual legislative proposals would have to show that certain broad representations of the specific issues involved in a legislative dossier, rather than technical aspects of the proposal, dominate the decision-making process; that this focus serves to unambiguously emphasize one (or very few) consequences of a policy proposal; and that this emphasis constitutes a broad categorization of what a legislative proposal is "all about," i.e. what outcome preference it targets. In contrast, the applicability of the focal point model would be called into doubt if these proposition did not hold true, specifically if committee members provided detailed, technical information to their fellow colleagues; if they simply supplied voting instructions without any necessary element of persuasion; or if there already were predetermined positions prior to committee deliberation.

This chapter investigates the mechanism of information provision by analyzing a series of recent legislative proposals as case studies. The cases are analyzed using interview data, basic content analysis of parliamentary debates, and multinomial logit analysis of individual roll-call votes. The legislative proposals analyzed concern:

\subsection{EU takeover legislation}

6.3. the statute and financing of EU-level political parties

6.4. proposals on fuel quality and emissions from motor vehicles

6.5. liability for environmental damage

6.6. the liberalization of port services in the $\mathrm{EU}$

6.7. EU citizenship and the free movement of people 
In what follows, the case studies serve as illustrations of how political processes and outcomes differ depending on how a legislative proposal is presented by committee specialists. Strategically deployed focal points influence the variable interpretation of what the issue at hand is "all about," thus shifting policy preferences during the process of parliamentary deliberation, with important consequences for legislative outcomes.

The analysis of each case study shares a common structure. A first section provides a brief overview of the content of the legislative proposals and an outline of the course of events of the decision-making process. The subsequent qualitative analysis of the decision-making process is based on interviews with MEPs and EP officials that were closely involved in the deliberation and/or the negotiation of the proposal. This part of the analysis serves a number of functions. First, it offers important details regarding the content of the proposal. Second, it provides insights into the deliberation and negotiation process concerning each proposal, and the roles of key legislators in steering the decision-making process. Finally, it provides critical insight into how the content and implications of the proposed legislation were presented to the MEPs not directly involved in the decision-making process. This is particularly important because it allows for the identification of the prevalent focal points dominating the discussion.

Next, I conduct simple content analyses of the EP debates concerning each legislative proposal. I first identify a series of keywords in each set of debates, which I then code consistent with the dominant focal points identified in the preceding qualitative analysis. I then use a content analysis program named TEXTPACK to provide frequency-of-use details for each category, and to identify keywords-in-context to check for systematic errors and inconsistencies.

Finally, I examine the outcomes of the legislative decision-making processes by analyzing the final votes taken on the EP floor, subject to the availability of recorded votes by 
name. These analyses are performed in a logit analysis framework. The possible outcome categories are votes in favor of the legislation (where the categorical variable assumes a value of 1), votes against (0), or abstentions (2). Some cases suffer from within-group multicollinearity with regard to the abstention category, however, as there is usually only a small number of abstentions for each vote. Hence, in most cases I treat abstentions as de facto votes against the proposed legislation (since under absolute majority rule, abstaining has the same effect as voting against) and use binary logit analysis instead of multinomial logit. If both options are feasible, I conduct binary logit as well as multinomial logit analyses and point out any substantively different results. For the sake of consistency of presentation across all six case studies, however, I only discuss the results of the binary logit analyses in the text and, where applicable, provide the results of the multinomial logit analyses in an appendix. Using CLARIFY, the raw output of the logit regressions is converted into substantively meaningful predicted probabilities.

The dependent variables in all of these analyses are the individual votes on the legislative report in the EP plenary. The independent variables fall into three categories. First, I use MEP NOMINATE coordinates on the two primary dimensions of the European political space to account for individual-level positions on the Left-Right and sovereignty-integration dimensions. These coordinates represent the classic economic Left-Right dimension and pro-/anti-integration divisions in the European Parliament, respectively (Hix, Noury, and Roland 2005). The variables range from -1 to 1 , where -1 indicates an extreme leftist position on the Left-Right dimension and an anti-EU position on the sovereignty-integration dimension.

Second, to determine if representation in the Council of Ministers or national-level Government-Opposition dynamics affects voting behavior in the European Parliament, I include a dichotomous variable based on the national government or opposition status of particular 
national party delegations, where a value of 1 means that a party was part of the national government.

Finally, I include different measurements for "national interests" with regard to each legislative proposal. For instance, I include "type of capitalism" dichotomous variables in the case of the proposals that would have economic implications for EU member states at the national level; ${ }^{139}$ a dichotomous variable indicating if member states have national legislation allowing same-sex marriages for the Union Citizenship proposal; and a variable accounting for national party finance rules for the legislation on an EU party statute.

The propositions of the focal point model find support in these analyses, as focal points are shown to significantly affect how legislative backbenchers interpret the content and consequences of the proposed legislative proposals. As such, they shape policy preferences and evidently influence vote patterns on the EP floor.

In each case, it is possible to predict voting patterns on the basis of the focal points dominating the deliberation process. This finding confirms hypothesis $\mathrm{H} 3 \mathrm{~b}$, and thus supports the contention of the focal point model. It also undermines the suggestion of the garbage-can model that policy outcomes are the result of a random decision-making process, and thus disconfirms H2b. In fact, specialized legislators have a considerable influence on the policy preferences of their less-informed colleagues. They can, and do, provide the bases for policy coalitions and, in turn, legislative outcomes.

\footnotetext{
${ }^{139}$ This set of variables falls into four categories: liberal market economy (Ireland and the United Kingdom); partial or family-oriented coordinated market economy (France, Italy, Spain, Greece and Portugal); sectoral coordinated market economy (Germany, Austria and Benelux countries); national coordinated market economy (Scandinavian countries) (Kitschelt et al. 1999; Rhodes and Van Apeldoorn 1997).
} 


\subsection{THE EU TAKEOVER DIRECTIVE}

The " $13^{\text {th }}$ directive on company law: takeover bids, protection of shareholders, workers' rights to information" (COD/1995/0341)" constituted one of the most high-profile pieces of legislation ever to pass through the EP. Its purpose was to establish common European-wide rules regulating the rights of shareholders and the use of defensive measures in the event of corporate takeover bids. By the time it was introduced by the European Commission in 1996, the idea of establishing a European level framework governing cross-border corporate takeovers had been on the EU agenda for many years. Early attempts to introduce Europe-wide takeover regulation date back to the early 1970s, when the Commission drafted its first directive for takeover bids. ${ }^{140}$ The proposal was discussed for some time with representatives from the member states, but the project was ultimately abandoned due to limited interest. The directive resurfaced ten years later, but the Commission draft was once again criticized widely and met with little attention on the part of the member states.

Over time, however, a considerable void in cross-border regulation in the European Union became increasingly apparent. Under mounting pressure, also from the European Parliament, the Commission presented another proposal for a takeover directive in January 1989. The proposal triggered intense debate and was criticized principally for not leaving enough latitude to national authorities. By the end of 1991, the Commission announced its intention to prepare yet another draft proposal, taking into account these arguments.

This new proposal, the $13^{\text {th }}$ Directive, was presented five years later. It was made more consistent with existing national regulation than was the case in previous attempts of reform and

\footnotetext{
${ }^{140}$ For more complete information and discussion of the directive's history and content, see the Web site of the EP
} http://www.europarl.eu.int) and Berglöf and Burkart (2003). 
proposed a 'framework directive,' containing general principles that member states would be obliged to follow when drafting their national takeover codes. As such, the legislation was less ambitious than previous proposals. It stipulated five general principles (Hix et al., forthcoming: 270): (1) equal treatment for all shareholders; (2) that the target of the takeover bid receives the necessary time and information to make a educated decision on the matter; (3) that the management board of the offeree company acts in the interests of the company and its shareholders; (4) that it be prohibited to create false markets in the securities of the offeree company; and (5) that offeree companies must not be hampered in the conduct of their business for any longer than necessary for a bid to purchase their shares. Another key element of the proposed legislation, following the British model of corporate governance, was a 'neutrality rule' whereby companies would not be allowed to take defensive measures against a takeover bid once a bid had been launched without gaining the specific approval of shareholders for the action.

The proposed legislation was deliberated in the EP for a period of five years. While a compromise agreement between Council and EP seemed quite possible in the initial stage of the decision-making process, controversy concerning the proposed legislation increased dramatically over time. In first reading, which took place in June 1996, the EP approved the report of the rapporteur in the responsible Legal Affairs Committee, Nicole Fontaine, a French member of the European People's Party group (EPP). It thus followed the recommendation of the committee, which had voted almost unanimously in favor. The EP proposed 22 amendments to the Commission proposal, including demands for definitional clarifications and measures to strengthen the rights of employees and their representatives. The Commission's amended 
proposal, as well as the Council's unanimous Common Position, incorporated most EP amendments without challenging the proposal's general principles. ${ }^{141}$

Following the EP election in June 1999, Ms. Fontaine became the President of the $5^{\text {th }}$ European Parliament and passed the rapporteurship of the $13^{\text {th }}$ Directive to her German EPP colleague Klaus-Heiner Lehne. The new rapporteur, however, assumed a position in the second reading that was " 180 degrees opposite to the first reading," according to a Commission official involved in the dossier. ${ }^{142}$ Under Mr. Lehne's leadership, the EP amended the Council's common position substantially with measures discouraging hostile takeover bids. Most importantly, it proposed amendments making it easier for the boards of target companies to use defensive measures, effectively replacing the British-style 'neutrality rule' with the German practice (Berglöf and Burkart, 2003: 187; Hix, Noury, and Gerard 2005). Due to this rejection of the Council's common position, the legislation went into conciliation. Following a long and intense conciliation procedure and an 8-7 vote by the EP delegation in favor of a compromise agreement, the takeover directive was rejected in July 2001. With the major EP party groups deeply divided, the vote had been declared 'free.' In the end, and based on the fact that the Parliament's Rules of Procedure state that a tied vote equals a rejection, the EP rejected the conciliation with a tied vote of 273 in favor, 273 against and 22 abstentions.

\subsubsection{Qualitative Analysis: Focal Points and the Legislative Process}

The qualitative analysis of the decision-making process concerning the takeover directive supports the proposition that strategically deployed focal points shifted policy preferences of

\footnotetext{
${ }^{141}$ EP Legislative Observatory.

${ }^{142}$ Respondent \#12.
} 
those MEPs not directly involved in the deliberation of the legislation. This shift in policy preferences, in turn, critically shaped policy outcomes. In the case at hand, three focal points shaped the process of contention surrounding the $13^{\text {th }}$ directive. These focal points took prominence at different points in time. In the early stages of the deliberation process, a focal point relating to the sovereignty-integration dimension was particularly pronounced. This focal point stressed the significance of completing the European single market in the realm of company law and was particularly notable during the first reading stage. It was gradually replaced, however, by two alternative focal points in the second and third reading stages, namely the issue of workers' rights and the notion of creating a "level playing-field" across the EU. The first of these two elements relates to the Left-Right divide by emphasizing the question of employee information and consultation in the case of a takeover or merger. The second raises concerns about the impact of the proposal on businesses in the different member states, a core constituency of all MEPs, by suggesting that the takeover directive would favor businesses in certain countries while putting others at a comparative disadvantage.

These focal points were introduced strategically at different stages of the proposal's lifecycle by the primary legislative actors in the European Parliament, who framed the political process in ways advantageous to their objectives. These actors were in principal members of the Committee on Legal Affairs and Citizens' Rights, and especially the two rapporteurs handling the dossier.

Early on in the legislation decision-making process, the proposal was considered by the $4^{\text {th }}$ European Parliament (1994-99) and treated by rapporteur Nicole Fontaine. Ms. Fontaine was strongly in favor of the directive. Upon presenting her report to the plenary on June 25, 1997, she 
declared that she hoped "with all my heart" that the EP would vote in favor of the proposal. ${ }^{143}$ She presented the dossier as a necessary step toward the completion of the European single market with due consideration to the principle of subsidiarity. ${ }^{144}$ Accordingly, and as the focal point model would predict, deliberation in the Parliament under her rapporteurship was dominated by the issues of harmonization and subsidiarity, with a particular focus on the question of what type of directive would best ensure an appropriate balance between the two.

Klaus-Heiner Lehne, however, the new rapporteur who replaced Ms. Fontaine before the second reading, presented the proposal to the incoming parliament in a dramatically different fashion. He portrayed the issue as being about the creation of a "level playing-field" across the EU, rather than about completing the single market. Thus simplifying the technical content of the proposal for his fellow parliamentarians, he shifted attention toward imbalances with regard to defensive measures that companies could take to protect themselves against hostile takeovers, ${ }^{145}$ despite the fact that the essence of the proposal was the same as in first reading stage. While the takeover directive required shareholders to approve any defensive measures enacted by managerial boards, the position of the rapporteur stressed the German corporate tradition giving the board of the target company substantial autonomy and authority to frustrate a takeover attempt. Mr. Lehne maintained that the directive, as proposed by the Commission, would put certain national companies at a disadvantage both relative to companies from other European countries and from the United States, allowing some corporations to initiate cross-border takeovers while being protected against hostile takeover bids themselves. ${ }^{146}$

\footnotetext{
${ }^{143}$ Debate of the European Parliament, June 25, 1997.

${ }^{144}$ Subsidiarity is the principle whereby the Union does not take action (except in the areas which fall within its exclusive competence) unless it is more effective than action taken at national, regional or local level.

${ }^{145}$ Respondent \#27.

${ }^{146}$ Debates of the European Parliament, December 12, 2000 and July 3, 2001.
} 
The second issue gaining prominence throughout the political process was that of employee information and consultation in takeover and merger activities. The discussion revolved around the specific question of employee consultation and information in the event of mergers and takeovers, but also featured an ever more prominent discussion about the desirability of mergers, and the question of shareholder versus stakeholder value. Once again, the complex repercussions of the legislative proposal were simplified, this time in terms of "workers' rights." The issue continuously gained in visibility throughout the legislative process,${ }^{147}$ which was somewhat surprising from the Commission's point of view since the issue had been discussed early on in the informal trialogue meetings between Commission, Council, and Parliament. According to a senior Commission official, a member of the Socialist group in the EP had been invited to the meetings specifically to ensure the coverage of issues relating to the consultation and information of employees. ${ }^{148}$ In these meetings, the issue was thought to have been taken care of by means of cross-references to existing legislation, to which the Socialist EP representative did not object. ${ }^{149}$

Rather than driven by major exogenous events or changes in the policy proposal, individual-level perceptions of the takeover directive changed as a result of deliberate lobbying. Rapporteur Lehne and the Socialist shadow rapporteur in the Legal Affairs Committee, Willy Rothley, played critical roles in this regard. According to Mr. Rothley, he and Mr. Lehne put a lot of energy into finding a majority against the proposal. ${ }^{150}$ Their efforts were aimed in two directions: the workers' rights focal point explicitly targeted the Left, while the level playingfield focal point was emphasized for the political Right, which was thought to be more concerned

\footnotetext{
${ }^{147}$ Respondent \#65; Respondent \#74.

148 Respondent \#50.

149 Respondent \#50; Respondent \#65.

${ }^{150}$ Respondent \#60.
} 
with national businesses. ${ }^{151}$ While Mr. Lehne stressed the level playing-field argument, Mr. Rothley emphasized the workers' protection side of the story in the Socialist group — despite his conviction that the directive, in reality, did not infringe on workers' rights. ${ }^{152}$

The findings of this qualitative analysis also confirm that focal points were not created from thin air, but reflected existing ideological preferences. The increasing discussion about "workers' rights" shifted attention toward an aspect of the proposal that could prominently place the issue on the Left-Right divide. It also emphasized to the Left that the proposal might negatively affect their core constituencies across the continent. At the same time, the "level playing-field" issue emphasized the repercussions of the directive for national businesses, another core constituency of most MEPs.

It is, moreover, evident that the focal points observable in the case of the takeover directive were indeed decision-making shortcuts, making a complex and technical proposal more tangible. Initially, the majority of parliamentarians were quite uninformed about the highly complex and technical takeover directive, ${ }^{153}$ and opinions were "all over the place." ${ }^{154}$ Therefore, MEPs had to rely on the few people who could evaluate the implications of the directive to lead them through the process, according to a Commission official. ${ }^{155}$

Hence, focal points appear to have a mediating impact on already existing ideological preferences. While ideological preferences and constituency concerns did not change, opposition to the directive emerged as the policy process progressed. ${ }^{156}$ Following the suggestions of the

\footnotetext{
${ }^{151}$ Respondent \#27; Respondent \#60; Respondent \#65.

${ }^{152}$ Respondent \#60.

${ }^{153}$ Respondent \#27; Respondent \#60; Respondent \#65; Respondent \#74.

${ }^{154}$ Respondent \#65.

${ }^{155}$ Respondent \#13.

${ }^{156}$ Respondent \#57.
} 
dominant focal points, everybody started to discover that they had something to protect, ${ }^{157}$ be it "the pearls of their national industries,"158 or the employees of target companies. ${ }^{159}$

\subsubsection{Content Analysis}

The shift in focal points during the course of the decision-making process concerning the takeover directive should also be evident in the parliamentary debates in first reading (June 25, 1997), second reading (December 12, 2000), and third reading (July 3 and 4, 2001). I test this proposition by coding a series of words and phrases consistent with the three focal points ("single market," "workers' rights," and "level playing -field") and by determining their frequency of use with the help of TEXTPACK. ${ }^{160}$

Based on the analysis above, we should expect to find that the single market focal point gets sidelined throughout the decision-making process, meaning that the number of references to this focal point decreases with each debate. At the same time, the workers' rights and level playing-field focal points gained in prominence over time, meaning that the number of references to these two focal points should increase between the first and third reading stage.

The results of the content analysis confirm these expectations, as Table 12 shows.

[Table 12 here]

In first reading, the "single market" focal point was referred to 64 times per 10,000 input words. This number drops to eleven references in second reading and 7 references in third

\footnotetext{
${ }^{157}$ Respondent \#24.

${ }^{158}$ Bouwman MEP, Debate of the European Parliament, July 3, 2001.

${ }^{159}$ Respondent \#74.

${ }^{160}$ Coding details can be found in the Appendix of Chapter 6.2.
} 
reading. Also as expected, the shift in focus toward the level playing-field and workers' rights focal points is evident in the debates preceding the second and third readings in the European Parliament. While there had not been a single mention of the "level playing-field" in the first reading debate in 1997, it was referred to 30 times per 10,000 input words in both the second and third reading debates. Finally, the workers' rights focal point was referenced 34 times per 10,000 input words in the first reading phase. This number increased to 39 in second and 46 in third reading.

\subsubsection{Voting Patterns: The Impact of the Legislative Process on Voting Outcomes}

On the basis of the qualitative analysis above, it is possible to formulate a series of hypotheses concerning the expected outcome of the decision-making process in the case of the takeover directive.

In the first reading stage, the single market issue was most prominent in the debate about the takeover directive. Accordingly, we should find that pro-/anti-integration positions should be significant predictors of voting behavior, with pro-European MEPs voting in favor of the directive. As established above, however, the focal point revolving around the completion of the single market became increasingly marginalized throughout the political process and was replaced by concerns about the level playing-field and workers' protection. I therefore hypothesize that pro-/anti-integration positions should not be significant predictors of voting behavior in the third reading stage.

Following Hooghe and Marks (1999, 2001), we may hypothesize that the political Left was initially in favor of the takeover directive, as it constituted a matter of market regulation at the EU level in the area of corporate governance. The political Right, on the other hand, wishing 
to combine a continent-wide market with minimal regulation at the EU level, should be more hesitant in its support for the directive. I thus hypothesize that more Leftist positions on the LeftRight dimension should increase the probability of support for the directive in the first reading stage. Given the rising focus on the workers' rights issue in later stages of the discussion, these tendencies should be reversed in the third reading stage: in the 2001 vote, more Leftist positions should decrease the probability of support for the directive.

Finally, since the level playing-field focal point was entirely absent from the debate in the first reading stage, constituency interests related to the comparative gains of national businesses should not constitute a significant predictor of voting behavior in the first reading stage. As a result of the rise of the issue throughout the process, however, we should expect to find that in the third reading stage, national considerations had a substantial impact on voting patterns. Specifically, we should find that parliamentarians from member states with liberal market economies supported the directive, since their equity-based systems already placed the shareholder at the center of regulatory and legal protections against hostile takeover bids (Berglöf and Burkart 2003). For these MEPs, the level playing-field argument actually highlighted perceived gains from the takeover directive. MEPs from countries with national coordinated market economies should also be expected to favor the directive, for similar reasons. In Sweden, for example, regulations dating back to the early 1970 s already required defensive actions to have shareholder approval. Moreover, the most widespread defensive practice in the Scandinavian countries is a system of dual class shares (Bennedsen and Nielsen 2004), which the takeover directive did not actually prohibit. For similar reasons, we should also observe that MEPs from partial coordinated market economies should be concerned about the impact of the legislation on the defensive actions available to their nations' companies. Finally, 
parliamentarians from sectoral market economies should largely opposed the directive on the basis of the level playing-field argument, which was perceived as a threat to established neocorporatist traditions at the national, sectoral, and firm levels.

The dependent variables in this analysis are the votes in the first and third readings. ${ }^{161}$ These variables are dichotomous. A value of zero equals a vote against the directive and a value of one means a vote in favor. ${ }^{162}$

The independent variables are the two ideology variables (Left-Right and sovereigntyintegration), the government status dichotomous variable, and a set of dichotomous variables for type of capitalism. ${ }^{163}$ Formally, the regression model can be expressed as:

$$
\begin{aligned}
& \text { VOTE }=\mathrm{a}+\beta_{1} \text { Left-Right }+\beta_{2} \text { Sovereignty-Integration }+\beta_{3} \text { Government Status }+\beta_{4} \\
& \text { Liberal Market Economy }+\beta_{5} \text { Partial Coordinated Market Economy }+\beta_{6} \text { Sectoral } \\
& \text { Coordinated Market Economy. }{ }^{164}
\end{aligned}
$$

The results in Table 13 show that this regression model explains a substantial part of the variance with a pseudo- $\mathrm{R}^{2}$ of 0.39 . Also, as predicted on the basis of the dominant focal point in the first reading stage, positions on the sovereignty-integration dimension constitute a highly statistically significant predictor of voting behavior in the roll-call vote of the first parliamentary

\footnotetext{
161 The vote in the second reading was not a roll-call vote and is thus not considered here.

${ }^{162}$ The results of the multinomial logit analysis of the plenary vote in first reading can be found in the Appendix of Chapter 6.2. Due to the small number of abstentions in the third reading vote a multinomial logit analysis of this vote is not possible.

${ }^{163}$ The "type of capitalism" variables fall into four categories: liberal market economy (Ireland and the United Kingdom); partial or family-oriented coordinated market economy (France, Italy, Spain, Greece and Portugal); sectoral coordinated market economy (Germany, Austria and Benelux countries); national coordinated market economy (Scandinavian countries).

164 "National Coordinated Market Economy" serves as the reference value; it is, however, possible to calculate predicted probabilities for this category using CLARIFY, which will be reported below.
} 
reading. Moreover, the sign of the coefficient indicates that a more pro-European attitude correlates positively with the probability of a Yes vote.

[Table 13 here]

Figure 29 presents the predicted probabilities of a Yes vote given levels of EU support. This figure illustrates the substantial impact of more pro-European positions on the probability of a vote in favor of the directive, across different types of capitalism. ${ }^{165}$

[Figure 29 here]

The results in Table 13 also show that, as expected, positions on the Left-Right dimension are statistically significant and negatively related to the dependent variable: leftists were more likely to vote in favor of the directive. This finding is evident in the downwardsloping lines in Figure 30, which represent the mean predicted probabilities of a Yes vote given positions on the Left-Right dimension, again differentiating between different types of capitalism.

[Figure 30 here]

Finally, Figure 31 shows the modest impact of government- or opposition-status of MEPs in their national member states, and thus their representation in the Council, which is not

\footnotetext{
${ }^{165}$ To calculate the probabilities presented in the following figures, I used CLARIFY and held the remaining variables constant at their means.
} 
surprising since the coefficient in Table 13 does not achieve statistical significance. The slope of the graphs is surprising, however, since representation in the Council of Ministers evidently decreases the probability of MEPs voting in favor of the takeover directive in first reading.

[Figure 31 here]

Contrary to our expectations, national economic considerations are highly statistically significant predictors of voting behavior, as the type of capitalism variables are significant and their coefficients quite substantial. Specifically, Figure 29, Figure 30, and Figure 31 demonstrate that MEPs from member states with partial coordinated market economies were most likely to support the legislation in first reading, followed by MEPs from sectoral and national coordinated market economies. Members from countries with liberal market economies were least likely to vote in favor of the takeover directive in first reading.

Comparing these results with the analysis of the third reading vote on the takeover directive demonstrates that preferences concerning the takeover directive were not stable across both votes. All predictor variables switch signs, as Table 14 illustrates.

[Table 14 here]

These results are consistent with the expectations of the focal point model, which can account for these switches in the signs of the coefficients. The sign of the sovereignty-integration variable, for example, switches from positive to negative: while pro-Europeans strongly 
supported the directive in the first reading stage, the relationship between support for the EU and support for the takeover directive is now reversed (compare Figure 29 and Figure 32).

[Figure 32 here]

One possible interpretation of this curious finding is that pro-European MEPs actually began to consider the directive to be harmful to the integration process as the level playing-field argument began to dominate the discussion. As a result, positions on the dimension did not become insignificant during the decision-making process. Yet, as the single market focal point was marginalized in the third reading stage, the slope of the graphs representing the changes in predicted probabilities along the sovereignty-integration dimension is less steep than in first reading, indicating its decreasing importance over time.

The simultaneous rise of the workers' right focal point also entails a switch in the direction of the Left-Right variable, as predicted above and illustrated in Figure 30 and Figure 33: while left-leaning MEPs had a greater probability of voting in favor of the directive in the first reading vote, they now show a greater probability to vote against. As Figure 33 shows, the mean predicted probability of a vote in favor of the directive increases as values on the LeftRight divide shift toward the Right.

[Figure 33 here]

Figure 34 shows that representation in the Council of Ministers, i.e., affiliation with a national party in government at home, entails a greater probability of MEPs supporting the 
takeover directive in third reading. This impact is especially pronounced for MEPs from liberal and partial coordinated market economies.

[Figure 34 here]

At last, considerations about the impact of the proposed legislation on national economic interests are indeed statistically significant in predicting voting behavior in the third-reading stage, when the level playing-field issue was especially prominent. The findings also support our expectations. As proposed above, members of parliament from liberal market economies were indeed very likely to vote in favor of the directive, as were MEPs from countries with national coordinated market economies. In contrast, members from partial coordinated market economies were less likely to support the proposed legislation, while parliamentarians from sectoral coordinated market economies were very unlikely to support the proposal.

In sum, a critical preference shift with regard to the ideology variables was a decrease in the perceived salience of the sovereignty-integration dimension by legislative backbenchers between the first and third reading stages, paired with a simultaneous increase in the perceived salience of the Left-Right divide. Figure 35 illustrates this shift spatially for a given legislator $\mathrm{MEP}_{\mathrm{x}}$. The takeover directive (i.e., the "New Policy") fell inside the elliptically shaped indifference curve in first reading (the solid line), when the sovereignty-integration dimension was perceived to be more salient with regard to the legislative proposal. In contrast, it was the status quo point that was the more preferred alternative in third reading, when the indifference curve is "squeezed" from the sides, indicating the greater salience of the Left-Right divide. 
Accordingly, the takeover directive passed through the EP plenary in first reading, but was rejected in favor of the status quo in third reading.

[Figure 35 here]

There was not simply a shift in the perceived salience of the two ideology dimension, however, but also a critical shift in the directional impact of the two dimensions. While the more pro-EU position entailed a greater probability of voting in favor of the takeover directive in first reading, its impact in third reading was reversed. Similarly, a more leftist position in first reading was associated with a greater probability to support the proposed legislation and a decreased probability of support in third reading. This impact cannot be shown spatially, but clearly influenced the outcome of the legislative decision-making process. A similar shift occurred in the case of the type of capitalism variables representing national economic interests.

\subsubsection{Conclusion}

The qualitative analysis of the takeover directive established that the interpretation of what constitutes the dominant aspect of a given legislative proposal can be traced back to one (or more) exogenously provided focal point(s). The analysis identified three competing focal points that took prominence at different points in time: the "single market" focal point, the "workers" rights" focal point, and the "level playing-field" focal point. Appealing to existing ideological predispositions, these strategically deployed focal points influenced the variable interpretation of what the issue at hand "was all about," thus shifting policy preferences during the process of 
parliamentary deliberation. Critical, in this regard, were a small number of specialized actors in the Legal Affairs Committee.

Subsequently, the quantitative analysis of voting behavior established that the strategically deployed focal points significantly shaped voting outcomes in the case of the EU takeover directive. It is thus evident that the outcome of the decision-making process was not due to the random confluence of problems, participants, preferences, and opportunities, but the result of a more structured process where strategic actors shaped policy preferences, thus providing the basis for policy outcomes. As hypothesized, these outcomes are indeed predictable on the basis of the prevalent focal point, which confirms Hypothesis $3 b$ and disconfirms Hypothesis $2 b$.

The analysis also confirms some of the central characteristics of focal points and the fashion in which they are employed in legislative decision-making. The prevailing focal points constituted very general representations of content and consequences of the particular policy issue under consideration, while the discussion of technical details of the legislation was kept at a minimum. There was also a distinct element of persuasion involved in the deliberation of the legislation, which defies the notion of predetermined positions. Finally, each focal point highlighted the importance of a specific consequence of the legislation and tied it to one particular outcome preference: the single market focal point emphasized the desirability of the legislation as a step toward further integration, making it pro-/anti-EU issue. The workers' rights focal point stressed the potential negative impact on employment and social fairness; as such, the issue as a Left-Right question. Finally, the level playing-field focal point highlighted how unbalanced the distribution of benefits of the legislation would be across member-states and thus targeted concerns about national constituents. Moreover, the case of the takeover directive 
demonstrates that focal points not only affect the salience of the ideological dimension, but can even influence the direction in which the dimensions matter.

\subsection{THE STATUTE AND FINANCING OF EU-LEVEL POLITICAL PARTIES}

Going back to the Maastricht Treaty, the EU has recognized the importance of European political parties in developing political debate in Europe, enhancing the quality of EU democracy, and improving the functioning of EU institutions. Building on this recognition, the purpose of the legislation titled "Political parties at European level: statute and financing" (COD/2003/0039) was to define the exact nature and purpose of EU-level political parties and to create a financing framework whereby EU-level political parties would be funded in part from the Community budget.

The legislative proposal was introduced by the Commission on February 19, 2003 and proposed a total annual budget of 8.4 million Euros for party funding. It stipulated that each European party would receive a flat-rate basic grant from the EU budget, plus a second component based on its number of MEPs. 25 percent of the budget of each party would still come from autonomous financing, including donations, which would have to be specified when exceeding EUR 100 and could not exceed EUR 5,000 a year per person or organization. To assure the transparency of party accounts, the Commission proposal specified that European parties that receive financing must provide annual records of their revenues, expenditures, statements of assets, and liabilities. ${ }^{166}$

\footnotetext{
${ }^{166}$ European Commission, RAPID Press Release: "Commission proposes rules on statute and financing of European political parties.” February 19, 2003.
} 
Eligibility for financing from the EU budget was tied to certain "minimum requirements" of democratic conduct, including provisions that EU parties must participate in elections to the EP, have clearly defined bodies responsible for financial management, and "respect [for] the basic purposes of the Union" with regard to freedom, democracy, human rights, and the rule of law. Eligibility was also dependent on a certain degree of representativeness in the EP or in a reasonable number of member states. Specifically, a European political party must have elected members in the EP, or be represented in national or regional parliaments in at least one third of the EU member states, or it must have obtained at least five percent of the votes in the most recent EP election in at least one third of the member states.

\subsubsection{Qualitative Analysis: Focal Points and the Legislative Process}

The proposal was treated in the EP by a German Social-Democrat, Jo Leinen (PES), on behalf of the Committee on Constitutional Affairs. In first reading, in June 2003, the EP decided to limit the scope of the directive to the question of party financing, leaving aside the issue of establishing a genuine legal statute for EU parties. It merely stipulated that EU parties must have a legal personality in the member state in which its seat is located (i.e., Belgium, for most parties). ${ }^{167}$ In this respect, it emphasized the urgent need for rules on party funding, given recent criticism by the EU Court of Auditors of the existing financing system. ${ }^{168}$ The Court had suggested that the current structure where the political parties were financed through a budget

\footnotetext{
${ }^{167}$ Having a legal personality allows a group of persons to act as if it were an individual for purposes such as lawsuits, property ownership, and contracts. This allows for easy conduct of business by having ownership, lawsuits, and agreements under the name of the legal entity instead of the several names of the people making up the entity. Here, a European-level legal personality would have entailed, for example, that European parties could hire their own staff, signs their own contracts, and be tax and criminally liable.

${ }^{168}$ The Court of Auditors checks EU revenue and expenditure for legality and regularity and ensures that financial management is sound.
} 
line that belongs to the EP party groups was questionable, because it violated the division between party and parliamentary faction.

The EP also amended the Commission proposal to be more inclusive of smaller parties by lowering the threshold for funding eligibility from one-third of the EU member states to onequarter and proposed that parties must have received at least three percent (rather than five percent) of the votes cast in those member states in the most recent EP election to receive funding. The EP report further specified that European parties must specify donors and donations exceeding EUR 500, as opposed to the EUR 100 proposed by the Commission. It also increased the threshold above which donations should not be accepted from EUR 5,000 to EUR 12,000 and proposed that European political parties should be allowed to charge membership fees, as long as they do not exceed 40 percent of the party's annual budget.

Finally, the EP position emphasized that funding provided by the EU budget should not be used for the direct financing of national or regional political parties, except for the financing of EP election campaigns or "party activity at any level directly associated with the politics of the EU."

Council accepted these changes in its common position, and the legislation entered into force on February 15, 2005.

The criticism of the Court of Auditors put a distinct time pressure on the European Parliament to get the finances of its parties in order and to establish European parties that were autonomous from their EP party groups before the end of the 2004 legislative term. ${ }^{169}$ Especially at a time when the financial structures of the European Parliament and its members had become

\footnotetext{
${ }^{169}$ Respondent \#67, Respondent \#40, Respondent \#23.
} 
under increasing scrutiny in the eye of the public, the need for legislation that would put European parties on a firmer, more defined, more transparent, and more accountable basis was widely acknowledged to make the system less vulnerable to attack. ${ }^{170}$

Yet, despite the broad recognition that a statute dealing, in particular, with the financing of European parties was urgently needed, there was considerable controversy within the EP with regard to the specifics of the proposal. Especially contested were the thresholds establishing the eligibility of parties for EU funding, ${ }^{171}$ the extent to which donations would be permitted, ${ }^{172}$ the purposes for which EU funding could be used, ${ }^{173}$ and the issue of tying funding to minimum democratic requirements. ${ }^{174}$ There was a relative consensus with regard to these issues among the three largest EP party groups (EPP, PES, Liberals), while the Greens were initially divided and the smaller groups, who felt disadvantaged by the Commission proposal, were largely opposed. ${ }^{175}$ With regard to the permissibility of donations, there was also a national aspect to the proposal, since certain member states put an upper limit on direct donations. ${ }^{176}$

The discussion at the plenary level did not, however, reflect the complexity of the issue at hand, ${ }^{177}$ either with regard to the question of financing or the legal status of EU parties, since MEPs "only have a general idea of how financing works." ${ }^{178}$ Instead, the issue was treated by a relatively small number of experts in the responsible Constitutional Affairs committee, ${ }^{179}$ who

\footnotetext{
${ }^{170}$ Respondent \#14, Respondent \#23.

${ }^{171}$ Respondent \#3, Respondent \#14, Respondent \#40, Respondent \#67.

172 Respondent \#23, Respondent \#40, Respondent \#41, Respondent \#63, Respondent \#67, Respondent \#37.

${ }^{173}$ Respondent \#40, Respondent \#41.

${ }^{174}$ Respondent \#41, Respondent \#5, Respondent \#67.

${ }^{175}$ Respondent \#40, Respondent \#67.

176 Respondent \#40.

177 Respondent \#3.

178 Respondent \#67

${ }^{179}$ Respondent \#67.
} 
"knew what they were talking about." 180 There was close cooperation among those specialists from a range of party groups, who "made their own agreement, which they then took to their groups," as one EP official remembers. ${ }^{181}$ But cooperation also extended beyond the EP to representatives from the European parties and from the Council. ${ }^{182}$ For example, the Socialist rapporteur closely conferred with the leader of the PES, Robin Cook, and its secretary general, Antony Beumer. ${ }^{183}$ In fact, the secretary generals of the main party groups played an important role in the negotiation process, while the rapporteur, Jo Leinen, was critical in forging the final compromise. ${ }^{184}$

As rapporteur, Mr. Leinen emphasized the role of European parties as building blocks of a federalist EU and as symbols of a politically integrated Europe. ${ }^{185}$ Hence, he considered the financing scheme as a first step toward genuine party organizations, a democratic infrastructure, and democratic political processes at the European level. ${ }^{186}$ The party directive was thus an issue that was discussed in reference to the sovereignty-integration dimension, ${ }^{187}$ and proponents and opponents of the proposal fell squarely into the pro- and anti-EU camps, respectively. Opposition against the proposal was based on resistance against anything that might constitute a building block of a transnational polity and transnational democratic processes. ${ }^{188}$ MEPs taking this position emphasized that EU parties were artificially constructed bodies that should not be subsidized with public money. ${ }^{189}$ Accordingly, two focal points dominated the process, both

\footnotetext{
${ }^{180}$ Respondent \#3.

181 Respondent \#67.

182 Respondent \#3, Respondent \#14, Respondent \#63, Respondent \#67.

183 Respondent \#14.

${ }^{184}$ Respondent \#3, Respondent \#14.

${ }^{185}$ Respondent \#3, Respondent \#67, Respondent \#40.

${ }^{186}$ Respondent \#40.

${ }^{187}$ Respondent \#37, Respondent \#40, Respondent \#41, Respondent \#63.

188 Respondent \#14.

189 Respondent \#5.
} 
relating to the sovereignty-integration dimension: the EU Democracy and artificial constructs focal points.

As a result of this focus on the role of parties in facilitating European democracy, as well as the close cooperation between key actors across party lines who managed to find agreement on the details of the proposal, there was broad support for the directive. It was, in fact, the strategy of the rapporteur to be as inclusive as possible. ${ }^{190}$ One key element ensuring a broad consensus was that potentially controversial aspects of the directive were deliberately removed from the agenda by the active participants in the deliberation process, and the rapporteur in particular. Specifically, it was argued that the "the time was not yet ripe" for a genuine party statute which would require the specification of the legal status or a European-level legal personality of EU parties. ${ }^{191}$ There was a distinct sense of uncertainty and insecurity about what it would mean if a European party would become active across member-state borders based on its European legal personality, ${ }^{192}$ as well as concern about the co-existence of national and EUlevel parties with regard to both European and domestic member state politics. ${ }^{193}$ Hence, in order to avoid splitting up the existing coalition in favor of the financing scheme or postpone the decision on the minimal solution focusing on party financing, ${ }^{194}$ it was decided in the Constitutional Affairs committee to keep the issue off the table and to view the proposal of EU party financing as a first step toward a genuine European party statute. ${ }^{195}$ Given the need for some legal status of EU parties, the final compromise stipulated that EU parties must have legal

\footnotetext{
${ }^{190}$ Respondent \#40, Respondent \#67.

${ }^{191}$ Respondent \#40, Respondent \#23, Respondent \#67.

192 Respondent \#40.

${ }^{193}$ Respondent \#41.

${ }^{194}$ Respondent \#3, Respondent \#67.

${ }^{195}$ Respondent \#23, Respondent \#41, Respondent \#63, Respondent \#67, Respondent \#3.
} 
personality in the member state in which its seat is located, which essentially referred to Belgium. $^{196}$

Therefore, the "real controversies" were effectively excluded from the final text, according to one EP official closely involved in the decision-making process, ${ }^{197}$ allowing the party experts to convince their party colleagues of their positions. ${ }^{198}$ As a result, the final agreement was not a genuine party statute, but merely a financing scheme addressing the immediately pressing issue of establishing an acceptable framework for the financing of EU parties. ${ }^{199}$ Given the controversy surrounding the issue of EU parties, however, and the longstanding skepticism toward the very concept paired with national concerns about the impact of establishing transnational parties with any legal status, it has been described as a "miracle" that the directive came into existence at all. ${ }^{200}$

\subsubsection{Content Analysis}

Since both focal points prevalent in the deliberation of the party directive related to the impact of EU level party financing on the democratic governance of the EU, we ought to find that references to the pros and cons of the directive in this regard should dominate the plenary debate in the first (and only) reading stage. This is indeed the case, as Table 16 shows. ${ }^{201}$ During the debate, speakers made 70 references (per 10,000 input words) to the "EU democracy" focal point, while the "artificial constructs" focal point was referred to only 30 times.

\footnotetext{
${ }^{196}$ Respondent \#41, Respondent \#40.

${ }^{197}$ Respondent \#63, Respondent \#67.

${ }^{198}$ Respondent \#67, Respondent \#14.

199 Respondent \#67, Respondent \#3, Respondent \#41, Respondent \#40.

${ }^{200}$ Respondent \#3, Respondent \#67, Respondent \#40.

${ }^{201}$ Coding details can be found in the Appendix of Chapter 6.3.
} 
The debate also shows that the issue of legal personality was, indeed, almost non-existent during the plenary debates, as only four references were made to the fact that the directive does not, in fact, constitute a genuine party statute providing EU parties with a European legal personality.

[Table 16 here]

\subsubsection{Voting Patterns: The Impact of the Legislative Process on Voting Outcomes}

The content analysis illustrates that the decision-making process in the case of the EU Party Statute was dominated by two focal points that relate to the sovereignty-integration dimension, as both the issue of EU democracy and the claim that EU parties are artificially constructed entities lacking legitimacy relate to this ideological dimension. Accordingly, we should expect to find that MEPs voted based on their positions on the sovereignty-integration dimension, with pro-European MEPs voting in favor and EU-skeptics against. In contrast, the Left-Right divide should be insignificant in explaining voting patterns, since the deliberation process did not feature any focal points relating to the Left-Right dimension.

The dependent variable in this binary logit analysis is the EP plenary vote in first reading, in which the Party Statute was adopted. These variables are dichotomous. A value of zero equals a vote against directive and a value of one means a vote in favor. ${ }^{202}$ The recurrent dependent variables are the two ideology variables (Left-Right and sovereignty-integration) and the

\footnotetext{
${ }^{202}$ The results of the multinomial logit analysis of the plenary vote in first reading can be found in the Appendix of Chapter 6.3.
} 
government status dichotomous variable. Additionally, I include a dichotomous variable that assumes a value of 1 if national party finance rules specify a ceiling on individual annual donations to political parties. I control for this factor because the most contentious issue providing for nationally-based divisions in the EP concerned the legality of party donations and the question of limiting donations to particular levels. ${ }^{203}$ My regression model is expressed formally

as:

VOTE $=a+\beta_{1}$ Left-Right $+\beta_{2}$ Sovereignty-Integration $+\beta_{3}$ Government-Opposition $+\beta_{4}$ National Ceiling on Party Donations.

The results of the analysis show that, as predicted, pro-European MEPs voted in favor of the EU Party Statute, as the highly statistically significant, positive coefficient of the sovereignty-integration variable in Table 17 shows. Also as expected, the Left-Right variable does not achieve statistical significance, at least when the other predictors are held constant at their means. The table also indicates that MEPs from member states that specify ceilings on party donations were more likely to support the legislation (a result that makes sense given that the new legislation at the EU level also sets such limits), while government or opposition status at the national level does not account for positions toward the Party Statute. Finally, the regression model explains a substantial 45 percent of the variance in the voting patterns, as the pseudo- $\mathrm{R}^{2}$ suggests.

[Table 17 here]

${ }^{203} \mathrm{EU}$ member states with a ceiling on how much an individual donor can contribute to a political party per year are: Belgium, France, Greece, Ireland, Italy, Portugal, and Spain. All other member states do not have a ceiling in place. 
Figure 39, Figure 40 and Figure 41 display the predicted probabilities of voting in favor of the Party Statute. ${ }^{204}$ The two graphs in Figure 39 confirm that the Left-Right divide was insubstantial in explaining votes in favor of the legislation, as MEPs on the Left were no more or less likely to support the Party Statute than MEPs on the Right.

[Figure 39 here]

In contrast, Figure 40 illustrates the substantial impact of positions on the sovereigntyintegration dimension in explaining vote choice. In fact, the probabilities of supporting the legislation as a function of pro-/anti-EU attitudes range from zero on the extreme EU-skeptic side of the spectrum to 100 percent at the pro-EU end.

[Figure 40 here]

Finally, Figure 41 shows that government or opposition status in the national arena, and thus representation in the EU Council, barely affects the probability of MEPs voting in favor of the Party Statute.

[Figure 41 here] ${ }^{204}$ To calculate the probabilities presented in the following figures, I used CLARIFY and held the remaining
variables constant at their means. 
In sum, the Party Statute was adopted by the European Parliament on the basis of MEP positions on the sovereignty-integration dimension, which confirms our expectations. ProEuropeans voted in favor of the legislation, while EU-skeptics opposed it. It was thus possible to predict voting patterns on the basis of the focal points dominating the deliberation of the legislative proposal, as hypothesis $\mathrm{H} 3 \mathrm{~b}$ maintained. This pattern is illustrated spatially in Figure 42, where $\mathrm{MEP}_{\mathrm{x} 1}$ represents any given pro-European MEP and $\mathrm{MEP}_{\mathrm{x} 2}$ represents an EU-skeptic MEP. The Party Statute ("New Policy") falls inside $\mathrm{MEP}_{\mathrm{x} 1}$ 's (solid) indifference curve and thus constitutes her preferred alternative. In contrast, the status quo point lies inside $\mathrm{MEP}_{\mathrm{x} 2}{ }^{\text {s }} \mathrm{s}$ indifference curve (represented by the dashed line), making it his preferred alternative.

[Figure 42 here]

\subsubsection{Conclusion}

The EU Party Statute does not constitute a case in which there was a measurable shift in policy positions over time, as the legislative proposal was accepted in first reading and, for this reason, involved only one final roll-call vote. It does provide for a study in consistency of our key expectations, however, most importantly by confirming the hypothesis that it is possible to predict voting patterns on the EP floor on the basis of the focal points prevailing in the deliberation of the dossier (H3b). This was indeed the case with the Party Statute, where the discussion centered on the implications of the legislation for the development of EU democracy and the role of transnational political parties in this process. The discussion took place at a very general level, however, and was characterized by broad representations of content and consequences of the particular policy issue under consideration. These findings derive from the 
qualitative analysis of the case at hand and the content analysis of the EP debate in first reading. Accordingly, vote choice in the EP plenary was based in principal on MEP positions along the sovereignty-integration dimension, as the quantitative analysis shows, while there was neither a Left-Right nor a distinct national interest component influencing how MEPs voted on the floor.

The emphasis on the sovereignty-integration dimension provided the basis of a broad cross-party coalition supporting the legislation, as the majority of MEPs shares a pro-EU sentiment. As discussed above, one factor ensuring this broad consensus was that potentially controversial aspects of the directive, most importantly the definition of a "legal personality" for EU parties, were deliberately kept off the agenda. As long as the time was perceived not to be "ripe" for the establishment of a genuine European-level legal personality, it was deemed preferable by the key actors to establish a pure party financing scheme presented as a first step toward a genuine European party statute. It was this minimal solution that secured the necessary support for the legislation.

\subsection{PROPOSALS ON FUEL QUALITY AND EMISSION STANDARDS FOR MOTOR VEHICLES}

In 1997, the European Parliament began discussing three legislative proposals regarding emission standards of both personal and non-personal motor vehicles and the quality of petrol and diesel fuels. While technically three separate proposals, the EP treated them as one bloc of legislation aimed to reduce emissions and improve air quality. The legislation followed and was introduced by the Commission on the basis of the "Auto-Oil program," established in 1994, which was to develop scientific methods to establish emission standards for vehicles. The Auto- 
Oil program involved an intense series of studies and negotiations between the Commission, auto manufacturers, and the oil industry focused on tougher standards for vehicle emissions and fuel quality. The idea was to use the expertise of these industries to establish the most cost-effective way to reduce the impact of pollution on air quality and human health. ${ }^{205}$

Two proposals concerned emission standards. The first, COD/1996/0164A, was supposed to tighten emission standards applicable to private cars and add new requirements, all in accordance with the results of the Auto-Oil program. The initial Commission proposal provided for a two-stage reduction in exhaust emissions: a first reduction in various pollutants was to be applied from the year 2000 onward to new types of vehicles and from 2001 onward to all new vehicles. In 2005, the second stage was to be implemented on the basis of industrial feasibility and technological progress. Additionally, the proposal included provisions to improve emissions test procedures, required petrol-driven cars to be equipped with an on-board diagnostic system (OBD), and provided new measures to enhance the testing of the conformity of the vehicles with durability requirements. The second proposal, COD/1996/0164B, targeted light commercial vehicles and also featured a two-stage approach. The first target dates ranged between the years 2000 and 2002 for different classes of non-personal vehicles and aimed to significantly reduce emissions of different pollutants against 1997 standards. A second regulatory stage was to be applied from 2005 onward, based on a new Commission proposal to be submitted to Parliament and Council in 1998.

The third element of the emissions package sought to improve the quality of fuel with a view to reducing emissions from automobiles (COD/1996/0163). It was to harmonize limit

\footnotetext{
${ }^{205}$ Commission of the European Communities (1996) "The European Auto Oil Programme" A report by the Directorate Generals for Industry, Energy and Environment, Civil Protection and Nuclear Safety (XI/361/96) para 2.2 .
} 
values for different parameters of lead-free petrol and diesel in the year 2000 and stipulated that afterwards, only those fuels complying with the specifications of the directive would be authorized for sale in the Member States. Furthermore, it provided for the development of a uniform system to monitor the quality of fuels distributed, as well as the gradual elimination of all leaded petrol by January 1, 2000. The initial proposal allowed for temporary exceptions from the limit values under specific circumstances, however, such as "serious socio-economic problems" or a "sudden change in the supply of crude oil." Moreover, all new fuel specifications were to be reviewed in light of the Community air quality objectives and the economic viability of the measures in the near future.

\subsubsection{Qualitative Analysis: Focal Points and the Legislative Process}

In its first reading reports on the emission standard proposals, the EP amended the Commission proposals to include a two-stage approach to the imposition of binding emission limits in 2000 and 2005, rather than indicative specifications for 2005, as favored by the Commission. The reports also called for tighter limits on exhaust emissions, the replacement of old vehicles or the retrofitting of anti-pollution devices, stricter emission control procedures, and the promotion of substitute fuels. Notably, the EP advocated the tool of tax incentives to encourage immediate compliance with stricter limits on pollutant emissions, which was one of the first times the use of such incentives was discussed as a genuine environmental instrument. The ultimate goal was to regulate the reduction of $\mathrm{CO} 2$ emissions to effectively make mandatory the 5-liter average car by 2005 and the 3-liter average car by 2010 .

Regarding the proposal on fuel quality, the EP also called for tighter mandatory minimum specifications than those proposed by the European Commission for petrol and diesel, as well as 
for the active use of tax incentives to facilitate the introduction of improved fuels. Parliament also introduced the possibility of derogation and a "phased-in approach," to enable Member States facing serious economic difficulties to continue to authorize use of fuels not complying with the strict levels suggested by the EP until January 1, 2005.

The modified Commission proposal and the Council's common position accepted some of these requests, such as the use of tax incentives and measures to encourage faster progress towards replacing existing vehicles with low-emission vehicles. However, it rejected the EP's key demands for tighter limit values and the replacement of indicative with mandatory values for 2005, both with regard to emissions and fuel quality standards.

Parliament re-tabled most of the amendments adopted in first reading that were not incorporated in the common position in second reading, insisting on stricter limits and mandatory values, despite the insistence of Commission and Council that they could not accept these demands. Accordingly, the matter went into conciliation at the end of June 1998, where agreement was reached on all the outstanding points. The key compromise lay in the Council delegation agreeing to compulsory limit values for 2005; in exchange, Parliament accepted the less stringent figures proposed by the Council for the specifications themselves (which were, however, a considerable improvement on the figures originally put forward by the Commission). ${ }^{206}$ The compromise was widely viewed as a success for Parliament, as it achieved the a adoption of a broader approach to the question of emissions and fuel quality whereby benefits to health and the environment were taken into account when assessing the cost of measures to improve air quality.

\footnotetext{
${ }^{206}$ The EP agreed to the Council's suggestions with the exception of Amendment 27 in the fuel quality directive, where limit values were left unchanged by the Council.
} 
Parliament subsequently adopted all three reports on September 15, 1998. It voted 454 to three, with seven abstentions, in favor of the proposal to reduce air pollution from passenger motor vehicles; 465 to eleven, with 3 abstentions, in favor of the emissions proposal concerning light commercial vehicles; and 474 to ten, with 3 abstentions, in favor of the proposal on fuel quality.

The treatment of these three proposals by the European Parliament began in late 1996 and early 1997, although the issues of fuel quality and emission standards had been on the table already for a number of years. The Commission proposal came out of the auto-oil program, where Commission, automobile manufacturers, and the oil industry had shared ideas while excluding other stakeholders, such as social associations, non-governmental organizations or representatives of the European Parliament. The Commission proposal was thus viewed with suspicion in the EP and perceived to be heavily biased in favor of the industry, at the expense of environmental standards.

Despite much controversy in the early stages of the proceedings and throughout the decision-making process, ${ }^{207}$ the emissions package was adopted by the European Parliament by overwhelming margins. The great majority of my respondents, when asked about this development, highlighted the role of the two rapporteurs in creating this result. These two individuals were Bernd Lange, a German member of the Socialist group, who was in charge of the legislation concerning emission standards (COD/1996/0164A and 0164B), and Heidi Hautala, a Finish Green, who became responsible for the fuel quality proposal (COD/1996/163).

\footnotetext{
${ }^{207}$ Respondent \#22, Respondent \#18, Respondent \#51.
} 
The two rapporteurs had a very close working relationship, coordinated their efforts, and were "very serious, very committed"208 to their objective of realizing an emissions proposal that was balanced and not as slanted toward the industry, as the Commission proposal was viewed. ${ }^{209}$ Their strategy revolved around three elements: to provide sound data challenging the dire cost estimates of the industry and the Commission, to seek a broadly acceptable compromise across all party lines, and to get the right people involved in the effort. According to a number of respondents, finding a compromise began even before the first reading. ${ }^{210}$ This effort "took a very, very long time," and involved a great number of technical meetings where the rapporteurs, EP officials, and representatives from the Council Presidency would "work and work and work."211

The emissions directives were very heavily lobbied, not just in the context of the auto-oil program, but also during the parliamentary deliberation process. Both the oil and the carmanufacturing industries were pressing hard for the Commission proposal, which they saw as beneficial to their aspirations, and floated numbers underscoring the great costs they saw themselves facing if the EP proposals were accepted. To counter these suggestions, the rapporteurs sought to back up their argumentation with detailed economic calculations, according to an EP official. ${ }^{212}$ Realizing that they would never get their proposals through otherwise, the rapporteurs had to provide "sound data to counteract" 213 the Commission proposal and were markedly successful, since the information was perceived as "great," in the words of

\footnotetext{
${ }^{208}$ Respondent \#51.

${ }^{209}$ Respondent \#18, Respondent \#51.

${ }^{210}$ Respondent \#18, Respondent \#62.

211 Respondent \#51.

212 Respondent \#18.

${ }^{213}$ Respondent \#18.
} 
one respondent, and "costs were acceptable according to that." 214 Moreover, the intrusive lobbying tactics of the industry, in combination with the evidently greatly exaggerated cost estimates, ${ }^{215}$ ultimately proved counterproductive for the industry's desired outcomes, as one EP official remembers. $^{216}$

The efforts of the two rapporteurs were targeted at a broad, cross-party coalition. Accordingly, both rapporteurs took realistic positions and did not "ask for the earth in the end." ${ }^{217} \mathrm{Mr}$. Lange, in particular, was perceived to be a very consensual rapporteur, who was cooperative and had a good working relationship with other actors across party lines. ${ }^{218}$ While pushing in the direction of less pollution, he always tried to bring on board the other political groups. ${ }^{219} \mathrm{He}$ was also perceived to be "extremely competent on the subject matter, which got him the reputation where he had good arguments, and in the end, people wouldn't question him. ${ }^{, 220}$ He was, in sum, trusted across party lines, ${ }^{221}$ because he was, according to one member of the environment committee,

"perfectly capable of speaking without any hypocrisy at a conference of industrialists or automobile manufacturers, but also at a conference of environmentalists - and making the same speech!",222

\footnotetext{
214 Respondent \#4.

215 Respondent \#4, Respondent \#18.

${ }^{216}$ Respondent \#18. With hindsight, a number of respondents highlighted the great discrepancy between what the cost estimates of the industry at the time and the actual costs of the legislation upon its implementation (Respondent \#4, Respondent \#77, Respondent \#42).

${ }^{217}$ Respondent \#51.

${ }^{218}$ Respondent \#9, Respondent \#42, Respondent \#47, Respondent \#51, Respondent \#77.

${ }^{219}$ Respondent \#62, Respondent \#77.

${ }^{220}$ Respondent \#42.

${ }^{221}$ Respondent \#47.

222 Respondent \#77.
} 
Despite some initial suspicion toward Ms. Hautala, as a Finish member of the Greens, ${ }^{223}$ at the end both rapporteurs had proved their consensual credentials and were considered to be reliable and trustworthy, rather than partisan actors. They initiated numerous informational meetings and engaged in their own "discreet lobbying" so that in the end "people felt that they were not getting any nasty surprises."224 They were "very astute" in getting the right people on board, according to one EP official, thus playing the political game while backing up their positions with the necessary data. Involving the right mix of participants was critical, as the following excerpt from an interview with an EP official highlights:

"We got the right people to be on the conciliation committee, the right people to sit in the final conciliation meetings from the EP side. You know, not too radical, people who could get it through, good negotiators.",225

This perception is confirmed by another official, who remembers the group of participants as "well-informed, not extremist and, as such, reliable. So therefore, people would follow."226 This very cooperative group included Ms. Hautala from the Greens, Mr. Lange and David Bowe (UK) from the PES, as well as Horst Schnellhardt and Karl-Heinz Florenz (Germany) from the EPP. ${ }^{227}$ The arguments put forth by this group of actors revolved around the question of "cost-effectiveness" (the principle favored by the industry) and "best available technology" (the principle advocated on the EP side). Politically, the proponents of more stringent environmental standards emphasized issues such as the impact of air quality and climate change on public health, a discussion that, in later stages of the legislative process, also

\footnotetext{
${ }^{223}$ Respondent \#18, Respondent \#51.

${ }^{224}$ Respondent \#51.

${ }^{225}$ Respondent \#18.

${ }^{226}$ Respondent \#51.

${ }^{227}$ Respondent \#4, Respondent \#22.
} 
referred to the recently negotiated Kyoto Protocol. ${ }^{228}$ The focal point presented by this group of individuals was thus one of consumer protection.

This consumer protection focal point so dominated the debate outside of the committee, where the technicalities of the proposal were discussed critically and controversially, that one MEP maintains that the business- and industry points of view and the "restrictions that [the legislation] would put in place" were not at all taken into account at the plenary level. There was, accordingly, a "lack of knowledge" concerning these implications of the legislation among regular parliamentarians, since "a lot of the reasoning arose from the committee and did not take account of different factors that we have across Europe."229 The opponents of the proposal thus presented an alternative focal point by emphasizing the potential negative impact of the legislation on industries across the EU.

In sum, the rapporteurs made sure that the process of decision-making in the EP was based on solid data and information disseminated across party groups by the right group of people, while their reputations as real environmental experts made a significant difference in creating the right context for compromise, according to one EP official. ${ }^{230}$ Furthermore, this effort took place in an atmosphere where the EP was only starting to use its new powers of legislation in the context of the co-decision procedure, which provided the institution and its members with a new sense of assertiveness vis-à-vis Council and Commission. As a result, the emissions issue is remembered as one of the first cases "where the EP took a strong stance early

\footnotetext{
${ }^{228}$ Respondent \#42, Respondent \#62, Respondent \#4.

${ }^{229}$ Respondent \#16.

${ }^{230}$ Respondent \#62.
} 
in the co-decision procedure,"231 and it was described by Ken Collins (PES, UK), chairman of Committee on the Environment of the European, as "a triumph for Parliament.",232

\subsubsection{Content Analysis}

For the content analysis of EP debates concerning the emissions proposals, I coded a series of keywords consistent with the two focal point identified above focusing on consumer protection and industry interests, respectively. ${ }^{233}$ We should expect to find that the consumer protection focal point gains in prominence throughout the course of the decision-making process, as it was emphasized by the primary actors in the environment committee, while the question of the impact of the proposal on EU industries was sidelined over time, meaning that the number of references to the industry interest focal point should decrease.

The analysis focuses on three debates in the EP plenary in April 1997, February 1998, and September 1998. These debates concerned the three proposals jointly, with the result that they do not correspond directly to the first, second, and third parliamentary readings. Specifically, the first debate concerned the EP's report in the first readings of the directives on emissions from private motor vehicles (COD/1996/0164A) as well as the fuel quality proposal (COD/1996/163). The second debate took place at the second reading stage for those two proposals, but also concerned the first reading EP report of the proposal on emissions from nonpersonal motor vehicles (COD/1996/164B). Finally, the third debate followed the conciliation procedures for all three proposals.

\footnotetext{
${ }^{231}$ Respondent \#42.

232 See OEIL.

${ }^{233}$ See the Appendix of Chapter 6.4. for a complete coding list.
} 
The content analysis confirms the expectation that there was an increase in references to the consumer protection focal point over time, which increasingly dominated the discussion. Table 19 shows that while there were only 133 references per 10,000 input words in the April 1997 debate, MEPs referred to the consumer protection issue 158 and 148 times per 10,000 input words in the second and third debates, respectively. At the same time, there were 69 references per 10,000 input words to the industry interest focal point in the first debate, a number that drops to 52 in the second debate. In the third debate, the number of references drops substantially to only 28 per 10,000 input words, indicating the decreasing importance of the industry interest issue.

[Table 19 here]

\subsubsection{Voting Patterns: The Impact of the Legislative Process on Voting Outcomes}

Based on these results, we should expect to find that in first reading, the positions of MEPs on both ideological dimensions should be significant predictors of voting choice in the EP plenary. With the industry interest focal point in particular playing a prominent role in the discussion of the proposals at that point in time, we should expect to find two voting patterns. First, members of the political Right should be less likely to support the proposals, since they ought to be more concerned with the perceived negative impact of the legislation on businesses. Second, Euroskeptics should be less inclined to support the legislation, as they are unlikely to support environmental regulation at the EU-level.

In contrast, the decreasing emphasis on the industry interest focal point should reduce the impact of the Left-Right and pro-/anti-EU dimensions in third reading, especially in combination 
with the ideologically more neutral consumer protection focal point dominating the debate, which should undermine ideology-based divisions.

Due to collinearity issues between certain vote outcomes and the type of capitalism variables, ${ }^{234}$ however, neither multinomial nor binary logit analyses are straightforward with regard to the emissions proposals. Table 20 and Table 21 show the frequencies of vote outcomes by type of capitalism for the first reading votes of proposals 163 and 164a. Of concern for this analysis are the empty cells, for example in the sectoral and national coordinated market economy categories for the 163 proposal, which indicate perfect collinearity between the predictor variable and certain vote outcomes (i.e., the sectoral coordinated market economy variable predicts the absence of abstentions perfectly, and the national coordinated market economy variable predicts the absence of No votes and abstentions perfectly). Also methodologically problematic are the cases of almost perfect collinearity, where the cell value is very small, such as the two instances of No votes for the liberal and sectoral market economy categories; here, the two variables almost perfectly predict the occurrences of No votes. ${ }^{235}$

[Table 20 here]

[Table 21 here]

${ }^{234}$ The "type of capitalism" variables fall into four categories: liberal market economy (Ireland and the United Kingdom); partial or family-oriented coordinated market economy (France, Italy, Spain, Greece and Portugal); sectoral coordinated market economy (Germany, Austria and Benelux countries); national coordinated market economy (Scandinavian countries).

${ }^{235}$ In situations where an independent variable almost perfectly predicts the occurrence of a certain outcome, STATA reports neither the standard error of that variable nor the chi-squared statistics for the whole model, making the substantive interpretation of the model impossible. 
As a result, I have to exclude the types of capitalism variables from this analysis to focus on the impact of the ideology variables. This simplified model is expressed as:

$$
\text { VOTE }=\mathrm{a}+\beta_{1} \text { Left-Right }+\beta_{2} \text { Sovereignty-Integration }
$$

The results of the simplified model, with only the two ideology variables as predictors, must be viewed with caution and serve here merely as illustrations of the likely impact and direction of the Left-Right and sovereignty-integration variables. Table 22 and Table 23 shows the result of the binary logit analyses for the first reading votes regarding proposals 163 and $164 a{ }^{236}$ The results suggest that in first reading, the expected significances of the predictors and the directions of their relationships with the dependent variables find confirmation in the empirical data. As hypothesized, both ideology variables are statistically significant in the two votes. The Left-Right variable correlates negatively with the dependent variable, indicating that MEPs on the political Right were more likely to oppose the legislative proposals; and the sovereignty-integration variable is positively related to the dependent variable, meaning that more pro-European MEPs were more likely to support the legislation.

[Table 22 here]

[Table 23 here]

\footnotetext{
${ }^{236}$ The results of the multinomial logit analysis, which mirror those of the binary logit analysis, are presented in the Appendix of Chapter 6.4.
} 
This vote pattern is also evident in the graphs presenting the predicted probability of votes in favor of the proposals. Figure 46 displays the predicted probability of a Yes vote given Left-Right positions, which decreases as we move toward the political Right. ${ }^{237}$

[Figure 46 here]

Figure 47 shows that the probability of voting in favor increases with the pro-integration stance of MEPs.

[Figure 47 here]

In third reading, the EP adopted the joint proposal on the quality of petrol and diesel fuels (163) with 474 votes to ten with three abstentions; the proposal to reduce air pollution from motor vehicles (164a) with 454 votes to three with seven abstentions; and the proposal to reduce air pollution from light commercial vehicles (164b) with 465 votes to 11 with three abstentions. Due to this overwhelming majority in favor of the three legislative proposals, there is insufficient variance in the dependent variables to run meaningful statistical analyses, making a direct comparison with vote patterns in first reading impossible. Instead, I provide descriptives of the MEPs who voted against the proposals or abstained.

Of the 15 MEPs who did not support the set of legislative proposals, 11 were French, three were Belgian, and one was Italian. Except for one member of the Union for Europe (UEP), all were non-attached MEPs. All are far to the political right, with an average score of 0.60 on

\footnotetext{
${ }^{237}$ To calculate the probabilities presented in the following figures, I used CLARIFY and held the remaining variables constant at their means.
} 
the Left-Right dimension, and all are pronounced Euroskeptics, with an average score of -0.78 on the sovereignty-integration dimension. Hence, aside from a very small group of non-attached, politically conservative, Euroskeptic MEPs, the rapporteurs actually managed to get the entire EP behind their positions in the final vote on the three proposals; the apparent left-right and pro/anti-EU divisions observable in first reading disappeared in third reading as the consumer protection focal point became prevalent. ${ }^{238}$

\subsubsection{Conclusion}

The analysis of the emissions and fuel quality directives demonstrates the substantial impact individual MEPs can have on a legislative outcomes, since the EP's campaign for tighter emissions and fuel quality standards was successful despite significant opposition in both Council and Commission. A cohesive EP, however, which supported the more stringent guidelines with an overwhelming majority under the leadership of a group of legislative specialists from different party groups, ultimately succeeded in securing its most important objectives.

The role of the two rapporteurs in securing this outcome constitutes an important reason for Parliament's achievement, according to the majority of my respondents, who highlighted their expertise, abilities, and willingness to seek a broad compromise across party lines as their recipe for success. The compromise was established between party experts in the responsible environment committee, and this "right mix" of people constituted the basis for people following the committee position.

${ }^{238}$ This reality precludes the spatial illustration of the shift in policy preferences over time. 
The proponents of the legislation advocated its merits by providing a "consumer protection" focal point that resonated with a large number of MEPs. This focal point affected voting behavior in first reading in the expected direction, which provides support for hypothesis H3b. Unfortunately, the data limitations for this set of proposals do not allow for as detailed an analysis as in other chapters.

The content analysis demonstrates, however, that the consumer protection focal point became increasingly dominant over time at the expense of a second focal point emphasizing the perceived negative impact of the legislation on the competitiveness of national industries. Accordingly, MEPs voted overwhelmingly in favor of the legislative proposals in third reading, while there had been substantial divisions earlier on.

\subsection{LIABILITY FOR ENVIRONMENTAL DAMAGE}

The purpose of the legislative proposal on "liability with regard to the prevention and remedying of environmental damage" (COD/2002/0021), introduced by the Commission in January 2002, was to create a regulatory framework that would establish an EU-wide system of liability for environmental damage. In the context of the proposed legislation, "environmental damage" included damage to wildlife and natural biodiversity protected at EU and national levels, to the water courses regulated by the Water Framework Directive (2000/60/EC), as well as land contamination which causes serious harm to human health. The basis for the legislation was the "polluter-pays principle," according to which the operator who has caused the damage, or who is

faced with an imminent threat of such damage occurring, should ultimately bear the cost associated with clean-up measures. Dating back almost a decade, when a Green Paper on 
Environmental Liability first introduced the principle in 1993, the polluter-pays principle was to provide the foundation for EU-level harmonization and regulatory control within the environmental field. The legislation was also building on a number of Parliamentary resolutions on the matter and a White Paper on Environmental Liability published in $2000{ }^{239}$

At the time the legislation was introduced, not all member states actually had legislation in place to address the issue of environmental liability, which was the case in Portugal and Greece, for example, and some member states' legislation did not adequately address the legislation's primary objective of "site clean-up" following pollution. The Commission proposal highlighted the need for this legislation by estimating that around 300,000 sites were already identified as contaminated or potentially contaminated across the EU, with clean-up costs estimated to total between EUR 55 and 106 billion. The lack of a harmonized framework at the EU level facilitated the exploitation of differences in national-level legislation and loopholes in the existing regulatory frameworks by economic actors, meaning that the cost of cleaning it up would come from public finances.

The objective of the liability legislation was to establish a framework that would either prevent or remedy environmental damage by forcing negligent operators to clean up polluted sites at their own expense, or to reimburse public authorities who may have taken restorative measures. Taking account of the subsidiarity principle, ${ }^{240}$ the directive aimed to provide a minimum standard for restoring damaged sites, while leaving particular decisions regarding the measures to be taken by or on behalf of such operators to national authorities. The Commission

\footnotetext{
${ }^{239}$ Green Papers are documents drafted by the European Commission that are intended to stimulate debate and launch a process of consultation at European level on a particular topic. These consultations may then lead to the publication of a White Paper, which are Commission documents containing proposals for Community action in a specific area.

${ }^{240}$ Subsidiarity is the principle whereby the Union does not take action (except in the areas which fall within its exclusive competence) unless it is more effective than action taken at national, regional or local level.
} 
proposal did, however, provide for the possibility that private actors or parties with a sufficient interest (such as environmental NGOs) could request appropriate action by the competent authorities at the national level and challenge their subsequent action or inaction.

The critical controversies regarding the environmental liability directive concerned the question of the Directive's scope, that is, what environmental damage and which occupational activities should be covered, and where they should apply; ${ }^{241}$ the exemptions and defenses available to alleged polluters; ${ }^{242}$ and the question of voluntary or compulsory insurance. ${ }^{243}$ In terms of scope, the directive included practices or activities involving heavy metals, dangerous chemicals, landfill sites and incineration plants, but explicitly excluded other risky activities, such as oil transport and drilling operations. With regard to exemptions, the Commission proposal excluded "damage caused by an emission or event expressly authorized in a permit" and activities which are believed to be safe for the environment according to "the state of scientific and technical knowledge" when they occur ("state of the art exception"). Finally, the Commission proposal sought to "encourage" operators to invest in prevention by making insurance against environmental damage voluntary, rather than compulsory.

\subsubsection{Qualitative Analysis: Focal Points and the Legislative Process}

Deliberation of the environmental liability directive in the EP was preceded by an unusually controversial conflict between the Environment and Legal Affairs Committees over which committee should be in charge of the proposal. ${ }^{244}$ The dossier was first given to the Environment Committee, but this decision was challenged by the Legal Affairs Committee. While the

\footnotetext{
${ }^{241}$ Respondent \#35, Respondent \#6.

${ }^{242}$ Respondent \#71, Respondent \#72, Respondent \#35, Respondent \#6.

243 Respondent \#29, Respondent \#35, Respondent \#6, Respondent \#71, Respondent \#34.

244 Respondent \#29, Respondent \#35, Respondent \#71, Respondent \#72.
} 
Environment Committee emphasized that the liability scheme concerned legislation specific to the environment and was being reviewed by the Council of Environment Ministers, the Legal Affairs Committee argued that it should be responsible because the issue concerned third party liability matters irrespective of the area of application. ${ }^{245}$ The conflict culminated in the extraordinary decision to have a plenary vote on the issue, rather than leave the decision to the conference of committee chairmen, which normally resolves competency conflicts but could not find agreement regarding this particular dossier. ${ }^{246}$ On July 3, 2002, the EP voted by 266 to 241 with 12 abstentions in favor of the Legal Affairs Committee. Toine Manders (ELDR, Netherlands) was chosen as the rapporteur. The Environment Committee would provide an opinion, with Mihail Papayannakis (GUE, Greece) as its rapporteur. Moreover, the Conference of Presidents decided to invoke Rule 47 of the EP's rules of procedure. ${ }^{247}$ Rule 47 describes the "enhanced cooperation procedure," which applies when the Conference of Presidents decides that a legislative proposal falls almost equally within the competence of two committees, or when different parts of the issue under consideration fall under the competence of two committees. Under the procedure, the two committees set a common time table and the rapporteur of the lead committee is supposed to seek agreement with the opinion draftsman on a joint text. Moreover, the amendments adopted in the opinion committee can be adopted by the lead committee without a vote.

Mr. Papayannakis was the first to table his report on the Commission proposal on behalf of the Environment Committee. In his report, he harshly criticized the proposal, starting with what he identified as inadequate definitions of key concepts such as biodiversity, land

\footnotetext{
${ }^{245}$ European Report: "Environment: Legal Affairs Committee to manage liability dossier.” July 6, 2002.

${ }^{246}$ Respondent \#29, Respondent \#35.

247 Respondent \#29, Respondent \#49, Respondent \#71, Respondent \#72.
} 
contamination, or soil and subsoil contamination. Also within the realm of definition, he highlighted that according to the Commission proposal, liability to restore "environmental damage" was triggered only above a degree of "seriousness," but that the proposal failed to define how the seriousness of damage was to be measured. In the opinion of the environment committee, measurement standards should include the extent and duration of the polluting impact, whether pollution is reversible or irreversible, and the sensitivity and rarity of the resources damaged.

The environment committee also wanted to extend the scope of the directive to include genetically-modified organisms (GMOs), cover damages associated with air pollution, and extend to all activities subject to Community environmental legislation, rather than the limited number of practices identified in the Commission proposal. It was also to include oil pollution and nuclear damage, which were excluded on the grounds that they are already covered by other international conventions. ${ }^{248}$ The Environment Committee rejected the "compliance with permit" and the "state of the art" exceptions specified in the Commission proposal, arguing that they undermined the effective implementation of the polluter-pays principle. Finally, the Environment Committee report demanded that insurance against environmental damage should be mandatory, rather than voluntary, to ensure that costs associated with clean-up measures would not, ultimately, fall upon taxpayers. $^{249}$

\footnotetext{
${ }^{248}$ This question raised some distinct national concerns and positions. Many Spanish members, for example, favored a strict liability framework that included both preventive and remediary measures following the recent "Prestige" oil spill, when an oil tanker sank in 2002 off the Galician coast, causing a massive oil spill. Thousands of kilometers of Spanish and French coastline were polluted and the local fishing industry devastated. The Prestige spill was the largest environmental disaster in Spanish history. Similarly, for MEPs from Austria and Ireland the question of including or excluding nuclear technologies in the scope of the directive was of special interest, because neither country uses nuclear energy for industrial purposes (Respondent \#35, Respondent \#2, Respondent \#6).

${ }^{249}$ European Report, "Environment: Eurochambers and Parliament critical of Environmental Liability Directive." January 22, 2003.
} 
Under Rule 47 of the Rules of Procedure, which defines the enhanced cooperation procedure, the lead committee can accept, without a vote, amendments from the opinion committee

"where they concern matters which the chairman of the committee responsible considers [...], after consulting the chairman of the committee asked for an opinion, to fall under the competence of the committee asked for an opinion, and which do not contradict other elements of the report."

With regard to the environmental liability dossier, this meant in practice that most amendments proposed in the opinion report of the Environment Committee were not included in the first reading report tabled by the Legal Affairs Committee, since the report drafted by rapporteur Toine Manders aimed to strike a balance between conflicting interests of industry and environmental concerns and significantly watered down the proposal by reducing the total number of amendments from 303 to $12 .{ }^{250}$ According to one respondent from the EPP, this was the result of the environment committee overstepping its competences by amending aspects of the reports that fell within the jurisdiction of the Legal Affairs Committee. ${ }^{251}$ Another respondent close to the rapporteur, however, explained that the enhanced cooperation procedure proved to be an exercise in "window-dressing" in the case of the environmental liability dossier, because in practice, it was the responsible rapporteur who decided what amendments "fall under the competence" of the opinion committee. ${ }^{252}$ This meant that Mr. Manders decided "strategically"

\footnotetext{
${ }^{250}$ European Report. "Environment: Liability proposal watered down in European Parliament.” May 3, 2003.

${ }^{251}$ Respondent \#49.

${ }^{252}$ Respondent \#71. Internal communication between the chairman of the Legal Affairs Committee, Guiseppe Gargani, and the chairwoman of the Environment Committee, Caroline Jackson, also indicates that the Environment Committee did not feel properly consulted with regard to the timetable, which according to Rule 47 of the Rules of Procedure ought to be jointly drawn up by the two committees (Jackson letter to Gargani, January 31, 2003).
} 
what amendments should be sent to the plenary. ${ }^{253}$ Another respondent confirmed this reality by acknowledging that the decision is a political one in the end, ${ }^{254}$ while an EPP member of the Legal Affairs committee explained:

"It is a huge advantage to be the main committee, and the rapporteur of the main committee, if he is arrogant enough, can bypass all the opinions. You have no legal obligation to take opinion amendments on board. You can practically say: let's reject all the amendments of the environment committee, and no one can blame you." ${ }^{.255}$

Members of the Environment Committee did blame the rapporteur for his decision to include only one of every four amendments they introduced, however. In fact, the issue triggered an angry exchange of letters between the chairmen of the two committees. ${ }^{256}$ There was no way of standing up against a majority of EPP and Liberals in the Legal Affairs Committee, however, of which the proponents of a less stringent framework for environmental liability were well aware. ${ }^{257}$ Accordingly, the Manders report was adopted in first reading by an 18 to 11 margin, against the votes of committee members from the Left.

The Manders report centered on a series of "compromise" amendments. These amendments broadened the definition of the term "European biodiversity" to all protected species and sites where they live; extended the Directive's scope to include nuclear and marine pollution (but only at the end of a transitional five-year period in the event that the relevant international agreements have not been ratified by the member states and/or the EU); sought to reduce the number of exemptions specified in the Commission proposal; and made financial

\footnotetext{
${ }^{253}$ Respondent \#71.

254 Respondent \#72.

255 Respondent \#35.

256 Respondent \#71.

${ }^{257}$ Respondent \#35, Respondent \#71, Respondent \#72, Respondent \#2, Respondent \#6.
} 
security systems mandatory. Nevertheless, the report was perceived to be too lenient for more environmentally-minded MEPs. Most importantly, the "compliance with permit" and the "state of the art" exceptions remained part of the proposal, while scope and definitions concerning environmental damage were seen as unclear and arbitrary. ${ }^{258}$ Effectively, the Manders report was perceived to exclude some of the greatest perceived threats to the environment, such as air pollution and genetically-modified organism, while providing exemptions that would allow operators to dodge the polluter-pays principle in practice. As a result, proponents of the stricter framework laid out in the report of the Environment Committee voted against the Manders report in committee and re-tabled their amendments in plenary. ${ }^{259}$

A number of the amendments seeking to strengthen the proposal were adopted in the EP plenary's first reading vote on May 14, 2003, if by very small margins. ${ }^{260}$ The EP thus adopted amendments broadening the definition of the term "biodiversity" to cover habitats and species protected under European as well as national legislation, and stipulated that those who are, or could be, responsible for potentially damaging activities should take preventive or restorative measures without governments requesting them to do so. Others amendments reduced drastically the number of exemptions permitting operators to avoid bearing the costs of environmental damage they have caused (by limiting these to cases of armed conflict and terrorist acts, exceptional and unavoidable natural phenomena, and to activities carried out within the framework of good agricultural and forestry practice). Finally, financial insurance systems for cases in which an operator cannot be held responsible would be mandatory, rather than

\footnotetext{
${ }^{258}$ European Report. "Environment: Liability proposal watered down in European Parliament.” May 3, 2003.

${ }^{259}$ Respondent \#29, Respondent \#72.

${ }^{260}$ See the Legislative Observatory (OEIL, available at http://www.europarl.eu.int/oeil) for details.
} 
voluntary, within six years after the directive enters into force. ${ }^{261}$ The complete report, which significantly strengthened the directive from an environmental perspective vis-à-vis the report of the Legal Affairs Committee, was adopted by 310 in favor, 177 against with 23 abstentions.

Accordingly, plenary actually departed from the position of the lead committee. ${ }^{262}$ This is quite unusual, since plenary follows the recommendation of the responsible committee most of the time. Instead, plenary followed the line of the Environment Committee and thus adopted the more stringent proposal. ${ }^{263}$ For example, there were two voting lists in the Liberal Group, that is, the document suggesting how Liberal MEPs should vote in plenary actually had two columns providing contradictory voting instruction. One was the vote suggestion of the rapporteur in the lead committee, Toine Manders, the other one the proposed positions of a senior Liberal member of the Environment Committee, Chris Davies. Liberal MEPs not familiar with the details of the dossier could then decide which one of their colleagues they trusted more when making their own vote choice. ${ }^{264}$ More environmentally-minded MEPs in the Liberal group would follow Mr. Davies, while others could decide to follow Mr. Manders' "industry-prone" approach. With a split voting list proposed by those two MEPs, "you know immediately whom to follow, irrespective of the topic that will be voted on," according to one Liberal respondent. ${ }^{265}$

The common position of the Council of Ministers was adopted on September 19, 2003, by qualified majority against the votes of Austria, Germany, and Ireland. The Council's common position accepted 26 of the EP's 48 amendments to the proposal, but leaned decisively toward the Commission proposal, rather than the more stringent EP position, with regard to the key

\footnotetext{
${ }^{261}$ EUObserver.com: "Environment: MEPs vote on 'polluter pays' rules." May 14, 2003 and "'Polluter pays' law one step closer." May 15, 2003.

${ }^{262}$ Respondent \#6, Respondent \#72.

${ }^{263}$ Respondent \#72.

${ }^{264}$ Respondent \#71, Respondent \#9.

${ }^{265}$ Respondent \#9.
} 
issues. Most importantly, it provided for member states to include the "compliance with permit" and the "state of the art" exemptions if they so chose, stipulated a voluntary rather than compulsory insurance regime, and excluded emissions and nuclear activities from the scope of the directive. ${ }^{266}$

Unlike in first reading, the EP did not take a strong environmental stance in the second reading, where it followed the recommendation of the rapporteur and adopted his report. ${ }^{267}$ The proponents of the Manders report were aided by the EP's decision-making rules, however, which stipulate the need for absolute majorities in second reading, that is, more than 50 percent of the total number of members. The rules of procedure thus made it less likely that the controversial amendments from first reading, in which a simple majority suffices, would be adopted in second reading.

While the Manders report in second reading proposed some measures that went beyond the Council's position (for example by including environmental damages linked to maritime navigation accidents in the directive's field of application), it actually weakened the overall stringency of the proposed legislation in other key areas. Most importantly, it accepted the Council's position of a voluntary, rather than mandatory, insurance scheme, but it left open the future possibility of a compulsory system of financial guarantees by asking the Commission to evaluate the insurance situation five years after the legislation's entry into force. If proper instruments of financial guarantee were not adopted by then, the EP would ask the Commission to submit proposals for an obligatory insurance scheme, first for water and soil damage, and later for damage to biodiversity and natural habitats. With regard to the second question of

\footnotetext{
${ }^{266}$ European Report: "Environment Council: Ministers take first steps towards EU Liability system.” June 18, 2003.

${ }^{267}$ See the Legislative Observatory (OEIL, available at http://www.europarl.eu.int/oeil) for details. See also: European Report: "Environment: Parliament resists effortrs to tighten up liability directive." December 20, 2003.
} 
controversy, the Legal Affairs Committee also accepted "permit" and "state of the art" defenses. The environmental liability legislation nevertheless went into conciliation, due to the small adjustments the EP made to the Council's common position.

The overall tone of the second reading report contradicted the more environmental line propagated by those in favor of a more stringent environmental framework for the liability legislation. In effect, it was an attempt by the political Right, under the leadership of rapporteur Toine Manders, to outvote the opposition, rather than to seek a broadly acceptable compromise. This step was preceded by extensive negotiations across party and committee lines, which proved to be unsuccessful. The reasons for this failure to build consensus are unclear, as respondents provide different accounts for the circumstances under which negotiations broke down. Some indicate that the compromise proposals made by the rapporteur were derived from negotiations that involved the opinion rapporteurs from the opinion committees, including $\mathrm{Mr}$. Papayannakis. ${ }^{268}$ Others are more skeptical of Mr. Manders' motives and his abilities to forge a broad political compromise; one respondent describes Mr. Manders' handling of the dossier as "an example of how not to do legislation.," 269 Despite any early attempts to arrive at a compromise, it is quite evident is that Mr. Manders eventually gave up on the idea of consensusbuilding and merely tried to push through his own agenda with the help of the EPP. ${ }^{270}$

Conciliation opened on January 27, 2004. The most important issue remained the question of voluntary versus obligatory insurance and when a voluntary system should be reevaluated. In this regard, the conciliation compromise of February 19, 2004, stipulated that the Commission would conduct an evaluation after six years from the legislation's entry into force

\footnotetext{
${ }^{268}$ Respondent \#35, Respondent \#71, Respondent \#6, Respondent \#72.

${ }^{269}$ Respondent \#9.

${ }^{270}$ Respondent \#71, Respondent \#72.
} 
and to determine the need for a harmonized mandatory financial securities framework. It would also address the issue of a ceiling for liability and the exclusion of low-risk activities from the mandatory insurance scheme. ${ }^{271}$ The EP accepted this compromise on March 31. The legislation was to enter into force by the end of the year, and national law would have to be introduced within three years. This outcome was significantly closer to the positions of the political Right, while some of the less stringent requests of the Environment Committee were included in the legislation. ${ }^{272}$ In the end, it was an outcome with which nobody was very content. ${ }^{273}$

One question that remains is whether this outcome would have been different had the environment committee been the lead committee. When asked directly, respondents provided contradictory assessements. Some maintained that the outcome would very likely have been different, ${ }^{274}$ while others acknowledge that this may have been the case. ${ }^{275}$ A third groupnotably all members of the EPP, whose positions regarding the issue were more or less realized in the final legislation-, maintain that the outcome would have been the same, since it is the EP plenary that has the final say with regard to any committee report. ${ }^{276}$

In reality, much would support the conclusion that there was at least a good chance the outcome would have been different with Environmental Affairs in charge. There even seems to have been such an assumption in parliament prior to the actual legislative process, since both committees competing for the lead lobbied hard, which is unlikely to have been just to gain prestige. In fact, the EPP chairman of the committee, Giuseppe Gargani, went against the chairwoman of the Environment Committee, Caroline Jackson, who was a British Conservative

\footnotetext{
${ }^{271}$ European Report: "Environment: Conciliation agreement clinched on liability directive." February 21, 2004.

272 Respondent \#35.

273 Respondent \#29.

${ }^{274}$ Respondent \#71, Respondent \#29, Respondent \#6, Respondent \#2.

${ }^{275}$ Respondent \#35, Respondent \#72.

${ }^{276}$ Respondent \#49, Respondent \#34, Respondent \#30.
} 
and thus a colleague from his own party group. Especially the conservatives and liberals in the Legal Affairs Committee assumed that their policy agenda was more likely to succeed with their committee in the lead. ${ }^{277}$ One EPP member explains:

\begin{abstract}
"We are stronger in legal affairs, because we have a strong alliance with the Liberals, but in Environmental Affairs, the Socialists are stronger, because they have an alliance with the Greens and the smaller groups, and the Liberals in that committee are maybe more left-leaning.,"278
\end{abstract}

The Legal Affairs Committee had two critical advantages as the lead committee. First, it could, and did, suppress those amendments from the Environment Committee that it viewed as politically undesirable. ${ }^{279}$ This authority was especially important in second reading, when a simple majority suffices to adopt amendments in committee, but an absolute majority is needed in plenary. The Legal Affairs committee thus had the de facto ability to decide what amendments had a good chance to stand or fall. ${ }^{280}$ This, in addition to the possibility of setting the tone of the debate, ${ }^{281}$ resulted in an increasing capacity for the Legal Affairs Committee to dominate the decision-making process after first reading.

Despite the evident disagreements over the content of the proposal, it was the initial conflict of competences that critically set the tone of the debate concerning the environmental liability legislation. As one EP official working closely with the rapporteur explains, at first, "nobody was interested" in this "technical, legally complex dossier that could only be understood

\footnotetext{
${ }^{277}$ Respondent \#35, Respondent \#2.

278 Respondent \#35.

${ }^{279}$ Respondent \#71.

${ }^{280}$ Respondent \#29.

281 Respondent \#2.
} 
by a few experts." 282 Over the course of the debate, however, the dossier was "made controversial" and "blown out of proportion. It was a hype!"283 The dossier was very heavily lobbied, ${ }^{284}$ and ultimately, there were a large number of people who were interested in the dossier. ${ }^{285}$ Nonetheless, it was only the key players who actually knew about the content and the potential implications of the dossier. ${ }^{286}$ Many other actors

"jumped in at a very late stage not knowing what it is all about, and these people are very easy targets for sentiments [...] If you use sentiment, if you avoid the debate on substance, it is very easy to convince people and drag them into your camp [...] It was a disadvantage in finding a compromise that this dossier was so politicized." 287

Three focal points dominated the debate concerning the environmental liability directive. The proponents of the legislation emphasized that the legislation would have to be realistic in striking a balance between environmental and industry concerns. This issue was summarized by references to the need for "workability," or implementability, of the legislation. ${ }^{288}$ A second focal point emphasized the desirability of the legislation from a pro-European point of view by emphasizing the need for "harmonization" of environmental regulation at the EU level. Finally, opponents of the legislation presented the dossier as a de facto "license to pollute," due to its limited scope and important exceptions to the rules.

\footnotetext{
282 Respondent \#71.

${ }^{283}$ Respondent \#71.

${ }^{284}$ Respondent \#6, Respondent \#71.

285 Respondent \#71, Respondent \#35, Respondent \#49, Respondent \#34.

${ }^{286}$ Respondent \#6, Respondent \#72.

${ }^{287}$ Respondent \#71.

${ }^{288}$ Respondent \#34, Respondent \#71.
} 


\subsubsection{Content Analysis}

For the content analysis, I coded a series of keywords consistent with the three focal points prevalent in the debate of the environmental liability dossier, that is, the "workability," "harmonization," and "license to pollute" focal points. ${ }^{289}$ Given the course of the deliberation process, we should expect to find that the license to pollute focal point should be referenced most during the first reading stage, when the conflict of competences between the Legal Affairs and Environment Committees was in full swing and the Environment Committee played a critical role in debate. This focal point should remain important across the three reading stages, since there was no broadly acceptable compromise agreement even at the end, but it should become less visible with the decreasing role of the Environment Committee at the later stages of the decision-making process.

The "workability" focal point should also feature prominently in all three reading stages. In contrast to the "license to pollute" focal point, however, it should increase in importance over time, since it constituted the primary element of argumentation in the Legal Affairs Committee. As the Legal Affairs Committee managed to sideline the Environment Committee, its own presentation of the issue should become increasingly dominant.

Finally, the number of references to the "harmonization" focal point should also increase over time, for the same reason as the "workability" focal point: the increasing dominance of the Legal Affairs Committee should result in an increase in references to one of its central lines of argument.

These expectations are generally confirmed in the TEXTPACK analysis, as Table 26 shows.

${ }^{289}$ Coding details can be found in the Appendix of Chapter 6.5. 
[Table 26 here]

As expected, the "license to pollute" focal point was marginalized during the course of the deliberation process. While it was referred to 123 times per 10,000 input words in the first reading debate, this number drops continuously to 74 references in second and 35 references in third reading. At the same time, the "workability" focal point gained in prominence between the first and second readings, when it was referred to 77 and 96 times, respectively, per 10,000 input words. Hence, it replaced the license to pollute focal point as the dominant focus of the discussion. However, it was mentioned only 43 times in third reading, when the third focal point centering on the subject of "harmonization" was much more prominent than in previous readings, especially in comparison to the number of references to the other two focal points. There were only 14 and nine references to the harmonization focal point in first and second reading (when the number of references to the other focal points was many times that amount), it was referred to 23 times in third reading (when the number of references to the other focal points was only slightly higher).

\subsubsection{Voting Patterns: The Impact of the Legislative Process on Voting Outcomes}

As nobody requested a roll-call vote in the third reading stage of the legislative process, this quantitative analysis is limited to only one vote, namely the vote on the first reading EP report. At that point in time, the Environment Committee still played a critical role under the enhanced cooperation procedure. Moreover, the conflict of competences between the Legal Affairs and Environment Committees had reached a second climax, following the initial EP vote putting the 
Legal Affairs Committee in charge of the legislation, as the Legal Affairs Committee had rejected the majority of amendments proposed in the Environment Committee opinion report. The Environment Committee re-introduced its amendments in the EP plenary, however; accordingly, the first reading report prescribed a strict liability framework that would not leave negligent operators much leeway in terms of scope and possible exemptions.

All three focal points identified in the qualitative analysis above were part of the deliberation process during the first reading stage. The "workability" and "license to pollute" focal points were presented as almost directly contradictory to one another, with the political Right emphasizing the need for a balanced framework that would take both environmental and business interests into account, and the political Left arguing that the proposed framework directive watered down the "polluter-pays" principle beyond recognition. The directive was thus discussed in a Left-Right context and, accordingly, we would expect the analysis to show that MEP positions on the Left-Right are statistically significant predictors of vote choice. In particular, legislators from the political left should be more likely to support the stringent first reading proposal, while those on the Right should oppose it.

At the same time, the 'harmonization' focal point constituted an emphasis on the need for an EU-level regulation facilitating the harmonization of environmental policy across the member states. Accordingly, we should expect MEP positions on the Sovereignty-Integration dimension to be statistically significant as well, with pro-Europeans more likely to support the legislation and EU-skeptics likely to oppose it.

The formal regression model is expressed as: 


$$
\begin{aligned}
& \text { VOTE }=\mathrm{a}+\beta_{1} \text { Left-Right }+\beta_{2} \text { Sovereignty-Integration }+\beta_{3} \text { Government Status }+\beta_{4} \\
& \text { Liberal Market Economy }+\beta_{5} \text { Partial Coordinated Market Economy }+\beta_{6} \text { Sectoral } \\
& \text { Coordinated Market Economy. }
\end{aligned}
$$

I conducted both binary logit and multinomial logit analyses, the results of which are almost identical. In what follows, I will present the results of the binary logit analysis. ${ }^{291}$

The results of the binary logit analysis confirm the expectations from above. As hypothesized, the coefficients of the two ideological variables are both statistically significant in the expected direction: Leftists and pro-Europeans are more likely to support the legislation. This result is evident in Table 27, which presents the raw binary logit estimates.

[Table 27 here]

Figure 50 provides the predicted probability of a vote in favor of the liability legislation given MEP positions on the Left-Right dimension. ${ }^{292}$

[Figure 50 here]

According to Figure 50, the probability of MEPs from the far Left, center-left, and even the political center supporting the legislation was quite high in the first reading vote, with some

\footnotetext{
${ }^{290}$ The "type of capitalism" variables fall into four categories: liberal market economy (Ireland and the United Kingdom); partial or family-oriented coordinated market economy (France, Italy, Spain, Greece and Portugal); sectoral coordinated market economy (Germany, Austria and Benelux countries); national coordinated market economy (Scandinavian countries). "National Coordinated Market Economy" serves as the reference value; it is, however, possible to calculate predicted probabilities for this category using CLARIFY, which will be reported below.

${ }^{291}$ Multinomial logit results can be found in the Appendix of Chapter 6.5.

${ }^{292}$ To calculate the probabilities presented in the following figures, I used CLARIFY and held the remaining variables constant at their means.
} 
variation between the four different types of capitalism. As we move further to the political Right, however, the probability of a vote in favor of the legislation drops substantially.

Figure 51 displays the predicted probabilities of a Yes vote given positions on the Sovereignty-Integration dimension. The figure demonstrates that vote choice in first reading was also a function of positions on this dimension, with pro-Europeans much more likely to support the legislation than EU-skeptics.

[Figure 51 here]

Figure 52 demonstrates that government status at home increased the probability of an MEP supporting the proposal, meaning that MEPs whose national parties were represented in the Council were more likely to vote in favor. This trend is most pronounced for legislators from sectoral coordinated market economies, who had the smallest initial inclination to support the legislation.

[Figure 52 here]

Finally, both figures show that MEPs from liberal market economies were most likely to support the legislation, followed by MEPs from member states with national and partial coordinated market economies. Members from sectoral coordinated market economies, in contrast, were relatively less inclined to support the strict liability framework. 


\subsubsection{Conclusion}

This analysis of the environmental liability legislation highlights the importance of the key participants in the legislation decision-making process, their configuration, and their interaction. It demonstrates, furthermore, that the level of controversy concerning particular pieces of legislation is difficult to forecast, since the initial conflict of competences between the Legal Affairs and Environment Committees set the stage for an unusually controversial deliberation process.

The role of the Environment Committee was critical indeed and shows what can happen in a legislative process when two competing sets of specialists are involved in the deliberation of a dossier. The Environment and Legal Affairs Committees presented the legislation in two fundamentally different fashions, and the Environment Committee, despite losing its initial role as the lead committee, succeeded in shaping vote choice during the first reading plenary vote. The legislative rules limited its role in second reading, however, where the Legal Affairs Committee had more leeway in drafting a report along the lines of its political objectives. As a result, the final piece of legislation reflects the position of the Legal Affairs Committee more than that of the Environment Committee.

Unfortunately for this analysis, the final vote in third reading was not recorded, making an explicit comparison between the first and third reading votes on the EP floor, and thus a direct evaluation of Hypotheses $3 \mathrm{~b}$ impossible. The qualitative analysis suggests, however, that positions on the sovereignty-integration dimension became more potent predictors over time, at the expense of the salience of the Left-Right divide. This is for two reasons. First, with the decreasing involvement of the Environment Committee, the "license to pollute" focal point played a gradually less important role in the deliberation process. This trend is confirmed in the 
content analysis and would likely entail a decrease in the perceived salience of the Left-Right dimension. Simultaneously, the prominence of the other two focal points increased, as the content analysis shows. The growing importance of these focal points likely entailed an increase in the salience of the sovereignty-integration dimension. While the harmonization focal point emphasized the desirability of a harmonized framework for environmental legislation at the EU level and thus explicitly stressed a pro-EU element in the policy proposal, the workability focal point underlined that it may be better to have a sub-optimal legislative framework than none at all.

All this is speculative, but the evidence presented in previous case studies supports the likelihood of this scenario. If this were indeed the case, the shape of a given legislator's $\left(\mathrm{MEP}_{\mathrm{x}}\right)$ indifference curves would resemble the illustration in Figure 53, meaning that focal points critically affected the policy preferences of EP backbenchers.

[Figure 53 here]

In first reading, the status quo point falls inside $\mathrm{MEP}_{\mathrm{x}}$ 's elliptically shaped indifference curve (the solid line), when the Left-Right divide is perceived to be more salient than the Sovereignty-Integration dimension. Accordingly, the EP tightens the provisions of the legislation considerably to make it more environmentally conscious. In contrast, it is the proposed legislation (i.e., the "New Policy") that constitutes the more preferred alternative in third reading. At this point in time, the indifference curve is "squeezed" from above and below (the dashed line), indicating the greater salience of the Sovereignty-Integration dimension. As a result, the 
directive on a common EU environmental liability framework is heavily amended in first reading, but adopted without these amendments in third reading.

\subsection{THE LIBERALIZATION OF PORT SERVICES IN THE EU}

The purpose of the directive on "port services: market access and financing of maritime ports" (COD/2001/0047), often referred to as the "port package," was to establish a legal framework that would ensure fair access to the port services market across the EU, where port services refers to technical-nautical pilotage services; towage and berthing; all cargo handling operations (including loading and unloading, stevedoring, stowage, transhipment and other intra-terminal transport); and passenger services (including embarkation and disembarkation). The opening of the port services market was to be achieved while providing member states with the opportunity to create specific rules within this framework that would take account of the ports' geographic characteristics as well as local, regional, and national singularities. The legislation was thus supposed to combine the principle of subsidiarity with the recognition and enforcement of the four freedoms (freedom of goods, persons, services, and capital) and existing EU competition rules. $^{293}$

At the time when the port services legislation was proposed by the Commission in early 2001, there was a great divergence of practice in the member states. While breaches of the existing regulations had been treated on a case-by-case basis in the past, the port package was to ensure a more systematic application of rules in the port sector to guarantee that all service providers would have a fair chance of entering the port services market. The overall goal was to

\footnotetext{
293 Subsidiarity is the principle whereby the Union does not take action (except in the areas which fall within its exclusive competence) unless it is more effective than action taken at national, regional or local level.
} 
avoid distortion of competition by improving and harmonizing national rules, regulations and practices.

\subsubsection{Qualitative Analysis: Focal Points and the Legislative Process}

The port services directive was one of the most controversial legislative proposals before the European Parliament during its $5^{\text {th }}$ term (1999-2004). The two most contested aspects of the proposal concerned the transparency of financial relations between member states and their ports and the range of services covered by the directive. The first was discussed in the context of "competition between harbors" (the financing of ports and port-related investments), while the second issue related to "competition within harbors" (the question of opening up the access to services in individual ports).

While the question of competition between ports was principally a source of interinstitutional disagreement between the EP on the one side and Council and Commission on the other, the question of services covered by the directive constituted a considerable source of controversy within the European Parliament. Two types of port services took center-stage, namely pilotage (the guiding of vessels in and out of port) and "self-handling" (the situation where a port user provides for its own port services personnel, rather than buying services from dock workers in the port, for example by using its own land-based personnel or sea-faring crew and equipment for cargo handling operations).

During the first parliamentary reading in November 2001, the EP amended the Commission proposal substantially. First, it included a provision requiring greater transparency with regard to public funding and the financial structures of European seaports. It also excluded pilotage from the directive, and restricted self-handling to port users whose vessels fly the flag of 
am EU member state. This was to decrease the risk of social dumping, where specialized dock workers would be replaced by under-qualified seafaring personnel not covered by existing social, safety, training, and environmental regulations. By authorizing only ships flying EU member state flags, the EP sought to prevent the use of "flags of convenience" to minimize self-handling costs.

Commission and Council did not accept the critical EP amendments concerning the transparency of financial relations and the scope of the directive, however, which the EP then reintroduced in second reading in March 2003. With regard to the question of self-handling, the EP sought to restrict authorization to seafaring crew members, rather than allowing the use of land-based personnel, and confirmed its insistence on permitting self-handling only for vessels flying the flag of an EU member state. It also insisted that self-handlers should be treated in the same way as other port service providers, meaning the same social standards and professional qualification requirements would apply. Once again, pilotage was to be completely excluded from the directive.

Following the EP's rejection of the Council's common position, the port package went into conciliation at the end of September 2003. The conciliation agreement outlined that selfhandling would be allowed only in cases where shipping companies use their own sea-faring crew and their own equipment. The agreement also stipulated that a member state may require self-handling to be subject to prior authorization in accordance with criteria relating to employment and social aspects, professional qualifications and environmental considerations, and that national rules on training requirements, professional qualifications, employment and social matters would not be affected directly by the legislation. 
With regard to pilotage, the compromise provided that this service should remain within the scope of the directive, but that the special importance of these services for the safety of maritime traffic would be emphasized. Moreover, the conciliation agreement specified that the national competent authorities may recognize the "compulsory nature" of pilotage and set rules for the service deemed necessary for reasons of safety and of public service requirements, including limiting pilotage services to a single provider. Hence, the compromise agreement left the question of prior authorization for both services to the discretion of the member states, thus confirming the position of Council and Commission on both issues.

Concerning financial relations, the compromise extended the directive to include the establishment of "fair and transparent conditions of competition both in and between Community ports." To that end, every port and port service provider would be required to disclose its financial relations to the member states and the Commission. The Commission and the member states would use this information to evaluate the need for fair competition, and the Commission would draft a set of common guidelines on state funding for ports within one year of the directive's entry into force.

The EP's conciliation delegation had passed the conciliation compromise with a very narrow majority, but the EP plenary rejected the agreement on November 20, 2003, with 209 MEPs voting in favor, 229 against, and 16 abstentions.

While the question of financial relations and public funding of ports constituted an immediate source of conflict between EP, Commission, and Council, the controversy within Parliament did not materialize until after the first parliamentary reading, which a number of respondents involved in the deliberation of the proposal remember as relatively easy. ${ }^{294}$ During

\footnotetext{
${ }^{294}$ Respondent \#70, Respondent \#78, Respondent \#19, Respondent \#25, Respondent \#1.
} 
the first reading, there was "some debate, but nobody was interested," according to one member of the responsible Committee on Regional Policy, Transport and Tourism; it was "a technical debate by those colleagues who have an interest in harbors or come from harbor areas." ${ }^{295}$ Moreover, since the inclusion of measures to improve the transparency of public funding of ports into the scope of the directive was broadly favored across party lines, ${ }^{296}$ the proposal passed smoothly through first reading.

Two developments, however, changed this dynamic during the process of deliberation in the later legislative stages. On the one hand, there was unquestionably an external factor, namely increasing pressure from stakeholders concerned about the effects of the legislation on existing structures, in particular from port authorities, who wanted to keep control of their ports, and port workers. In particular, the labor unions in the North Sea harbors in Germany, the Netherlands, and Belgium, representing the highly organized dock-workers, increasingly showed their opposition publicly, the climax being a number of strikes, as well as vocal and unruly demonstrations at the EP in Brussels and Strasbourg. Secondly, there was a change of mood within the EP, with the political left becoming more skeptical toward what was increasingly perceived to be one of many EU "liberalization initiatives." 297 This new focus on the merits of liberalization and privatization, placed in the broader context of globalization, constituted a significant change of focus from the first reading, where it played no role whatsoever. ${ }^{298}$ Now, the political Left maintained that the proposal was setting conditions for competition amongst service providers within harbors at the expense of highly qualified dock workers and, as a result,

\footnotetext{
295 Respondent \#78, also: Respondent \#19.

${ }^{296}$ Respondent \#32, Respondent \#55, Respondent \#1.

${ }^{297}$ Respondent \#78.

${ }^{298}$ Respondent \#78.
} 
of "safety standards and security norms." 299 Hence, "liberalization" and its negative implications for dock workers and maritime safety became an increasingly prevalent focal point for the opponents of the directive.

The proponents of opening up European ports to competition, in contrast, maintained that ports were too expensive and a burden on the EU economy as a whole. In their view, the European economy could become more competitive by cutting excessive costs caused by rigid and protectionist structures. Operating ports could be more transparent, efficient, and less expensive, which would, according to the proponents, benefit the overall aim of the Lisbon Agenda to make the EU the most competitive economy in the world by 2010 . Therefore, the efficiency and competitiveness of the EU economy would improve if the port package were approved, which was the principal focal point for those in favor of the proposal.

This latter position was the one shared and promoted by the rapporteur responsible for the port services directive, the German Christian-Democrat Georg Jarzembowski. As a German Christian-Democrat, Mr. Jarzembowski was not perceived to be a pure economic liberal, but a socially-oriented politician who in principle favored the involvement of social partners and trade unions in economic governance. With regard to liberalization issues, however, he was always considered to be "the first to propose liberalization on transport issues." ${ }^{300}$ As a result, the political Left maintained that "when the rapporteur speaks of reducing the cost of port services he really means cutting wages, jobs and social protection." ${ }^{301}$

Mr. Jarzembowski enjoys a reputation across party lines as one of the principal specialists on transportation issue. He is also known and respected as a skillful politician and tough

\footnotetext{
${ }^{299}$ Respondent \#78.

${ }^{300}$ Respondent \#78.

301 Arlette Laguiller (GUE/NGL, France), as cited in European Report: "Shipping: Parliament excludes pilotage from liberalisation of port services.” March 12, 2003.
} 
negotiator with strong principles and objectives. While generally not perceived as dogmatic, even some of his party colleagues view him as headstrong and insistent on his own positions, making it difficult at times to pursue an agenda of compromise across party lines. ${ }^{302}$ At the same time, Mr. Jarzembowski does consider what is feasible politically and often walks a fine line between what is desirable from his personal point of view and acceptable to others. Respondents generally characterized him not as the kind of rapporteur who instinctively seeks a compromise that is broadly acceptable across party lines, but one who sticks to his own positions when possible and is willing to take political gambles if he sees the odds to be in his favor. As some respondents indicated, however, Mr. Jarzembowski occasionally underestimates the extent of the opposition to his proposals at times ${ }^{303}$ and this was also the case with regard to the port services directive. ${ }^{304}$ He evidently misjudged the majorities he could muster in the EP plenary, especially in the decisive third reading vote following the conciliation procedure between EP and Council.

While a time period of six weeks, with a possible two week extension, is officially allocated to a conciliation between EP and Council, the process in the case of the port package took a single day until the issue was put to a vote in the conciliation committee. There was concern among the proponents of the proposal that a drawn-out negotiation process would undermine existing support for the directive, and the "right side of the room was really pressing for an immediate solution," according to an EP official. ${ }^{305}$ The rapporteur pursued the strategy of finding a compromise with the Council of Ministers, which was not willing to give into the demands of the Left, and once he realized that there was probably no possibility of "finding an

\footnotetext{
302 Respondent \#25, Respondent \#70.

303 Respondent \#55.

${ }^{304}$ Respondent \#19, Respondent \#32, Respondent \#44, Respondent \#70.

305 Respondent \#28.
} 
agreement with the Socialists, ${ }^{306}$ he negotiated a compromise solution with the Council and tried to push it through in parliament. Hence, much negotiation took place behind closed doors throughout the summer months preceding the conciliation procedure. While there had been no official exchange of text between Council and EP, just hours before the first conciliation meeting on September 29, 2003, a working document suddenly appeared "out of the blue," as one respondent remembers. ${ }^{307}$ Evidently, Mr. Jarzembowski speculated that he had the necessary majority in plenary to push this text through plenary with the votes of the Liberals, in particular, once it was accepted in the conciliation procedure. He was even willing to give up the support of a portion of his EPP colleagues, since he expected defectors from other party groups to make up for this loss. ${ }^{308}$

The most contested element in the conciliation text concerned the authorization procedure in the case of self-handling. The question was whether prior authorization by national authorities was to be voluntary, as the compromise agreement stipulated, or mandatory, as the critics of the proposal demanded. The conciliation committee voted in favor of the conciliation result to be forwarded to the EP plenary in a contested 8-7 vote. This outcome came as a surprise to the opponents of the directive in the committee, since the Socialist Vice President of the EP, Mr. Imbeni, unexpectedly voted in favor of the conciliation result. Mr. Imbeni justified this stance arguing that, for institutional reasons, he wanted to leave the final vote to the EP plenary and not bring the proposal down himself. ${ }^{309}$ To many of his party colleagues, however, this explanation was unacceptable; one Socialist remembers having been furious at the time. ${ }^{310} \mathrm{Mr}$.

\footnotetext{
${ }^{306}$ Respondent \#32.

307 Respondent \#28.

${ }^{308}$ Respondent \#32.

309 Respondent \#28.

310 Respondent \#43.
} 
Imbeni's Socialist colleagues suspected that he had cut a deal with the negotiators from the Parliament's Right and the Council behind their backs. ${ }^{311}$

The outcome of the vote in the conciliation committee was extremely close and in part due to some political maneuvering on the part of the rapporteur. As one respondent present in the conciliation meetings maintains, ${ }^{312}$ a number of Flemish and Dutch EPP members who were to vote on the compromise agreement and would have rejected it were substituted, at the very last minute, by the rapporteur and group coordinator to ensure the approval of the compromise agreement. This type of maneuvering explains why in the case of the port services directive, the committee position in favor of the proposal did not translate into a positive vote in the EP plenary, where the proposal was defeated with 209 MEPs voting in favor, 229 against, and 16 abstentions. Mr. Jarzembowski arranged for his position to pass through conciliation rapidly and took a gamble in plenary, where he believed he had the majority necessary for the proposal to pass, rather than continuing to negotiate a compromise text that might have satisfied some of his opponents. This compromise may well have been possible, however, especially with regard to the authorization procedure that could have been made "a little more water-proof." 313 While this is purely speculative, two respondents from opposite sides of the political spectrum did indicate in interview that they would have been willing to accept a compromise where the opening of the self-handling sector to competition was coupled with strict mandatory prior authorization. One economic liberal from the EPP side, though not satisfied even with the conciliation compromise "from a competitive perspective," indicated that he would have allowed "self-handling with or without the prior authorization," 314 while a Socialist from a North-Sea country maintains that she

\footnotetext{
311 Respondent \#43.

312 Respondent \#28.

313 Respondent \#28.

314 Respondent \#76.
} 
would have supported a compromise providing for self-handling with prior authorization. ${ }^{315}$ But according to the critics of the directive, the rigid positions of the key actors in committee on the conservative side made this agreement impossible. $^{316}$

The Socialists had two primary objectives in the second and third reading stages: to exclude both pilotage and self-handling from the scope of the directive $\mathrm{e}^{317}$ and they felt that in second reading, they were "almost there." 318 This sense made them fairly optimistic for the conciliation procedure and the third reading vote, but the strategy by the rapporteur to push the compromise agreement, including a provision for the liberalization of self-handling, through the conciliation committee spoiled their efforts before genuine negotiations even started. ${ }^{319}$ The fact that a Socialist Vice-President was the one breaking the tie in favor of sending the compromise agreement to the plenary caused a particular stir among the Socialists dealing with the directive. The perception that a deal had been cut behind the Socialists' back between the rapporteur, the responsible Commissioner Ms. De Palacio, the Council negotiators, and Mr. Imbeni, intensified the opposition to the directive among the Socialist members handling the dossier on behalf of their party group. ${ }^{320}$ The firm positions of Mr. Jarzembowski and Ms. De Palacio in particular angered the opponents of the directive, as they were perceived to be unresponsive to their arguments. $^{321}$

As a result, the active participants from the political Left began lobbying heavily to ensure a cohesive party line against the directive in the third reading vote, ${ }^{322}$ an effort facilitated

\footnotetext{
${ }^{315}$ Respondent \#75.

316 Respondent \#43.

${ }^{317}$ Respondent \#78, Respondent \#43, Respondent \#19.

318 Respondent \#43, Respondent \#1.

${ }^{319}$ Respondent \#28.

${ }^{320}$ Respondent \#43, Respondent \#78.

${ }^{321}$ Respondent \#43, Respondent \#70.

322 Respondent \#43, Respondent \#70, Respondent \#1.
} 
by the increasing outside pressure against the proposal by the dock workers, a key constituency of the Left. ${ }^{323}$ One official from the Greens remembers that he mobilized his faction strongly: "We made sure that everybody takes part in the vote." $" 324$ Similarly, a Socialist respondent described her efforts to bring the proposal down as follows:

"I wrote to them [the Socialist MEPs] saying 'be there! Don't lose this, this is a major fight.' [...] I worked like hell to get a position with everyone. [...] Normally we try to handle the discussions in the committee working group, because it is difficult on very technical issues to take positions in the big group. But on this ports thing, we had a very heavy discussion in the group and got the group's support to do it like this. It was absolutely a convincing effort." ${ }^{325}$

This reality is especially noteworthy because transport issues usually do not get much exposure in the PES group, ${ }^{326}$ where deliberation and positioning is usually left to the experts. ${ }^{327}$ Here, as in other groups, it was the policy experts and other legislators with a particular stake in the issue $\mathrm{e}^{328}$ who led the effort to establish a firm and cohesive line with regard to the port package. ${ }^{329}$ This effort was especially directed at those MEPs on the political Left from the Southern EU member states, ${ }^{330}$ who thought that opening their port services to competition would give their ports a competitive advantage over the highly structured ports in the Northern member states. ${ }^{331}$ In the end, however, the lobbying campaign on the principle of anti-

\footnotetext{
${ }^{323}$ Respondent \#78, Respondent \#55, Respondent \#44.

${ }^{324}$ Respondent \#1.

325 Respondent \#43.

${ }^{326}$ Respondent \#43, Respondent \#19.

${ }^{327}$ Respondent \#19.

${ }^{328}$ Respondent \#1, Respondent \#25, Respondent \#70.

${ }^{329}$ Respondent \#1, Respondent \#43, Respondent \#19, Respondent \#70, Respondent \#75.

${ }^{330}$ Respondent \#70, Respondent \#75, Respondent \#43, Respondent \#78.

331 Respondent \#31.
} 
liberalization paid off: "We won over most of our comrades from the Southern countries on the principle of liberalization," one Dutch Socialist remembers. ${ }^{332}$

This principle was communicated in a quite emotional fashion, however. ${ }^{333}$ Even one opponent of the directive acknowledges that the anti-liberalization drive was at least in part based on mistaken interpretations of the directive's consequences, which would have coupled liberalization with "very strong" elements of regulation. ${ }^{334}$ Instead, critical nuances were excluded from the discussion. As a result, a "vulgarized debate" ultimately turned an issue of "liberalization of services with regulation both at the European and the national level" into one of "complete liberalization." Discussion centered on a number of emotional key phrases like "social dumping" and featured frequent references to a symbolic busload of Bulgarians, Chinese, Africans, Argentineans, Malaysians, or Filipinos "coming to self-handle ships, while the others would be fired from their very secure jobs." ${ }^{, 335}$ As one member of the leftist GUE group explained in interview:

"I imagine it like this: some seaman from Burundi climbs in Piraeus [i.e. the harbor of Athens] on a crane and has to read the instruction manual in Greek, which he can't. So the whole thing is absurd!" 336

Partially due to this simplified debate, one member of the transportation committee suspects that MEPs lacking the necessary expertise with regard to transport issues to genuinely evaluate the actual extent of the "liberalization" instituted by the port services directive opposed

\footnotetext{
${ }^{332}$ This effort was quite successful. While the political Left (i.e. those with Nominate scores smaller than 0 ) had been quite divided in first reading (120-147-22; Right $=164-83-9)$, it was much more cohesive in third reading (19199-4; Right = 168-19-12). In the PES, 52 MEPs had voted against the proposal in first reading and 107 in favor, while in third reading, 128 voted against, 10 in favor, and 3 abstained).

${ }^{333}$ Respondent \#78.

${ }^{334}$ Respondent \#25.

${ }^{335}$ Respondent \#78.

${ }^{336}$ Respondent \#44.
} 
a policy proposal that they may have supported if they had the necessary background knowledge and considered the dossier more carefully. ${ }^{337}$ Another respondent maintains, quite similarly, that despite the substantial degree of public attention to the issue and the high level of controversy in the EP, the majority of MEPs voting had no substantiated opinion regarding the port package. ${ }^{338}$

\subsubsection{Content Analysis}

This shift in the discussion of the port package should also be evident in the parliamentary debates in first reading (November 13, 2001), second reading (March 10, 2003), and third reading (November 18, 2003), a proposition tested using content analysis. As in previous sections, a series of words and phrases was coded consistent with the two focal points (the consequences of "liberalization" on the one hand, and the improvement of "EU competitiveness" on the other) to determine their frequency of use. ${ }^{339}$

Based on the qualitative analysis above, we should expect to find that the question of the competitiveness of the European economy should be sidelined by an increasing focus on the negative impact of the liberalization of port services. References to the competitiveness focal point should thus decrease over time, while the liberalization issue should be raised increasingly in the later stages of the legislative process.

The results of the content analysis confirm these expectations, as Table 29 shows.

[Table 29 here]

\footnotetext{
${ }^{337}$ Respondent \#25.

${ }_{338}^{338}$ Respondent \#1.

${ }^{339}$ Coding details can be found in the Appendix of Chapter 6.6.
} 
The first reading debate featured 114 references per 10,000 input words to the EU competitiveness focal point, a number that declines steadily to 77 references in second and only 69 references in third reading. In contrast, the liberalization focal point is referenced 135 times in first, 283 times in second, and 292 times in third reading (all per 10,000 input words), showing its increasing dominance in the discussion concerning the port services directive.

Moreover, a second content analysis shows that that the liberalization issue not only moved to the center of the debate, but was also discussed in a more emotional and severe fashion. For this analysis, I coded references to the liberalization issue by intensity. The most extreme references include such terms as "abuse," "cowboy ports," "crooks," "pirate workers," "ultra-liberal," "slavery," as well as references to the symbolic "bus load" of Africans, Argentineans, or Malaysians. Table 30 shows that the use of such extreme terminology jumped from three incidents per 10,000 input words in first reading to 21 and 20 , respectively, in the second and third reading stages.

[Table 30 here]

\subsubsection{Voting Patterns: The Impact of the Legislative Process on Voting Outcomes}

It is hypothesized $(\mathrm{H} 3 \mathrm{~b})$ that we should be able to predict voting patterns in plenary on the basis of the dominant focal points. This quantitative analysis tests this proposition and serves to determine if prevailing focal points actually provided the basis for the formation of policy coalitions, i.e., if they supplied a mutually acceptable equilibrium providing the basis for policy coalitions. 
On the basis of the qualitative analysis above, it is possible to formulate a series of specific hypotheses regarding the outcomes of the decision-making process in the case of the port package. We should expect to find that in first reading, MEPs vote based on their positions on the Left-Right divide as well as the sovereignty-integration dimension, since both the liberalization and the competitiveness focal points were important elements of parliamentary deliberation. Specifically, due to the emphasis on the competitiveness of the EU economy, proEuropean MEPs should be more likely to support the proposal. Moreover, legislators from the political right should be more likely to support the proposal, since the question of liberalization did factor into the discussion of the port package.

By the time of the third parliamentary reading stage, however, the focus of the debate had shifted substantially away from the question of EU competitiveness toward the liberalization issue and its perceived implications. As a result, the impact of MEP positions on the sovereigntyintegration dimension should be less pronounced in third reading. Instead, the port package should be more of a left-right issue than it was in first reading, meaning that MEP positions on the Left-Right dimensions should be more potent predictors of voting patterns. Specifically, the political Left should be strongly opposed to the proposal, while the political Right should be strongly in favor.

The dependent variables in this analysis are the votes in the first and third readings. ${ }^{340}$ These variables are dichotomous. A value of zero equals a vote against the directive and a value of one means a vote in favor. ${ }^{341}$ The predictor variables in this analysis, as described above, are MEP NOMINATE scores on the two ideological dimensions, the government-opposition

\footnotetext{
340 The vote in the second reading was not a roll-call vote and is thus not considered here.

${ }^{341}$ The results of the multinomial logit analysis of the plenary vote in first reading can be found in the Appendix of Chapter 6.6. Due to the small number of abstentions in the third reading vote a multinomial logit analysis of this vote is not possible.
} 
dichotomous variable, and dichotomous variables accounting for "type of capitalism."342 Formally, the regression model reads:
VOTE $=a+\beta_{1}$ Left-Right $+\beta_{2}$ Sovereignty-Integration $+\beta_{3}$ Government Status $+\beta_{4}$ Liberal Market Economy $+\beta_{5}$ Partial Coordinated Market Economy $+\beta_{6}$ Sectoral Coordinated Market Economy. ${ }^{343}$

The results of the binary logit analysis confirm the expectations from above. In first reading, as hypothesized, the coefficients of the two ideological variables are statistically significant in the expected direction, with pro-Europeans and legislators from the political Right more likely to support the port package. Moreover, the pseudo- $\mathrm{R}^{2}$ of 0.30 suggests that the regression model accounts for a respectable level of the variance in voting patterns. This result is evident in Table 31, which presents the raw binary logit estimates.

[Table 31 here]

To facilitate the interpretation of these results, I calculated predicted probabilities using CLARIFY, which are presented in graphical form. Figure 57 displays the predicted probabilities of a vote in favor of the proposal along given Left-Right positions. ${ }^{344}$

\footnotetext{
${ }^{342}$ The "type of capitalism" variables fall into four categories: liberal market economy (Ireland and the United Kingdom); partial or family-oriented coordinated market economy (France, Italy, Spain, Greece and Portugal); sectoral coordinated market economy (Germany, Austria and Benelux countries); national coordinated market economy (Scandinavian countries).

343 "National Coordinated Market Economy" serves as the reference value; it is, however, possible to calculate predicted probabilities for this category using CLARIFY, which will be reported below.

${ }^{344}$ To calculate the probabilities presented in the following figures, I used CLARIFY and held the remaining variables constant at their means.
} 
[Figure 57 here]

This figure confirms that the probability of supporting the proposal in first reading increases the further to the right an MEP is located on the Left-Right dimension, for all four types of capitalism. The impact of Left-Right positions increases across the range of the LeftRight dimension by about 50 percent for MEPs from member states with liberal market economies, about 70 percent for MEPs from partial and coordinated market economies, and a little more than 60 percent for MEPs from member states with sectoral coordinated market economies.

Moreover, Figure 57 demonstrates that MEPs from liberal market economies are least likely to vote in favor of the port package, while legislators from sectoral coordinated market economies are most likely to support it. This trend is also evident in Figure 58, which presents the predicted probabilities of Yes votes along the sovereignty-integration dimension.

[Figure 58 here]

The figure demonstrates that the probability of supporting the proposal rises with increasing pro-EU attitudes of legislators. It also shows that the impact of positions on the sovereignty-integration dimension is quite substantial: the probabilities of voting in favor of the port package increase by about 60 percent across the range of the sovereignty-integration dimension for MEPs from liberal market economies, by about 80 percent for MEPs from partial and national coordinated market economies, and by almost 80 percent for MEPs from sectoral coordinated market economies. 
Finally, Figure 59 shows that government status at the national level entails a slightly decreased probability of supporting the port package in first reading.

[Figure 59 here]

The impact of a shift in focal points between first and third reading is evident in the analysis of the third reading vote, the results of which are presented in Table 32. It shows that the coefficient of the Left-Right variable increases from 1.91 in first reading to 6.45 in third reading, while the coefficient of the sovereignty-integration variable not only decreases from 2.31 to 0.70 , but actually becomes statistically insignificant when the other independent variables are held constant at their means.

[Table 32 here]

This trend is also evident in the predicted probabilities, for the Left-Right and sovereignty-integration dimensions in the EP's third reading vote. Figure 60 demonstrates that the probability of voting in favor of the directive increases dramatically across the Left-Right divide.

[Figure 60 here]

As hypothesized, the impact of positions on the Left-Right divide is much more pronounced in third than in first reading. The probability of voting in favor of the port package 
increases by 100 percent across the range of the Left-Right variable, meaning that MEPs on the far left end of the spectrum have a 100 percent probability of voting against the proposal, while those on the far right have a 100 percent probability of voting in favor. This applies for all four types of capitalism. In fact, even MEPs on the moderate left, with NOMINATE scores around 0.5 , are almost certain to oppose the port package in third reading, while MEPs on the centerright, with NOMINATE scores of 0.5 , are almost certain to support it.

Meanwhile, the impact of positions on the sovereignty-integration dimension is moderate and much less than in first reading, as Figure 61 demonstrates. The probability of voting in favor of the port package increases by only around 30 percent as we move from the anti-EU to the proEU side of the spectrum.

[Figure 61 here]

Figure 62 displays the predicted probabilities of voting in favor of the proposal as a function of national party government status. It shows that being in government at home, which at the EU level means being represented in the Council of Ministers, slightly increases the probability of supporting the port package in third reading across the four "types of capitalism."

[Figure 62 here]

Finally, it is noteworthy that MEPs from member states with partial and sectoral coordinated market economies are less likely to support the port package in third reading than they were in first reading. While this result is not surprising for members from sectoral 
coordinated market economies, since the voluntary nature of the authorization procedures for self-handling stipulated in the conciliation compromise threatens existing structures in the North Sea ports in particular, this finding is less expected for members from partial coordinated market economies. It does confirm, however, that the political left was evidently successful in convincing their members from the Southern EU countries to oppose the port package in the final EP vote.

To summarize, the critical preference shift among legislators not directly involved in the deliberation of the port package was an increase in the perceived salience of the Left-Right divide between the first and third reading stages, at the expense of the salience of the sovereignty-integration dimension. This trend is illustrated in Figure 63 for a given legislator $\mathrm{MEP}_{\mathrm{x}}$.

[Figure 63 here]

In first reading, the port package (the "New Policy") fell inside the elliptically shaped indifference curve (the solid line), when the sovereignty-integration dimension was perceived to be more salient than the Left-Right divide. In contrast, it was the status quo point that was the more preferred alternative in third reading, as it falls inside the dashed indifference curve. At this point in time, the indifference curve is "squeezed" from the sides, indicating the greater salience of the Left-Right divide. Accordingly, the directive on market access to port services passed through the EP plenary in first reading, but was rejected in favor of the status quo in third reading. 


\subsubsection{Conclusion}

The analysis of the decision-making process in the case of the port services directive supports the expectations of the focal point model. First, it is evident that there was a distinct set of focal points emphasizing the perceived impact of the proposed legislation upon its implementation. As suggested by the focal point model, these focal points constituted broad representations of the content and consequences of the proposed legislation. As such, technical aspects of the proposal were largely absent from the discussion on the EP floor, where broad categorizations of what the legislation was "all about" dominated the deliberation. The focal points highlighted, on the one hand, the perceived positive impact of the port package on the competitiveness of the European economy by making port services less expensive and increasing the efficiency of the port sector across the EU, as well as within individual ports. This emphasis was fairly pronounced in first reading, but was sidelined by an increasing focus on a second aspect of the port services directive when the focal point emphasizing the perceived impact of "negative liberalization" on the job security of port workers and maritime safety gained prominence. Both focal points were provided by committee experts and picked up in the general discussion regarding the port package, as the content analysis demonstrates.

The quantitative analysis of EP votes in the first and third reading stages of the codecision procedure provides evidence for the proposition that a shift in focal points entails a shift in policy-preferences, and thus affects political outcomes. Accordingly, it was possible to predict voting patterns on the basis of the prevailing focal points, which confirms hypothesis H3b. While the positions of individual MEPs on the sovereignty-integration ideological dimension were potent predictors of voting patterns when the competitiveness of the European economy was perceived to be at stake in first reading, these positions became less salient over time. Therefore, 
pro-European MEPs had a greater probability of voting in favor of the directive in first reading, while a pro-EU attitude had little effect in third reading.

Positions on the Left-Right divide constitute statistically significant predictors of voting behavior in both the first and third reading stage, but the rising perception of the legislation at hand as a Left-Right issue also substantially increased the impact of Left-Right positions on vote choice in third reading. This impact is so pronounced in third reading that even a moderate leftof-center MEP was almost certain to oppose the directive, while a moderate right-of-center MEP was equally assured to vote in favor.

The case of the port service directive also emphasizes how the political process and its participants play a significant role in affecting policy outcomes. Particularly noteworthy is the fact that the perceived lack of willingness on the part of the rapporteur to cooperate and actively seek a compromise across party lines backfired in the end. Mr. Jarzembowski's strategy of trying to narrowly outvote the opponents of the proposal, rather than seek a compromise agreement that would be broadly acceptable, not only failed, but actually incensed the opponents of the directive. The perception that a deal had been struck between Commission, Council, the political Right in the EP, and one Socialist EP Vice-President created a special motivation for the active opposition to defeat the proposal completely. The fact that the rapporteur failed to get his own party on board while irritating the skeptics with supposedly furtive dealings ultimately brought the legislation down.

In sum, as long as the port package was viewed at least in part in terms of its European merit, as was the case in first reading, the policy coalition in favor of the legislation was in the majority. This changed over the course of the decision-making process, and in third reading, a 
leftist policy-coalition in combination with a small number of defectors from the EPP ultimately defeated the proposal.

\subsection{EUROPEAN UNION CITIZENSHIP AND THE FREE MOVEMENT OF PEOPLE}

The purpose of the legislative proposal titled "Union citizenship: free movement and residence for citizens and their families within the Member States' territory" (reference number $\mathrm{COD} / 2001 / 0111$ ) was to enhance the rights of movement and residence of EU citizens across the European Union member states. Based on the premise that the freedom of movement constitutes an integral part of the European integration process, the legislation was to create a common framework of legislation to harmonize the legal status of the EU citizen into a single set of rules. $^{345}$

The underlying concept of the proposal was to enable EU citizens to move between member states on similar terms as the citizens of each member state. Moving around across the EU for the purpose of changing residence or jobs was to become comparable to nationals moving around within their own member state. Accordingly, administrative and legal hurdles should be kept at a minimum.

The proposal was to form a single instrument streamlining the arrangements for exercising the freedom of movement within the EU while providing for legal clarity. In this

\footnotetext{
${ }^{345}$ EU citizenship is based in principal on four Treaty articles. Article 14 enshrines the "four freedoms" for the movement of goods, persons, services and capital. Article 17 confers EU citizenship to all nationals of a member state. Article 18 grants EU citizens the "right to move and reside freely within the territory of the Member States," while Article 39 bans employment and payment discrimination on grounds of nationality. It also allows member state workers to travel and work freely across the EU and to reside in all member states for job purposes.
} 
effort, it was to fuse existing regulations and legislation into one coherent whole, thus replacing two existing regulations and nine directives. In this process, it was supposed to:

- streamline the arrangements for exercising freedom of movement;

- extend the right of residence without formalities to six months;

- grant the right of permanent residence after four years of residence in the host member state;

- make it easier for Union citizens' family members to exercise the right to move and reside freely, irrespective of nationality;

- tighten up the definitions of restrictions on the right of residence. ${ }^{346}$

While the existing legislation was based on different parts of the EC Treaty as their legal foundation and concerned particular categories of people (e.g. legislation applying specifically to students), the new, comprehensive directive was to pertain more broadly to all citizens of the EU and their families - regardless of nationality. In sum, the proposal was to substantially simplify the formalities for EU citizens and their families to exercise their rights of movement and residence across member states, cutting back barriers to the bare essentials.

\subsubsection{Qualitative Analysis: Focal Points and the Legislative Process}

The directive on Union Citizenship constitutes a case where the level and nature of controversy would have been difficult to foresee prior to the start of the political deliberation and decisionmaking process. On the face of it, the directive was about the free movement of people across the EU and the integration of existing legislation covering different aspects of the free movement of citizens. It was supposed to attach a practical value to the concept of EU citizenship by fusing

\footnotetext{
346 European Commission, RAPID Press Release: “Commission wishes to enhance Union citizens' right of movement and residence." May 23, 2001.
} 
different existing aspects of EU citizenship into a cohesive whole. ${ }^{347}$ This fundamental purpose was hardly controversial in view of the general pro-European outlook in the $\mathrm{EP},{ }^{348}$ since the great majority of MEPs agrees with and favors the principle of dual national and EU citizenships. ${ }^{349}$

Several aspect of the proposal exhibited initial potential for controversy, such as immigration and the coordination of social security systems, but it was difficult to anticipate that the key issue would turn out to be one of family definition, and specifically the extension of citizenship rights to non-traditional and same-sex couples. In fact, the initial resistance on the part of the EU member states, for example, centered around their reluctance to enhance the residence rights of family members who are not EU citizens, not the definition of what constitutes a family. ${ }^{350}$ While the relevance of the gay rights issue may have been obvious to those directly concerned with the issue, it was not apparent to most. Uninvolved members of parliament only realized the significance of the issue once the process had started. ${ }^{351}$

Throughout the decision-making process, two opposing groups of committee members emphasized what they perceived to be the critical aspects of the Union Citizenship directive. For the center-left, joined by the committee members from the Liberals, the most important angle of the debate was that the extension of the citizenship rights should not exclude those not covered by traditional definitions of what constitutes a family. To them, it was obvious that if you broaden citizens' rights, "you have to say to whom," as one MEP stressed in interview. This group of committee members argued that the principle of mutual recognition, extended to issues

\footnotetext{
${ }^{347}$ Respondent \#59.

${ }^{348}$ Respondent \#66.

${ }^{349}$ Respondent \#11.

350 European Report: "Free Movement: Member states wary of plan to boost EU citizens' residence rights." February 23, 2002.

${ }^{351}$ Respondent \#59.
} 
in the realm of Justice and Home Affairs, constituted a reasonable basis for this process. ${ }^{352}$ In effect, they provided a focal point emphasizing the question of family definition.

In response, the political right argued that the principle of subsidiarity bestowed the EU member states with the prerogative of defining marriage, and that EU level definitions should not be "imposed" upon the member states. Most importantly, committee members from the conservative spectrum framed the issue in terms of the practical value of the legislation to the every-day life of EU citizens.

There is a general consensus among the respondents interviewed that without the family definition issue assuming such a prominent role, the directive would have been much less, or not at all, controversial. Even issues such as the circumstances allowing for the forceful expulsion of EU citizens and the time frame for achieving permanent residency, ${ }^{353}$ which were of special importance to the Council throughout the co-decision procedure and were initially considered to be crucial issues by EP insiders, ${ }^{354}$ proved to be all but irrelevant in the deliberations of the EP. $^{355}$

The configuration of actors was crucial in bringing these issues to the forefront of the debate. The question of family definition in particular became so prominent in the debate because of the presence of a number of MEPs in the responsible committee for whom gay rights were of critical, if not primary, importance. Moreover, these members sat in the key groups of the EP and together formed a strong, intergroup lobby for the extension of the directive to same-

\footnotetext{
${ }^{352}$ Respondent \#7.

${ }^{353}$ The question of expulsion refers to the circumstances under which EU citizens can be expelled from the territory of a host member state if they have resided there for many years, in particular when they were born and have resided there throughout their life. The final compromise allowed such expulsion only where there are imperative grounds of public security, while the right of permanent residence applied to all Union citizens and their family members who have resided in the host member state during a continuous period of five years without becoming subject to an expulsion measure.

${ }^{354}$ Respondent \#8.

${ }^{355}$ Respondent \#11.
} 
sex couples. This group consisted of Mr. Cashman and Ms. Swiebel for the PES, Ms. Buitenweg and Ms. Lambert for the Greens, and Ms. Ludford for the Liberals. These members represented a majority in the EP at the time that took a progressive approach with regard to value politics such as civil liberties, where the Liberals consistently backed the political Left in the Civil Liberties committee. $^{356}$

The delegates pushing the initiative constituted the key people of the parliamentary majority coalition in this particular policy area in the responsible committee and were able to muster a majority across party groups. This particular configuration of individuals was critical, according to one EP official, who maintains with regard to the gay rights issue that "if Cashman had been sitting with the UEN and Buitenweg had been unattached, it would not really have mattered." Instead, as one official explains, the debate was dominated by the right "mixture of people for making a difference in terms of policy outcome."357

This group of people stood in sharp opposition to the rapporteur in the responsible committee, an Italian MEP from the EPP, whose handling of the dossier constitutes an important aspect of the deliberation and decision-making process. From the beginning, there was a strong perception on the part of the gay rights proponents that appointing Mr. Santini as a Catholic, Italian conservative was not a sensible decision in the case of this particular dossier. At that point in time, however, it was not yet apparent that the family definition issue would be so high on the agenda, and one MEP suggests that Mr. Santini himself might have been unaware of what "he put his hands on. ${ }^{, 358}$ Mr. Santini looked at the issue from a very narrow perspective, and it may have never occurred to him that this issue might involve the question of family definition and

\footnotetext{
${ }^{356}$ Respondent \#59, Respondent \#7.

357 Respondent \#59; also: Respondent \#66.

358 Respondent \#38.
} 
same-sex couples. As the deliberation process unfolded, he began "to discover that EU citizenship involved all kinds of other questions," in the words of one MEP. ${ }^{359}$

Mr. Santini thus appeared hardly open for compromise on the family definition question in first reading, at least in the perception of his political opponents. This view is confirmed by the fact that Mr. Santini insisted in his explanatory statement to the first reading report that “"spouse' must necessarily mean a heterosexual spouse" and that he "considers it preferable to state this explicitly in the directive itself." ${ }^{360}$ One Socialist MEP sums up this sentiment as follows:

"[The issue] could have been less controversial if somebody else had written it, somebody else who might not have aroused the controversies that were there in the committee and was not going to stake them up. You can never prove that, but there were certain people who had given up taking reports on immigration, because they knew they were not going to get them through, because they know the way the committee was thinking. And I think Santini in some ways was a bit naïve in his approach, and illadvised in terms of what he could get through committee and what he couldn't." ${ }^{361}$

Mr. Santini indeed tried to push through his position in committee, without realizing that he did not have the majority support for it, and the discussion in first reading was very harsh and even poisonous. It went beyond issues and took on a combative personal tone aimed at $\mathrm{Mr}$. Santini by some of the proponents of the family definition issue, who openly called him "Padre," in reference to his Catholicism and conservatism. ${ }^{362}$

\footnotetext{
${ }^{359}$ Respondent \#21.

${ }^{360}$ Explanatory Statement to the First Reading "Report on the proposal for a European Parliament and Council directive on the right of citizens of the Union and their family members to move and reside freely within the territory of the member states (COD/2001/0111); available at http://www.europarl.eu.int

${ }^{361}$ Respondent \#21.

${ }^{362}$ Respondent \#8.
} 
Mr. Santini's position, which was shared by his party colleagues, was that it was not up to Europe to define what constitutes a family, but that these types of definition should be the responsibility of the member states. ${ }^{363}$ In this sense, he was the representative of his party group, rather than an agent of committee or parliament as a whole. ${ }^{364}$ Initially, this position meant that Mr. Santini was unwilling to include any definition of family whatsoever, and he argued that the proposal as amended by the center-left majority in committee would have entailed "reverse discrimination," where Europeans would enjoy more rights than the nationals of a member state. One result of Mr. Santini's perceived stubbornness was that there were actually separate coordinating meetings between the responsible people of PES, Greens, ELDR, and GUE, which were kept purposely secret from the rapporteur himself. ${ }^{365}$

In first reading, Mr. Santini was outvoted both in committee (by a 23-16 margin, with one abstention, in favor of the report including the broad definitions of family) and in plenary (where 269 MEPs voted in favor, 225 voted against, and 46 abstained). Unhappy with this outcome, the rapporteur considered withdrawing his name from the procedure but decided to stay on, also in view of the second reading, where the gay rights proponents were unlikely to achieve the qualified majority necessary to force through their position against the opposition of the EPP. ${ }^{366}$ Moreover, neither the Commission in its modified legislative proposal, nor the Council in its Common Position, accepted the radical amendments giving the right of residence to the same-sex spouses and the registered or unmarried partners of EU citizens. Mr. Santini did realize, however, that he needed to be fairly neutral in second reading and to try not to upset anybody unnecessarily, and also that he might need to make some concessions on the family definition

\footnotetext{
${ }^{363}$ Respondent \#64, Respondent \#11.

364 Respondent \#21.

365 Respondent \#7.

${ }^{366}$ Respondent \#8.
} 
issue. ${ }^{367}$ Even some of his political opponents acknowledge that he moved away from his initial stance of representing his party group toward the wider job of legislating for the Parliament as a whole. $^{368}$

In second reading, Mr. Santini advocated a compromise package that allowed some mutual recognition, despite his personal beliefs and his stance in first reading that all definitions should be left to the member states. The compromise stipulated that the definition of "family member" also includes the registered partner if the legislation of the host member state treats registered partnership as equivalent to marriage, meaning that same-sex partnerships would be recognized across the borders of member states whose national status quo recognized these types of partnerships. Moreover, Article 3 of the second reading report was made to state that member states should "facilitate entry and residence" for "the partner with whom the Union citizen has a durable relationship, duly attested," and that the burden of proof when denying entry or residence lay with the member state. This article was left purposely vague to allow for an ultimate interpretation by the European Court of Justice. ${ }^{369}$ Moreover, the compromise could be regarded as a first step toward the full recognition of the citizenship rights of same-sex couples in that it automatically expanded its scope once national authorities passed regulations inclusive of these partnerships.

This compromise hardly satisfied anybody, despite the understanding of many involved that the proposal, in fact, constituted a major step forward in terms of citizenship and the free movement of people across the Union. ${ }^{370}$ Its practical implications with regard to the conciliation of existing legislation were quite substantial, and it promised to make life easier for citizens

\footnotetext{
${ }^{367}$ Respondent \#8.

${ }^{368}$ Respondent \#38.

369 Respondent \#8.

${ }^{370}$ Respondent \#59, Respondent \#8.
} 
moving across the EU, since the movement of people was no longer to be bound to the professional status of the person anymore but simply to his status as an EU citizen. In fact, the compromise could be interpreted as a broad reinterpretation of what constitutes a "foreigner" in the EU member states, as one EP official maintains.

Yet, the prominent role of the family definition issue throughout the process did not lead many members of Parliament to perceive the compromise package as a particularly satisfying outcome. This perception was exacerbated by the distinct sense of victory of the center-left after the first parliamentary reading, and the expectation to achieve the same result in second reading. Given the mechanics of the co-decision procedure this was unlikely, however, since the proponents of a broad family definition needed a qualified majority of 314 votes in second reading for their amendment to stand. In order to succeed, they actually would have had to win over some members from the EPP, which appeared to stand solidly behind their rapporteur. Also important was the prospect of imminent enlargement, and specifically the accession of Poland to the EU, ${ }^{371}$ since the center-left suspected that Poland would under no circumstances agree to a compromise deal in the Council that included any concession to same-sex couples, such as the watered down compromise package. Moreover, the compromise with the Council was negotiated with the then-Italian Council Presidency, which had identified the issue as one of its key priorities and was very keen to push through the directive. The Italian was followed by the Irish Presidency, however, and there was a realization that the Irish had "no intention of touching this with a very, very long pole," according to one respondent. ${ }^{372}$

Hence, there was growing sense in the cross-party coalition pushing for a broad family definition that an agreement might not be possible under the terms spelled out in first reading.

\footnotetext{
${ }^{371}$ Respondent \#7, Respondent \#38, Respondent \#8.

372 Respondent \#59.
} 
For this reason, the group coordinators of PES and Liberals, Anna Terron and Sarah Ludford, decided that it was preferable to achieve a compromise result that did not go as far as had been hoped. They decided to promote the improved proposal, rather than go into conciliation and take the risk of letting the entire procedure lapse, and were able to convince their party groups of the merit of this decision. The selling point was that it was better to have some result than no result. Therefore, the emphasis put on the two focal points from the previous reading stage began to shift, with the family definition issue becoming less salient for some critical committee members who had previously supported the extension of citizens' rights to non-traditional partnerships. At the same time, the question of facilitating mobility through the dismantling of existing barriers, and the fusion of existing legislation into one coherent whole, increased in importance.

In the end, providing legislation for the free movement of citizens across the EU had priority. Hence, the responsible committee passed the compromise agreement by a broad 23-4 margin; the plenary followed suit by rejecting all amendments to the Council's common position, thus adopting the proposal in second reading excluding the broad definition of what constitutes a family.

\subsubsection{Content Analysis}

To test the proposition that the way issues were presented shifted between the first and second reading stages, I conduct a simple content analysis of the EP debates at both points in time.

I coded a series of words and phrases as consistent with either one of the two prevalent focal points, i.e., the question of family definition and the practical value of the legislation. ${ }^{373}$

\footnotetext{
${ }^{373}$ Coding details are provided in the Appendix of Chapter 6.7.
} 
Based on the analysis above, we should expect the family definition question to dominate the discussion in the first reading debate, with the practical value issue of secondary, yet noteworthy, importance. In second reading, this trend should be reversed. The TEXTPACK output confirms these expectations, as Table 34 shows.

[Table 34 here]

MEPs referred to the family definition issue 95 times per 10,000 input words in the first reading debate, while the practical value issue yields only 73 references. In second reading, this pattern is reversed: the question of family definition was raised only 52 times per 10,000 input words, while the practical value issue was referred to 87 times. We can thus see that the total number of references to the family definition question drops from 95 to 52 in first reading, while the number of references to the practical value issue increases from 73 to 87 .

\subsubsection{Voting Patterns: The Impact of the Legislative Process on Voting Outcomes}

Hypothesis $3 \mathrm{~b}$ maintains that we should be able to predict voting patterns in plenary on the basis of the prevailing focal points. This quantitative section, using logit regression analysis, will test this proposition. Overall, the analysis will determine if the prevalent focal points actually provided the basis for the formation of policy coalition, that is, if they supplied a mutually acceptable equilibrium around which policy coalitions revolved.

On the basis of the qualitative analysis above, it is possible to formulate a series of hypotheses concerning the expected outcome of the decision-making process in the case of the Union Citizenship directive. Since the family definition issue dominated the deliberation process 
during the first reading stage and relates to the Left-Right dimension, we should expect to find that MEPs voted based on their positions on the Left-Right dimension. Specifically, MEPs from the political left should vote in favor and MEPs from the political right against the proposal including the broad definition of what constitutes a family. The practical value question was not absent from the debate in first reading, however, and relates to the sovereignty-integration dimension. Therefore, positions on the sovereignty-integration dimension should also matter in explaining vote choice, but to a lesser degree. Specifically, we should expect that pro-European MEPs voted in favor of the directive.

Unfortunately, the Union Citizenship dossier was adopted in second reading, where there are no final votes on legislative resolutions. The critical amendment extending citizens' rights to non-traditional partnerships and families, however, was voted on by roll-call vote in second reading. This amendment (Amendment 4) constituted the most controversial aspect of the legislative proposal throughout the decision-making process. In fact, its inclusion in the first reading draft determined the major dividing lines in the EP. Therefore, we can compare the positions MEPs assumed toward the legislative resolution in first reading with their positions toward the family definition amendment in second reading. The vote on Amendment 4 thus serves as a proxy for the non-existent vote on the final legislative resolution in second reading.

Since the focus of the debate shifted away from the family definition issue toward the practical implications of the Citizenship dossier, we should expect to find that MEP's positions on the Left-Right dimension are irrelevant as predictors of voting patterns in second reading. Positions on the sovereignty-integration dimension, in contrast, should become the critical explanatory variable. Since pro-Europeans should now be inclined to reject the family definition 
amendment, we should expect to find that a more pro-European position entails a greater probability of voting against the amendment.

The dependent variables in this analysis are the individual votes on the legislative report in first reading and on Amendment 4 in second reading. These variables are dichotomous. A value of zero equals a vote against directive and a value of one means a vote in favor. ${ }^{374}$

MEP NOMINATE coordinates account for individual-level positions on the Left-Right and sovereignty-integration dimension. A dichotomous variable based on the national government or opposition status of particular national party delegations measures representation in the Council of Ministers. Finally, I include a dichotomous variable with a value of 1 for MEPs from member states where national legislation allows same-sex marriages. This variable assumes a value of 0 for all member states except Denmark and the Netherlands.

My regression model is expressed formally as:

VOTE $=a+\beta_{1}$ Left-Right $+\beta_{2}$ Sovereignty-Integration $+\beta_{3}$ Government-Opposition $+\beta_{4}$ Same-Sex Marriage.

The results of the analysis are presented in Table 35, which suggests that the regression model explains a substantial part of the variance, with a pseudo- $\mathrm{R}^{2}$ of 0.55 . It also shows that, as predicted, MEPs from the political left voted in favor of the legislative report including the broad family definition in first reading, while MEPs from the political right strongly opposed it, as the negative coefficient of the Left-Right variable demonstrates.

\footnotetext{
${ }^{374}$ The results of the multinomial logit analysis of the plenary vote in first reading can be found in the Appendix of Chapter 6.7. Due to the small number of abstentions in second reading, where only two MEPs abstained with regard to Amendment 4, a multinomial logit analysis of this vote is not possible.
} 
[Table 35 here]

Figure 67 illustrates the impact of the Left-Right predictor. The predicted probability of MEPs voting in favor of the proposal declines the more they are positioned toward the political Right. ${ }^{375}$ This decline is very substantial, as MEPs on the far left had a 100 percent probability of voting in favor of the directive, and MEPs on the far right had a 100 percent probability to vote against. Not surprisingly, MEPs from countries that allow for same-sex marriages are more inclined to support the proposal.

[Figure 67 here]

The positive sign of the sovereignty-integration variable in Table 35, as well as the scope of the graphs in Figure 68, confirms the expectation that MEPs with more pro-EU attitudes are more likely to support the legislation. Moving from the EU-skeptics on the left of the x-axis toward the Europhiles on the right increases the probability of a yes vote by close to 100 percent. Once again, this trend is consistent for all MEPs, but more pronounced from member states with national legislation allowing same-sex marriage.

[Figure 68 here]

\footnotetext{
${ }^{375}$ To calculate the probabilities presented in the following figures, I used CLARIFY and held the remaining variables constant at their means.
} 
Finally, the negative coefficient of the government status variable in Table 35 and downward sloping graphs in Figure 69 demonstrates that MEPs from parties that are in opposition in their national political arenas have a greater probability of voting in favor of the legislation in first reading, which makes sense given that the Council, where government MEPs are represented, opposed the broad family definition.

[Figure 69 here]

Table 36 displays the results of the binomial logit regression result of the second reading vote on Amendment 4. The negative coefficient of the Left-Right variable shows that MEPs from the political right remained strongly opposed to the broad definition of what constitutes a family. Similarly, government status at home still results in a smaller probability of voting in favor of the same-sex family definition amendment, which was opposed by the Council. Unlike in first reading, however, a more pro-European attitude now entails a smaller probability of supporting the legislation: the coefficient of the sovereignty-integration variable now features a negative sign. Finally, unlike in first reading, MEPs from countries that allow same-sex marriages actually have a smaller probability to vote in favor of the amendment. This is likely because their status quo was not affected by the compromise agreement providing for "mutual recognition" between those member states already providing for same-sex marriages.

[Table 36 here] 
Figure 70 displays the predicted probabilities of votes in favor of the legislation in second reading. It shows that Left-Right positions were not irrelevant in explaining positions toward the family definition amendment in second reading, but that only the very far left voted in favor. The probability of supporting the amendment already drops substantially when moving from the far to the center-left. MEPs to the right of the center-left were certain to vote against the amendment. In fact, the probability of voting in favor of the amendment decreases by 100 percent between NOMINATE scores of -1 and 0 on the Left-Right divide, that is, along half of the range of the variable.

[Figure 70 here]

Figure 71 illustrates the expected shift in the policy preferences of pro-European MEPs. While pro-EU attitudes entailed a greater probability of supporting the proposal in first reading including the broad family definition, this trend is now reversed, as the downward slopes indicate.

[Figure 71 here]

Finally, Figure 72 shows the minimal impact of government or opposition status in the second reading vote. For opposition as well as government parties, the probability of voting in favor of amendment 4 was small or even insubstantial.

[Figure 72 here] 
In sum, the critical change between the first and second reading stages was a shift in the positions of the political center and the center-left. While the political right consistently opposed a broad family definition, and the far left consistently promoted it, the center and center-left switched from a position of support to one of opposition. Specifically, the analysis suggests that the policy preferences of MEPs shifted as the sovereignty-integration dimension became more salient during the second-reading stage. Figure 73 and Figure 74 illustrate this shift spatially for the Liberals (ELDR) and Socialists (PES). Both figures show that the broad definition of what constitutes a family (labeled Policy I) lies inside the indifference curves of ELDR and PES in first reading, which are represented by the solid lines. These indifference curves have an elliptical shape and are "squeezed" from the sides, indicating that the horizontal Left-Right dimension is more salient (because the more important a dimension is to an actor, the more small changes in the policy affect her satisfaction). In contrast, the second reading indifference curves, represented by the dashed lines, are "squeezed" from above and below. These curves illustrate that when the vertical sovereignty-integration dimension is more salient, as was the case for ELDR and PES in second reading, it is Policy II that lies inside the indifference curves and is thus their preferred alternative. Policy II, in the case at hand, is the final compromise agreement stipulating that same-sex partnerships would be recognized across the borders of member states whose national status quo recognized these types of partnerships.

[Figure 73 here]

[Figure 74 here] 
Figure 75 and Figure 76 display and confirm the voting patterns in more detail: while pro-EU legislators, especially from the political center and the center-left, were very likely to support the radical Union Citizenship proposal in first reading, they were very unlikely to support the broad definition of what constitutes a family in second reading. These MEPs evidently followed their political leaders in the responsible committee when choosing to support a diluted legislative proposal over the alternative of letting the entire procedure lapse. The shift in focal points thus entailed a critical change in voting patterns, which confirms Hypothesis $3 b$. As a result, the only MEPs in favor of the radical definition of what constitutes a family in second reading were those on the far left, as well as Euroskeptic left-of-center MEPs.

[Figure 75 here]

[Figure 76 here]

\subsubsection{Conclusion}

This chapter provides solid evidence in favor of the focal point model. It shows that policy preferences shift even when outcome preferences remain stable, and that in the case of the Union Citizenship directive, policy preference shifts were the result of a change in the way critical actors on the political center and the center-left viewed and presented the proposal to their colleagues. While they initially assumed positions toward the proposal based on their outcome preferences on the Left-Right divide, they decided during the second-reading stage that realizing 
a proposal establishing a comprehensive notion of EU citizenship broadly favorable for a majority of EU citizens took precedence over the definitional issues propagated in first reading.

The transmission mechanism for these positions from committee to plenary is also noteworthy in view of the general findings in the preceding chapter. While Socialists, Liberals, Greens, and members of the GUE faction voted solidly in favor of the report including the amendment establishing a broad family definition in first reading, only Greens and GUE MEPs stuck to this position in the committee vote on the compromise report in second reading. Following their committee representatives throughout the procedure, 84 percent of all Socialists and Liberals voted in favor of the proposal in the first reading plenary vote (with 15 percent abstaining and only 1 percent voting against), while in second reading, 97 percent voted against Amendment 4 and only 3 percent in favor. This demonstrates that when committee members shift their own policy preferences and the focus of the debate, they affect the policy preferences of their party members in plenary. We can thus predict voting patterns on the basis of the prevailing focal points, which confirms Hypothesis $3 b$.

In sum, the first reading stage of the legislative process featured a dominant Left-Right focal point, which provided the basis for a policy coalition of Socialists, Greens, Liberals, and the far left. The family definition focal point provided a basis for this policy coalition because it appealed to the outcome preferences of MEPs on the Left-Right divide. In second reading, the focal point, and thus the general direction of the debate, shifted away from the Left-Right conceptualization of the Citizenship issue toward a pro-/anti-EU view. As a result, MEPs in plenary, following their committee representatives, perceived their positions on the sovereigntyintegration dimension as more salient to the decision at hand, and a new policy coalition of pro- 
Europeans consisting of political right, center, and center-left pushed the proposal through against the votes of the far left.

The qualitative analysis confirms our expectations about the characteristics of focal points and how they are disseminated among MEPs not directly involved in the dossier. It demonstrates that deliberations were dominated not by technical details of the proposal, but by broad representations of what the legislative proposal was all about, since the prevalent focal points emphasized the question of "citizenship for whom" (the family definition question) and the actual implications of the legislation (the practical value issue). These focal points emphasized the perceived consequences of the proposal, rather than its technical details, and targeted the outcome preferences of the EP's backbenchers: the family definition issue was a clear left-right issue, while the practical value of the legislation to EU citizens was an issue relating broadly to the question of EU integration and, consequently, the outcome preferences of other MEPs with regard to the integration process as such. The focal points were provided and propagated by the members of the responsible committee, and the configuration of the key players was critical in shaping the decision-making process. These actors did not simply provide voting instructions, however; in fact, even the powerful group coordinators had to "sell" the compromise package to their party groups. This was especially noticeable on the political left, where support for the broad definition of what constitutes a family was deep rooted. As a result, party positions toward the proposal were not predetermined, but actually shifted during the deliberation process. 


\subsection{SUMMARY AND CONCLUSION}

The primary purpose of this chapter has been to evaluate the merits of two competing explanations for decision-making processes in the EP. The first explanation builds on the garbage-can theory and emphasizes that policy outcomes are the random results of decisionmaking processes as problems, solutions, participants, (problematic) preferences, and choice opportunities converge. According to this model, outcome-equilibria are random (H2b).

The focal point model, in contrast, suggests that policy outcomes are the result of a more structured process in which legislative specialists create opportunities for policy choice through the provision of focal points. These focal points shape the normative evaluation of the legislative proposal by those legislators not directly involved in the deliberation and negotiation process, which in turn affects policy preferences, policy coalitions, and policy outcomes. Outcome equilibria are thus neither predetermined nor random, but predictable on the basis of the prevailing focal points $(\mathrm{H} 3 b)$.

The case studies broadly support the propositions of the focal point model as they demonstrate that focal points significantly affect how legislative backbenchers perceive the content and implications of different legislative proposals, shape policy preferences, and influence vote patterns on the EP floor. In fact, the quantitative analyses of plenary voting show that it was possible in each case to predict voting patterns on the basis of the prevailing focal points, which confirms hypothesis $\mathrm{H} 3 \mathrm{~b}$ and undermines the suggestion that policy outcomes are largely due to an unstructured and random decision-making process (H2b). Strategic and specialized actors in the EP are capable of shaping the policy preferences of their less-informed colleagues, thus providing the basis for policy coalitions and legislative outcomes. 
Each case study featured a set of distinct focal points emphasizing the perceived impact of the proposed legislation upon its implementation; these provided the bases of the general normative interpretations of what constituted the dominant aspects of each policy proposal. As expected, these focal points were broad representations of the content and consequences of the proposed legislation, while technical details were largely absent from the discussion outside the responsible committee. Focal points broadly highlighted the potential consequences of the legislation, thus appealing to the existing outcome preferences of EP backbenchers. They were not created from thin air, but reflected and targeted stable ideological predispositions in an effort to sway policy preferences one way or another. As a result, the level of controversy concerning particular pieces of legislation was difficult to forecast, because deliberation and decisionmaking processes depended to a substantial extent on the configuration and interactions of key actors. In the case of the Union Citizenship proposal, for example, the presentation of the issue in terms of family definition and non-traditional partnerships provided for a level of contention that was unexpected even by other MEPs.

Finally, the case studies reveal a level of importance of persuasion in EP decision-making that defies the notion of predetermined individual and party positions. Rather, policy preferences can and do shift even when outcome preference remain stable and are the result of a change in the way critical actors present a piece of legislation to their non-specialized colleagues. Therefore, if the issue specialists modify their own positions and the focus of the debate, or when new actors enter the stage and gain prominence, policy preferences and outcomes shift accordingly.

While the case studies share a great number of characteristics — such as the importance of particular actors and their configuration in shaping decision-making processes, the absence of 
detailed and technical discussions on the EP floor, and the possibility of predicting voting patterns on the basis of the dominant focal points - each legislative proposal also features particularities that shed additional light on the nature of deliberation and policy making in the EP. The analysis of the Union Citizenship proposal, for example, demonstrates that a seemingly non-controversial issue becomes highly contested when certain aspects of it are highlighted by a key group of committee specialists. In contrast, the Party Statute analysis shows how controversy is stifled when contentious issues, such as the legal personality of EU-level political parties, are deliberatively kept off the agenda.

The Emissions chapter illustrates that legislation can pass with an overwhelming margin when critical actors steer it successfully through both the committee and plenary stages, even if there appears to be an "objective interest" not to support legislation that evidently hurts key industries. The Port Package, in contrast, featured a rapporteur that was perceived as uncooperative and thus faced an uphill battle that he ultimately lost. A similar lesson can be drawn from the Environmental Liability proposal, which also demonstrates the importance of which committee handles the legislation and shows that two distinct set of specialists in separate committees may provide competing focal points. If this is the case, a high level of controversy is the obvious result.

Finally, the analysis of the Takeover Directive demonstrates that focal points not only affect the salience of the two ideology dimensions when decisions are made on the EP floor, but that they may even influence the direction in which the dimension matter.

To review, Chapters 4 and 5 examined broad patterns of information provision in the EP and linked the positions and vote choices of legislative backbenchers to the positions of their specialized colleagues in the responsible EP committee. These analyses demonstrate that 
legislators in plenary follow their committee specialists when taking a position toward the issue, and that the positions of committee members are powerful predictors of voting patterns on the EP floor. Accordingly, it was concluded that outcome-equilibria in EP decision-making are far from predetermined.

We were left wondering if outcome-equilibria were the random results of decisionmaking processes or the product of a more structured process where certain outcome-equilibria were more likely than others. The examination of the six case studies provides evidence for the latter, as the provision of focal points creates opportunities for policy choice by making certain outcome equilibria more likely than others. The focal point model thus constitutes the only model whose propositions finds empirical support in the analyses. 


\subsection{CONCLUSION AND CONTRIBUTIONS}

\subsection{SUMMARY OF FINDINGS}

This dissertation introduced and tested a model of policy preference formation that emphasizes the dynamic relationship between structure, agent, and political process in legislative decisionmaking. The theory tied the question of policy choice to the dimensionality of the normative political space and the strategic actions of parliamentary agenda-setters. The model proposed that structural factors, such as ideology, shape policy preferences to the extent that legislative specialists successfully link them to specific policy proposals through the provision of informational focal points. These focal points shift attention toward particular aspects of a legislative proposal, thus shaping the normative interpretations of its content and consequences. This, in turn, affects the policy preferences of legislators not directly involved with a particular policy proposal. The dominant focal points provide the basis for the formation of policy coalitions and, as such, they critically affect policy outcomes.

The empirical evidence presented in Chapters 4-6 supports the propositions of the focal point model outlined in the theory chapter (Chapter 3). It allowed for the dismissal of both the exogenous preference and garbage can models, whose hypotheses were systematically disconfirmed.

Chapters 4 (Information Flow and the Role of Specialized Committees) and 5 (Committee Positions and Voting on the Floor) made a general case for the impact of committee deliberation 
and decisions on EP decisions by examining the broader patterns of information provision in the EP. In particular, they linked individual-level voting patterns in the EP plenary to the positions of members of the parliament's standing committees. Chapter 4 demonstrated that the specialized members of the EP's standing committees serve as the principal providers of information to EP legislators not directly involved with a given legislative proposal. Limited by time and resource constraints, and lacking information about the content and consequences of the proposal and the necessary expertise to form well-grounded judgments on detailed legislation, these backbenchers adopt the positions of their specialized party colleagues. This strategy is evidently based on the assumption that these positions most closely resemble what they would favor if they possessed the resources and expertise required to genuinely judge the content and likely implications of a specific policy proposal.

In this process, much depends on the configuration of actors involved, their reputations, and their interaction. Consequently, policy outcomes are uncertain and cannot be predicted $a$ priori, which contradicted the first proposition of the exogenous preference model (H1a). Instead, both individual and party positions were found to be the endogenous product of the information provision and decision-making process, which lent support to hypotheses $\mathrm{H} 2 \mathrm{a}$ and H3a.

The analysis of the roll-call vote data in Chapter 5 demonstrated that backbenchers follow their committee representatives when voting in plenary, since the positions of EP committee members are shown to be significant predictors of MEP voting patterns on the EP floor. MEPs rely primarily on their national party delegation colleagues in the committee responsible for a piece of legislation when making their vote choices on the EP floor, if they have national party representatives sitting on the committee. This is not the case more than 40 percent 
of the time, however, meaning that in the majority of cases, MEPs follow the representatives of their EP party group when voting on the EP floor. National affiliation, in contrast, barely matters when predicting plenary votes on the basis of the preceding committee vote. This pattern is evident with regard to votes in favor of and opposition to a proposal, as well as abstentions.

Furthermore, the results indicate that MEPs compare the positions of their different representatives in the committee, that is, committee members who share their national affiliation, transnational party group affiliation, or national party affiliation. When choosing their own positions toward a policy proposal, members "triangulate" the information they receive, in particular from their party group and national delegation representatives. When these positions diverge, the resulting vote in plenary is quite uncertain. When both share a common position, however, the probability of a backbencher voting accordingly in plenary is 97 percent for Yes votes, 98 percent for a No votes, and 80 percent for abstentions

The roll-call vote evidence thus undermined hypothesis $\mathrm{H} 1 \mathrm{~b}$ of the exogenous preferences model, which stated that outcome-equilibria are predetermined, since voting patterns in plenary are shown to be quite uncertain. Depending on the configuration of committee actors and the pattern of who is represented by whom, individual-level positions and collective voting patterns on the EP floor varied substantially. Accordingly, both hypotheses derived from the exogenous preference model were now disconfirmed.

This left us to consider the respective validity of the garbage-can and focal point models. The critical question concerned the extent to which outcome-equilibria were the random results of decision-making processes. While the garbage-can model suggested that particular outcomes are due to a largely random process through which problems, actors, and opportunities converge (H2b), the focal point model considered outcomes to be neither predetermined nor random. 
Instead, focal points provided by committee specialists constitute the basis of policy preferences. They create opportunities for policy choice by making certain outcome equilibria more likely than others, thus making outcome-equilibria non-random (H3b).

In an effort to evaluate these two rival hypotheses, the case studies in Chapter 6 examined EP decision-making processes in more detail, with a special focus on the role of focal points as mechanisms of information provision. The detailed investigation of a series of legislative proposals from different policy areas demonstrated that policy making processes and outcomes are, at least in part, a function of how a legislative proposal is presented by committee specialists in relation to the two dominant ideological dimensions in the EP. Strategically deployed focal points influenced the prevailing normative interpretation of the proposals at hand, which in turn impacted the policy preferences of legislative backbenchers. The qualitative and quantitative evidence in each of the case studies demonstrated that focal points influence policy preferences, which evidently shaped voting patterns in the plenary, since it was possible to predict voting patterns on the basis of the focal points dominating the deliberation process. This finding confirmed hypothesis $\mathrm{H} 3 \mathrm{~b}$ and undermined the contention of that garbage-can model that policy outcomes are the result of a random decision-making process (H2b). Accordingly, only the propositions of the focal point model were found to hold, as Table 38 illustrates.

[Table 38 here] 


\subsection{CONTRIBUTIONS TO EU STUDIES}

This research demonstrates that the two-dimensional structure of the European ideological space notably influences political behavior in the European Parliament, but that it does so via a dynamic agent-structure relationship. While the political choices of European parliamentarians are indeed critically influenced by their locations on both the sovereignty-integration and the Left-Right dimensions, the respective salience of these dimensions is determined by the process of political contestation and the strategic behavior of key legislators such as rapporteurs, shadow rapporteurs, and party coordinators in the responsible committees. The interplay of structure, actors, and process decisively influences voting patterns in the EP plenary, and thus legislative outcomes.

The analysis also sheds light on the nature and extent of party control in the EP. Past research has emphasized the role of EP party groups in establishing and enforcing common and cohesive party positions when examining policy preferences and voting patterns in the EP. Of particular interest has been the empirical puzzle of why MEPs generally follow the party line given that the transnational EP party groups do not possess the sanctioning powers available to party organizations at the national level, most importantly the possibility of barring defectors from re-election. The most common explanation emphasizes the role of "soft power," such as the carrot-and-stick approach of granting or refusing committee membership or the responsibility for drafting legislative reports. These studies share a common assumption that MEPs would vote differently in the absence of party control.

My research offers an alternative explanation not only to the question of party cohesion, but also for processes of legislative decision-making in the EP more generally. Most importantly, it rejects the basic assumption that policy choice in the EP is simply a matter of party control. 
Instead, I identify policy expertise, asymmetrically distributed information, shared ideology, and interpersonal trust as the basis for decision-making in the EP. My analysis shows that legislative backbenchers respond to their lack of expertise in many policy areas-which is exacerbated by time and resource constraints - by delegating decision-making authority to a subset of specialized legislators, making them the agents of the chamber as a whole. They follow the specialized colleagues they consider closest to their own preference ideal points, usually fellow party members, essentially "trusting" their judgment when forming their own policy preferences. This is based on the assumption that the positions of these experts approximate the positions they would take if they possessed perfect information about a given legislative proposal.

If this is indeed the case, party control and sanctioning powers have little to do with levels of party cohesion in the EP, as common and unified party positions are the by-product of an information provision process where less-informed MEPs simply adopt the positions of their well-informed party colleagues in committee.

This proposition touches upon one of the key conclusions in Chapter 5 concerning Simon Hix' argument that party cohesion breaks down when national party delegations in the same EP party group take opposing policy positions (Hix 2002). While my analysis confirms this pattern, it is not simply the result of national party delegations being the principal with the most potent threat of sanction. Instead, the key to this pattern is once again the asymmetric distribution of information among MEPs: members are most likely to adopt the positions of their national party colleagues because they trust the information they receive from these experts more than that of their party group experts from different national party delegations, or their national representatives from different parties. Only if they are not represented by a national party member do they rely more heavily upon EP party group experts. Finally, when both national 
party and EP party group specialists agree and provide a common set of information, these two bases of trust combine and make it almost certain that EP backbenchers will follow their lead. ${ }^{376}$

These conclusions raise important questions about the nature of party control in the EP that ought to be addressed in future research. While party control in the EP is not simply a matter of the degree of sanctioning power, there is a high likelihood of cohesive party positions as only a small number of active participants deliberate and negotiate on behalf of their uninvolved party colleagues. Moreover, the structure of the EP party groups as a series of information filters facilitates a smooth transmission of this position from the committee to the floor, making the formation of a common party position quite likely in most cases (see section 4.5., The Creation of a Party Line, in Chapter 4). It is, once again, important to emphasize in this context that a party line in the EP is not usually imposed from above by the party group leadership, but is endogenous to the deliberation process. Party leadership in the EP is a fluid concept, as those members actively participating in the decision-making process regarding a legislative proposal act as the de facto leaders of their parties.

In sum, this dissertation adds to our knowledge of law-making in the EU and advances our understanding of political contestation and voting behavior in the European Parliament. As such, it contributes to the recent and increasingly prevalent literature on the EP, as well as to the body of more general studies focusing on EU 'politics' rather than 'integration' as the principal dependent variable.

376 This triangulation of information also means that MEPs who lack expertise in the specific policy area under consideration (the principals) can avoid abdicating control over legislative outcomes by comparing the information they receive from different agents (legislative experts in the responsible committee). Competition between information providers is thus institutionalized in the patterns of EP decision-making (see Lupia and McCubbins 1994: 370). 


\subsection{CONTRIBUTIONS TO LEGISLATIVE STUDIES}

As direct representatives of the people with a mandate to make decisions on their behalf, legislators are assumed to make informed choices when deliberating and passing new laws. In this sense, legislative decision-making appears to be an example of "committee voting," where there are "few voters, participants can propose new alternatives, the individual implications of the decisions may be very large, and participants are well informed about the alternatives" (Hinich and Munger 1997: 12). My research challenges one central part of the conceptualization of legislative decision-making as committee voting, however, namely the assumption that legislators are necessarily well informed about the policy alternatives on the table. In this regard, policy choice in legislative politics more closely resembles a mass elections model, where voters are assumed to possess only a limited amount of information on the choices they face.

Accordingly, my model of legislative decision-making exhibits characteristics of both committee voting and mass elections. The critical difference, of course, is that the element of choice for legislative backbenchers is not a candidate (as in mass elections), but a policy being decided under conditions of uncertainty and asymmetric information. The role of ideology in both mass elections and legislative decision-making may be quite similar, however, according to my research.

Hinich and Munger (1997: 180-211) articulate a mass election model that recognizes the utility of ideology as a decision-making "short-cut" or heuristic that helps voters choose among complicated alternatives. Ideology is conceived of as a shared belief system that reduces the number of conflict dimensions from an n-dimensional issue-space into an ideological space with many fewer dimensions. In this ideological space, issues cluster along the dominant ideological dimensions, which reduces the voters' costs of gathering information by "summarizing" a large 
number of potential dimensions of conflict. My theory and empirical results suggest that ideology can serve a similar function for legislative backbenchers confronted with a number of complex policy alternatives, a possibility that ought to be specified and examined in future research.

This dissertation makes an additional contribution to the legislative studies literature by emphasizing the demand for a greater focus on the interaction of structures, agents, and decisionmaking processes when examining law-making in different legislative settings. Most importantly, it emphasizes the significance of the normative dimensions of collective action, while stressing the conscious interaction of these structural elements with distinctly strategic considerations in the legislative process: the provision of focal points is constrained by the normative and political context within which the provider operates. In order for focal points to be effective in shaping policy choice, they must reflect already existing outcome preferences, that is, they have to appeal to the other legislators' exogenous sets of norms and values. The provision of focal points is thus constrained by the existing ideological space; as argued above, focal points cannot be "free-floating." Within these constraints, however, strategically provided focal points serve as intervening variables linking outcome preferences with specific policy proposals.

The research thus questions the conceptualization of preferences as exogenous inputs into legislative decision-making processes. It emphasizes the endogeneity of preferences under conditions of uncertainty and conflicting objectives and thus challenges the assumption that the conversion of policy-makers' ideological and constituency interests into policy preferences is direct and automatic. Instead, the empirical evidence demonstrates that the policy preferences of legislators are neither fixed nor exogenous. 
While the "objective interests" of policy-makers (such as the ideological predispositions and constituency concerns of legislators) serve as the basis for the decisions they make in supporting or opposing particular policies, these objective interests can be at odds with each other. As a result, policy-makers do consider different policy outcomes as desirable, especially when they lack the expertise and resources to build genuine cause-and-effect knowledge concerning specific legislative proposals. In taking a position toward the Union Citizenship directive, for example, most Christian-Democrats in the EP favored the implementation of a genuine and tangible concept of EU citizenship, but opposed the broadly inclusive definition of what constitutes a family. In this case, as in many others, the translation of objective interests (or outcome preferences) into policy preferences and actual policy choice was a complicated process involving complex decisions under conditions of competing interests, substantive uncertainty, and asymmetric information.

Therefore, it is important for researchers interested in questions of policy choice-in legislative settings as well as other arenas of political decision-making - to make a strict analytic distinction between outcome and policy preferences, and to expound the problems associated with the translation of the former into the latter. Conceptualizing outcome preferences as an exogenous "input" into decision-making processes is warranted as these preferences are largely fixed or generally stable. It is, however, critical to identify the policy preferences of decisionmakers and the process by which these policy preferences come about; in this context, consideration of the interaction between structure, actors, and processes is imperative.

The goal of this dissertation was to explain decision-making in the European Parliament and to determine how the outcome preferences of its members translate into the positions they take toward particular legislative proposals. The focal point theory provides a compelling 
account for this process. Scholars seeking to better understand the politics in the European Union, as well as those interested in legislative decision-making, will be able to use this research as a spring-board for their analyses. 
APPENDIX A

CHAPTER 2 


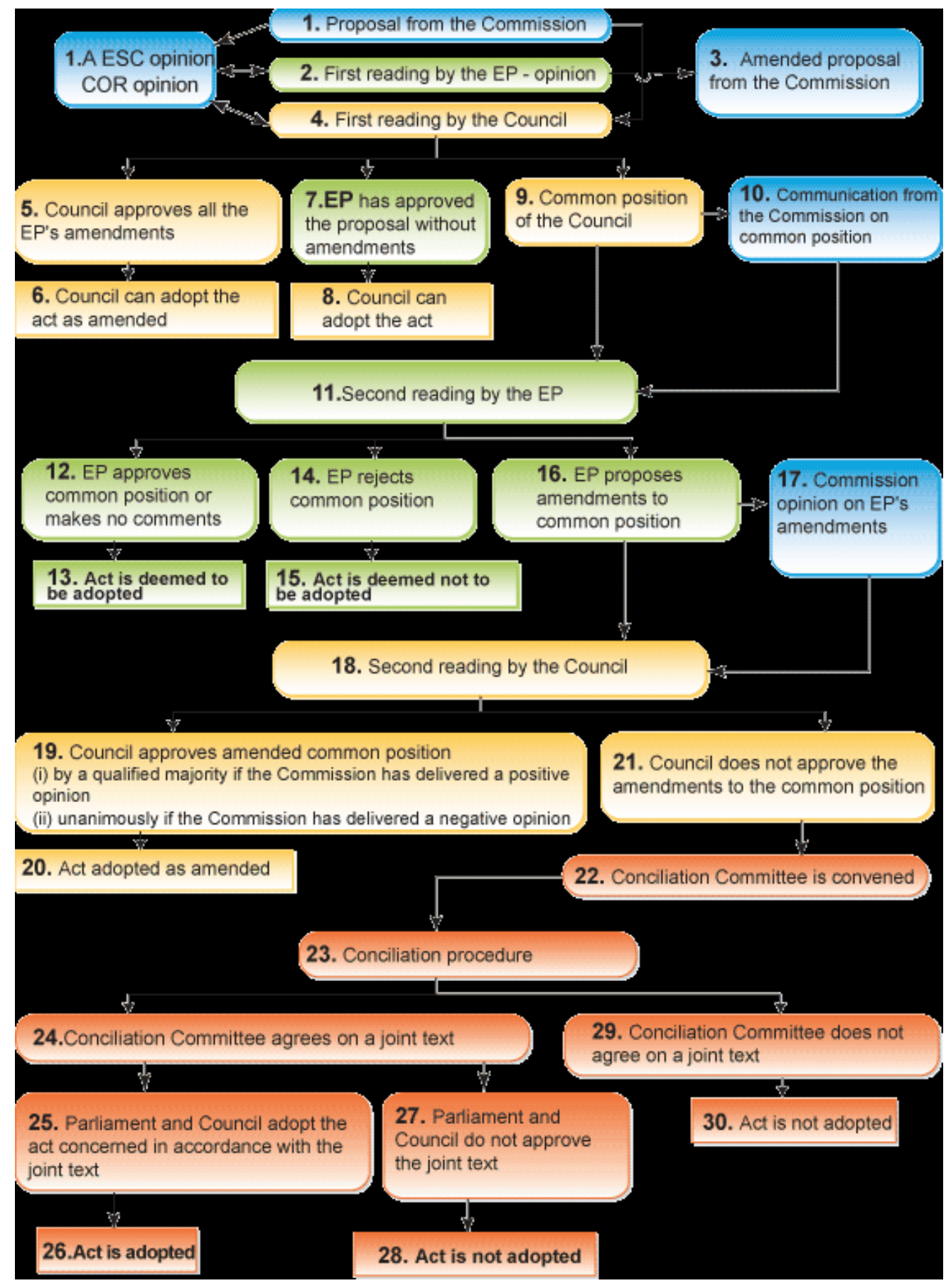

Figure 1: The Co-Decision Procedure ${ }^{377}$

${ }^{377}$ Available at:http://europa.eu.int/comm/codecision/images/diagram_en.gif 


\section{APPENDIX B}

\section{CHAPTER 3}

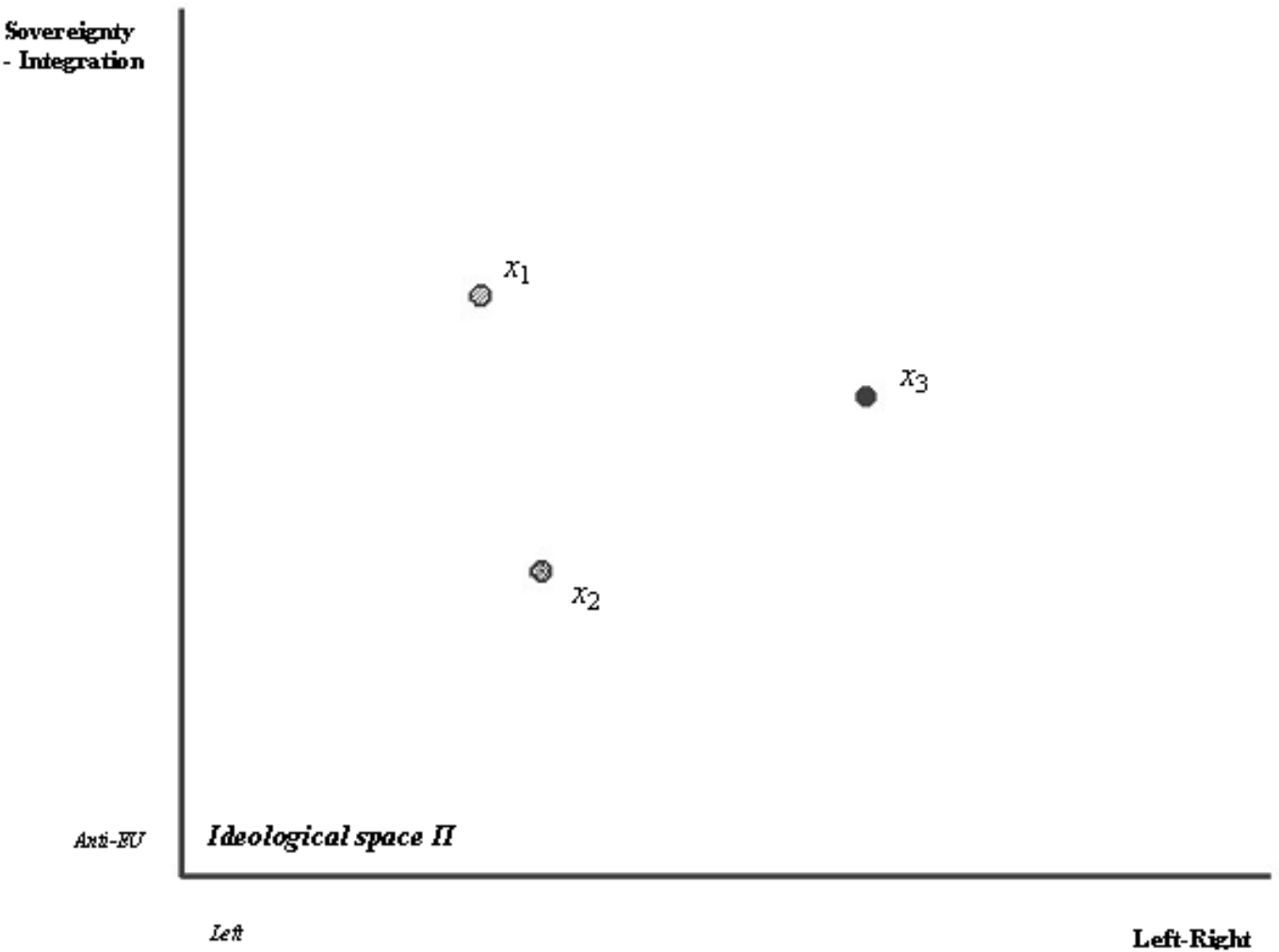

Figure 2: Ideological space П 


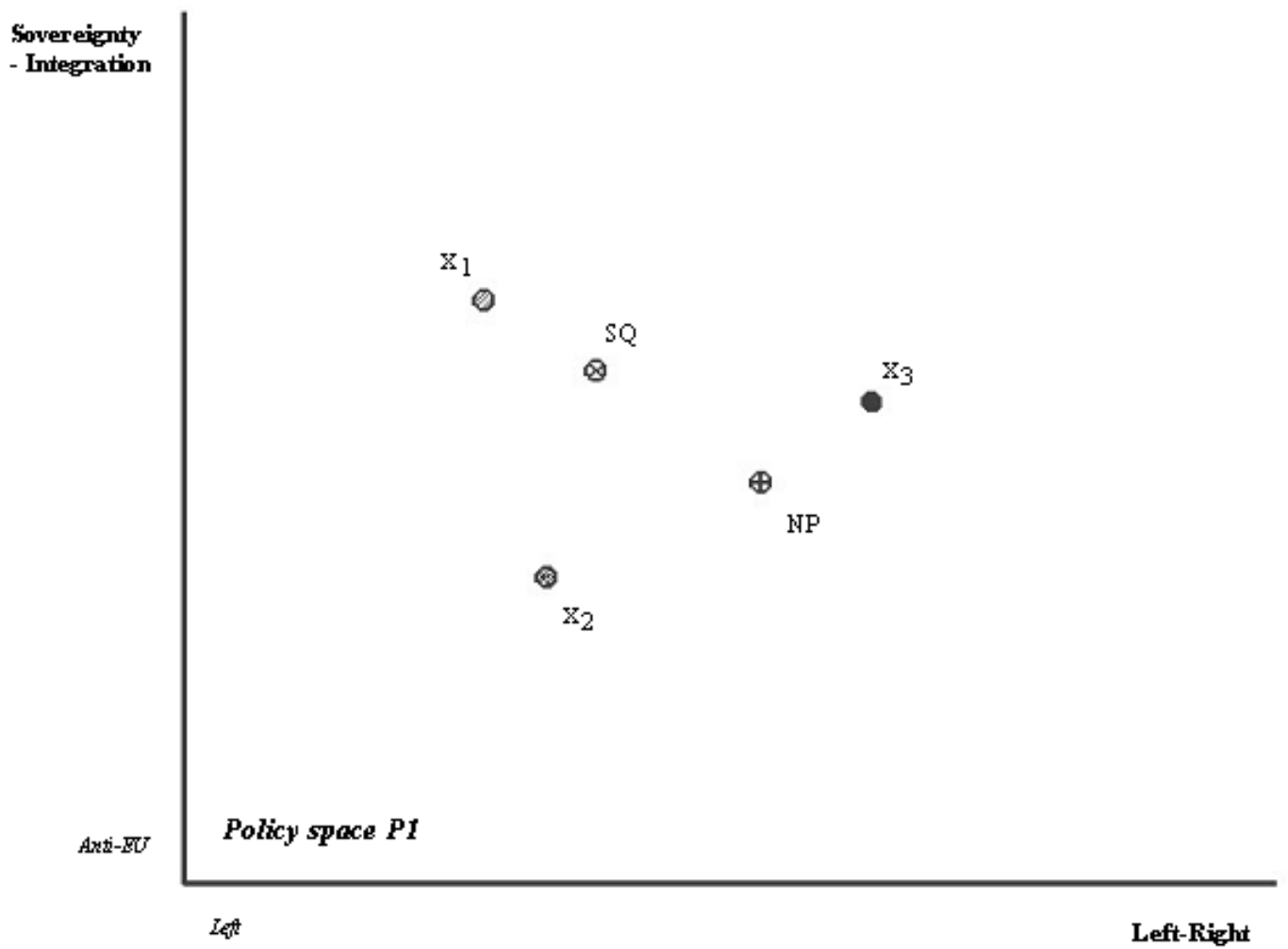

Figure 3: Policy space P1. 


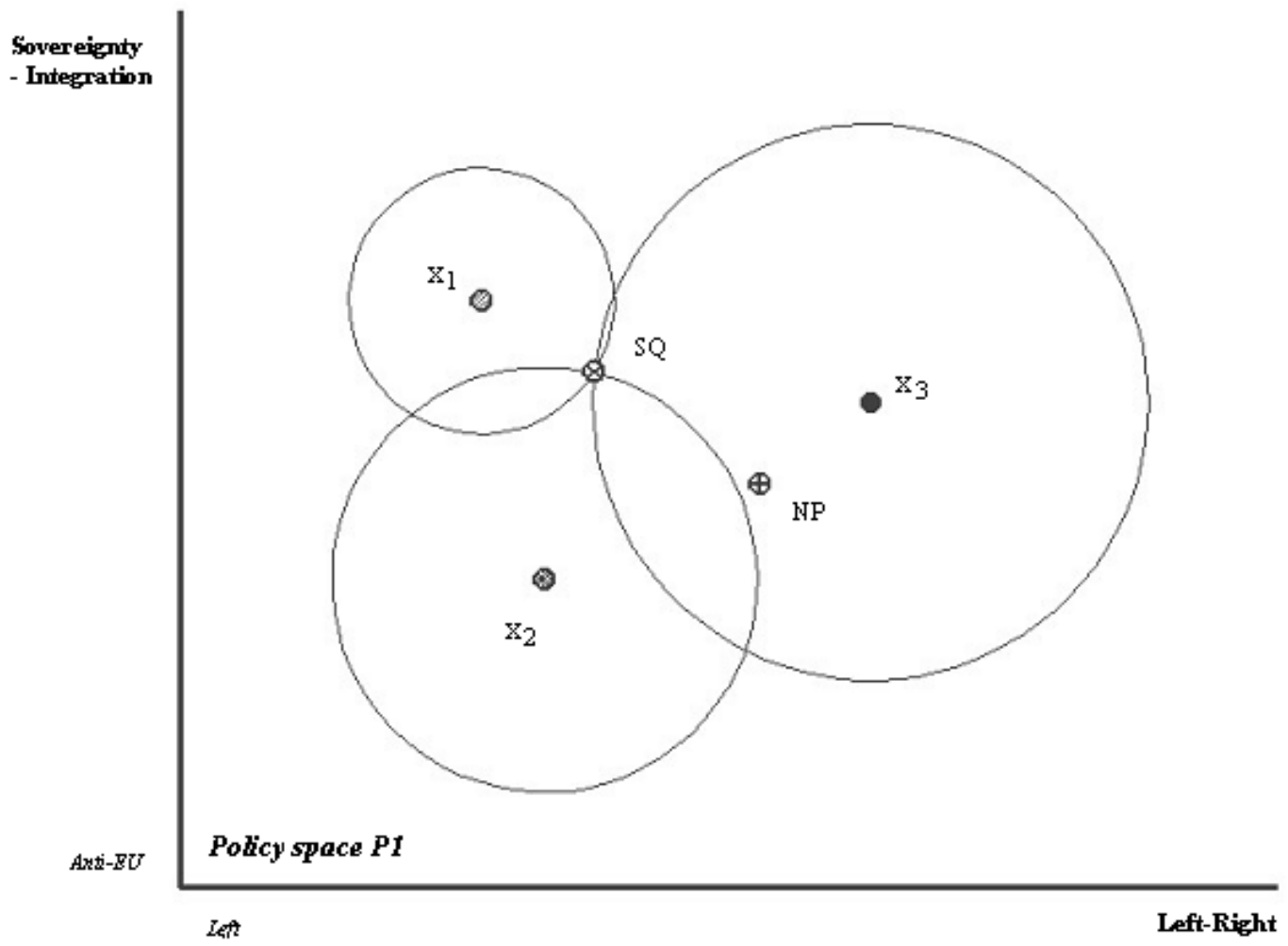

Figure 4: Policy space P1, with indifference curves. 


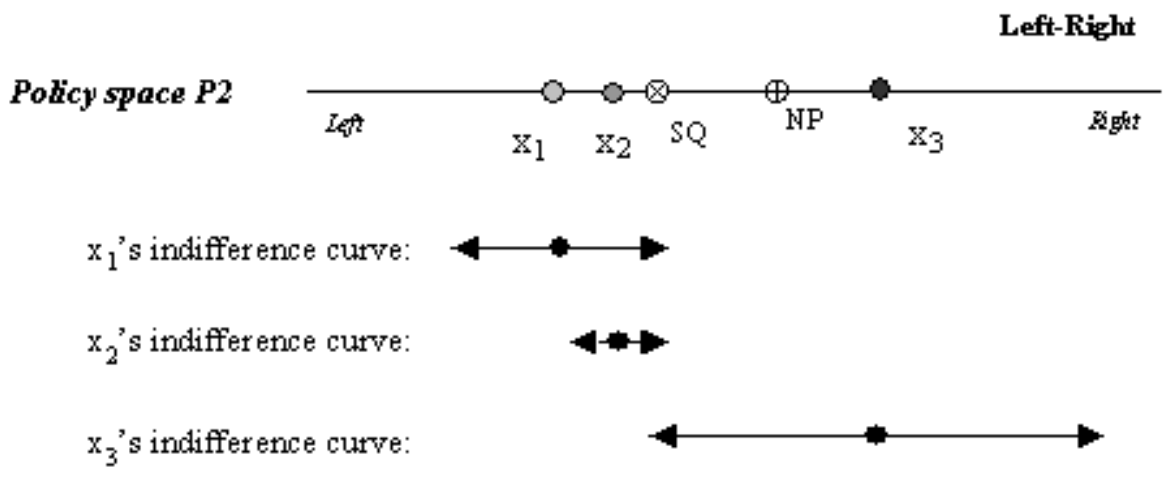

Figure 5: Policy space P2.

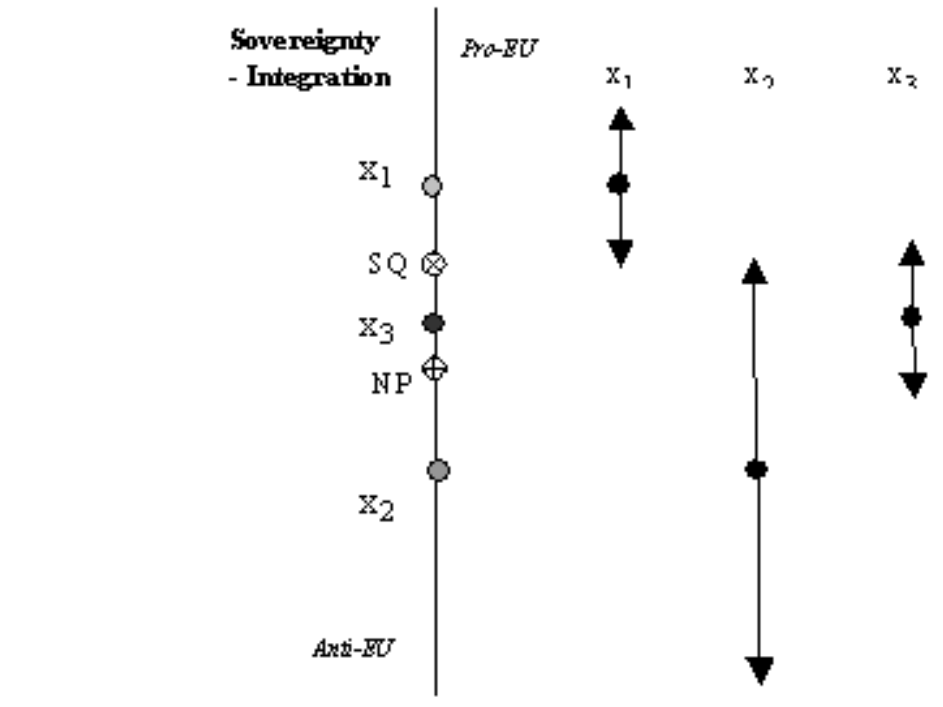

Policy space P3

Figure 6: Policy space P3. 


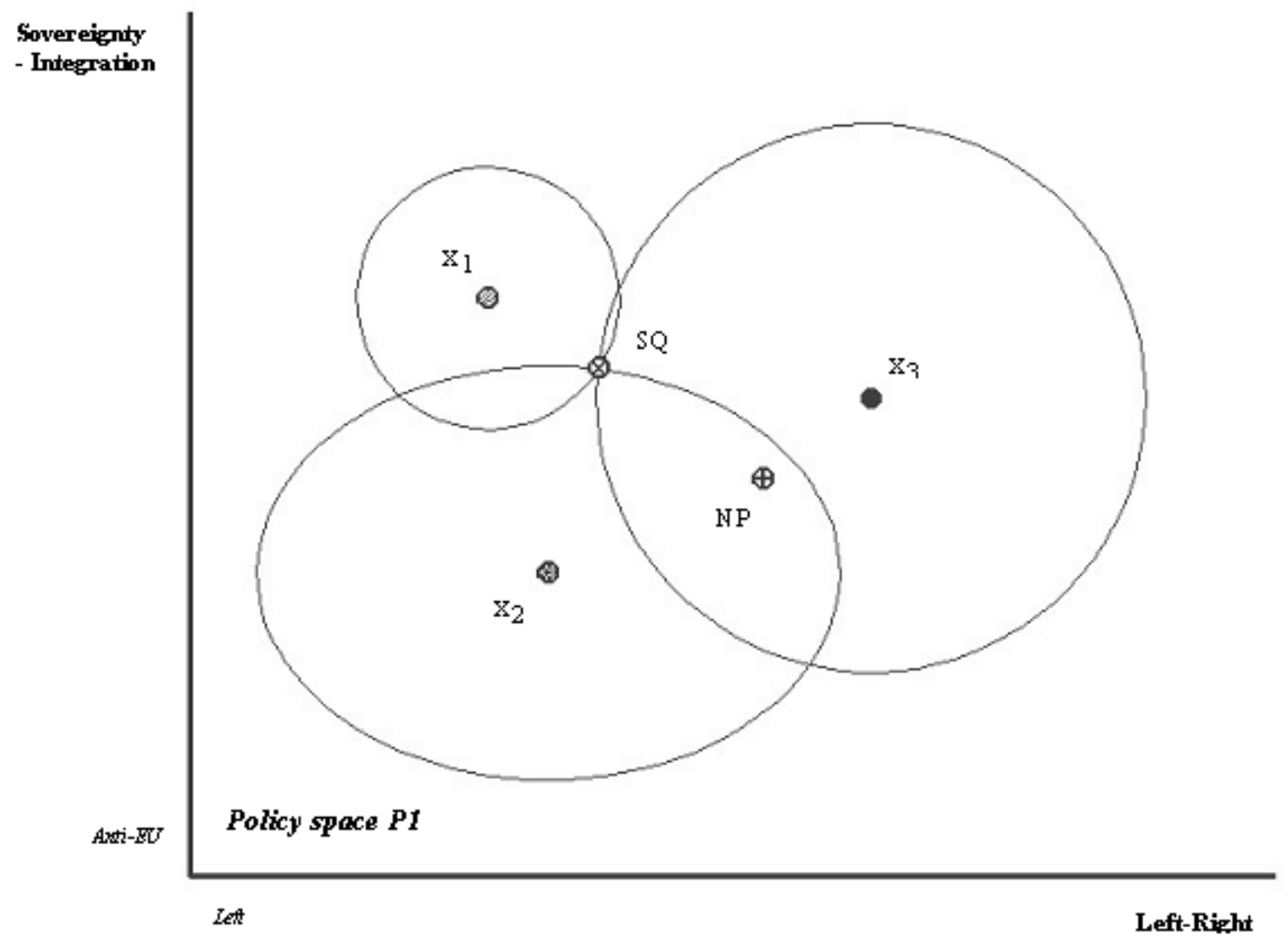

Figure 7: Policy space P1, greater salience of sovereignty-integration dimension, x2. 


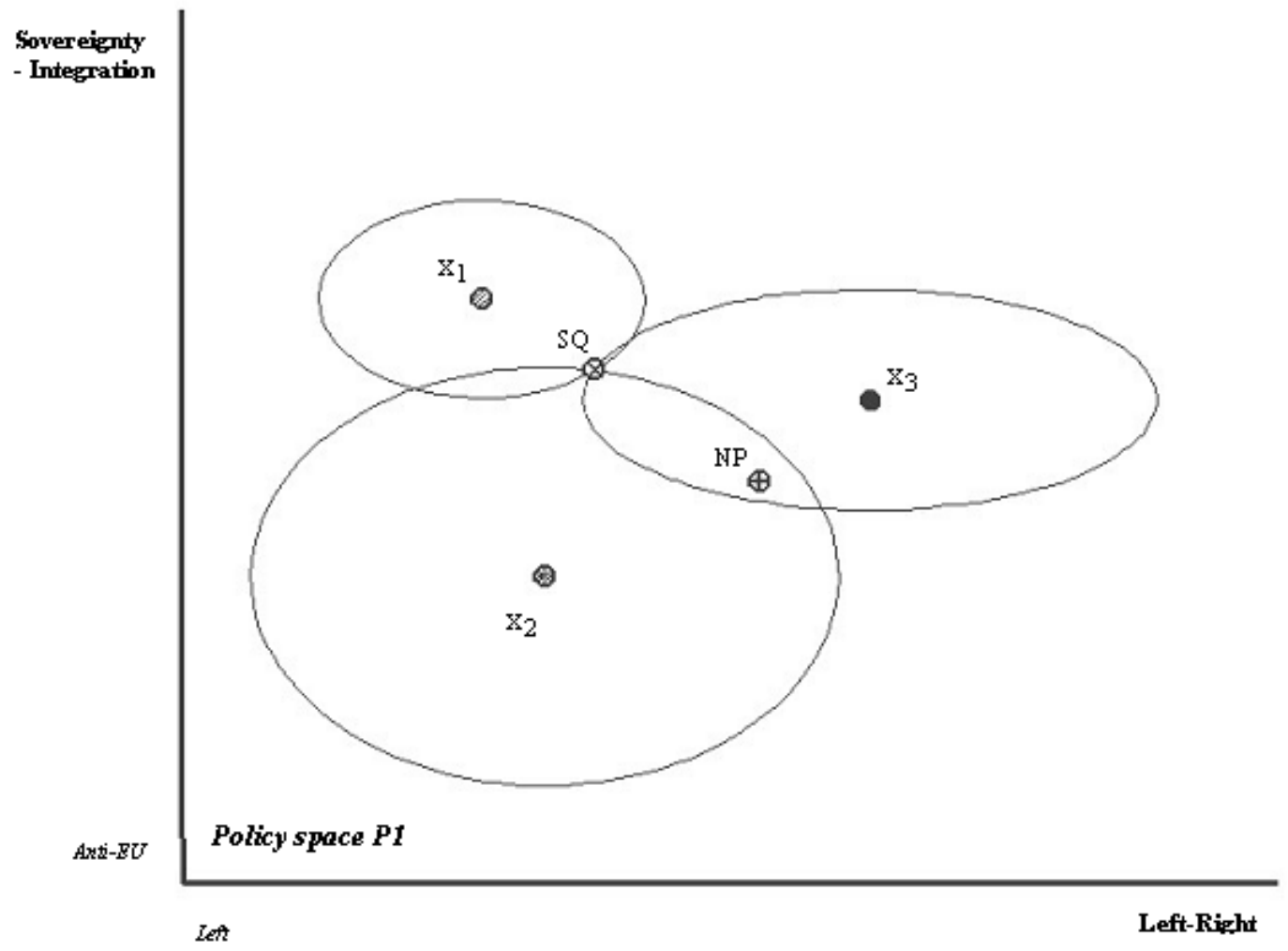

Figure 8: Policy space P1, greater salience of sovereignty-integration dimension, x1, x2, x3. 


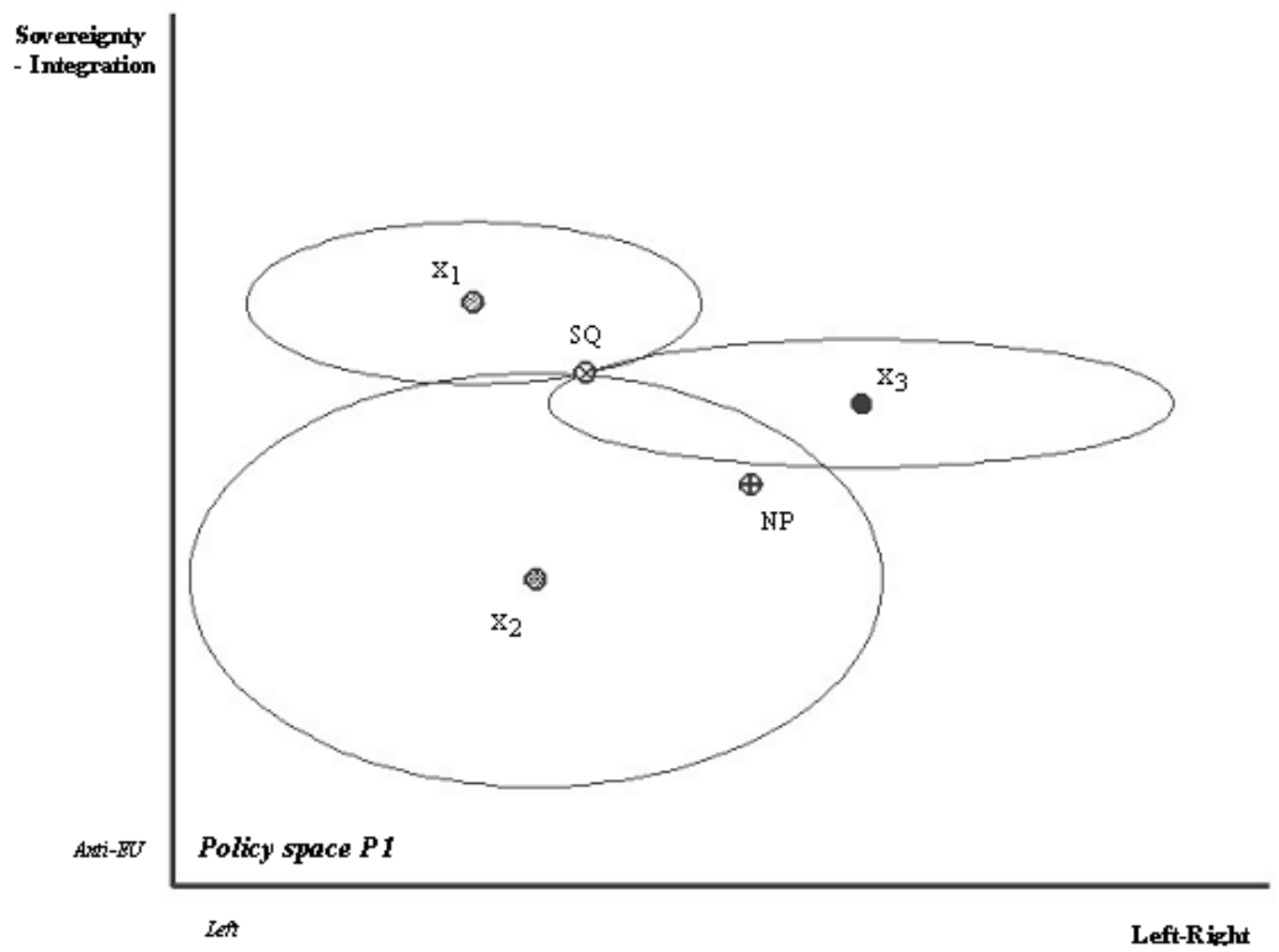

Figure 9: Policy space P1, greater salience of sovereignty-integration dimension, x1, x2, x3. 


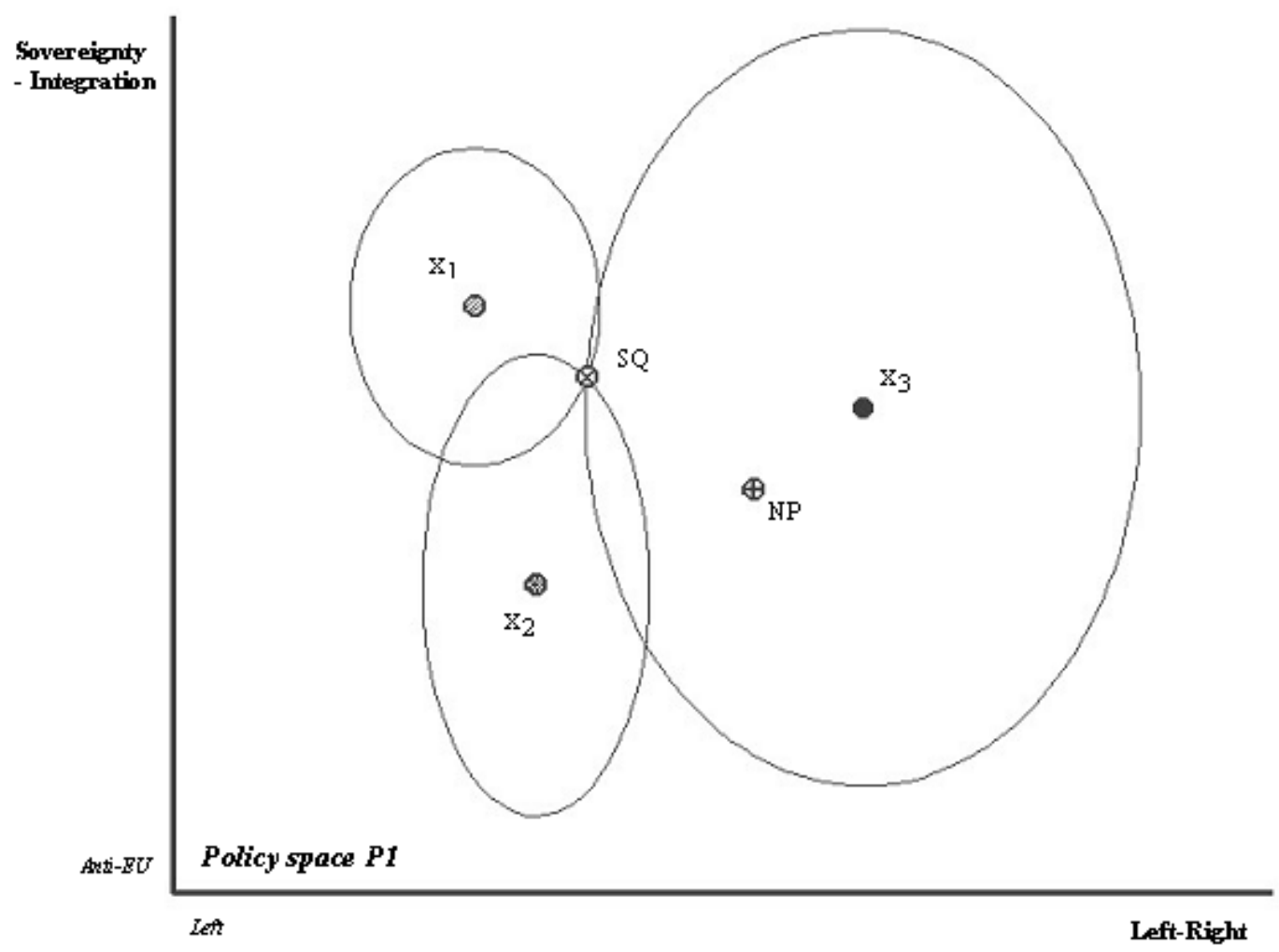

Figure 10: Policy space P1, greater salience of Left-Right dimension, x1, x2, x3. 


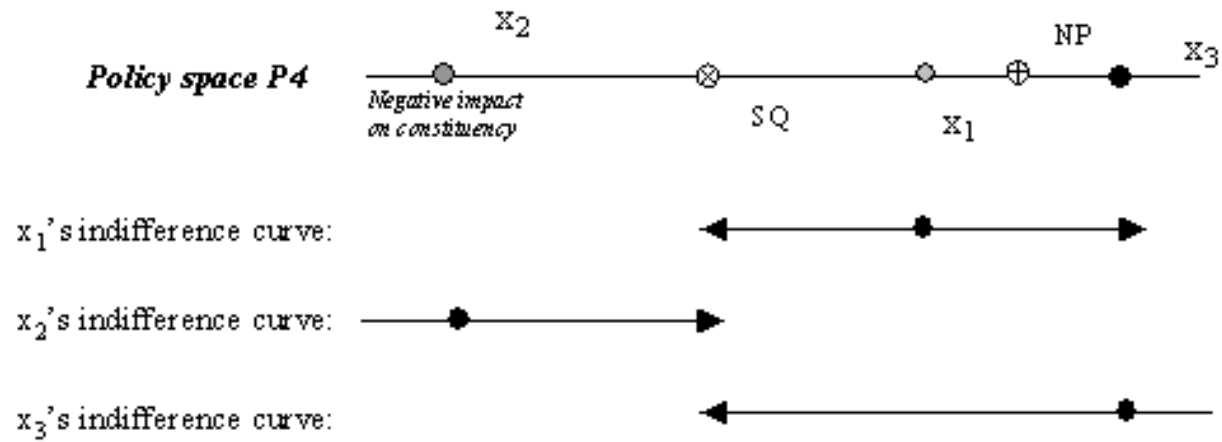

Figure 11: Policy space P4.

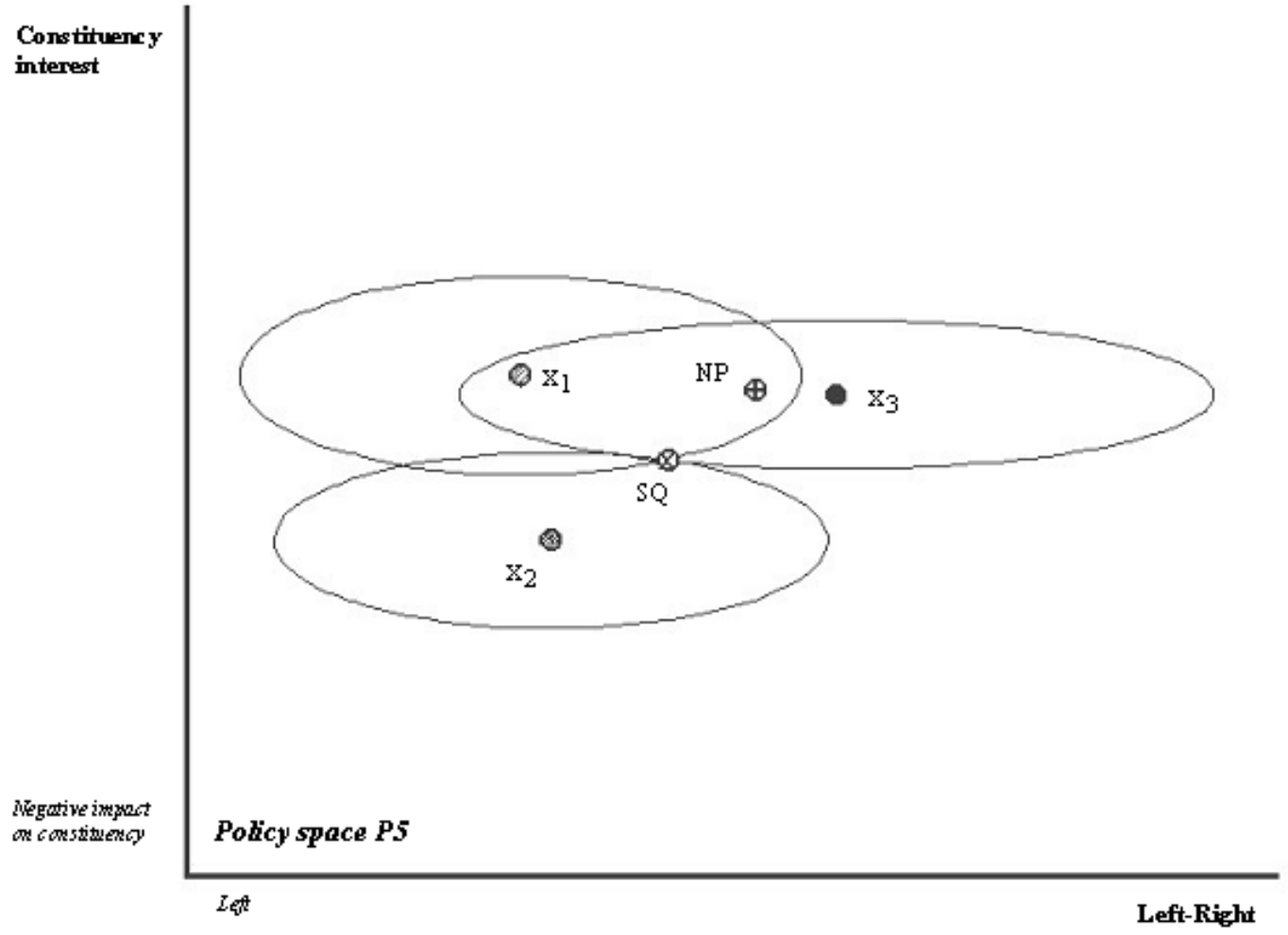

Figure 12: Policy space P5. 


\section{APPENDIX C}

\section{CHAPTER 5}

Table 1: Frequencies and Descriptives.

\begin{tabular}{|c|c|c|c|c|c|c|c|}
\hline & \multicolumn{2}{|c|}{ Frequencies } & $\mathbf{N}$ & Min & Max & Mean & Std. Dev. \\
\hline Vote & $\begin{array}{l}\text { Yes Votes: } \\
\text { No Votes: } \\
\text { Abstentions: } \\
\text { Missing: } \\
\text { Total: }\end{array}$ & $\begin{array}{l}32,674 \\
5,656 \\
2,244 \\
0 \\
40,574\end{array}$ & 40,574 & 0 & 2 & .92 & .433 \\
\hline $\begin{array}{ll}\text { EP } & \text { Party } \\
\text { Group } & \end{array}$ & $\begin{array}{l}\text { Yes Votes: } \\
\text { No Votes: } \\
\text { Abstentions: } \\
\text { Missing: } \\
\text { Total: }\end{array}$ & $\begin{array}{l}33,678 \\
4,419 \\
927 \\
1,550 \\
40,574\end{array}$ & 39,024 & 0 & 2 & .91 & .359 \\
\hline $\begin{array}{l}\text { National } \\
\text { Group }\end{array}$ & $\begin{array}{l}\text { Yes Votes: } \\
\text { No Votes: } \\
\text { Abstentions: } \\
\text { Missing: } \\
\text { Total: }\end{array}$ & $\begin{array}{l}29,860 \\
2,946 \\
453 \\
7,315 \\
40,574\end{array}$ & 33,259 & 0 & 2 & .93 & .311 \\
\hline $\begin{array}{l}\text { National Party } \\
\text { Delegation }\end{array}$ & $\begin{array}{l}\text { Yes Votes: } \\
\text { No Votes: } \\
\text { Abstentions: } \\
\text { Missing: } \\
\text { Total: }\end{array}$ & $\begin{array}{l}19,399 \\
2,923 \\
946 \\
17,306 \\
40,574 \\
\end{array}$ & 23,268 & 0 & 2 & .92 & .399 \\
\hline $\begin{array}{l}\text { Left-Right } \\
\text { Dimension } \\
\text { (NOMINATE) }\end{array}$ & $\begin{array}{l}\text { Missing: } \\
\text { Total: }\end{array}$ & $\begin{array}{l}907 \\
40,574\end{array}$ & 39,667 & -.886 & .862 & -.02 & .49 \\
\hline $\begin{array}{l}\text { Sovereignty- } \\
\text { Integration } \\
\text { Dimension } \\
\text { (NOMINATE) }\end{array}$ & $\begin{array}{l}\text { Missing: } \\
\text { Total: }\end{array}$ & $\begin{array}{l}907 \\
40,574\end{array}$ & 39,667 & $\begin{array}{l}-.934 \\
\end{array}$ & .944 & .10 & .42 \\
\hline
\end{tabular}


Table 2: Multinomial logit regression estimates.

\begin{tabular}{lcc}
\hline & No Vote & Yes Vote \\
\hline & & $-1.83 * * *$ \\
EP Party Group & $-5.27 * * *$ & $(.28)$ \\
& $(.37)$ & -.02 \\
National Group & -.27 & $(.20)$ \\
& $(.29)$ & $-3.79 * * *$ \\
National Party Delegation & $-8.53 * * *$ & $(.17)$ \\
& $(.27)$ & $9.79 * * *$ \\
Constant & $13.96 * * *$ & $(.36)$ \\
& $(.47)$ & \\
Number of cases & 20,027 & \\
Log pseudo-likelihood & -3546.82 & 0.57 \\
Pseudo R & & \\
& &
\end{tabular}




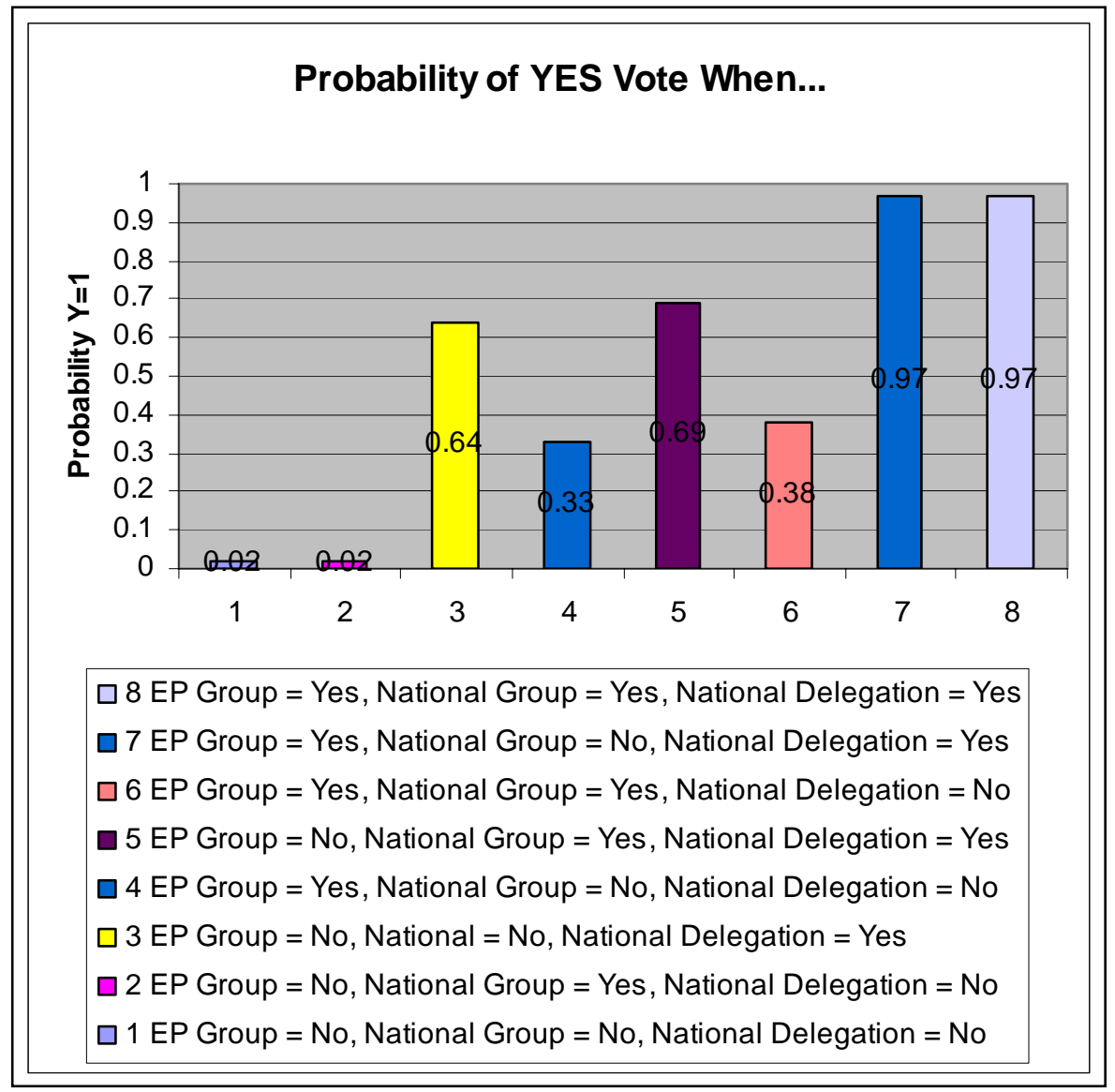

Figure 13: Probabilities of a YES vote, missing cases deleted listwise. 


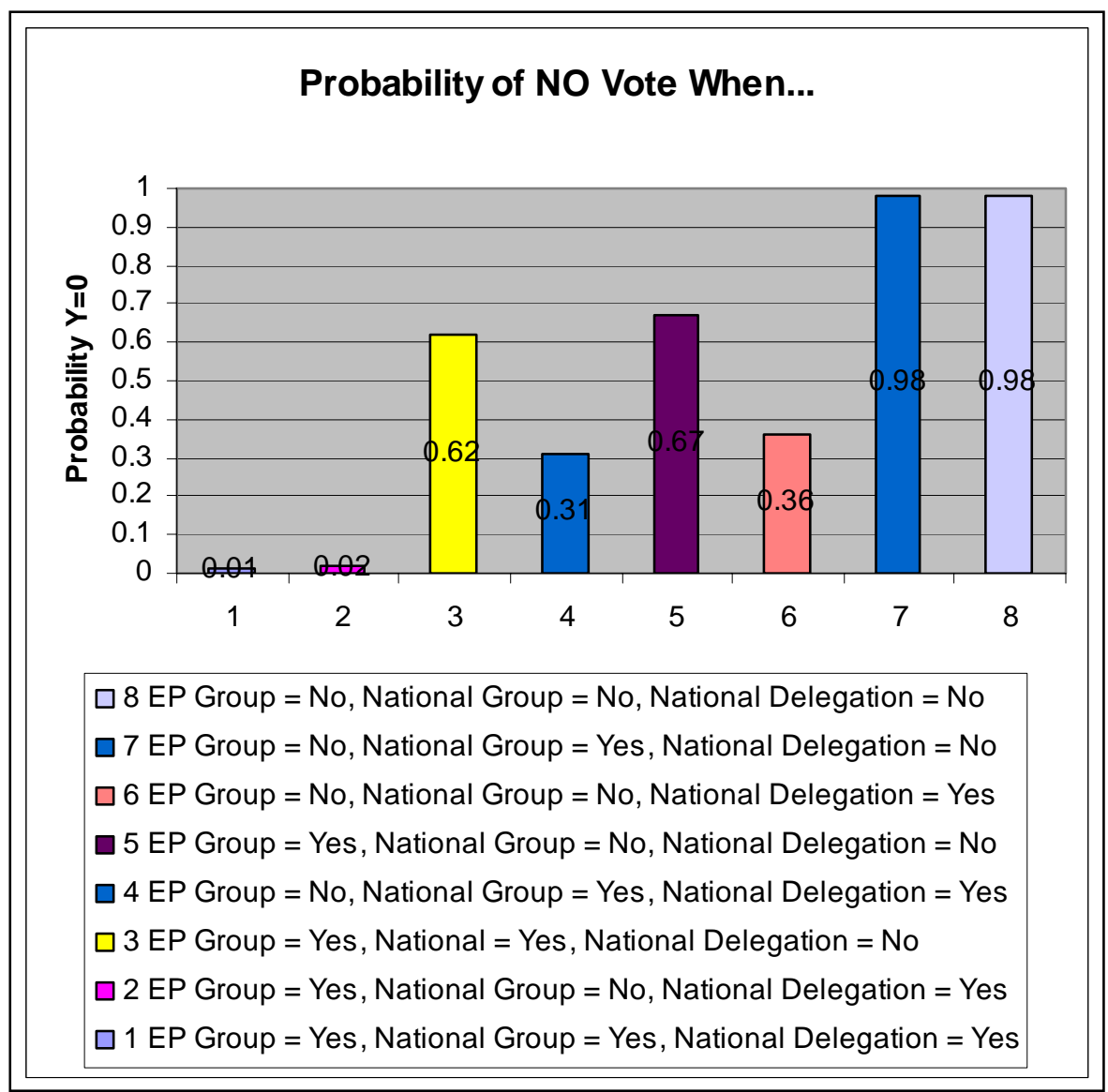

Figure 14: Probabilities of a NO vote, missing cases deleted listwise. 


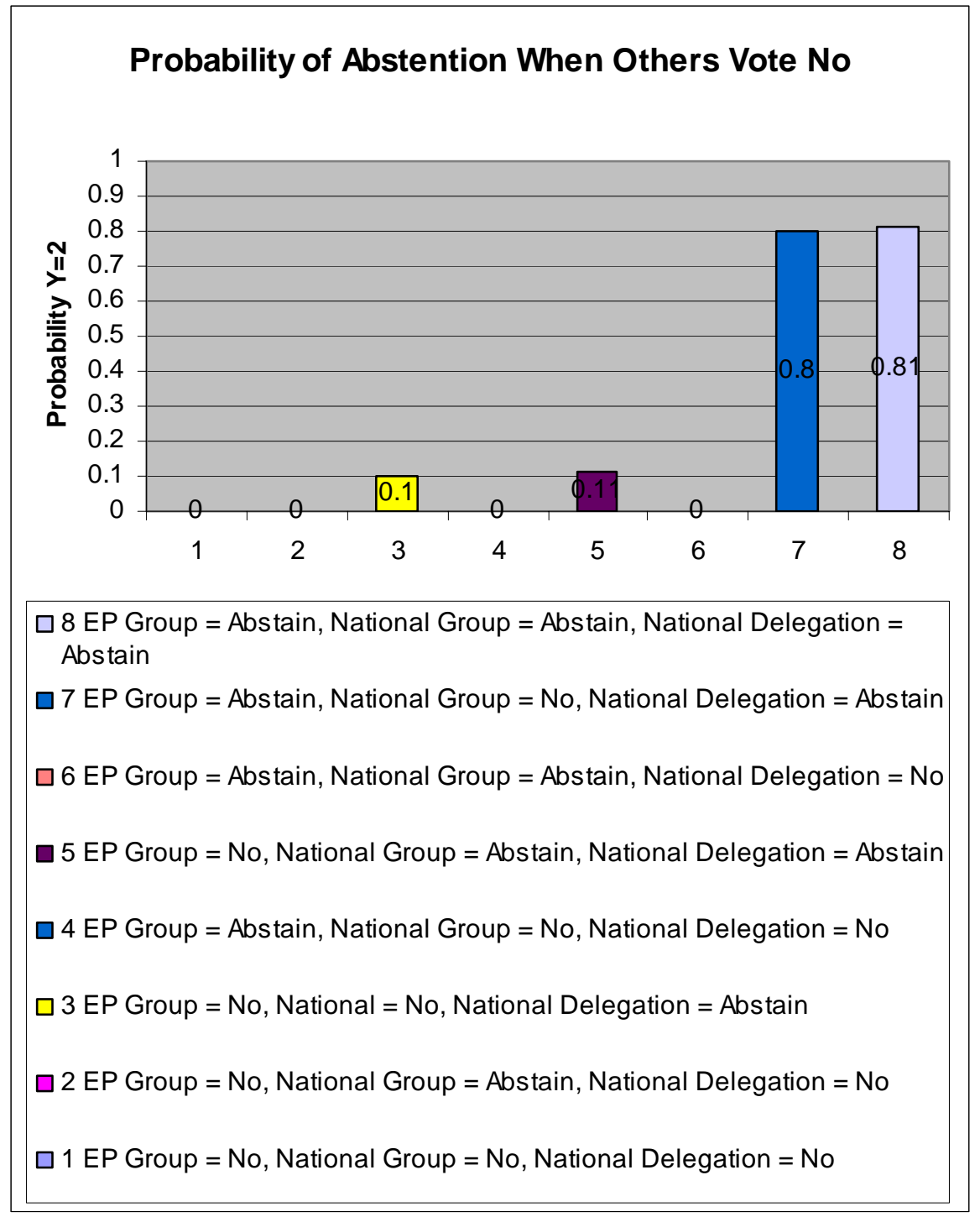

Figure 15: Probabilities of abstaining when others vote NO, missing cases deleted listwise. 


\section{Probability of Abstention When Others Vote Yes}

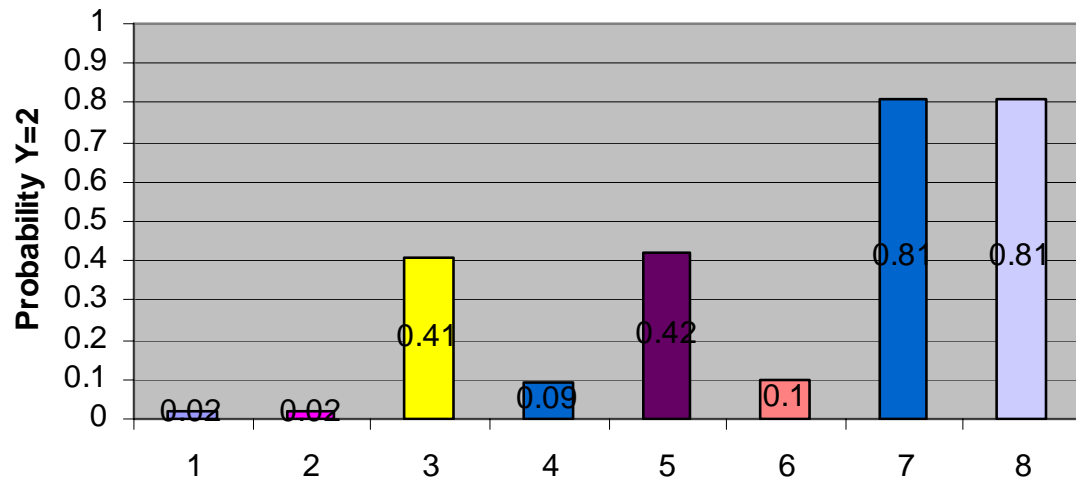

$\square 8$ EP Group = Abstain, National Group = Abstain, National Delegation $=$ Abstain

$\square 7$ EP Group = Abstain, National Group = Yes, National Delegation = Abstain $\square 6$ EP Group = Abstain, National Group = Abstain, National Delegation $=$ Yes $\square 5$ EP Group = Yes, National Group = Abstain, National Delegation = Abstain

$\square 4$ EP Group = Abstain, National Group = Yes, National Delegation $=$ Yes

$\square 3$ EP Group $=$ Yes, National $=$ Yes, National Delegation $=$ Abstain

$\square 2$ EP Group = Yes, National Group = Abstain, National Delegation $=$ Yes

$\square 1 \mathrm{EP}$ Group = Yes, National Group $=$ Yes, National Delegation = Yes

Figure 16: Probabilities of abstaining when others vote YES, missing cases deleted listwise. 
Table 3: Multinomial logit regression estimates excluding "National Party Delegation.”

\begin{tabular}{lcc}
\hline & No Vote & Yes Vote \\
\hline EP Party Group & $-6.01 * * *$ & $-2.12^{* * *}$ \\
National Group & $(.23)$ & $(.19)$ \\
Constant & $-1.02 * * *$ & .02 \\
& $(.16)$ & $(.12)$ \\
Number of cases & $6.74 * * *$ & $(.26)$ \\
Log pseudo-likelihood & $(.30)$ & \\
Pseudo R & 11,822 &
\end{tabular}

Note: Table entries are multinomial logit estimates. The omitted (baseline) choice for each column is "Abstention." Robust standard errors appear in parentheses. Statistical significance is indicated as follows: $* * *<0.001$ level; $* *<0.01 ; *<0.05$ 


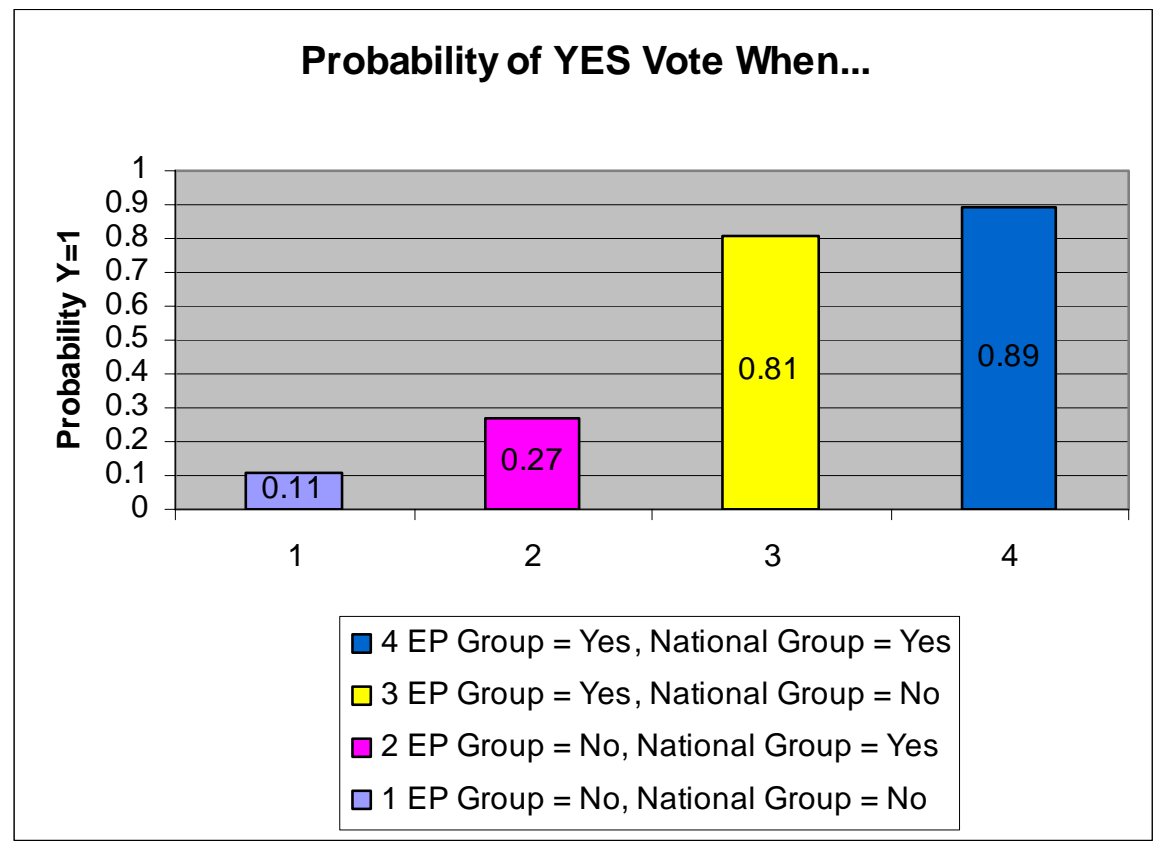

Figure 17: Probabilities of a YES vote, excl. "National Party Delegation," listwise deletion. 


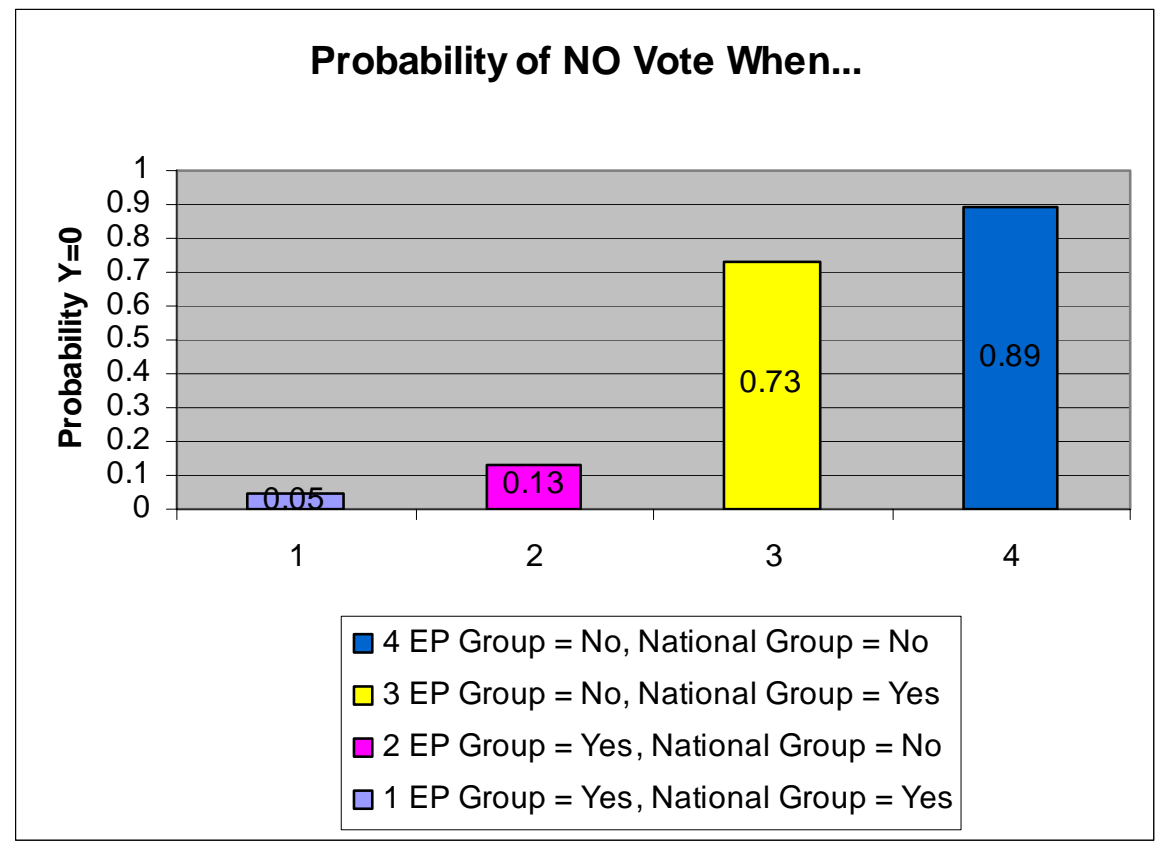

Figure 18: Probabilities of a NO vote, excl. "National Party Delegation," listwise deletion. 


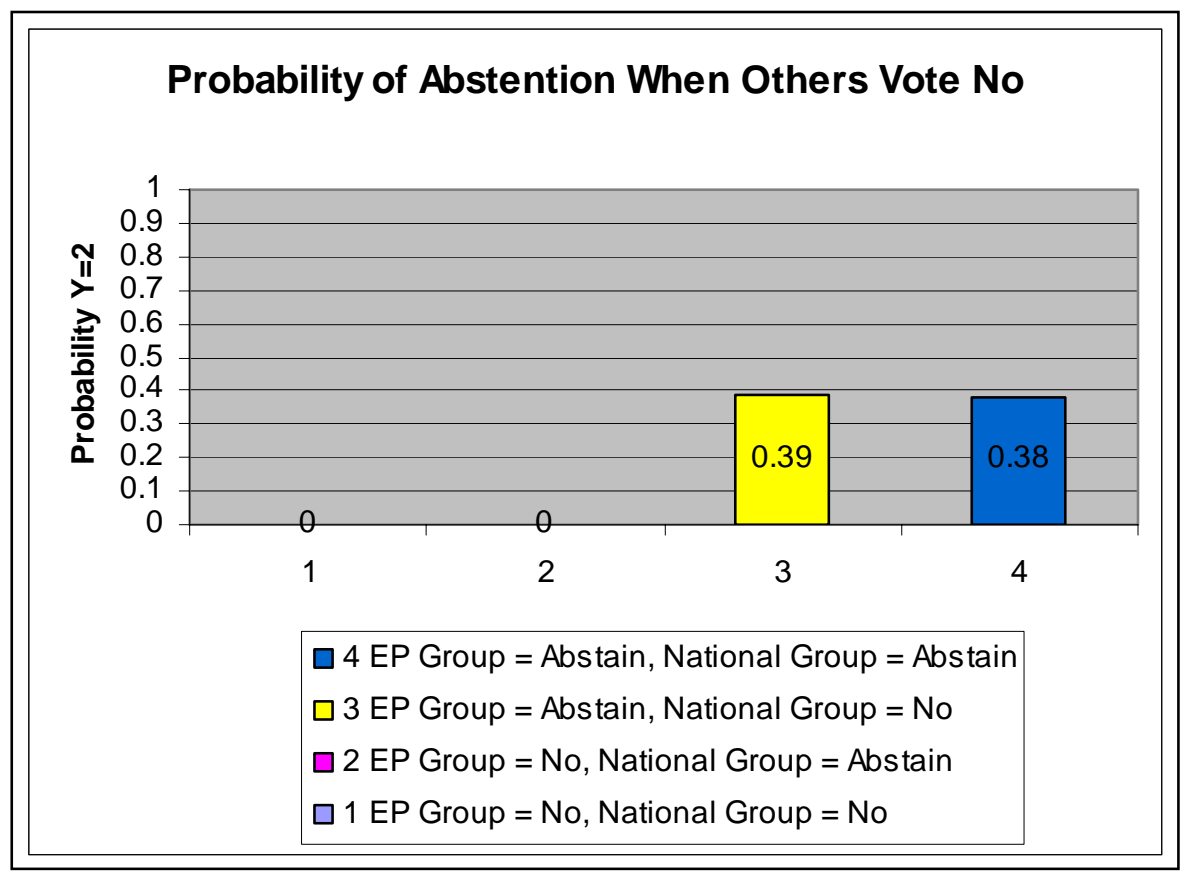

Figure 19: Prob. of abstain. when others vote NO, excl. "Natl. Party Del.," listwise deletion. 


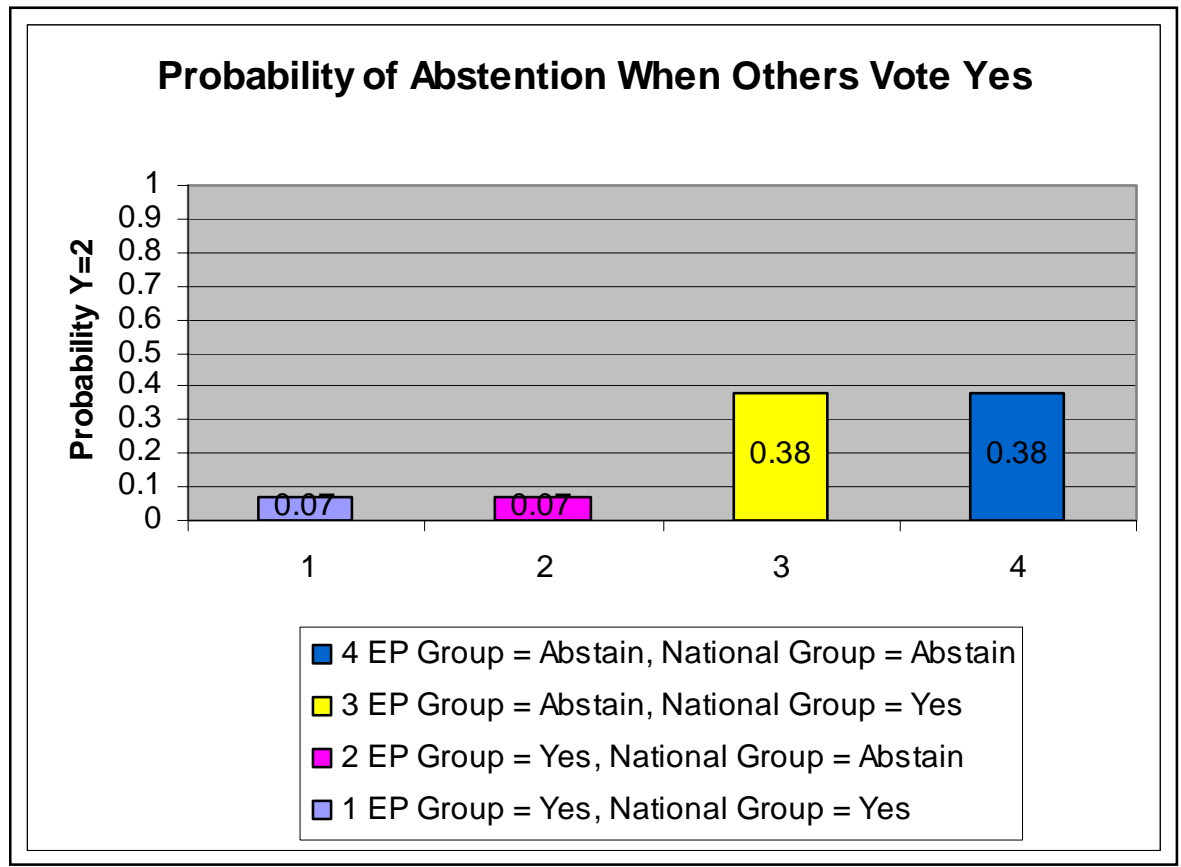

Figure 20: Prob. of abstain. when others vote YES, excl. "Natl. Party Del.," listwise deletion. 


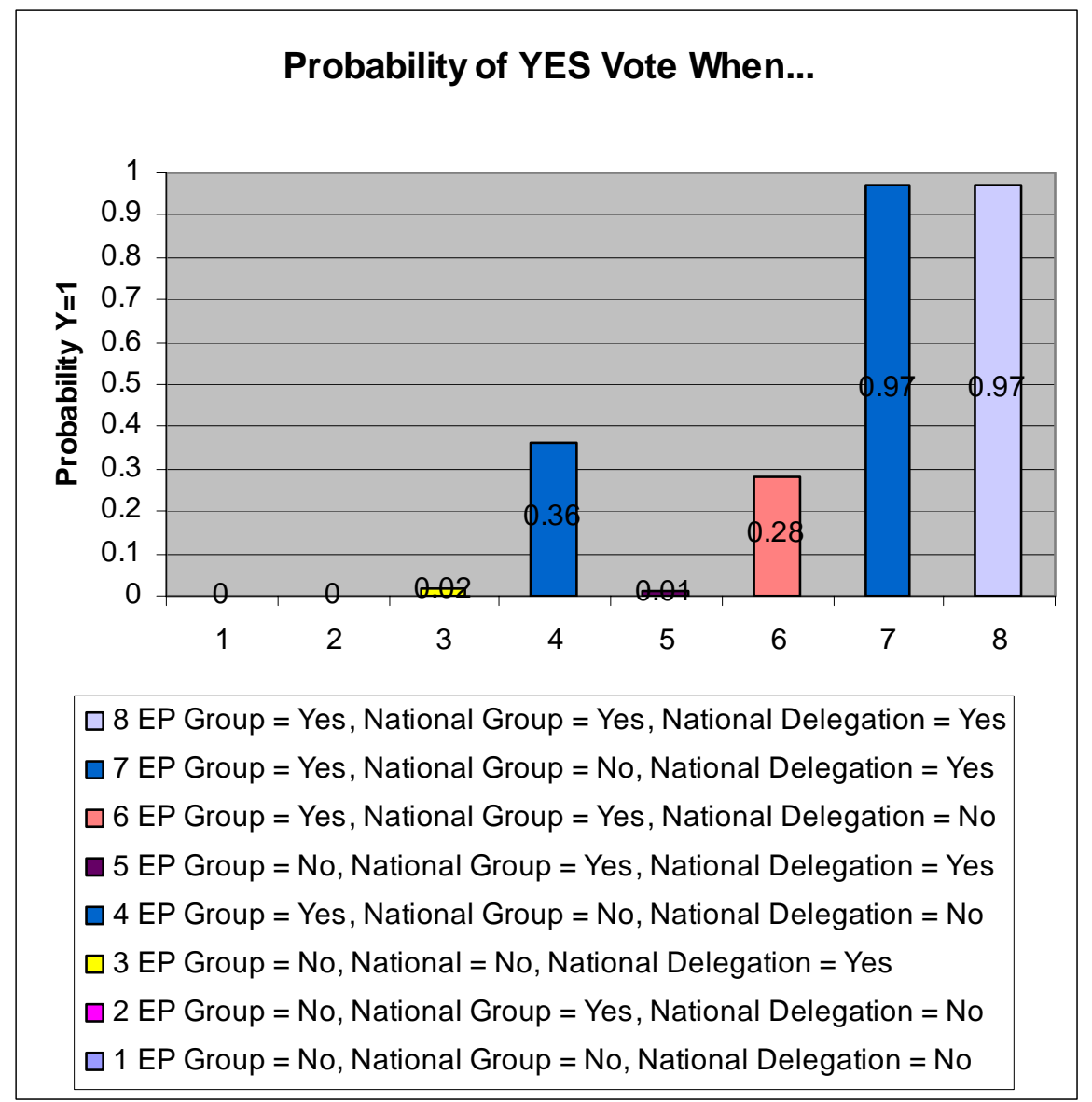

Figure 21: Probabilities of YES vote, Committee subsample 1. ${ }^{378}$

${ }^{378}$ Votes from the following committees are included in this subsample: Committee on Citizens' Freedoms and Rights, Justice and Home Affairs; Committee on Constitutional Affairs; Committee on Culture, Youth, Education, the Media and Sport; Committee on Development and Cooperation; Committee on Economic and Monetary Affairs; Committee on Employment and Social Affairs; Committee on Industry, External Trade, Research and Energy; Committee on Women's Rights and Equal Opportunities. 


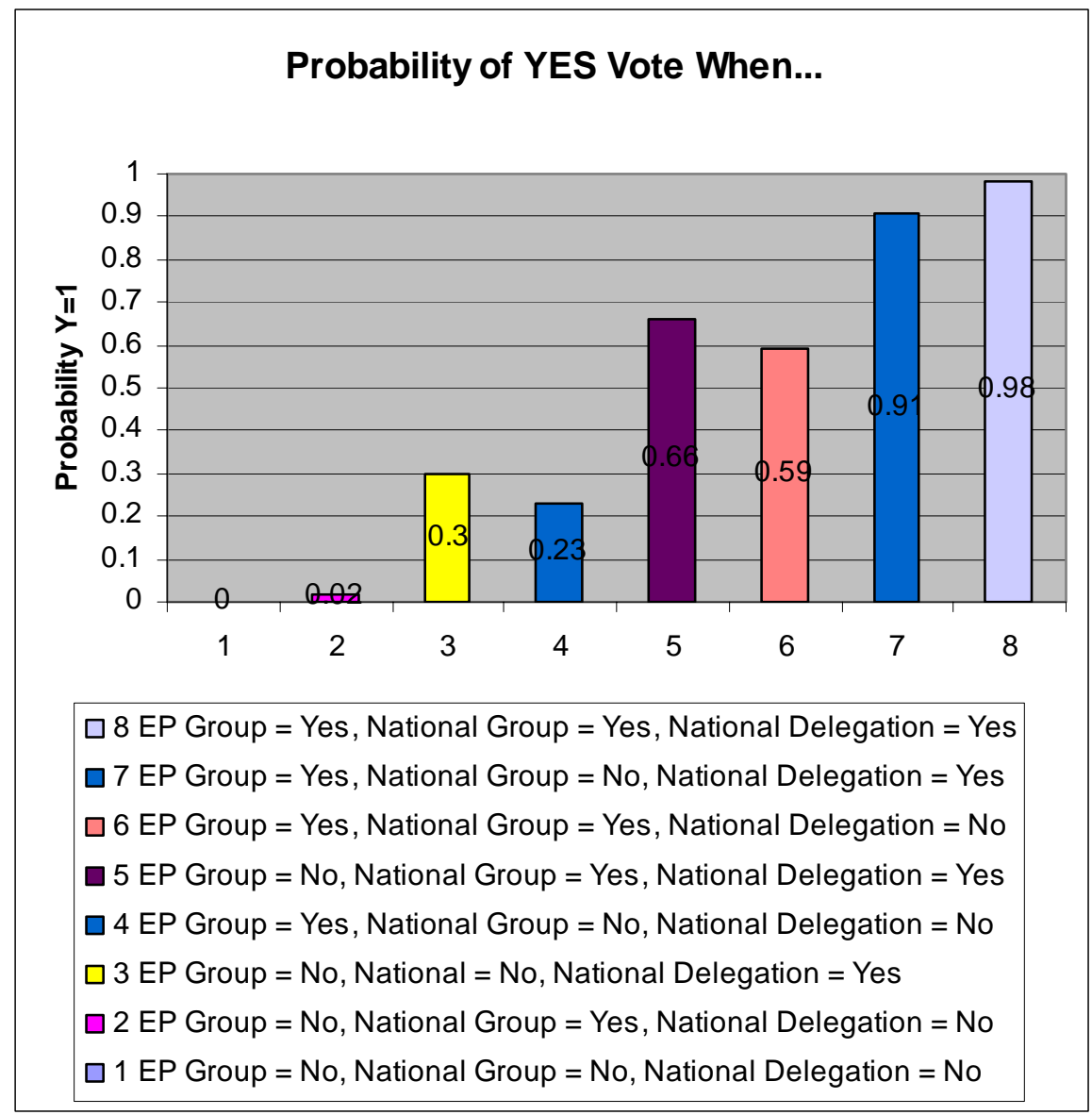

Figure 22: Probabilities of YES vote, Environment Committee. 


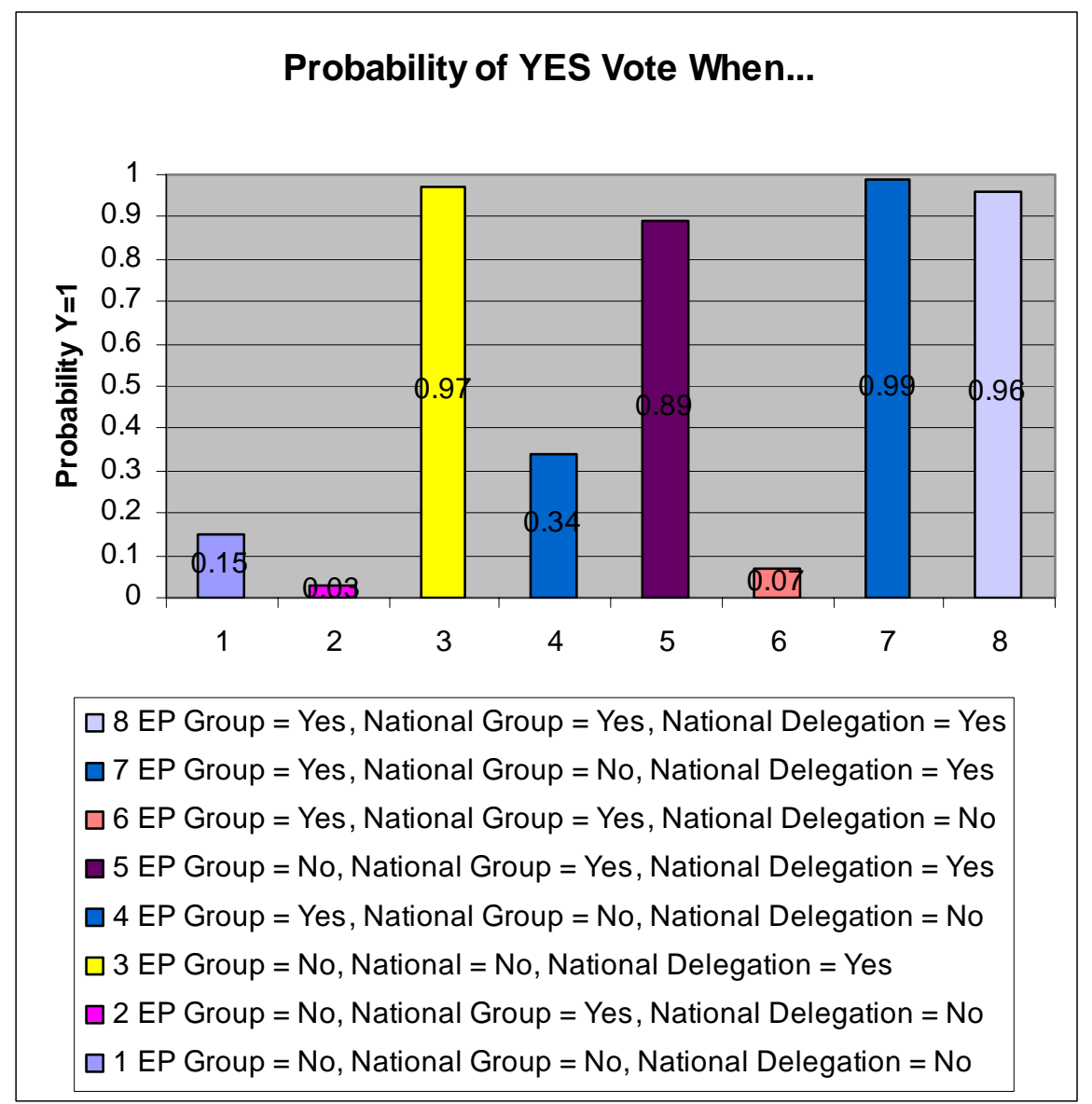

Figure 23: Probabilities of YES vote, Legal Affairs Committee. 


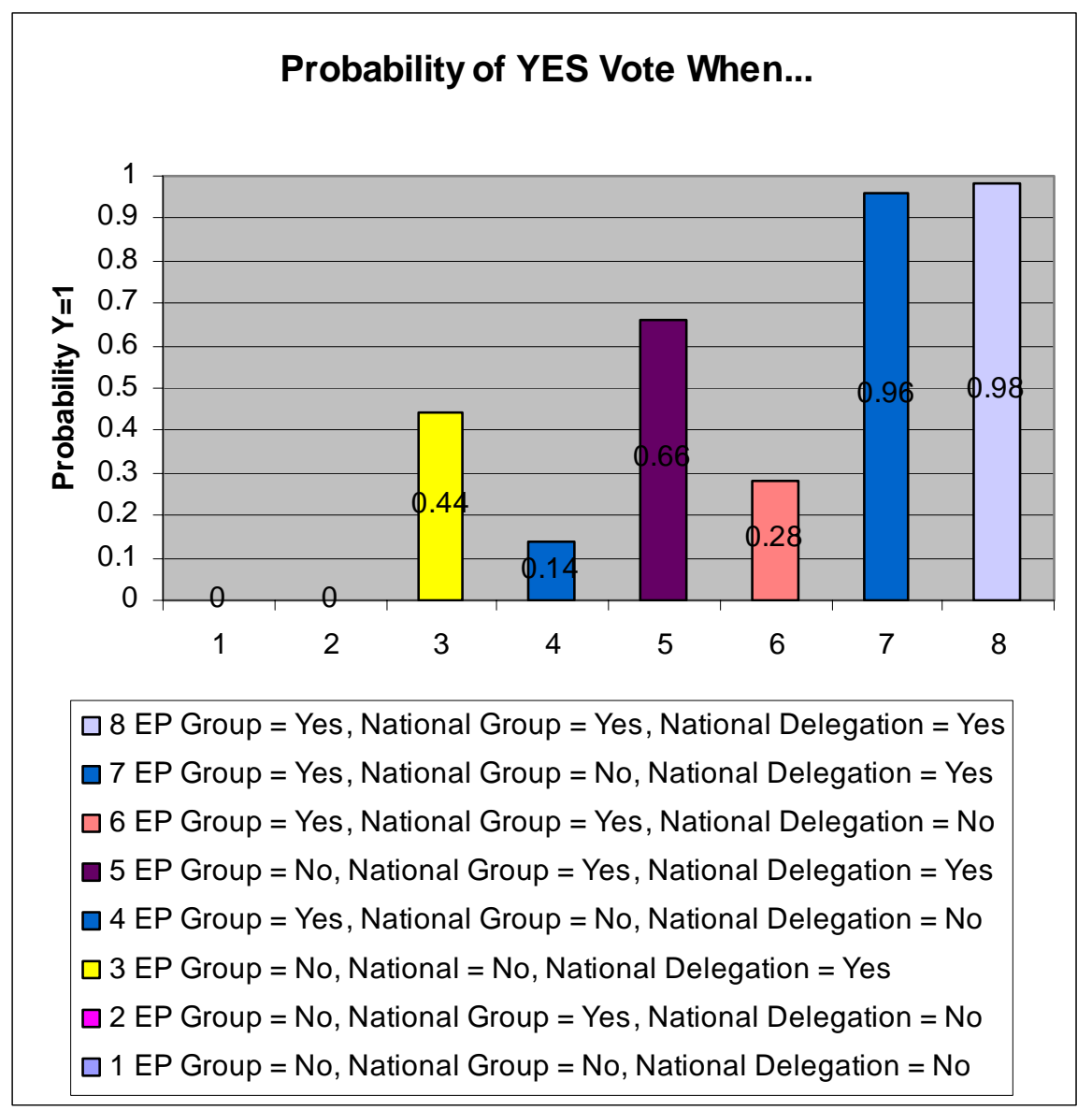

Figure 24: Probabilities of YES vote, Transport Committee. 


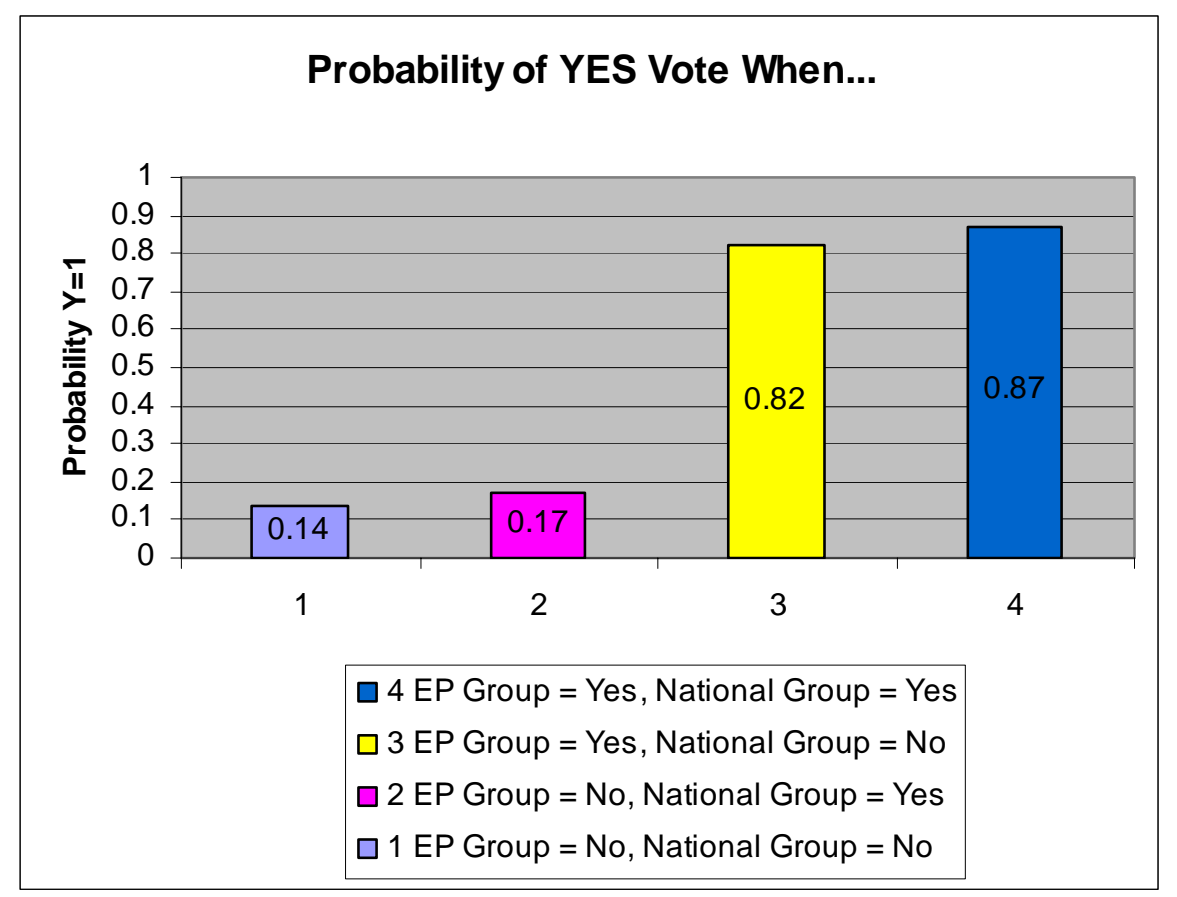

Figure 25: Probabilities of YES vote when excl. "Natl. Party Del.," Committee subsample 1. ${ }^{379}$

${ }^{379}$ Votes from the following committees are included in this subsample: Committee on Citizens' Freedoms and Rights, Justice and Home Affairs; Committee on Constitutional Affairs; Committee on Culture, Youth, Education, the Media and Sport; Committee on Development and Cooperation; Committee on Economic and Monetary Affairs; Committee on Employment and Social Affairs; Committee on Industry, External Trade, Research and Energy; Committee on Women's Rights and Equal Opportunities. 


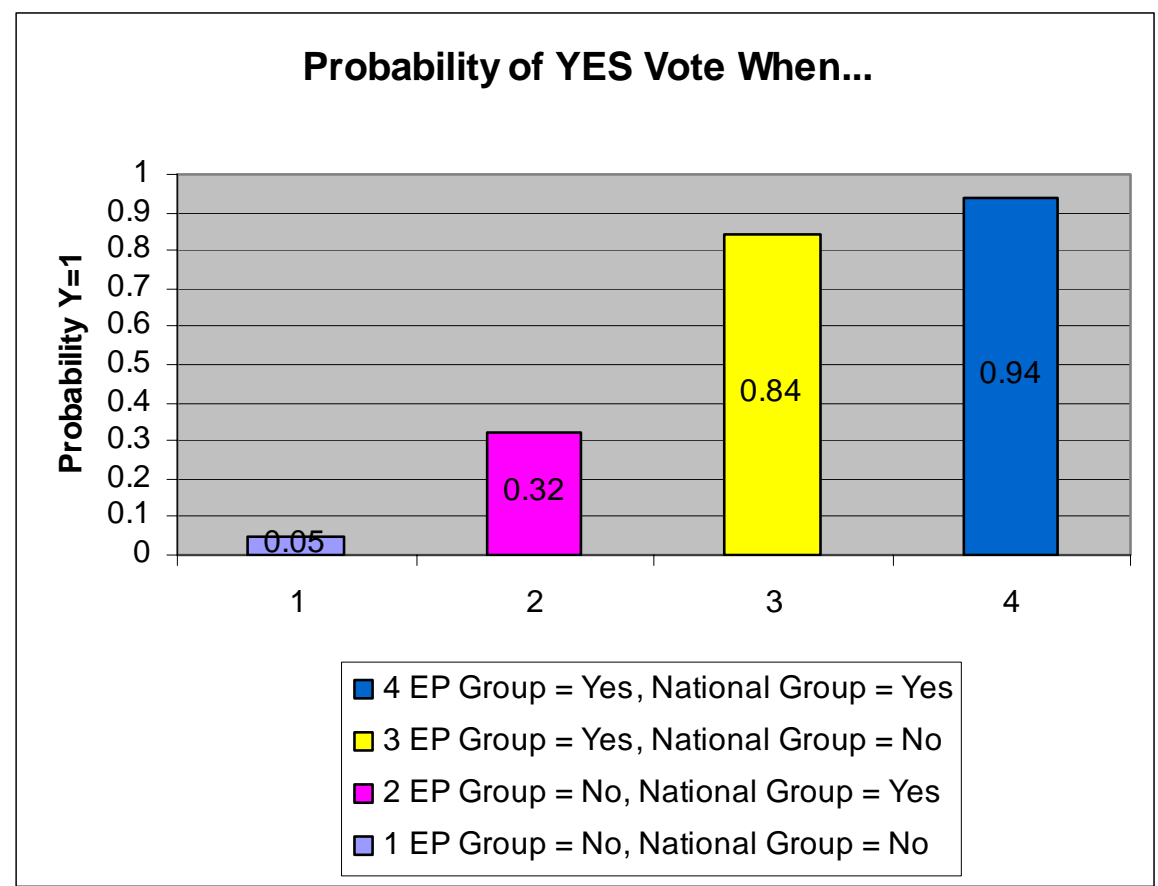

Figure 26: Probabilities of YES vote when excl. "Natl. Party Del.," Environment Committee. 


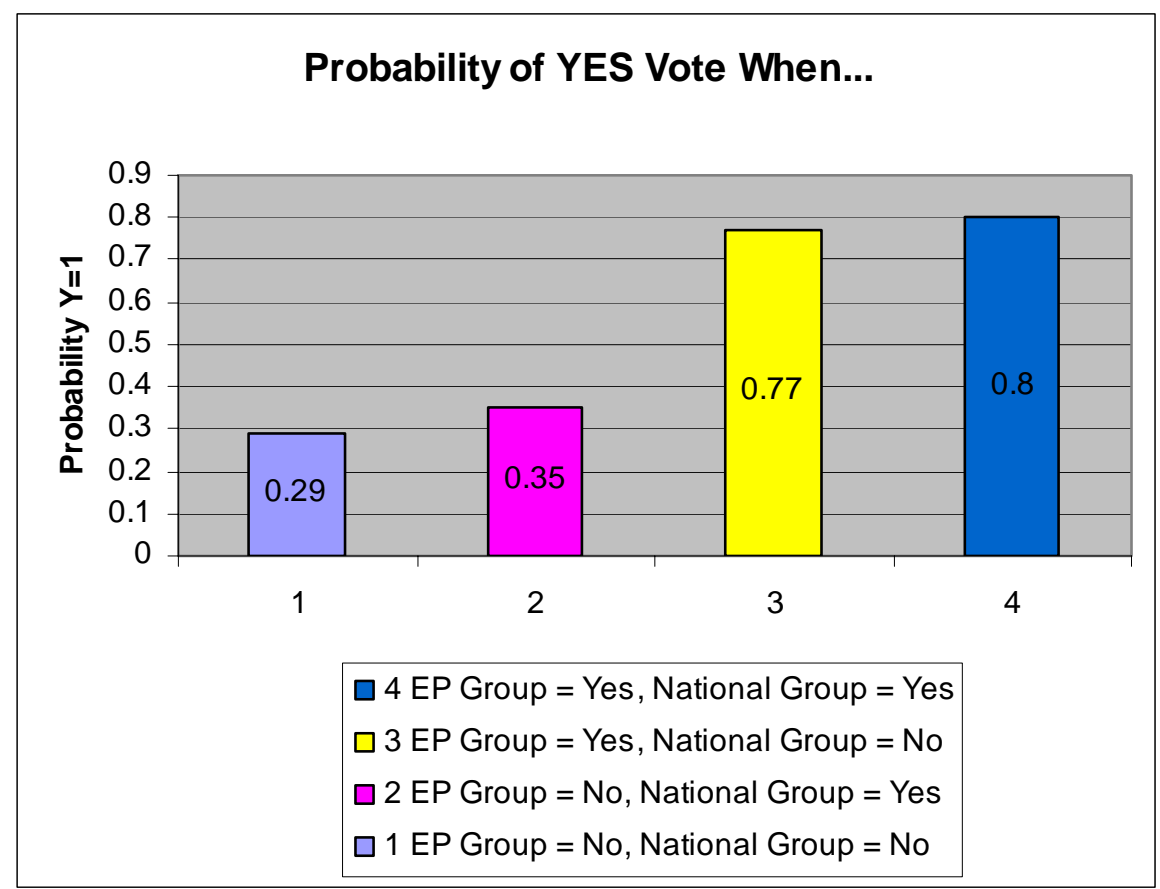

Figure 27: Probabilities of YES vote when excl. "Natl. Party Del.," Legal Affairs Committee. 


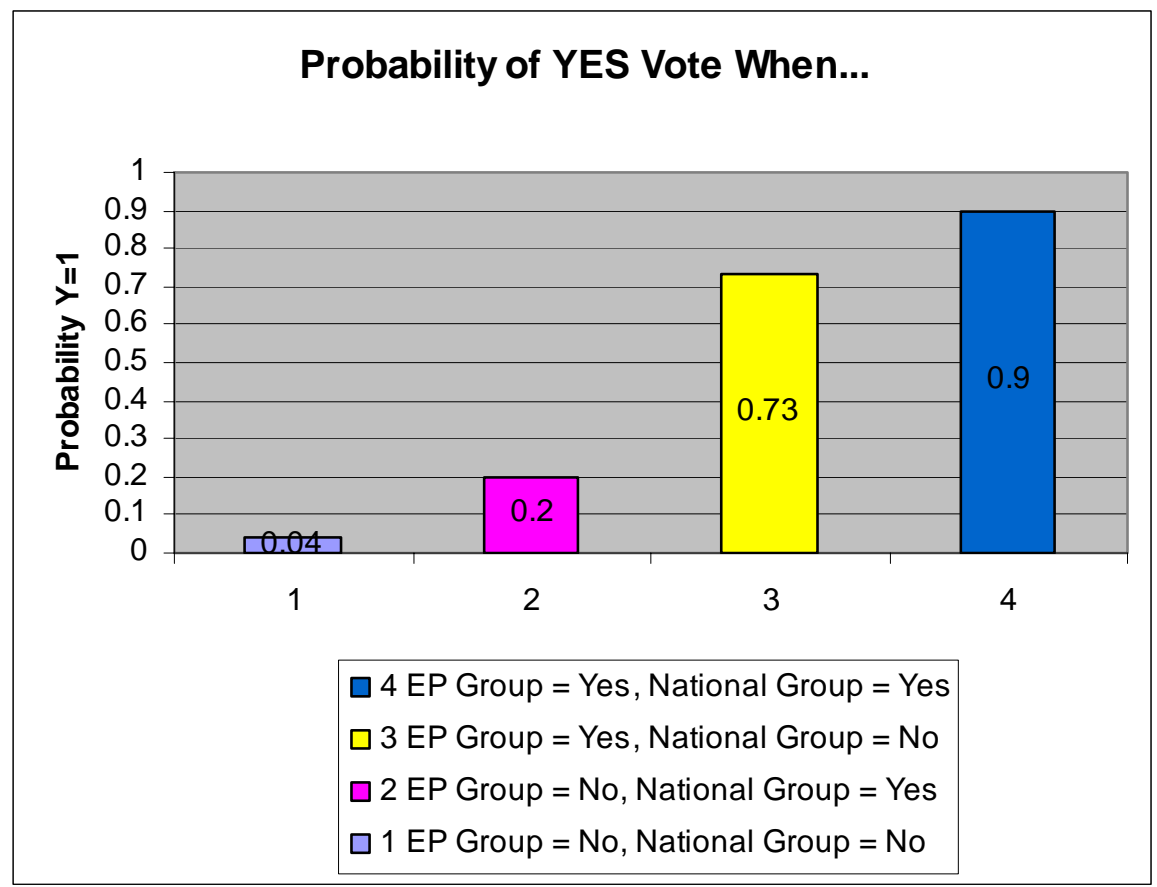

Figure 28: Probabilities of YES vote when excl. "Natl. Party Del.," Transport Committee. 
Table 4:Multinomial logit regression estimates, Committee subsample $1 .{ }^{380}$

\begin{tabular}{lcc}
\hline & No Vote & Yes Vote \\
\hline EP Party Group & $-10.60^{* * *}$ & $-1.62^{* * *}$ \\
National Group & $(.99)$ & $(.27)$ \\
& .56 & .19 \\
National Party Delegation & $(.51)$ & $(.24)$ \\
& $-10.00^{* * *}$ & $-4.67^{* * *}$ \\
Constant & $(.72)$ & $(.27)$ \\
& $19.59^{* * *}$ & $10.02^{* * *}$ \\
Number of cases & $(1.28)$ & $(.49)$ \\
Log pseudo-likelihood & 5,218 & \\
Pseudo R & -1006.23 &
\end{tabular}

Note: Table entries are multinomial logit estimates. The omitted (baseline) choice for each column is "Abstention." Robust standard errors appear in parentheses. Statistical significance is indicated as follows: ***<0.001 level; **<0.01;*<0.05

${ }^{380}$ Votes from the following committees are included in this subsample: Committee on Citizens' Freedoms and Rights, Justice and Home Affairs; Committee on Constitutional Affairs; Committee on Culture, Youth, Education, the Media and Sport; Committee on Development and Cooperation; Committee on Economic and Monetary Affairs; Committee on Employment and Social Affairs; Committee on Industry, External Trade, Research and Energy; Committee on Women's Rights and Equal Opportunities. 
Table 5: Multinomial logit regression estimates, Environment Committee.

\begin{tabular}{lcc}
\hline & No Vote & Yes Vote \\
\hline EP Party Group & $-8.67 * * *$ & $-4.38^{* * * *}$ \\
& $(.71)$ & $(.49)$ \\
National Group & .25 & $1.85^{* * *}$ \\
& $(.41)$ & $(.28)$ \\
National Party Delegation & $-6.32^{* * *}$ & $-1.73^{* * *}$ \\
& $(.62)$ & $(.49)$ \\
Constant & $14.32^{* * *}$ & $8.81 * * *$ \\
& $(.84)$ & $(.57)$ \\
Number of cases & 7,221 & \\
Log pseudo-likelihood & -876.41 & \\
Pseudo R & 0.65 & \\
\end{tabular}

Note: Table entries are multinomial logit estimates. The omitted (baseline) choice for each column is "Abstention." Robust standard errors appear in parentheses. Statistical significance is indicated as follows: $* * *<0.001$ level; $* *<0.01 ; *<0.05$ 
Table 6: Multinomial logit regression estimates, Legal Affairs Committee.

\begin{tabular}{lcc}
\hline & No Vote & Yes Vote \\
\hline & & \\
EP Party Group & -.19 & .90 \\
National Group & $.79)$ & $(.75)$ \\
& .43 & -1.66 \\
National Party Delegation & $(1.21)$ & $(1.25)$ \\
& $-4.33^{* * *}$ & $2.22^{*}$ \\
Constant & $(.90)$ & $2.94)$ \\
& $4.26^{* * *}$ & $(1.17)$ \\
Number of cases & $(1.13)$ & \\
Log pseudo-likelihood & 3,109 & \\
Pseudo R &
\end{tabular}

Note: Table entries are multinomial logit estimates. The omitted (baseline) choice for each column is "Abstention." Robust standard errors appear in parentheses. Statistical significance is indicated as follows: $* * *<0.001$ level; $* *<0.01 ; *<0.05$ 
Table 7: Multinomial logit regression estimates, Transport Committee.

\begin{tabular}{lcc}
\hline & No Vote & Yes Vote \\
\hline & & \\
EP Party Group & $-6.23^{* * *}$ & -2.50 \\
National Group & $(1.74)$ & $(1.69)$ \\
& -1.48 & -.56 \\
National Party Delegation & $(.95)$ & $(.88)$ \\
& $-9.10^{* * *}$ & $-3.74^{* * *}$ \\
Constant & $(1.13)$ & $(1.05)$ \\
& $16.93^{* * *}$ & $\left(1.34^{* * *}\right.$ \\
Number of cases & $(1.60)$ & \\
Log pseudo-likelihood & 4,479 & \\
Pseudo R & -672.03 &
\end{tabular}

Note: Table entries are multinomial logit estimates. The omitted (baseline) choice for each column is "Abstention." Robust standard errors appear in parentheses. Statistical significance is indicated as follows: $* * *<0.001$ level; $* *<0.01 ; *<0.05$ 
Table 8: Multinomial logit estimates excl. "Natl. Party Del.," Committee subsample 1. ${ }^{381}$

\begin{tabular}{lcc}
\hline & No Vote & Yes Vote \\
\hline \multirow{2}{*}{ EP Party Group } & $-6.34 * * *$ & $-1.69^{* * *}$ \\
National Group & $(.39)$ & $(.30)$ \\
& .16 & $.40^{*}$ \\
Constant & $(.26)$ & $(.20)$ \\
& $5.44^{* * *}$ & $(.42)$ \\
Number of cases & $(.51)$ & \\
Log pseudo-likelihood & 3,451 & \\
Pseudo R & -1651.26 &
\end{tabular}

Note: Table entries are multinomial logit estimates. The omitted (baseline) choice for each column is "Abstention." Robust standard errors appear in parentheses. Statistical significance is indicated as follows: $* * *<0.001$ level; $* *<0.01 ; *<0.05$

${ }^{381}$ Votes from the following committees are included in this subsample: Committee on Citizens' Freedoms and Rights, Justice and Home Affairs; Committee on Constitutional Affairs; Committee on Culture, Youth, Education, the Media and Sport; Committee on Development and Cooperation; Committee on Economic and Monetary Affairs; Committee on Employment and Social Affairs; Committee on Industry, External Trade, Research and Energy; Committee on Women's Rights and Equal Opportunities. 
Table 9: Multinomial logit estimates excl. "Natl. Party Del.," Environment Committee.

\begin{tabular}{lcc}
\hline & No Vote & Yes Vote \\
\hline EP Party Group & $-8.29 * * *$ & $-3.53 * * *$ \\
& $(.41)$ & $(.28)$ \\
National Group & $-2.68^{* * *}$ & -.50 \\
& $(.38)$ & $(.28)$ \\
Constant & $10.15^{* * *}$ & $(.48)$ \\
& $(.58)$ & \\
Number of cases & 3,911 & \\
Log pseudo-likelihood & -1204.36 &
\end{tabular}

Note: Table entries are multinomial logit estimates. The omitted (baseline) choice for each column is "Abstention." Robust standard errors appear in parentheses. Statistical significance is indicated as follows: $* * *<0.001$ level; $* *<0.01 ; *<0.05$ 
Table 10: Multinomial logit estimates excl. "Natl. Party Del.," Legal Affairs Committee.

\begin{tabular}{lcc}
\hline & No Vote & Yes Vote \\
\hline EP Party Group & $-1.30 * * *$ & $.99 *$ \\
& $(.38)$ & $(.41)$ \\
National Group & $-.90^{* * *}$ & $-.53^{*}$ \\
Constant & $(.27)$ & $(.25)$ \\
& $2.72 * * *$ & $\left(.90^{* * *}\right.$ \\
Number of cases & $(.37)$ & \\
Log pseudo-likelihood & 1,874 & \\
Pseudo R & -1269.65 &
\end{tabular}

Note: Table entries are multinomial logit estimates. The omitted (baseline) choice for each column is "Abstention." Robust standard errors appear in parentheses. Statistical significance is indicated as follows: $* * *<0.001$ level; $* *<0.01 ; *<0.05$ 
Table 11: Multinomial logit estimates excl. "Natl. Party Del.," Transport Committee.

\begin{tabular}{lcc}
\hline & No Vote & Yes Vote \\
\hline \multirow{2}{*}{ EP Party Group } & $-8.20^{* * *}$ & $-3.89^{* * *}$ \\
National Group & $(.44)$ & $(.31)$ \\
& $-1.94^{* * *}$ & -.18 \\
Constant & $(.37)$ & $(.30)$ \\
& $10.21 * * *$ & $(.50)$ \\
Number of cases & $(.62)$ & \\
Log pseudo-likelihood & 2,586 & \\
Pseudo R & -1075.79 &
\end{tabular}

Note: Table entries are multinomial logit estimates. The omitted (baseline) choice for each column is "Abstention." Robust standard errors appear in parentheses. Statistical significance is indicated as follows: $* * *<0.001$ level; $* *<0.01 ; *<0.05$ 


\section{APPENDIX D}

\section{CHAPTER 6.2.}

Table 12: Frequencies-of-use, content analysis 6.2.

\begin{tabular}{|c|c|c|c|c|}
\hline & $\begin{array}{c}\text { \# of input } \\
\text { words }\end{array}$ & $\begin{array}{c}\text { \# of references } \\
\text { to single } \\
\text { market. }\end{array}$ & $\begin{array}{c}\text { \# of references } \\
\text { to workers' } \\
\text { rights. }\end{array}$ & $\begin{array}{l}\text { \# of references } \\
\text { to level } \\
\text { playing-field. }\end{array}$ \\
\hline $\begin{array}{l}1{ }^{\text {st }} \text { Reading } \\
\text { (adjusted by \# of } \\
\text { input words) }\end{array}$ & $\begin{array}{c}4,067 \\
(10,000) \\
10 \text { speakers }\end{array}$ & $\begin{array}{c}26 \\
(64) \\
5 \text { speakers }\end{array}$ & $\begin{array}{c}14 \\
(34) \\
4 \text { speakers }\end{array}$ & \\
\hline $\begin{array}{l}2^{\text {nd }} \text { Reading Debate } \\
\text { (adjusted by \# of } \\
\text { input words) }\end{array}$ & $\begin{array}{c}5,593 \\
(10,000) \\
15 \text { speakers }\end{array}$ & $\begin{array}{c}6 \\
(11) \\
4 \text { speakers }\end{array}$ & $\begin{array}{c}22 \\
(39) \\
8 \text { speakers }\end{array}$ & $\begin{array}{c}17 \\
(30) \\
5 \text { speakers }\end{array}$ \\
\hline $\begin{array}{l}3^{\text {rd }} \text { Reading Debate } \\
\text { (adjusted by \# of } \\
\text { input words) }\end{array}$ & $\begin{array}{c}11,940 \\
(10,000) \\
26 \text { speakers }\end{array}$ & $\begin{array}{c}8 \\
(7) \\
7 \text { speakers }\end{array}$ & $\begin{array}{c}55 \\
(46) \\
18 \text { speakers }\end{array}$ & $\begin{array}{c}36 \\
(30) \\
11 \text { speakers }\end{array}$ \\
\hline
\end{tabular}


Table 13: Binomial logit regression estimates, first reading vote, 6.2 .

Floor Vote, First Reading

Left-Right Dimension

Sovereignty-Integration Dimension

Government Status

Liberal Market Economy

Partial Coordinated Market Economy

Sectoral Coordinated Market Economy

Constant

Number of cases

Log pseudo-likelihood

Pseudo $\mathrm{R}^{2}$
$-1.83 * * *$

$2.57 * * *$

$(.53)$

$-.53$

$(.50)$

$-3.20 * * *$

(.69)

$3.01 * * *$

(.60)

$1.13 *$

(.48)

1.01 *

(.47)

359

$-118.29$

0.39

$* * *=$ significant at 0.001 level; $* *=$ significant at 0.01 level; $*=$ significant at 0.05 level Dependent Variable: Vote: $1=$ for, $0=$ against, abstain $=0$ 


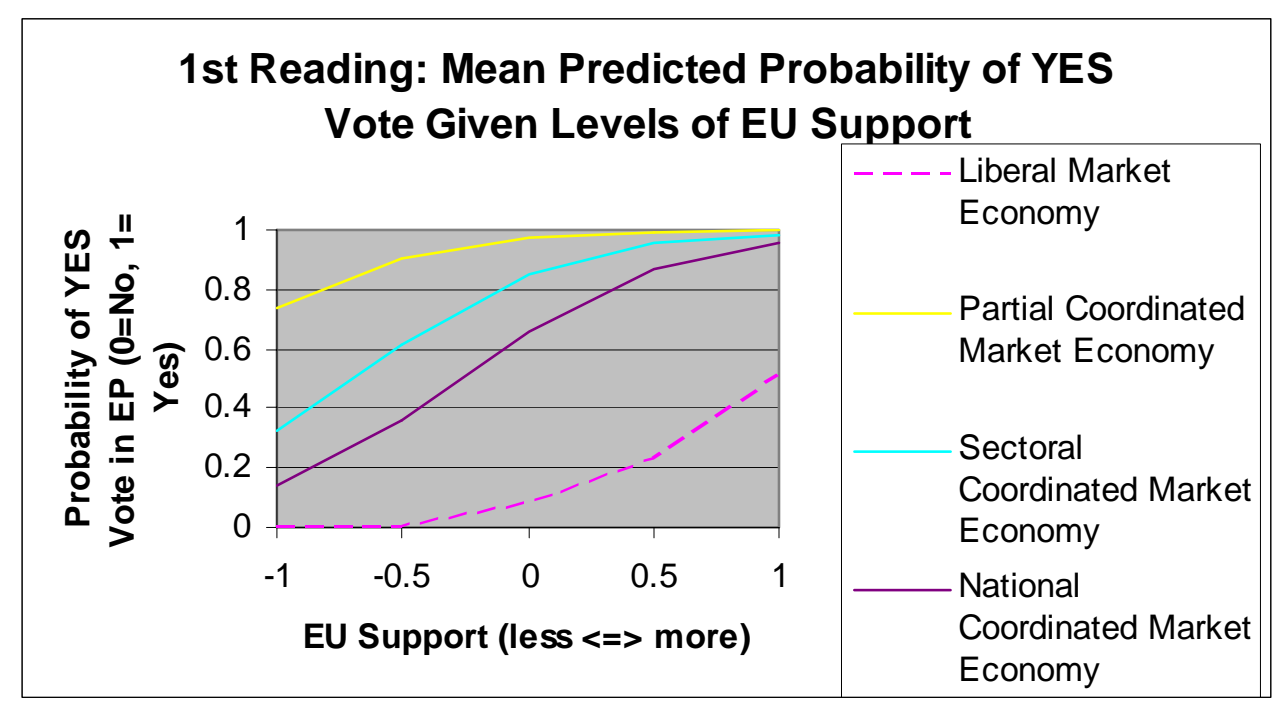

Figure 29: Probabilities 6.2. A

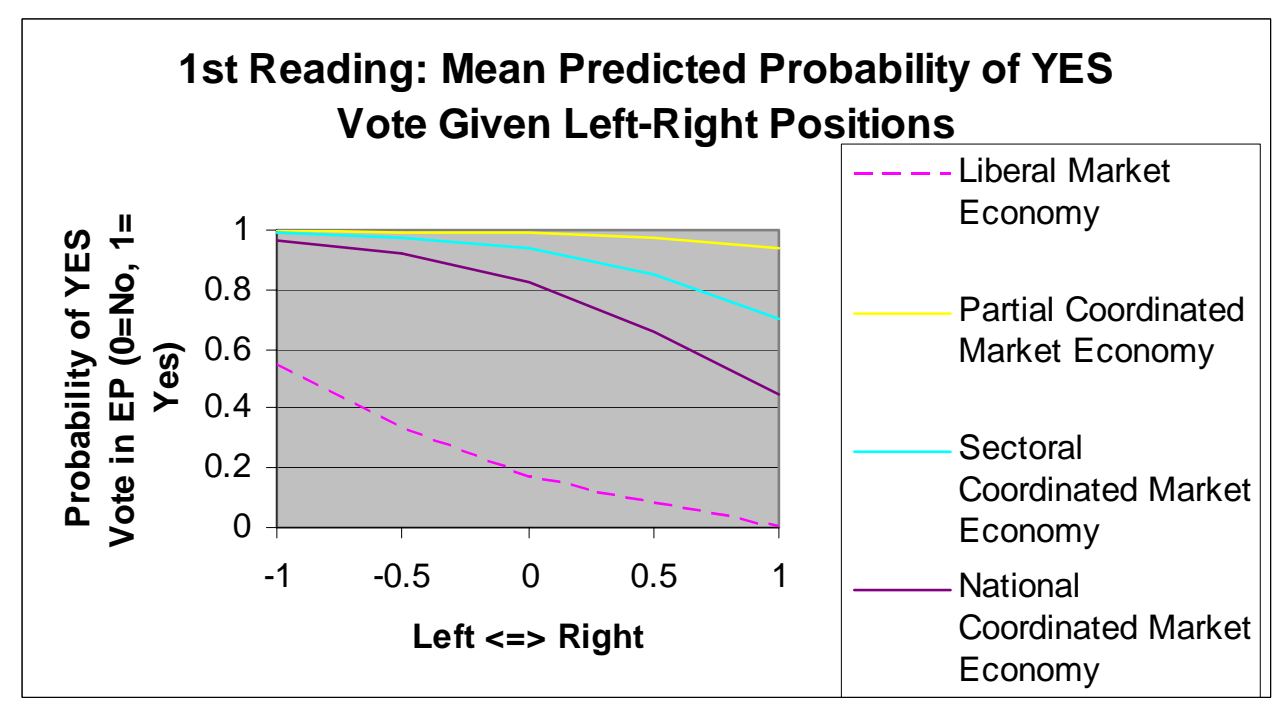

Figure 30: Probabilities 6.2. B 


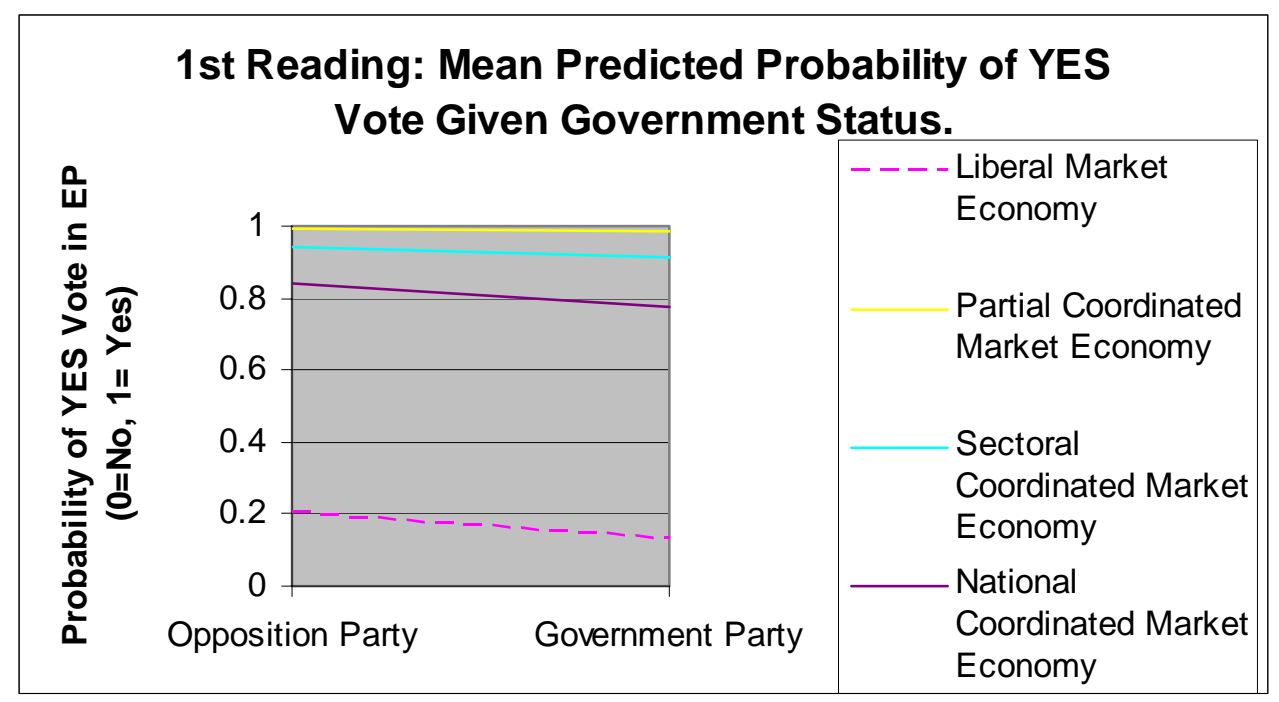

Figure 31: Probabilities 6.2. C 
Table 14: Binomial logit regression estimates, third reading vote, 6.2 .

Floor Vote, Third Reading

Left-Right Dimension

Sovereignty-Integration Dimension

Government Status

Liberal Market Economy

Partial Coordinated Market Economy

Sectoral Coordinated Market Economy

Constant

Number of cases

Log pseudo-likelihood

Pseudo ${ }^{2}$
$2.13 * * *$

(.33)

$-.76^{*}$

(.30)

$2.42 * * *$

$.36)$

.03

(.59)

$-2.38 * * *$

(.48)

$-4.77 * * *$

(.54)

$1.59 * * *$

(.44)

560

$-237.50$

0.39

*** = significant at 0.001 level; $* *=$ significant at 0.01 level; $*=$ significant at 0.05 level

Dependent Variable: Vote: $1=$ for, $0=$ against, abstain $=0$ 


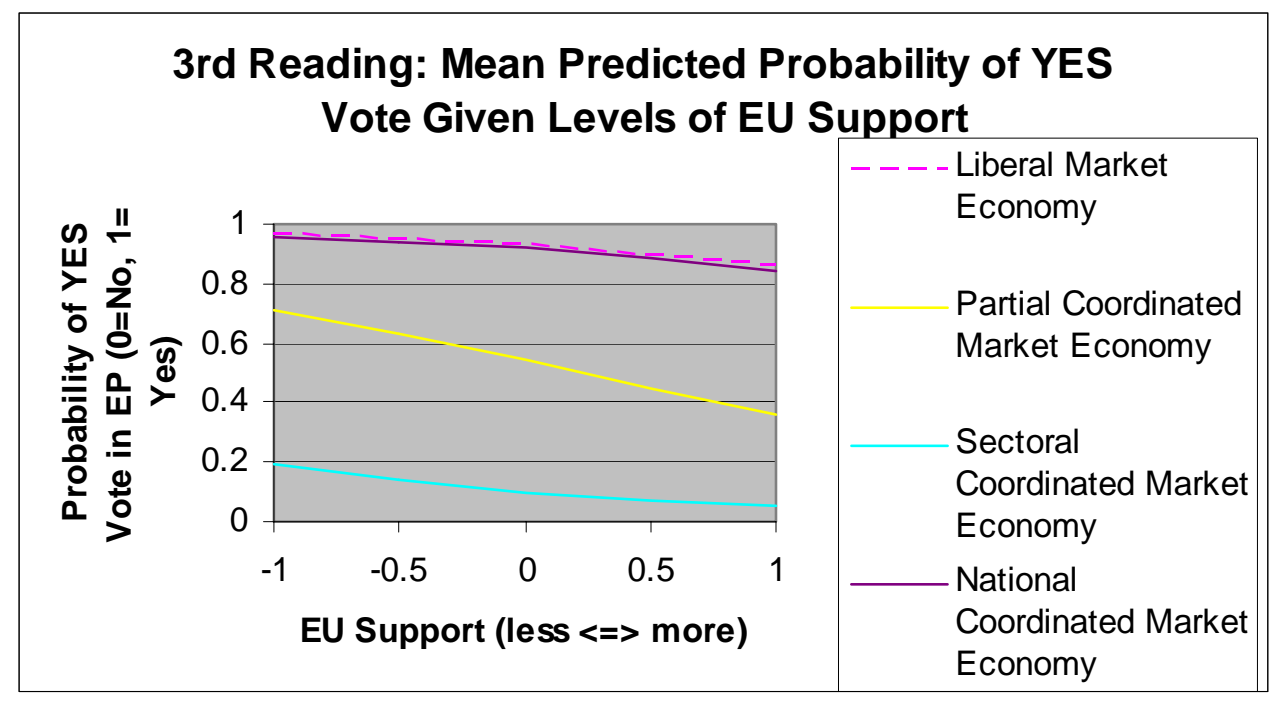

Figure 32: Probabilities 6.2. D

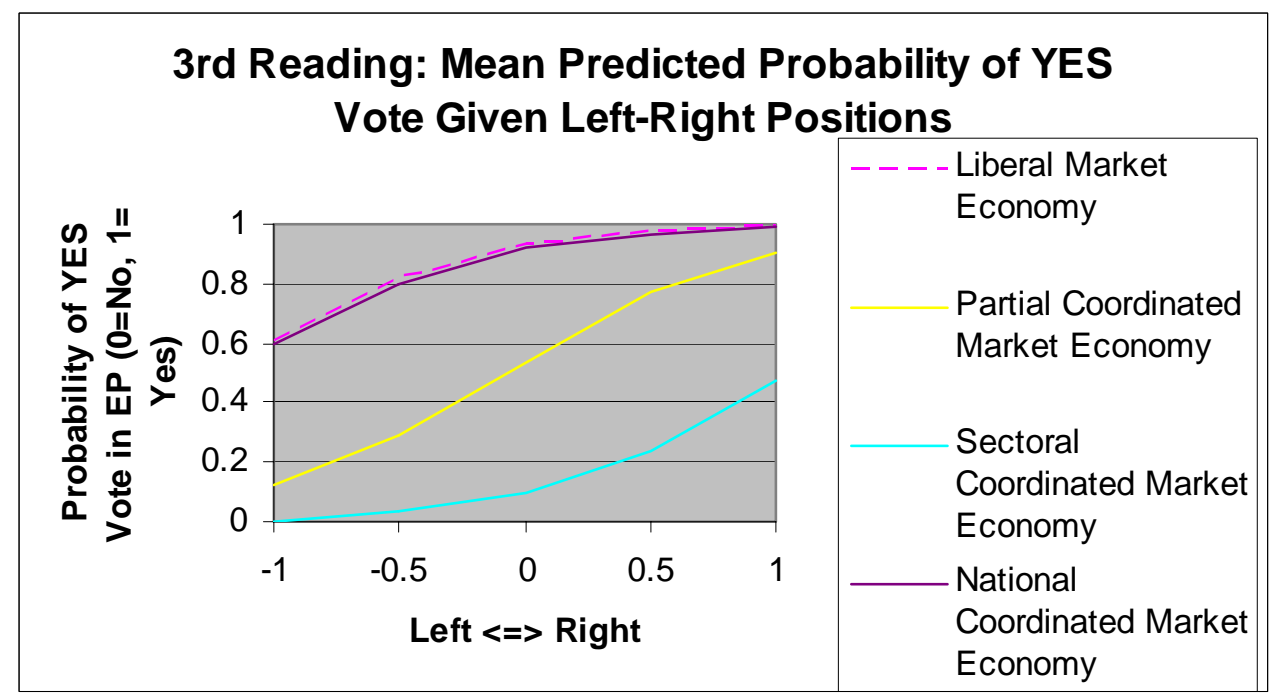

Figure 33: Probabilities 6.2. E 


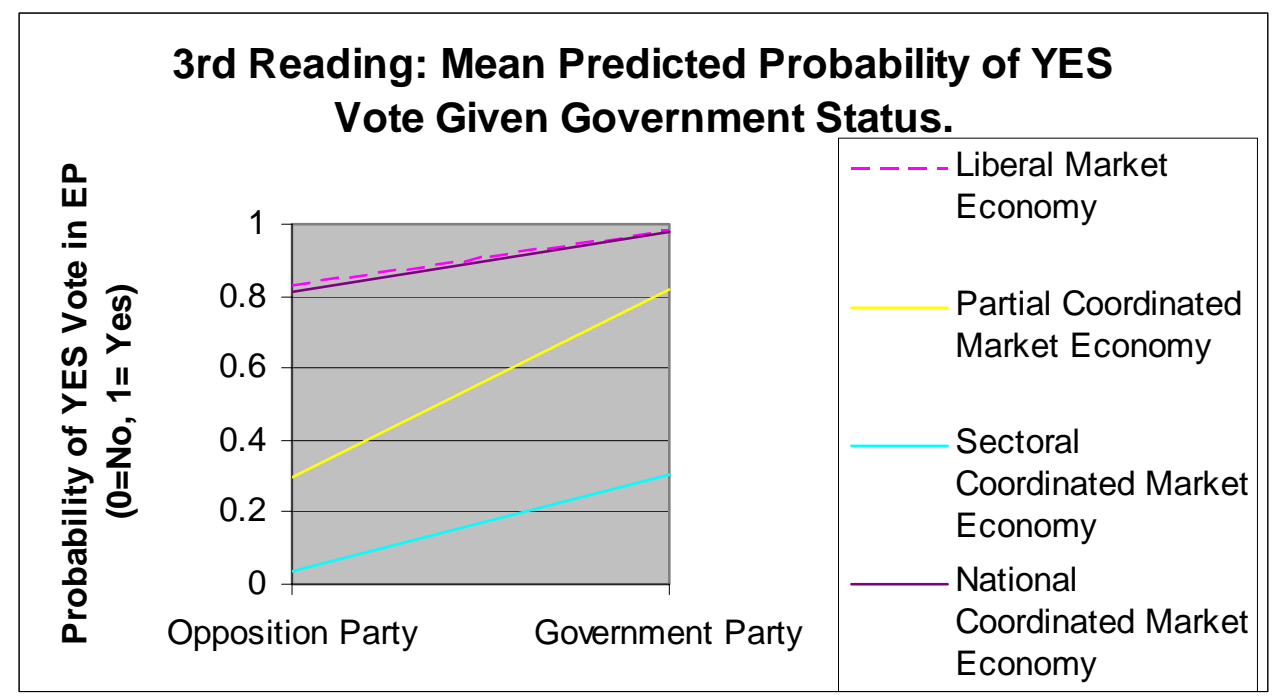

Figure 34: Probabilities 6.2. F 


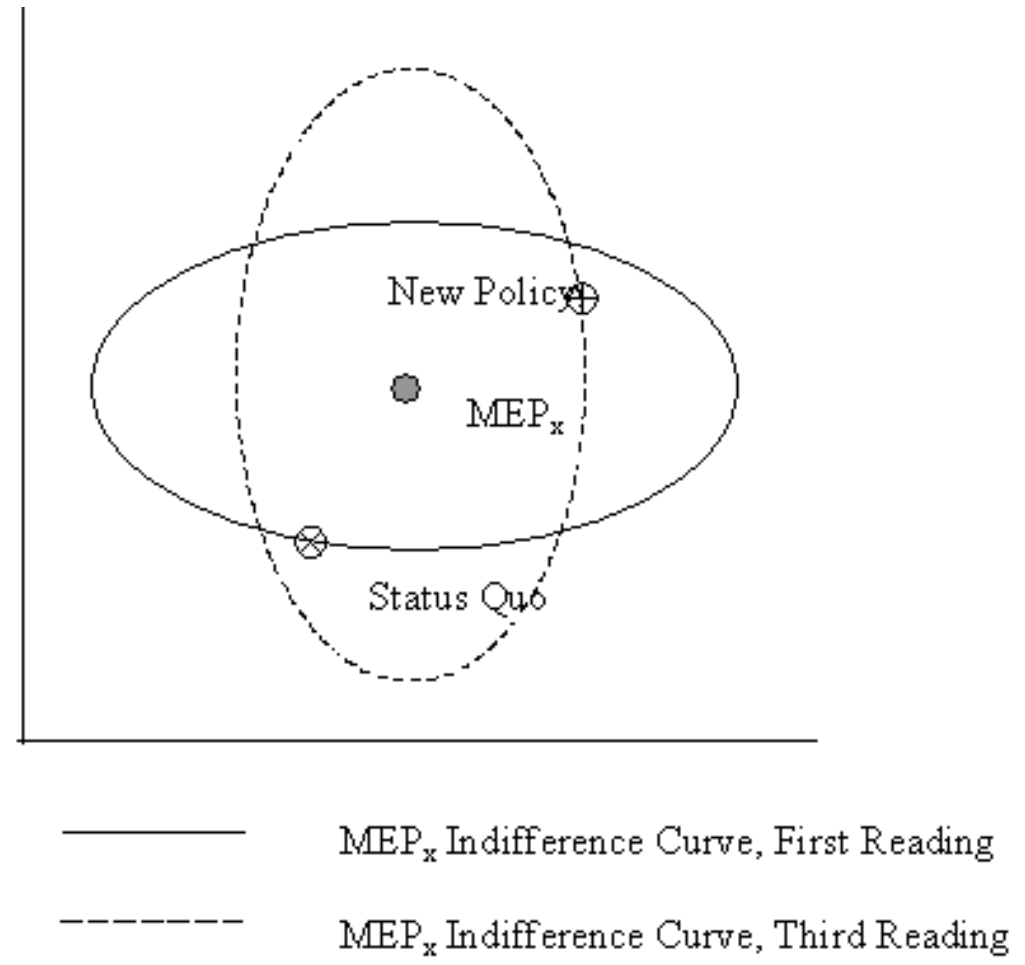

Figure 35: Policy Space 6.2. 


\section{TEXTPACK Analysis}

Focal Point 1: Single Market

community dimension; harmoniz- (and relevant endings); internal market; single market; subsidiarity; harmonization directive; framework directive; "vessel of the European Union"

\section{Focal Point 2: Workers’ Right}

consultation; inform and consult; "mergers go wrong"; employ- (and relevant endings); job- (and relevant endings); restructur- (and relevant endings); social; stakeholder; trade unions; trade unionists; works councils; unemploy- (and relevant endings); worker- (and relevant endings); workforce

\section{Focal Point 3: Level Playing-Field}

Article 9; defens- (and relevant endings); Electricité de France; EdF; hostile action; level playing field; neutral- (and relevant endings); poison pills; unfairness.

\section{Keywords-in-context}

Cat $=$ focal point category: Cat $0001=$ Single Market, Cat $0002=$ Workers' Right, Cat $0003=$ Level Playing-Field

ID1: Speaker ID

ID2: Paragraph ID

ID3: Line ID

EP Debate, first reading (June 25, 1997):

\section{Cat ID1 ID2 ID3}

$000100000500000200002 \mathrm{n}$ to opt for a framework directive .

000100000900000200001 or at least a framework directive .

000100000500000300001 proposal is a framework directive by nature .

$000100000600000200003 \mathrm{w}$, and then a framework directive containing certai 000100000300000300002 the form of a framework directive establishing gene 000100000600000200001 proposal for a framework directive on takeover bids 000100000300000500002 ive of minimal harmonization, as the Legal Affairs 
000100000500000200005 nes is through harmonization and not through volunta 000100000600000200002 osed a classic harmonization directive , but it was $000100000300000200002 \mathrm{ng}$ less than a harmonization directive .

000100000300000300006 felt that the harmonization initially suggested wen 000100000300000300002 hieve detailed harmonization of the rules in force $\mathrm{i}$ $000100000600000200004 \mathrm{~d}$, and a mild harmonization - even if the Commissio 000100000300000500003 an attempt at harmonization - even with limited obj 000100000400000400003 ot possible to harmonize everything and the example 000100000400000400004 be practically harmonized throughout almost all the 000100000900000200002 o complete the internal market . 000100000900000200004 st spur to the internal market . 000100000900000200003 as regards the internal market for the past twenty y $000100000300000800002 \mathrm{n}$ the European single market .

000100000600000200003 hen, when the single market came into force, the C 000100000500000100004 tection in the single market in the event of a takeo 000100000500000100002 e principle of subsidiarity, on the basis of the ex 000100000900000300004 this - one is subsidiarity and, paradoxically, th 000100000300000300004 e principle of subsidiarity and leave the Member Sta 000100000400000300001 e principle of subsidiarity has been used in a rathe 000100000400000200005 e principle of subsidiarity is applied to overcome $t$ 000100000900000300004 rogress of the vessel of the European Union and ther 000200000300000700005 gned to enable employee information to be improved . 000200000300000700004 mation for the employees .

000200000300000500002 olders and the employees of the companies targeted . 000200000700000400003 This gives employment but not real competitive $\mathrm{j}$ 000200000700000400002 er showing how employment has progressed . 000200001000000200002 nd workmanlike job . 000200000800000400001 alone 12,500 job losses were due to takeovers and 000200000700000400003 al competitive jobs . 000200001000000300001 ust look after jobs and so on . $000200001000000300002 \quad$ But jobs will be much more in peril unles 000200000300000800001 ean Union that social dimension which it so grievous 000200000300000800002 y, equity and social equilibrium in the European si $000200000300000600001 \mathrm{~h}$ directive on worker participation, the tenth dire 000200001000000300003 the savings of workers all over Europe .

EP Debate, second reading (December 12, 2000):

Cat ID1 ID2 ID3

000100001100000100002 ed by a useful framework directive, although, as M 000100000100000100009 pposed to be a framework directive .

000100001500000400001 objective of a framework directive on employment, $\mathrm{w}$ 000100001500000100004 not achieve a single market in capital and will und 
000100000300000200003 Within the single market investors, be they pri 000100000300000200002 The European single market is a pan-European marke 000200001500000400001 while employee consultation is the objective of a fr 000200001500000400001 ear that while employee consultation is the objectiv 000200000600000300001 he position of employees .

000200000700000100003 echnicians and employees who actually turn the wheel 000200001300000100006 om my previous employer .

$000200001500000400001 \mathrm{k}$ directive on employment, we also believe that a s 000200001200000100002 up this whole job again.

000200000700000100004 ttle about the job losses and closures caused by alm $000200000400000500002 \mathrm{~s}$ which affect jobs .

00020000030000040000211 be European jobs and European prosperity . 000200001200000200007 ow that $70 \%$ of mergers go wrong .

000200000400000500002 there is staff restructuring, redundancies and so o $000200001000000200003 \mathrm{t}$ of corporate restructuring necessary to build that 000200001200000300007 ed Kingdom the social differences are widening ever 000200001200000200001 ny hint of the social model that keeps being paraded 000200001200000200005 become a major social problem if we do not cushion $t$ 000200001000000500002 in to keep the socialists happy and he is prepared $t$ 000200000700000200002 soever for the workers, it would at least prevent $t$ 000200000700000100003 mention of the workers, technicians and employees $\mathrm{w}$ 000200000400000500003 important that workers and their representatives sho 000200000400000500001 rticipation of workers when there is a takeover bid 000200001500000400001 ded to consult workforces and their representatives 000300000100000400001 s directive is Article 9.

000300000100000500004 That is why Article 9 also needs to be amended . 000300000100000500003 end result of Article 9 as it now stands would be t 000300001000000300001 the changes in Article 9 to allow company boards the 000300000400000800002 carry out some defensive manoeuvres when it is not $p$ 000300000900000400002 en the door to defensive measures, we shall perhaps $000300001000000300001 \mathrm{~s}$ the right to defensive measures to frustrate takeo $000300001500000200001 \mathrm{~s}$ the right to defensive measures to frustrate takeo 000300001000000200004 be blocked by hostile action or poison pills . 000300000100000400002 be to create a level playing field in Europe . 000300000100000500001 at there is no level playing field in Europe either 000300000100000400003 we not have a level playing field with North Americ 000300000900000400001 nd the duty of neutrality, there will be no point $t$ 000300000400000800001 to the duty of neutrality . 000300000100000400007 obligation of neutrality in Europe . 000300000900000200002 mplete duty of neutrality recommended by the Council 000300001000000200004 tile action or poison pills . 
EP Debate, third reading (July 3, 2001)):

\section{Cat ID1 ID2 ID3}

000100003100000200003 ad day for the internal market, and a bad day for E 000100001000000100003 talk about the internal market, but also about the 000100001100000100002 ing within the internal market .

000100000400000200003 eration of the internal market may be impeded . 000100003700000100004 tortion of the internal market principles .

$000100003000000100003 \mathrm{f}$ the European single market .

000100000800000200006 mponent of the single market and is in the interests 000100000800000200005 rds creating a single market in corporate ownership 000200001000000200002 ore, but also consultation .

000200002800000300002 nformation and consultation .

000200003600000100004 sion of worker consultation and indeed, in some Mem 000200001000000200001 nformation and consultation are also currently under 000200001000000400003 say and better consultation as a matter of principle 000200001000000400005 regulated this consultation aspect properly from the 000200002800000200001 o real genuine consultation of the workforce .

000200003600000100005 vote for fewer consultation rights than we wish to s 000200002800000300006 nformation and consultation with rights for workers 000200000200000300004 the Council on employee rights to information .

000200000600000300006 nions or other employees ' representatives will have $000200003300000200004 \mathrm{o}$ those of the employees, that the new proposal cre 000200000500000400005 often also be employees .

000200001000000100005 anisations and employees . 000200003400000200001 e interests of employees .

$000200003800000100004 \mathrm{e}$ interests of employees and consumers .

$000200003400000200002 \mathrm{~s}$ and needs of employees and consumers in conjunctio 000200001300000200002 information to employees at three points in the dire 000200001300000200001 e interests of employees in a takeover bid . 000200002800000100003 e interests of employees in a takeover bid . 000200000600000300007 he view of the employees is . 000200000600000300002 unionists and employees of companies throughout Eur 000200003800000100007 nsequences for employment, social cohesion in an ar 000200003700000100003 view to future employment .

000200002800000300003 mmunautaire of employment rights in the EU, or in $\mathrm{t}$ 000200001300000200004 obligations to inform and consult under either natio 000200001300000100002 resident, the job Parliament has here today is quit $000200000500000100003 \mathrm{~d}$ a marvellous job in very difficult circumstances . $000200000600000300005 \mathrm{~s}$ in regard to jobs and the location of work . $000200003800000100007 \mathrm{r}$ employment, social cohesion in an area around the $000200001000000100003 \mathrm{t}$ the European social model, as opposed to the Angl 000200000300000300001 tions of their social organs .

000200001100000200002 dvice from the social partners in the Netherlands kn 000200001000000100004 ssioners about socially responsible entrepreneurship 
000200001000000300004 s councils and trade unions, when I encountered dif $000200002700000100005 \mathrm{nts}$, that the trade unions and economic organisatio $000200000600000300006 \quad$ The trade unions or other employees ' rep 000200000400000200003 ing workers to unemployment, is much greater than $\mathrm{t}$ 000200003600000100004 e extension of worker consultation and indeed, in s 000200003700000100003 the benefit of workers, and openness must be offere 000200002800000300006 ith rights for workers, even though mergers and tak 000200000700000100002 an companies, workers and savers urgently need a Eu 000200000900000300003 Parliament on workers and their representatives bei 000200000400000300005 The workers are invited to the table but 000200000400000300004 irective, the workers are the unwanted guests . 000200003600000100005 rights of some workers at the expense of others, no 000200000400000300007 rovided by the workers is just seen as another docum 000200003500000200001 information of workers mandatory, the situation sti 000200000400000200003 ely condemning workers to unemployment, is much gre 000200003500000200001 all aspects of workers' and minority shareholders' a $000200000900000300001 \mathrm{t}$ two issues : workers' participation and the obliga 000200002800000200001 ltation of the workforce .

000200003600000100003 de to give the workforce greater access to informati 000200002800000200002 rmation to the workforce in the process of a takeove 000200001000000300004 as advisor to works councils and trade unions, whe 000300001300000200002 le 6 ( 2 ) and Article 9 (1d).

000300001300000300001 no secret that Article 9, and the right of boards $\mathrm{t}$ 000300001300000400005 ieve a deal on Article 9 : we forced the Commission $000300000200000400003 \quad$ However, Article 9 and Amendments Nos 20 and 1 $000300001300000400003 \quad$ Article 9 and restrictions on frustra $000300001300000400006 \mathrm{y}$ of reviewing Article 9 in the light of the finding 000300000300000100004 ically changed Article 9 of the common position, en $000300001100000400002 \quad$ Article 9 only prohibits the legal pr 000300001300000400007 ompliance with Article 9 until 2006 . 000300000700000100005 he directive - Article 9 - is a step in the right di 000300000700000200002 subsidiary of Electricité de France to take control 000300001300000300001 boards to take defensive action without shareholder 000300000900000400001 ainst allowing defensive manoeuvres, far from deser 000300000900000400001 ow any type of defensive manoeuvring as was suggeste 000300000800000100003 e able to take defensive measures, but when managem $000300000200000300002 \mathrm{f}$ contention : defensive measures, squeeze-out and $000300000300000100005 \quad$ The defensive measures could have been su 000300000300000200003 ned to discuss defensive measures to the introductio 000300000300000100004 board to take defensive measures without consulting 000300003900000200001 , while other defensive techniques or instruments a 000300000100000300002 do not have a level playing field, if national leg 000300000300000200003 ting a sort of level playing field, that is common 000300000200000300002 olders and the level playing field . 000300000600000200001 e absence of a level playing field . 000300000600000200003 nywhere near a level playing field. 
000300000600000200002 ve closer to a level playing field by throwing out $t$ 000300000300000300001 is to create a level playing field does exist : the 000300001100000500006 deed provide a level playing field in Europe and cou 000300000100000100005 ed to create a level playing field in Europe as rega 000300000100000300002 know where the level playing field is .

000300000100000100009 rective on the level playing field to come into forc 000300003100000100006 ired to remain neutral, as the interests of owners 000300001300000300002 iged to remain neutral or passive .

000300000900000300001 obligation to neutrality imposed on boards of manag 000300000100000400011 troduce strict neutrality which would ultimately lea 000300000600000200001 es, about the unfairness of the absence of a level 
Table 15: Multinomial logit regression estimates, first reading vote, 6.2.

\begin{tabular}{lcc}
\hline & No Vote & Yes Vote \\
\hline Left-Right Dimension & $3.74^{* * *}$ & -.23 \\
& $(1.03)$ & $(.59)$ \\
Sovereignty-Integration Dimension & $-3.53^{* *}$ & .81 \\
& $(1.19)$ & $(.82)$ \\
Government Status & .62 & -.21 \\
Liberal Market Economy & $(.82)$ & $(.53)$ \\
& .51 & $-2.45^{* *}$ \\
Partial Coordinated Market Economy & $.91)$ & $(.90)$ \\
Sectoral Coordinated Market Economy & -2.72 & $2.05^{*}$ \\
& $(1.46)$ & $(.92)$ \\
Constant & .10 & 1.50 \\
& $(1.14)$ & $(.91)$ \\
Number of cases & .10 & $1.96^{* *}$ \\
Log pseudo-likelihood & $(.85)$ & $(.75)$ \\
Pseudo R & 359 & \\
\end{tabular}

Note: Table entries are multinomial logit estimates. The omitted (baseline) choice for each column is "Abstention." Robust standard errors appear in parentheses. Statistical significance is indicated as follows: $* * *<0.001$ level; $* *<0.01 ; *<0.05$ 


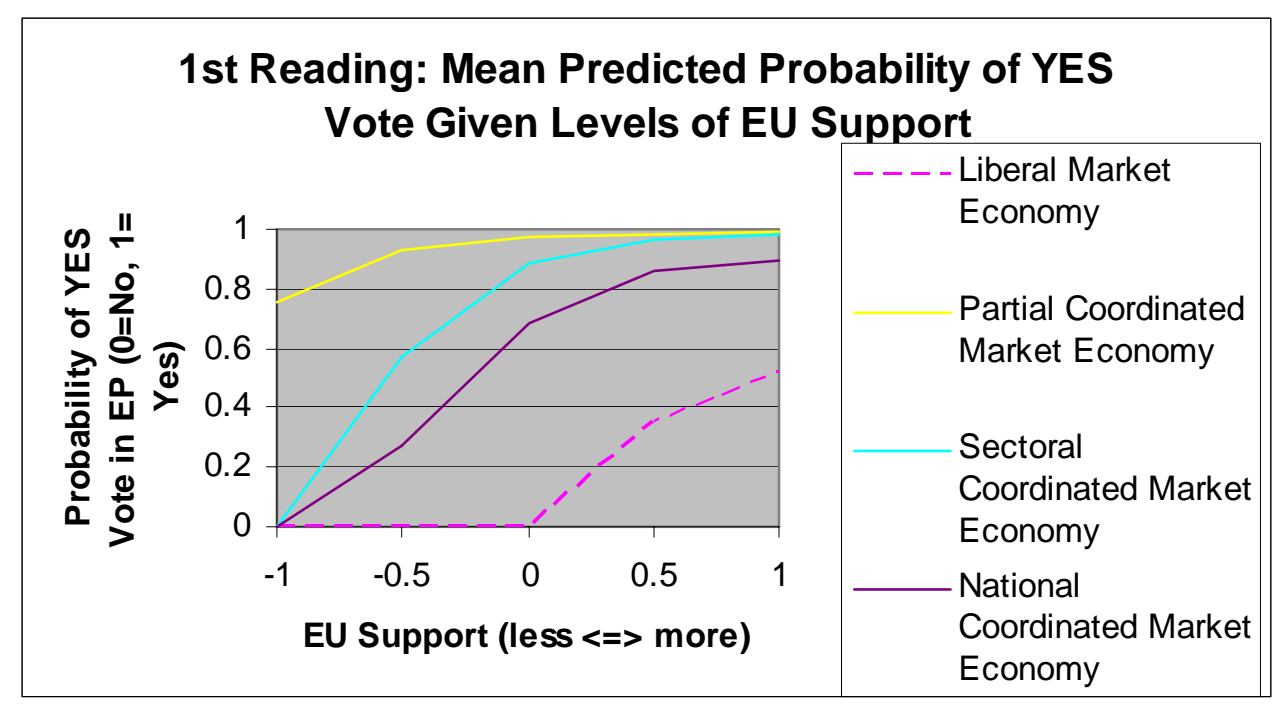

Figure 36: Probabilities 6.2. G

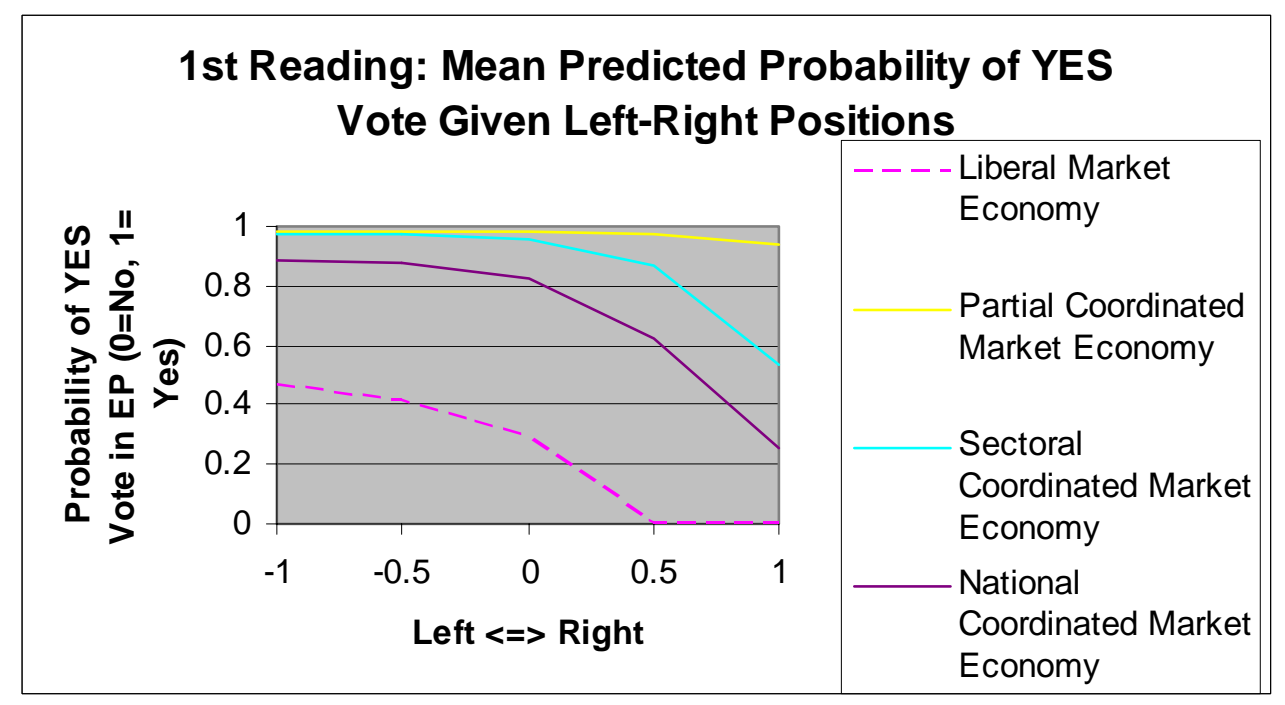

Figure 37: Probabilities 6.2. H 


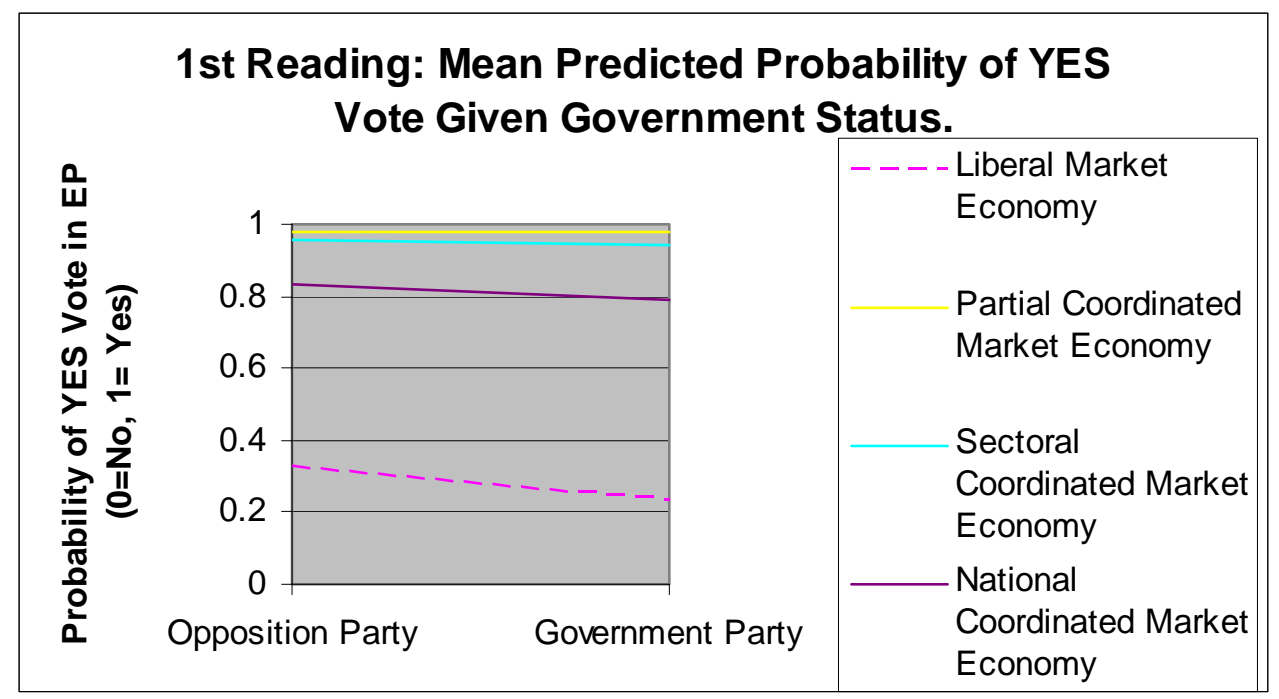

Figure 38: Probabilities 6.2. I 


\section{APPENDIX E}

\section{CHAPTER 6.3.}

Table 16: Frequencies-of-use, content analysis 6.3.

\begin{tabular}{|c|c|c|c|c|}
\hline & $\begin{array}{c}\text { \# of input } \\
\text { words }\end{array}$ & $\begin{array}{c}\text { \# of references to } \\
\text { EU Democracy. }\end{array}$ & $\begin{array}{c}\text { \# of references to } \\
\text { artificial } \\
\text { constructs. }\end{array}$ & $\begin{array}{c}\text { \# references to } \\
\text { legal } \\
\text { personality. }\end{array}$ \\
\hline $\begin{array}{c}\text { Debate } \\
\text { First }\end{array}$ & $\begin{array}{c}9,916 \\
(10,000)\end{array}$ & $\begin{array}{c}69 \\
(70)\end{array}$ & $\begin{array}{c}31 \\
(31)\end{array}$ & $\begin{array}{c}(4) \\
\text { Reading }\end{array}$ \\
23 speakers & 20 speakers & 14 speakers & 2 speakers \\
\hline
\end{tabular}


Table 17: Binomial logit regression estimates, first reading vote, 6.3 .

Floor Vote, First Reading

Left-Right Dimension

$-.08$

$(26$

Sovereignty-Integration Dimension

$5.30 * * *$

(63)

Government Status

National Ceiling on Party Donations

Constant

Number of cases

Log pseudo-likelihood

Pseudo $\mathrm{R}^{2}$

$* * *=$ significant at 0.001 level; $* *=$ significant at 0.01 level; $*=$ significant at 0.05 level Dependent Variable: Vote: $1=$ for, $0=$ against, abstain $=0$

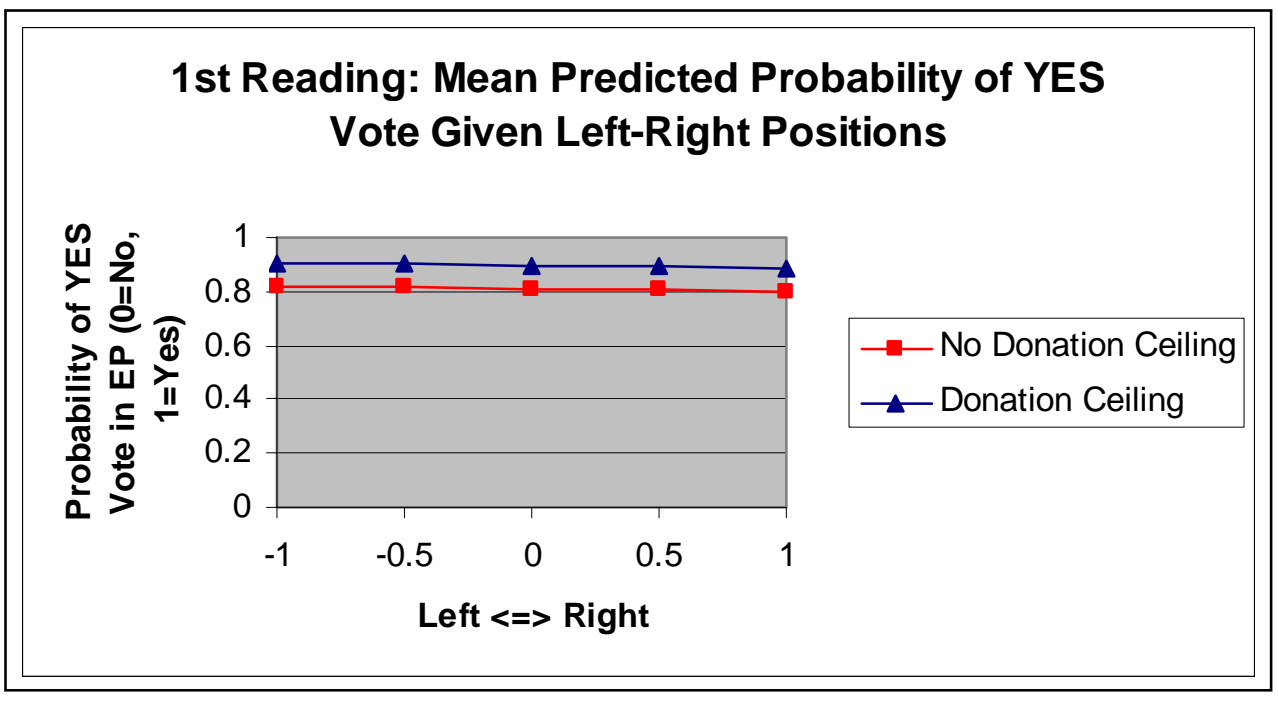

Figure 39: Probabilities 6.3. A 


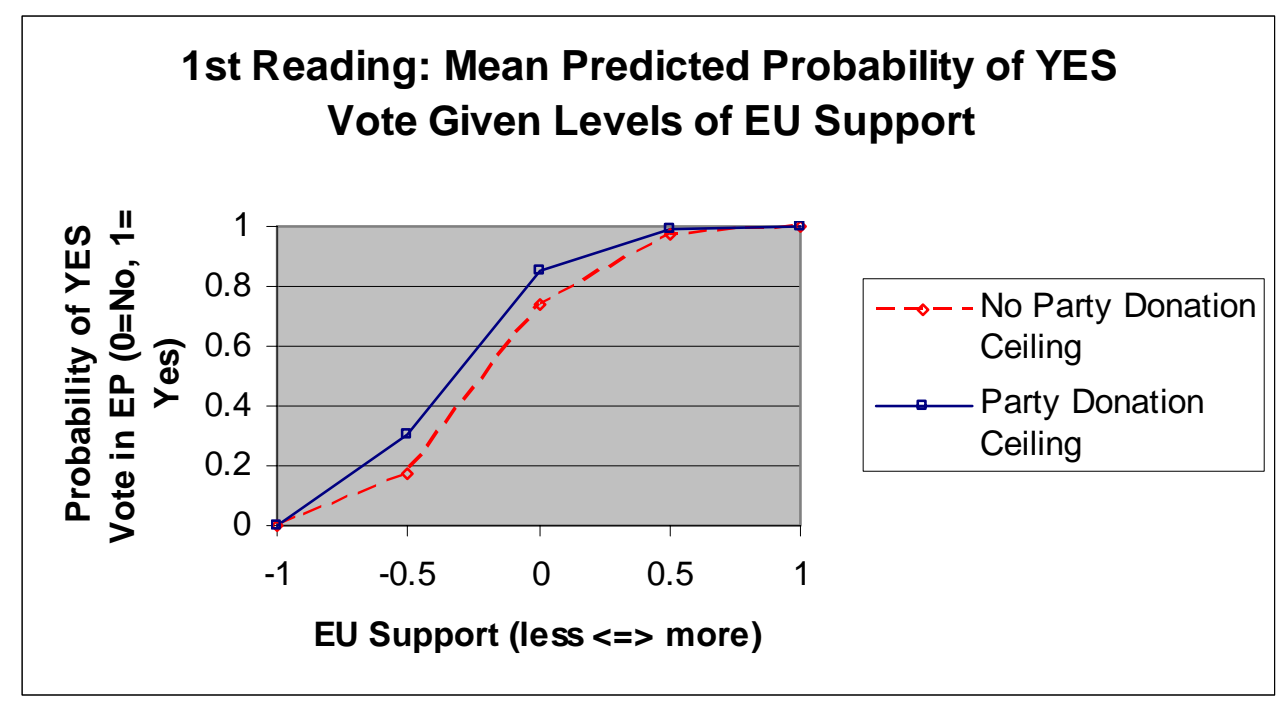

Figure 40: Probabilities 6.3. B

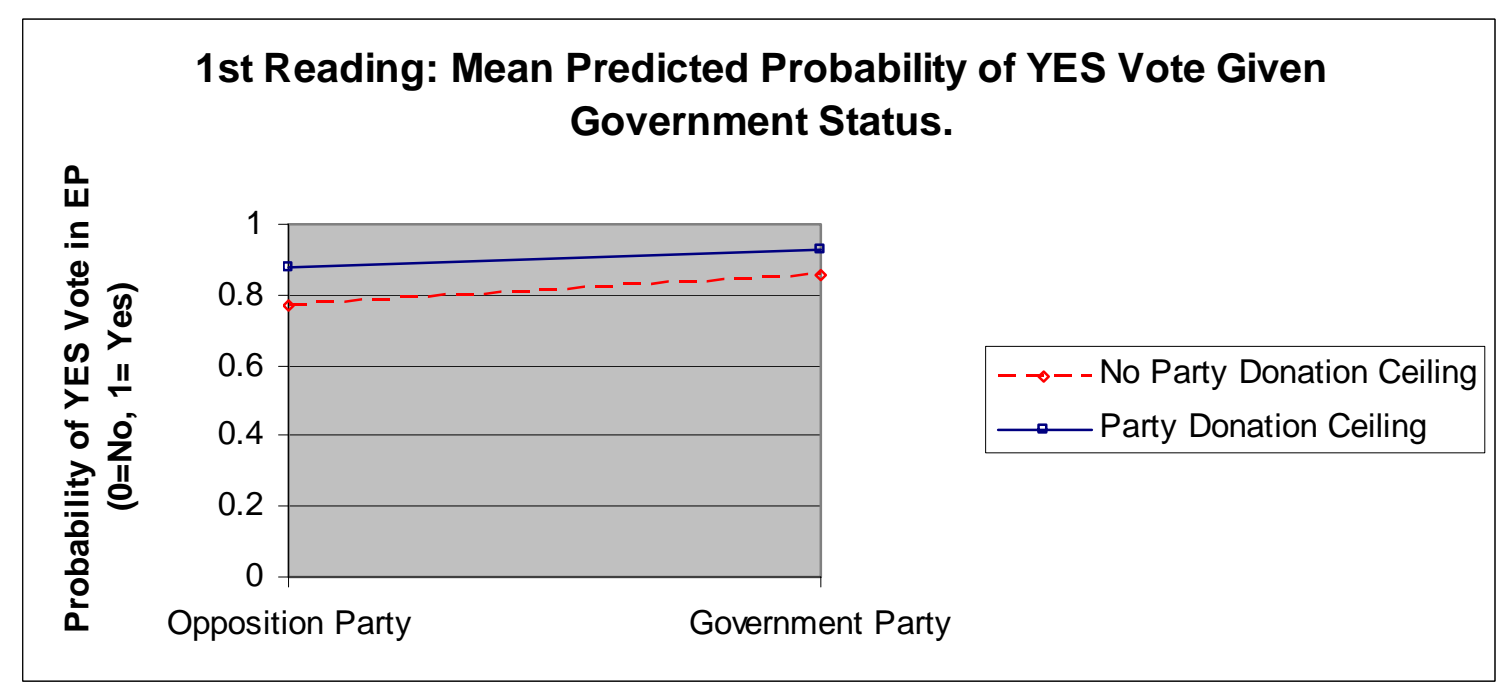

Figure 41: Probabilities 6.3. C 


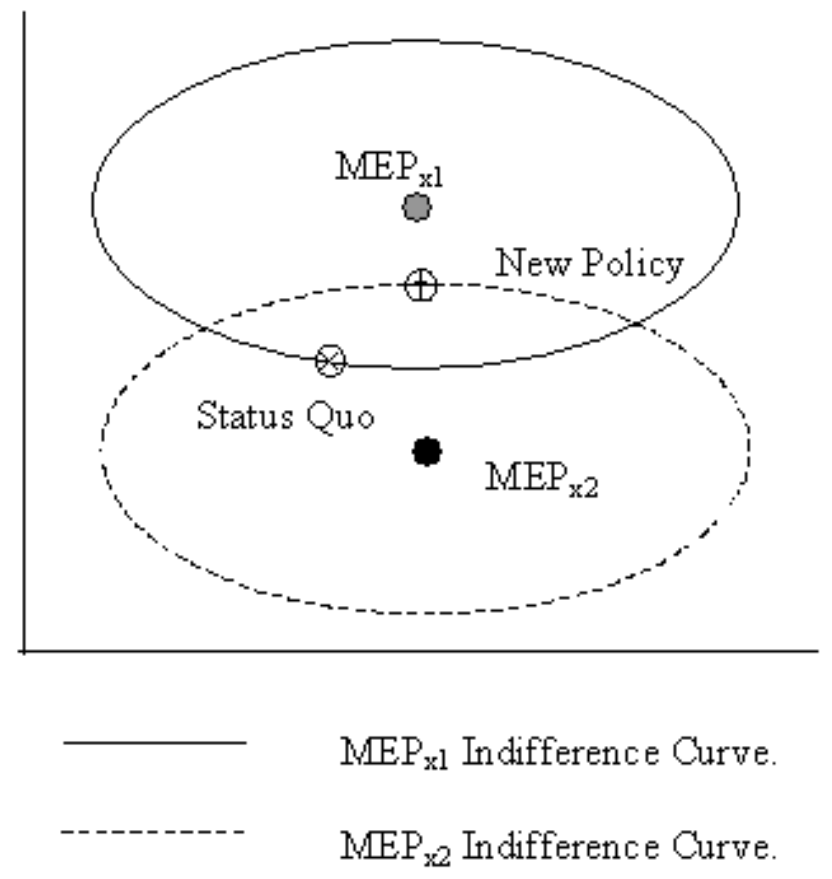

Figure 42: Policy Space 6.3. 


\section{TEXTPACK Analysis}

\section{Focal Point 1: EU Democracy}

accountability, clarity, constitutionalisation, integration, legitimacy, unification, democr(and relevant endings), transparen- (and relevant endings), European ideal, European objectives.

\section{Focal Point 2: EU Parties as Artificial Constructs}

artificial, banquets, beanfeasts, corruption, opaque, secret, totalitarian, discriminat- (and relevant endings), tax- (and relevant endings), pile of cash, so-called European political parties, Warsaw Pact.

Alternative (hypothetical) issue presentation: Legal Personality. actual European statute, legal personality, legal persons

\section{Keywords-in-context}

Cat $=$ focal point category: Cat $0001=\mathrm{EU}$ democracy, Cat $0002=$ artificial constructs, Cat $0003=$ legal personality

ID1: Speaker ID

ID2: Paragraph ID

ID3: Line ID

EP Debate, first reading (June 18, 2003):

Cat ID1 ID2 ID3

$000100001600000200012 \mathrm{e} \mathrm{light} \mathrm{of} \mathrm{the} \mathrm{European} \mathrm{ideal} \mathrm{it} \mathrm{is} \mathrm{not} \mathrm{very} \mathrm{fair,}$ 000100000500000200005 al and serious European objectives . 000100000500000300003 ansparency and accountability . 000100001800000200002 upport for the clarity and even-handedness with whic 000100001000000300004 , openness and clarity in political work and in the 000100001100000200003 plement to the constitutionalisation of the Treaties $000100000500000300002 \quad$ The constitutionalisation process in whic 000100002000000100002 , there is no democracy, and to that I have to add 000100000500000300001 vital sinew of democracy, articulating the anxietie 
000100001500000300003 es not promote democracy, it reduces it . $000100001500000100002 \mathrm{n}$ contemporary democracy, the role played by them $\mathrm{i}$ 000100001400000300004 I know that democracy, which serves the public s 000100000100000100002 be no European democracy . 000100000100000700006 o for European democracy . 000100001700000300001 cy of national democracy . $000100001600000100013 \quad$ Is that democracy? 000100001900000200003 ce of European democracy and a European public gives 000100001700000400003 nition dilutes democracy and infantilises the voter 000100001700000300002 that a working democracy at European Union level is 000100000900000100003 an artificial democracy from scratch. 000100000500000200007 parliamentary democracy in Europe . 000100000900000100003 aging a living democracy instead of creating an arti 000100001000000100005 parliamentary democracy is characterised by politic 000100001900000200001 hat a European democracy or a European public can be 000100001800000300001 which European democracy rests .

000100001700000300003 In a pure democracy there should be as few rest 000100002000000100002 at there is no democracy without gender equality . 000100001400000200003 me, as a mere democrat, that when an elected repre 000100001000000100004 efficient and democratic, and to bring it closer $\mathrm{t}$ 000100001000000300005 ean level more democratic .

000100001700000300002 sals are truly democratic.

000100001700000400007 than with the democratic Europe to which we are not 000100001600000100011 as presented a democratic argument in favour of this $000100001100000200001 \quad$ The democratic benefits of giving Europea 000100001100000100005 strengthen the democratic character of the European 000100001200000200001 laced over the democratic element in this proposal . 000100001000000400004 equirement for democratic legitimacy, both of which 000100001000000400005 hich it enjoys democratic legitimacy and has partner 000100001900000200001 ite wrong in a democratic perspective .

000100001000000200006 nd loophole in democratic politics .

$000100001000000400006 \mathrm{ng}$ loophole in democratic politics and thereby to en 000100001000000300001 is loophole in democratic politics closed.

$000100000300000500001 \quad$ In every democratic state the world over, thi 000100002200000100002 he thought the democratic system was not great, but 000100001700000500005 peans, honest democrats and sincere lovers of freed 000100000600000100004 nced that, as integration continues to progress, $t$ 000100001000000400004 for democratic legitimacy, both of which must be pr 000100001000000400005 oys democratic legitimacy and has partners . 000100001100000200002 epening of the legitimacy of the European institutio 000100001400000300002 evade all the transparencies . 000100000400000200001 an exercise in transparency, no more, no less . 000100001000000300004 eating greater transparency, openness and clarity i $000100000200000300001 \mathrm{~s}$ of financial transparency .

000100001000000400006 ensure greater transparency and 000100000500000300003 principles of transparency and accountability . 
$000100001100000200007 \mathrm{ng}$, it brings transparency and protection of the pa 000100000100000500005 provided that transparency exists and controls are 000100000100000100003 one of greater transparency in European politics can 000100001400000200005 not sure that transparency in corruption is a great 000100001800000300004 parties, with transparency of financing as its prin 000100000600000300002 safeguard the transparency of party finances, whic 000100001000000100004 ke Europe more transparent, efficient and democrati 000100001300000100005 hat the aid is transparent .

000100001400000200004 but it will be transparent .

000100000400000300003 that a clear, transparent and limited system where 000100000100000500003 to be made as transparent as possible .

000100000400000200002 on a clear and transparent footing the method by whi 000100001200000100002 mple, clear, transparent ground rules for the poli 000100001200000200003 avour of clear transparent rules, but I am not in $\mathrm{f}$ 000200002300000100004 s particularly artificial .

000200000900000100003 of creating an artificial democracy from scratch . 000200001200000100007 I see it, an artificial need .

000200000800000100002 al parties are artificial products that are in no po 000200001700000100003 synthesise an artificial sense of European identity 000200001300000100003 all manner of banquets held by European political p 000200001300000200006 od junkets and beanfeasts around Europe at the taxpa 000200001400000200003 that is called corruption .

000200001400000200005 ransparency in corruption is a great step forward . 000200002100000300001 proposed rules discriminate against political partie 000200000700000300002 ts is actively discriminated against by a criterion $000200001700000200002 \quad$ It discriminates overtly against some pa $000200002000000200005 \mathrm{~d}$ refrain from discrimination, if we ourselves are 000200001700000200001 e of political discrimination .

000200001000000400005 not amount to discrimination against small groups, 000200001500000200002 prohibits 'any discrimination based on any grounds s 000200001300000200002 are closed and opaque affairs .

$000200001600000200005 \mathrm{~g}$ to receive a pile of cash for what are really meet 000200001600000100005 and in secret.

000200001600000200005 not join these so-called European political parties 000200002200000200002 to have their tax money used to ensure that the pol 000200001700000100003 money through taxation in order to synthesise an ar 000200001700000100004 arn that their taxes were subsidising European polit 000200001200000100009 the individual taxpayer, it exists solely on paper 000200001300000100003 hen, that the taxpayer will have to finance and pay 000200002300000100003 from European taxpayers are deployed to accelerate 000200001300000200006 Europe at the taxpayers' expense .

000200001200000100003 to the use of taxpayers' money for political partie 000200001200000200002 tely must give taxpayers' money to European parties 000200000800000200003 e proposal has totalitarian features .

$000200001700000400007 \mathrm{~g}$ with the old Warsaw Pact than with the democratic 000300000100000600002 the form of an actual European statute, perhaps yet 
000300000100000600002 onfer European legal personality, but the financing $000300001800000200003 \mathrm{f}$ the parties' legal personality, clarification of $000300001800000200001 \mathrm{cal}$ parties as legal persons has not yet been confir 
Table 18: Multinomial logit regression estimates, first reading vote, 6.3 .

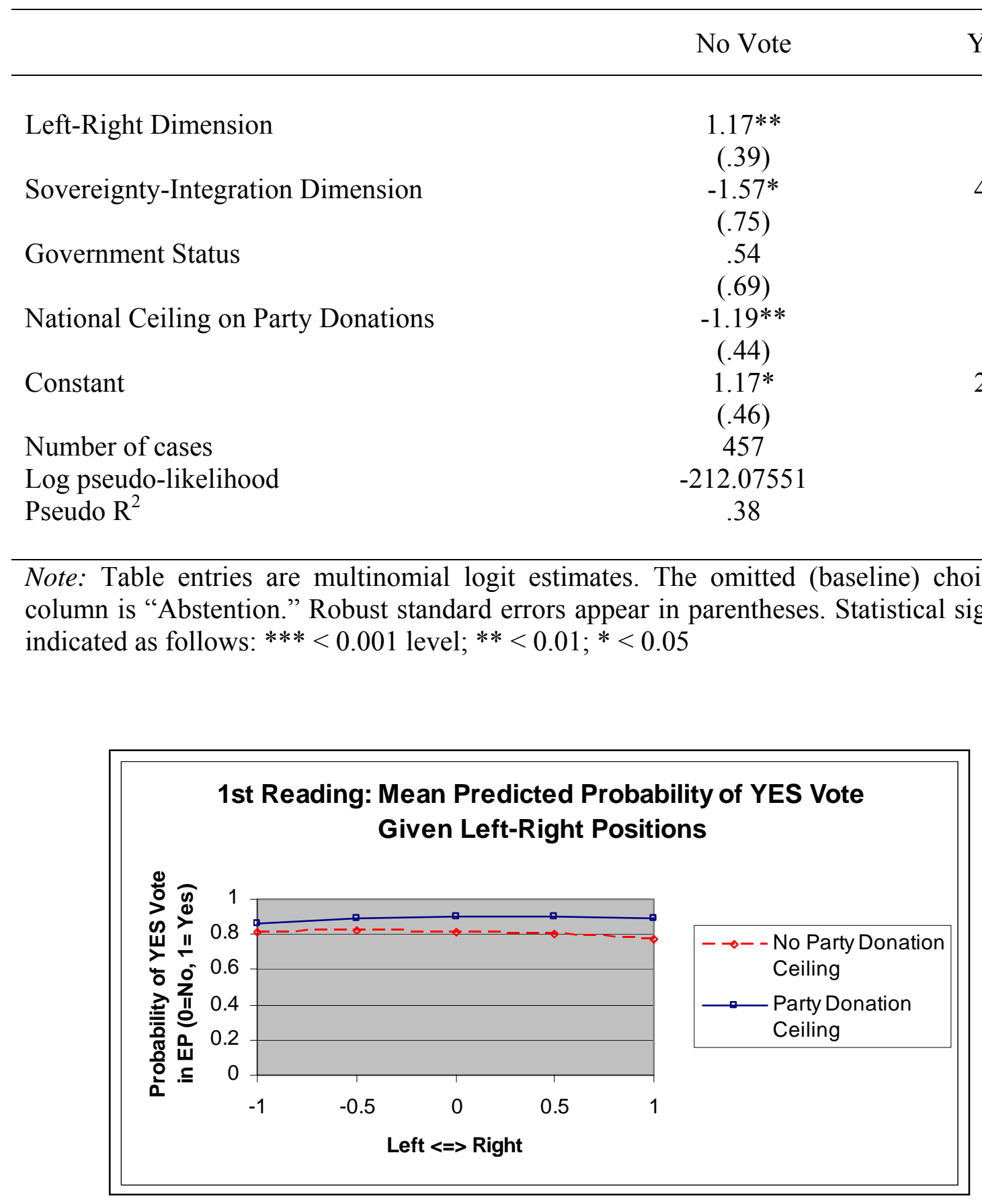

Figure 43: Probabilities 6.3. D 


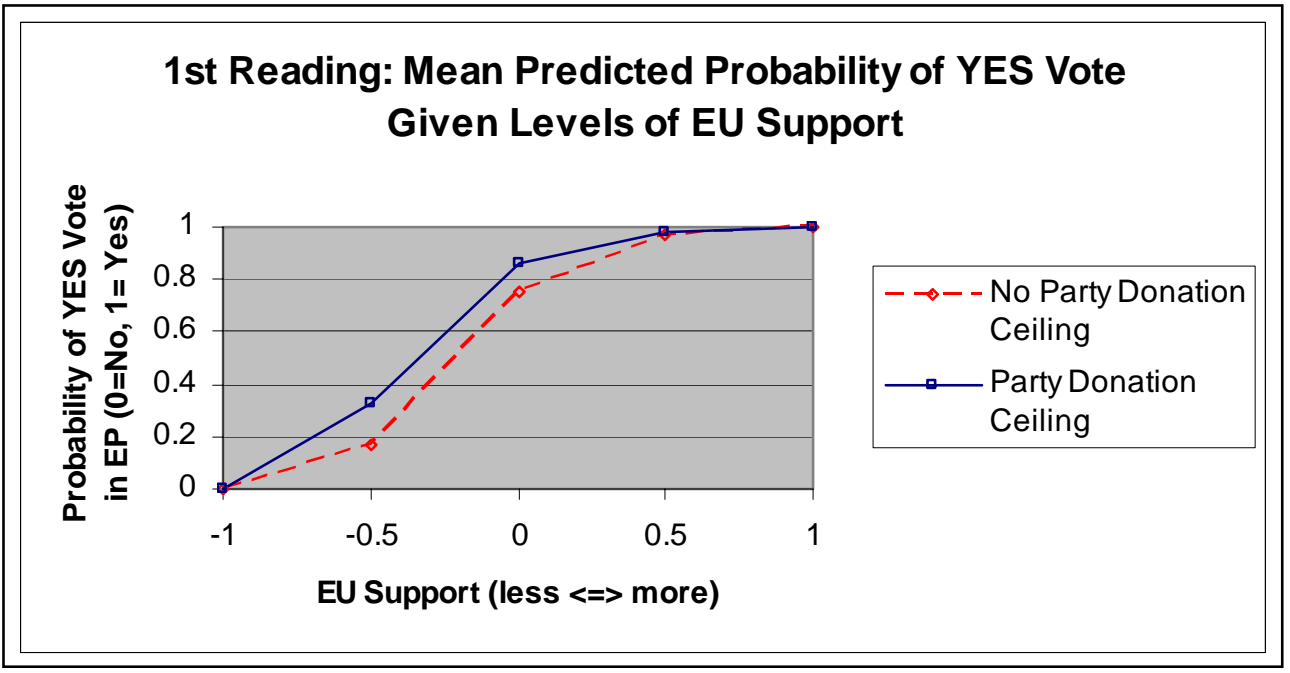

Figure 44: Probabilities 6.3. E

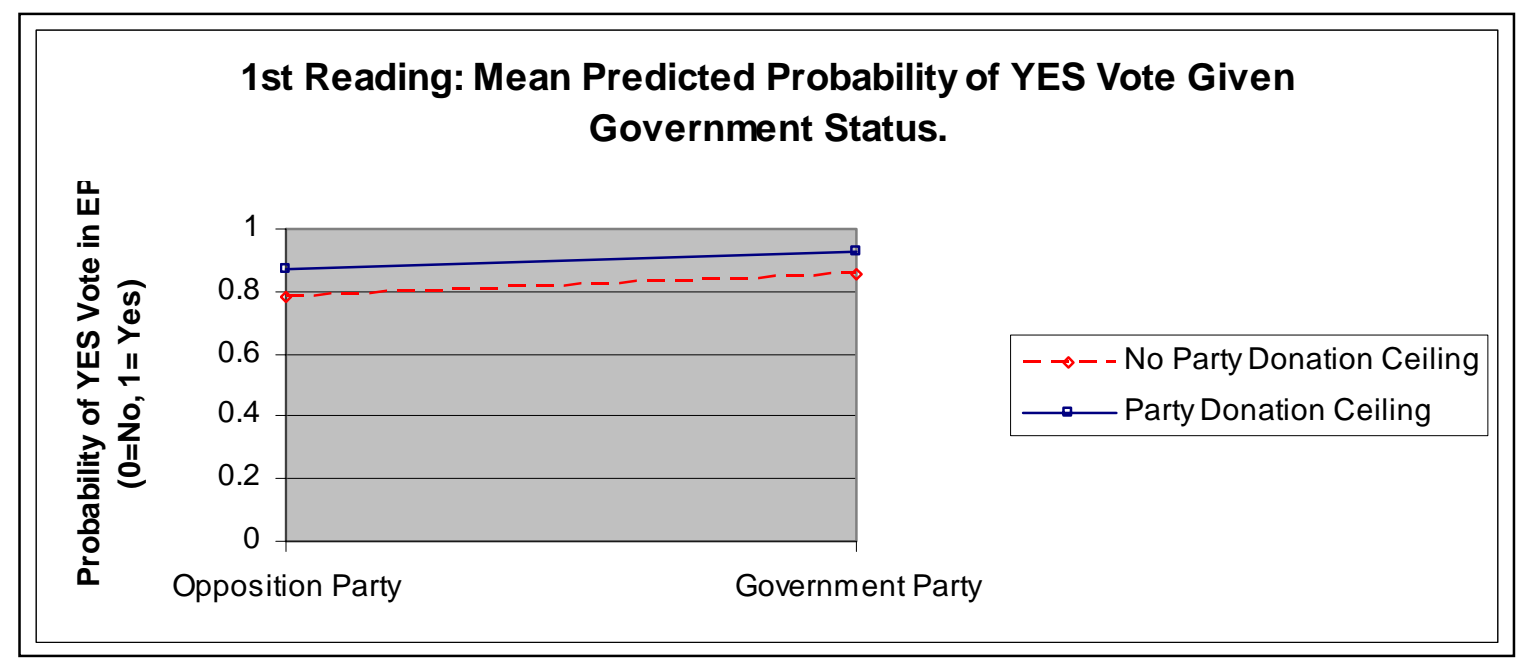

Figure 45: Probabilities 6.3. F 


\section{APPENDIX F}

\section{CHAPTER 6.4.}

Table 19: Frequencies-of-use, content analysis, 6.4.

\begin{tabular}{|c|c|c|c|}
\hline & \# of input words & $\begin{array}{c}\text { \# of references to } \\
\text { consumer protection. }\end{array}$ & $\begin{array}{c}\text { \# of references to } \\
\text { industry interest. }\end{array}$ \\
\hline $\begin{array}{c}\text { Debate 1 } \\
\text { (April 1997) }\end{array}$ & $\begin{array}{c}(15,326 \\
32 \text { speakers }\end{array}$ & $\begin{array}{c}204 \\
(133)\end{array}$ & $\begin{array}{c}106 \\
(69)\end{array}$ \\
\hline Debate 2 & 13,216 & 31 speakers & 31 speakers \\
(Febr. 1998) & $(10,000)$ & 210 & 68 \\
& 29 speakers & $(158)$ & $(52)$ \\
\hline Debate 3 & 6,502 & 29 speakers & 27 speakers \\
(Sept. 1998) & $(10,000)$ & 96 & 18 \\
& 13 speakers & $(148)$ & $(28)$ \\
& \multicolumn{2}{c}{13 speakers } & \multicolumn{2}{c}{} \\
\hline
\end{tabular}

Table 20: Frequencies of vote outcomes by type of capitalism, multinomial logit, 6.4.

\begin{tabular}{|cc|c|c|c|c|}
\hline & & Liberal & Partial & Sectoral & National \\
\hline 163 & 0 & 2 & 34 & 2 & 42 \\
& 1 & 53 & 75 & 155 & \\
& 2 & 10 & 39 & & 40 \\
\hline $164 a$ & 0 & 3 & 29 & 149 & 5 \\
& 1 & 52 & 22 & 5 & \\
& 2 & 8 & & & \\
\end{tabular}


Table 21: Frequencies of vote outcomes by type of capitalism, binary logit, 6.4.

\begin{tabular}{|cc|c|c|c|c|}
\hline & & Liberal & Partial & Sectoral & National \\
\hline 163 & 0 & 12 & 73 & 2 & 42 \\
\hline $164 a$ & 1 & 53 & 75 & 155 & 40 \\
\hline
\end{tabular}

Table 22: Binomial logit regression estimates, first reading vote, 6.4., 1996/163.

Floor Vote, First Reading

Left-Right Dimension

$-3.24 * * *$

$(.50)$

Sovereignty-Integration Dimension

$.75 * *$

$(.27)$

Constant

$1.98 * * *$

$(.24)$

Number of cases

412

Log pseudo-likelihood

$-159.43$

Pseudo $\mathrm{R}^{2}$

0.25

$* * *=$ significant at 0.001 level; $* *=$ significant at 0.01 level; $*=$ significant at 0.05 level Dependent Variable: Vote: $1=$ for, $0=$ against, abstain $=0$ 
Table 23: Binomial logit regression estimates, first reading vote, 6.4., 1996/164a.

Floor Vote, First Reading

Left-Right Dimension

$-3.27 * * *$

Sovereignty-Integration Dimension

$2.11 * * *$

$(.37)$

Constant

$2.13 * * *$

(.31)

Number of cases

411

Log pseudo-likelihood

$-128.88$

Pseudo $\mathrm{R}^{2}$

0.32

$* * *=$ significant at 0.001 level; $* *=$ significant at 0.01 level; $*=$ significant at 0.05 level Dependent Variable: Vote: $1=$ for, $0=$ against, abstain $=0$

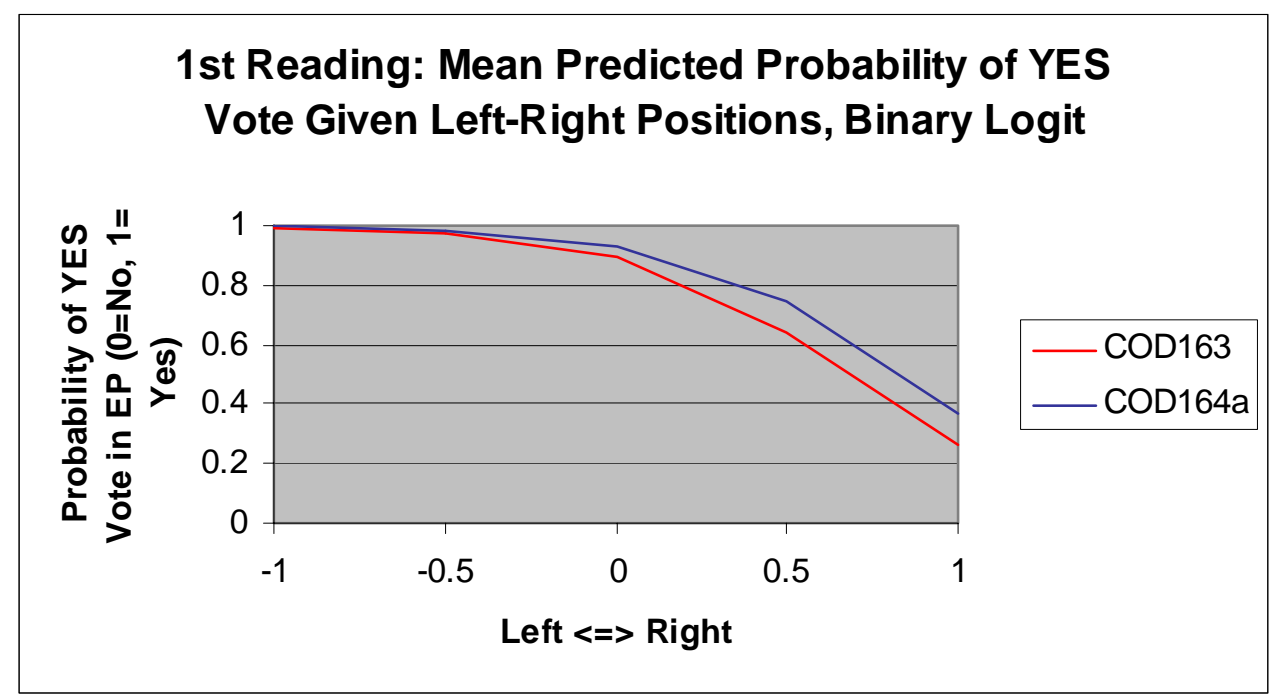

Figure 46: Probabilities 6.4. A 


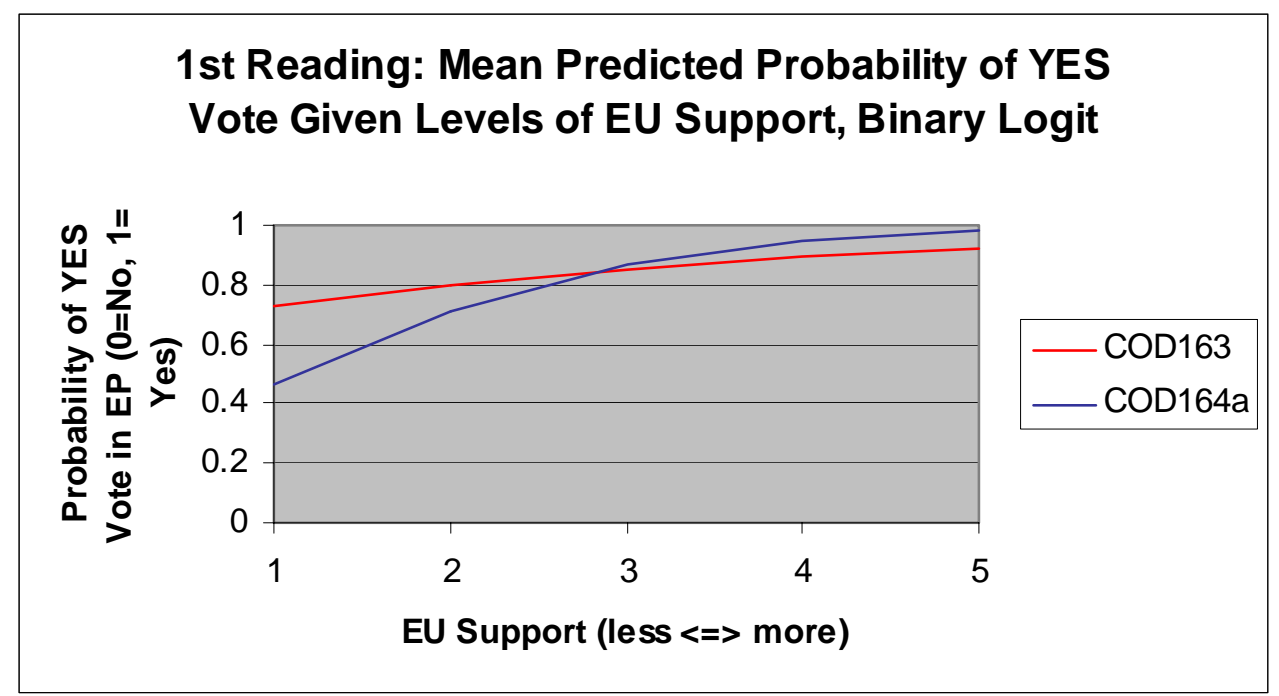

Figure 47: Probabilities 6.4. B 


\section{TEXTPACK Analysis}

\section{Focal Point 1: Consumer Protection.}

acid, alternative, asthma- (and relevant endings), cancer- (and relevant endings), carcinogenic, cardio-vascular, children, clean- (and relevant endings), crop- (and relevant endings), death- (and relevant endings), die prematurely, disease, ecolog- (and relevant endings), energy, environment- (and relevant endings), eutrophication, greenhouse effect, harm, health(and relevant endings), human, illness- (and relevant endings), innovati- (and relevant endings), Kyoto, lung complaints, mortality, pollut- (and relevant endings), quality, Rio, safety, sustainable, technical development, technical feasibility, technically feasible, toxic, WHO, World Health Organization

\section{Focal Point 2: Industry Interest.}

American- (and relevant endings), closures, competit- (and relevant endings), cost- (and relevant endings), economic- (and relevant endings), egalitarianism, employment, flexibility, Japanese, jobs, Korean, labour market, manufacturers, small and medium-sized businesses,

monopoly, north- (and relevant endings), shareholder value, SMEs, social, solidarity, south- (and relevant endings), unemployment, United States, US legislation, world markets

\section{Keywords-in-context}

Cat $=$ focal point category: Cat $0001=$ consumer protection, Cat $0002=$ industry interest

ID1: Speaker ID

ID2: Paragraph ID

ID3: Line ID

Debate 1 (April 9, 1997):

\section{Cat ID1 ID2 ID3}

000100000400000400002 ot taken, the Rio Conference commitment - to be rev $000100000300000400002 \mathrm{~d}$ laid down by WHO .

000100000300000300004 cording to the WHO standards . 000100000300000300001 values of the World Health Organization . 000100002400000500005 an be no other alternative . 000100000900000300004 research into alternative car engines and measures 000100000900000200003 on systems and alternative energy sources . 000100000900000200003 or, examining alternative fuels, alternative propu 
000100000900000200003 native fuels, alternative propulsion systems and al 000100000900000300004 , we also want alternative solutions set out for the 000100002900000300003 ffocating from asthma, with waiting rooms full of c 000100002900000300003 the number of asthma patients in Amsterdam had incr 000100002100000200006 ces are highly carcinogenic .

000100002900000300003 rooms full of children where the doctors told me th 000100000300000600005 it can develop clean, environmentally friendly fuel 000100000100000600006 iesel which is clean and respects our health . 000100000100000600003 ries producing clean diesel, but not for Europe . 000100001900000400002 ines, we need clean directors too, because they do 000100001900000400002 ' t just need clean engines, we need clean directo 000100001400000600002 catalysts and clean fuels are introduced.

000100001400000100004 ight, because clean fuels enable advanced engine te 000100001800000200001 to develop the clean technologies more swiftly if we 000100001600000200004 advantages for clean vehicles could then be introduc 000100000800000300006 ens will enjoy cleaner, healthier air and lives wil 000100000800000300001 two bonuses : cleaner air in Europe and achieving t 000100001000000200005 at will enable cleaner cars to be developed and also 000100003000000100005 will lead to a cleaner environment .

000100003000000200001 in terms of a cleaner environment and the saving of $000100001000000200004 \mathrm{t}$ will give us cleaner fuel .

$000100000600000300002 \mathrm{t}$ of producing cleaner fuels . 000100003100000100007 endly cars and cleaner fuels . 000100000100000700004 ople with lung disease, fewer people in receipt of 000100000100000700001 ith is what we ecologists call the internalization o 000100003200000300003 ing sources of energy, such as solar power or hydro 000100000400000400002 lieves that if energy measures are not taken, the R 000100003200000200002 importance of energy saving and reduction of emissi 000100000900000200003 nd alternative energy sources . 000100003200000300003 or hydrogenic energy sources .

000100002200000400001 e of renewable energy sources for vehicles . 000100001000000300002 protecting our environment, the health of our peopl 000100000200000200005 terests of our environment . 000100001900000500002 thing for the environment. $000100003000000100005 \mathrm{~d}$ to a cleaner environment .

000100001800000100002 improving the environment and enhancing the role of 000100000200000500005 tors, for the environment and for the consumer, so 000100001400000300002 nefits for the environment and human health of combi 000100000900000300005 tection of the environment and public health cannot 000100002300000200002 tection of the environment and the health of our cit 000100001000000200003 tection of the environment and the public health of $000100003000000200001 \mathrm{~s}$ of a cleaner environment and the saving of lives . 000100001800000400001 to improve the environment and this Parliament had $t$ 000100003000000100002 mitment to the environment as far as cars are concer $000100001700000400002 \mathrm{~d}$ consider the environment but also oppose certain $\mathrm{p}$ 000100003000000200002 uestioning the environment committee that new comput 
$000100002000000100004 \quad$ The environment is, perhaps, the first $000100002000000400003 \quad$ The environment is improving without cons 000100002900000100005 ne priority in environment policy and climate policy 000100002500000100002 to improve the environment proposed in the Auto / Oi 000100000200000600004 claimed to be environment-friendly because they con 000100002200000300001 ote the use of environment-friendly engines and fuel 000100002000000100006 e increasingly environment-friendly motor vehicles a 0001000032000002000021 , as well as environmental, importance of energy 000100000900000300002 : the views of environmental NGOs should be taken in 000100002900000100009 izations, the environmental experts and the health 000100003000000200003 o has a strong environmental impact .

000100003000000400006 ant to look at environmental issues as a whole . 000100002100000300002 ontrary to all environmental logic, France, which 000100003000000200002 more extensive environmental measures .

000100000200000800005 major European environmental organizations and $40 \mathrm{mi}$ 000100000400000100002 political and environmental package of great merit 000100001900000600001 e can cure our environmental patient without doing $\mathrm{t}$ $000100001400000600003 \quad$ An environmental policy which creates or 000100002700000100002 unemployment, environmental pollution and many othe $000100000900000100002 \mathrm{n}$ proposals on environmental protection, taking acc $000100002000000300001 \mathrm{r}$ economic nor environmental sense, and fail to tak 000100001100000100005 an acceptable environmental solution.

000100002700000400003 ere the better environmental standards in the three 000100001100000300003 the necessary environmental standards which have be 000100000800000300001 eading edge of environmental technology .

000100002700000100003 ion to be made environmentally compatible, turning 000100000200000900004 ars must be as environmentally compatible as we can 000100000200000900003 green light to environmentally compatible cars ! 000100000300000600005 evelop clean, environmentally friendly fuels, its 000100003100000100007 re calling for environmentally more friendly cars an 000100002200000300005 lution and the greenhouse effect .

000100002100000200006 , reducing the greenhouse effect linked to the carbo 000100001400000400004 o where is the harm in that?

000100001800000100002 eness, public health, improving the environment an $000100000100000600006 \mathrm{~d}$ respects our health .

000100000100000700004 ss spending on health . 000100000300000200005 ity and public health . 000100000800000200002 ed to costs to health . 000100001600000200008 tice to public health . 000100003100000100005 es a danger to health . 000100001800000300001 sons of public health because we think it is necessa 000100000900000300005 ent and public health cannot be cost-effectiveness, 000100000100000700004 impact on the health economy must also be calculate 000100001800000300001 lly recognized health hazard .

000100001000000200003 and the public health of Europe 's citizens, but a 000100001400000300002 ment and human health of combining strict vehicle em 
000100002300000200002 onment and the health of our citizens, who can only 000100001000000300002 ironment, the health of our people and the future $p$ 000100002400000200002 to give to the health of this generation and the fut $000100000300000600007 \quad$ The health of those we represent in this 000100002900000100009 xperts and the health specialists?

000100000700000200006 Fourthly, the health studies commissioned by the Co 000100000100000400005 ality of human health unless we base ourselves on gu 000100002900000300002 pollution and health - I certainly have done .

000100000800000300006 njoy cleaner, healthier air and lives will be saved 000100001000000200008 ive our people healthier air to breathe and call, $\mathrm{h}$ 000100002500000100003 the social and human costs of the current level of $p$ 000100001400000300002 nvironment and human health of combining strict vehi 000100000100000400005 the quality of human health unless we base ourselves 000100002400000200002 e prospects of human life on earth .

000100001300000300001 om respiratory illness .

000100002300000100003 causes serious illnesses and therefore triggers high 000100002600000500003 the future and innovation .

000100002700000300002 reduction and innovation.

000100001300000200001 Programme was innovative but it had two problems : 000100002700000100003 o come up with innovative ideas and technically soun 000100001600000500002 e emissions of pollutants, not forgetting CO2 .

000100000200000500001 e particles of pollutants by comparison with a diese 000100000400000600004 ours those who pollute least .

000100000400000600006 ful cars which pollute more .

000100001700000300005 vehicles only pollute towns and there are many othe 000100000400000700001 ansforming the polluted air we now have in Europe in 000100000200000900001 e most heavily polluted city, Athens, and confirme $000100000300000100006 \mathrm{r}$ is seriously polluted on days like this .

$000100003100000100005 \quad$ polluted urban air which poses a dang 000100000400000600005 ghter and less polluting, should have tax exemption 000100000400000700001 king fuel less polluting .

000100002100000100003 , or use less polluting fuels, and they are more s 000100000900000300006 etter and less polluting fuels : the effort should b 000100002200000100003 , namely less polluting motor vehicles .

000100002200000200002 vehicles less polluting seem too high.

000100002000000100005 ions to combat pollution, an improvement in fuel qu $000100003200000300003 \mathrm{~ms}$ of reducing pollution, but that new engines shou 000100002900000300003 o with the air pollution, of which cars are clearly 000100000200000700005 times as much pollution . 000100000800000100002 of atmospheric pollution . $000100000900000200001 \mathrm{r}$ for reducing pollution . 000100001700000300005 other forms of pollution . 000100002800000100002 st atmospheric pollution . 000100003100000100002 of atmospheric pollution . 000100002500000100003 rrent level of pollution; second, the objectives $t$ 000100002300000100002 ce atmospheric pollution and based on a different ap 
000100002900000300002 to do with air pollution and health - I certainly ha 000100002700000100002 environmental pollution and many others, too. 000100002200000300005 prime cause of pollution and the greenhouse effect . 000100000100000400005 e fighting air pollution and therefore we will not b $000100002300000100003 \mathrm{~s}$, levels are pollution are increasing, especially 000100002000000200001 last 20 years pollution caused by motor vehicles ha 000100002300000100003 , atmospheric pollution causes serious illnesses an 000100001600000200007 permitted air pollution is much too low .

000100000300000300004 city where air pollution makes it unhealthy to live 000100003100000100003 this source of pollution which must be tackled if we 000100001600000200008 mean value of pollution within an area of $4 \mathrm{~km} 2$ fai 000100001500000300003 for better air quality, because above 200 ppm this 000100000400000300001 relate to air quality, carbon dioxide emissions, 000100002700000400003 roving of fuel quality, incidentally, is one of th 000100000900000300004 ovement of air quality, like support for research i 000100000100000100002 report on fuel quality, on behalf of the Committee 000100000600000300001 issue of fuel quality, since this has a prompt imp 0001000003000005000071 of the right quality . 000100000400000300001 ons, and fuel quality . 000100001400000100004 improving air quality . 000100001500000600002 ovement of air quality . 000100002100000100002 to improve air quality . $000100002400000300006 \mathrm{f}$ gains in air quality . 000100002700000400001 ovement in air quality . 000100000900000300007 oth for better quality / less noxious fuels and for 000100002000000100005 vement in fuel quality and control of emissions from 000100002100000300004 to better air quality and encourage the use of bio000100000300000200005 ulture, water quality and public health .

000100001500000200001 for better air quality are disturbing problems calli 000100003100000200002 eve better air quality at a reasonable price .

000100003100000100009 ls , urban air quality can be improved more rapidly 000100000200000500002 we need better quality fuel for all vehicles, new o 000100000100000400001 target for air quality in 2010 .

000100000800000300004 for better air quality in Northamptonshire .

000100000200000500002 ard to the air quality in cities like Athens and Mad 000100000300000100006 rements of air quality in the city tell us that the 0001000028000001000031 you that the quality of Finnish fuels already exce 000100000100000600005 efit from this quality of diesel?

000100003000000200003 applies to the quality of fuel, where it is possibl 000100003100000100009 to improve the quality of fuels, urban air quality 000100003100000200004 vements in the quality of fuels in Finland . 000100000100000400005 improving the quality of human health unless we bas 000100000600000300001 impact on the quality of the air . 000100003100000100006 improving the quality of the air . 000100002800000100002 vements in the quality of the air and to protect peo 000100000100000400008 nterest in the quality of the product served to them 
000100000100000300002 measuring air quality over 4 square kilometres, in 000100001400000100003 o propose fuel quality specifications .

000100002300000100002 nance and fuel quality specifications .

000100000800000200004 ement for fuel quality were all included in my opini 000100000300000300002 measuring air quality which conflicts with our own 000100002000000400004 e principle of sustainable development .

000100001200000100005 move towards a sustainable society, the use of cars $000100001100000200001 \mathrm{n}$ research and technical development .

000100001100000200002 mmission, but technical development in this area is 000100003100000100008 e issue of the technical development of vehicles and 000100001900000100005 efit ratio and technical feasibility .

$000100001900000300002 \quad$ This is technically feasible even today, and 000200001700000200003 ency low , the American, Japanese and Korean govern $000200001700000200004 \quad$ The American government goes even further 000200001700000200003 the American, Japanese and Korean governments are $g$ 000200000600000200004 rapidly, the Japanese will .

000200001700000200003 , Japanese and Korean governments are giving their $\mathrm{m}$ 000200000200000200003 t company with US legislation we shall be the losers $000200000100000600004 \quad$ For the United States and Japan . 000200001300000300006 Thirdly, the cost, as passed to customers, is no 000200003000000200003 els at a lower cost, which also has a strong enviro $000200002000000200002 \mathrm{t}$ a reasonable cost .

000200003100000200005 ely reasonable cost .

000200001900000600001 damage to the cost / benefit principle .

000200001900000100005 arises of the cost / benefit ratio and technical fe 000200002200000400001 ded to promote cost / benefits, energy-saving and $\mathrm{r}$ 000200000300000200002 se most of the cost calculations came from industry 000200000500000400001 ciation of the cost differential impact by Member St 000200000300000200003 account in its cost estimates the external costs of $000200000900000300005 \mathrm{r}$ part of that cost falls directly on the consumers 000200001000000300002 it is a small cost for protecting our environment, 000200000500000400001 fferentials in cost for the refining industry betwee 000200001000000300001 at an average cost of ECU 10 per year, per motoris 000200000300000200004 ission put the cost of car transport to society at 2 000200000600000300002 restimated the cost of producing cleaner fuels . 000200003000000200001 nalysis of the cost of the different measures is req $000200002100000200001 \quad$ The cost of the first option is exorbitan 000200001400000400002 sing, it will cost them ECU 0 .

000200002500000100003 , the economic cost to the consumer and industry, a 000200001500000500003 olve excessive cost without appreciable benefit .

000200000100000700003 to talk about cost-benefit . 000200000300000200001 ther than true cost-benefit analysis . 000200003200000200001 the need for a cost-benefit analysis linked to the $\mathrm{r}$ 000200000200000300004 ant to adopt a cost-effective, practical approach $h$ 000200000900000300005 alth cannot be cost-effectiveness, because the grea 000200000100000700002 , the idea of cost-effectiveness . 
000200003200000200001 ne itself to a cost-effectiveness analysis, but emp 0002000015000006000020 , based on a cost-effectiveness analysis, represe 000200000800000200003 romise between cost-effectiveness and the best avail 000200000300000200001 e principle of cost-effectiveness rather than true c 000200001500000300003 account of the cost-effectiveness relationship in th 000200000200000700007 tests, a very costeffective measure because manufac 000200003200000200001 on of external costs, a matter which we have, more 000200002300000100003 rs high social costs, and, unfortunately, despite 000200001000000300001 we examine the costs, they will be recouped from th 000200000100000700001 rnalization of costs .

000200001300000300003 the grounds of costs .

000200002000000100010 ot respected, costs are increased, leading to a do 000200000300000200002 an interest in costs being high, measures which mig 000200002300000200001 oubtedly imply costs for manufacturers, and, in a 000200001400000400001 e today - that costs increase as a result .

$000200000300000200003 \mathrm{~s}$ the external costs of motor vehicle transport .

000200002500000100003 cial and human costs of the current level of polluti 000200002200000200002 view that the costs projected by the Commission for 000200002000000100011 reased vehicle costs slow down sales and renewal of 000200000800000200002 as opposed to costs to health.

000200000800000200002 alance between costs to industry as opposed to costs 000200002000000200003 deadlines and costs which, ultimately, the consum 000200002000000400003 , and without costs which have to be borne by motor 000200000100000400007 I say that the economic basis of this Auto / Oil stu 000200002500000100003 , fifth, the economic cost to the consumer and ind 000200001000000200003 ens, but also economic development and ensuring Eur 000200001000000200003 ope ' s future economic development and progress . 000200001500000600002 imperatives of economic efficiency and the indispens 000200002200000300001 lief and other economic incentives to the industry $t$ $000200002000000300001 \mathrm{~s}$ make neither economic nor environmental sense, an 000200001700000200001 lways had this economic system imposed on us in area 000200002300000200001 solidarity and egalitarianism, these should not imp $000200002000000100011 \mathrm{~d}$ consequently employment, without creating new job 000200002800000200009 uate degree of flexibility should be introduced into 000200002800000200009 , a degree of flexibility which would be determined 000200001700000100002 esents $10 \%$ of jobs . $000200002000000100011 \mathrm{t}$ creating new jobs . 000200002400000300005 giving people jobs but also meeting increasingly st 000200002000000100002 nology and the labour market .

$000200002300000200001 \mathrm{mply}$ costs for manufacturers, and, in a Europe uni 0002000001000002000041 groups, car manufacturers and oil refiners, and 000200002100000200004 e European car manufacturers and the advocates of bi $000200000100000300001 \mathrm{ps}$, the motor manufacturers and the oil companies $\mathrm{w}$ 000200000200000700007 easure because manufacturers are naturally keen not 000200000200000800002 that some car manufacturers are unenthusiastic, an 000200000200000500006 one, and that manufacturers are working towards Eur 
000200001700000200003 e giving their manufacturers considerable assistance 000200000900000300003 rovided by the manufacturers themselves, as has alr 000200002000000100003 motor vehicle manufacturers to take on additional c 000200001900000500004 loitation of a monopoly position, which is of cours $000200002800000200008000 \mathrm{~km}$ further north, this is certainly not the cas 000200002800000200006 anced, but in northern Finland, i . 000200000500000400001 dustry between northern and southern countries . 000200000900000300008 ntries, while northern ones use North Sea fuels . 000200002800000200002 Finland as the northernmost country in the European $000200002600000500002 \mathrm{~s}$ to have been shareholder value . 000200003200000200002 mphasis to the social, as well as environmental , i 000200002500000100003 First, the social and human costs of the current 000200001700000100002 nd the ensuing social cataclysm, especially in our 000200002300000100003 triggers high social costs, and, unfortunately, 000200000900000300002 o involve more social players : the views of environ 000200002000000100003 them to assume social responsibilities as well . 000200000100000700004 in receipt of social security and less spending on 000200002300000200001 on a basis of solidarity and egalitarianism, these 000200000900000300008 point out that southern European countries will have 000200002800000200006 In southern Finland, spring may already $000200000500000400001 \mathrm{n}$ northern and southern countries .

000200000900000300008 we all know, southern countries get their fuel sup 000200000500000400002 nal period for southern states, because we have to 000200002700000100002 e at present : unemployment, environmental pollutio 000200002700000100003 be sold on the world markets, relying on the abilit 000200000800000300002 ur cars to all world markets and set a standard for

Debate 2 (February 17, 1998):

\section{Cat ID1 ID2 ID3}

000100001200000300001 ally after the Kyoto Summit . 000100000900000100002 king about the Kyoto Summit and CO2 emissions . 000100000900000100004 ication on the Kyoto Summit issued at the end of 199 000100001000000300008 That way the Kyoto agreements might be achieved . 000100000200000100004 cording to the WHO . 000100002600000100002 dations of the World Health Organization . 000100000800000100003 mage caused by acid rain - mean that we need clear , $000100000900000200002 \mathrm{t}$ networks and alternative fuels . 000100000400000100002 suffering from asthma caused by car fumes if we meet 000100000100000300009 ar disorders, asthmatic conditions, especially in 000100002600000200001 nesses such as cancer; and the Lange report propose 000100002100000200003 ion are highly cancerogenic .

000100000100000300009 traffic causes cardio-vascular disorders, asthmatic 
000100002100000200002 ead content in children ' s blood in risk zones and 000100002000000100006 om lead reduce children 's intelligence levels .

000100000100000300009 especially in children, and there are lung complai 000100000400000100003 ch to bring up children, to live and to work . 000100002000000100005 ory disease in children and $19 \%$ of cases of pulmona 000100000400000400003 ities in which children and adults can live free of 000100000400000100002 fewer European children will be suffering from asthm 000100000100000900011 ause they want clean, environmentally friendly cars $000100001800000100010 \quad$ Only clean, safe cars can legitimize rene 000100001200000100002 ght to breathe clean air and protect their health . 000100000100000200002 oner, we need clean air in Europe .

000100002600000100002 ble to breathe clean air in their cities, and the A 000100001300000500004 Demand for clean fuels would bring this investme 000100000200000200002 ssions are not cleaned up, opposition to cars on th 00010000040000010000311 be better, cleaner and healthier places in which 000100000400000400003 we have those cleaner cities in which children and 000100000400000100008 turers to make cleaner engines and also oblige oil c 000100000200000100008 s down we need cleaner fuels, especially with so ma 000100000200000300007 convinced that cleaner fuels must be on the market e 000100000400000100008 panies to make cleaner petrol and diesel fuels . 000100000200000300005 e to invest in cleaner production technology . 000100002200000200003 uce better and cleaner products . 000100000100000300008 rs have become cleaner since 1970 - not voluntarily 000100002200000300002 he adoption of cleaner technology will not serve to 000100000200000200007 of making fuel cleaner were, for example, in terms 000100000400000400002 e avoidance of crop damage and eutrophication . 000100000800000100003 high number of deaths and serious harm caused by air 00010000020000010000440000 people die prematurely every year from air $\mathrm{p}$ 000100002000000100005 of respiratory disease in children and $19 \%$ of cases 000100001700000100002 President, in ecological terms Mrs Hautala and Mr L 000100001600000200003 ble sources of energy .

000100002900000100002 take, for the environment, for industry and for em 000100002100000100003 health and the environment, maintaining the values 000100000300000200003 ortance of the environment, we should not go too fa 000100000100000300009 ication of the environment .

000100001200000400003 health and the environment . 000100001300000400004 enefit for the environment . 000100001500000200001 nature and the environment . 000100001900000300004 to improve the environment . 000100002500000300003 out Europe 's environment . 000100000700000400004 ovement of the environment again by years . 000100000600000200005 ovement of the environment against pollution . 000100000600000200006 harmful to the environment and, consequently, the 000100000300000300003 ess, help the environment and create new jobs . 000100002700000300006 protecting the environment and enhancing our capacit $000100000700000400003 \mathrm{t}$ both for our environment and for the economy . 
000100001600000100002 improving the environment and human health . 000100000500000300004 onomy, on the environment and on health . 000100002000000100004 e issue of the environment and public health . 000100001400000300001 at the working environment and the ability to compet 000100002600000200001 impact on the environment as well as on the industr 000100001400000200001 best possible environment for each of our citizens 000100001900000300006 antee that the environment has been manifestly impro $000100000600000500003 \mathrm{~h}$ for a better environment is a battle that may leav 000100001800000300001 Finally, the environment is not the enemy of emplo 000100001700000100009 , neither the environment nor the car or oil indust 000100001100000300001 espect for the environment with respect for work and 000100001300000400011 o what are the environmental advantages?

$000100002000000300002 \mathrm{~s}$ aware of the environmental advantages of unleaded 000100002900000300003 ties, both at environmental and industrial level . 0001000013000004000151 that a major environmental benefit . 000100000200000300002 fair to ignore environmental concerns, just because 000100002000000300003 industry to an environmental contract with society a 000100001700000100006 the number one environmental enemy .

000100002000000300006 the absence of environmental investment in the secto 000100000300000300001 go all out for environmental objectives the next . $000100001900000300002 \quad$ From the environmental point of view the sulph 000100000100000200003 ty of life and environmental quality in Europe, and 000100001800000300003 ide behind the environmental question to justify the 000100000100000300004 ake the car as environmentally friendly as possible 000100002400000100006 etter and more environmentally friendly car on the $\mathrm{m}$ 000100000100000900011 y want clean, environmentally friendly cars .

000100001100000500001 concentrated, environmentally friendly diesel oil . 000100002200000300004 ies which make environmentally friendly products . 000100000400000400002 rop damage and eutrophication .

000100001800000100005 e and that the greenhouse effect is threatening us . 000100000800000100003 hs and serious harm caused by air pollution, largel $000100000200000200007 \mathrm{rms}$ of risk to health, $55 \%$ too high and, as regar 000100002400000300001 population 's health, and it is also one of the Co 000100002100000200002 hreaten public health, and that recent studies conf 000100001200000100004 right to good health, as provided for by the Treat 000100000200000100009 for people 's health .

000100000500000300004 ronment and on health .

000100001200000100002 protect their health.

000100001600000100002 ment and human health .

000100001600000100003 cts people 's health .

000100002000000100004 ent and public health . 000100002200000100003 and people 's health .

000100002000000100005 tial to public health : 7 to $10 \%$ of cases of respir 000100000400000400002 ty, in public health and also the avoidance of crop 000100001400000200001 ull freedom of health and safety .

000100002100000100003 defend public health and the environment, maintain 
000100001200000400003 , that is, of health and the environment .

000100002500000300004 to people ' s health by emissions from leaded petro

000100000200000100005 reness of this health hazard has only grown in recen 000100001800000100006 ty of life and health of our people .

000100002400000100007 market and the health of our population .

000100001200000200001 fuels when the health of their shareholders and clie

000100000200000200001 ed to see that health organizations have recently be

000100002700000400004 European Union health policy, thanks to this Parlia 000100001200000300003 o this serious health problem .

000100002100000400002 inue to breath health-threatening, polluted air . 000100000400000100003 , cleaner and healthier places in which to bring up 000100002400000200005 are remarkably healthy; they are making enormous pr 000100000600000500004 annot stop the healthy ones who want to move ahead . 000100001500000200001 xploitation of human beings and the destruction of $\mathrm{n}$ 000100001600000100002 nvironment and human health .

000100000100000300003 system is the human lung.

000100000400000400003 of respiratory illness .

$000100002000000100005 \mathrm{~s}$ of pulmonary illnesses are but a few figures that 000100002600000200001 ausing serious illnesses such as cancer; and the La $000100002700000300006 \mathrm{r}$ capacity for innovation .

000100001600000200002 ould encourage innovation if demands were made on in 000100000500000500004 ssible for our innovation-minded industry . $000100000500000300006 \mathrm{ch}$ will assist innovative industries .

000100000800000200001 ith the use of innovative transport systems . 000100000100000300009 and there are lung complaints caused by particles $\mathrm{i}$ 000100001600000100004 een increasing mortality and air pollution caused by 000100001300000200005 nology so that pollutants are reduced; and second, 000100001300000200005 uality so that pollutants are totally eliminated or 000100001300000200001 e emissions of pollutants from motor vehicles . 000100002100000200003 ne, and other pollutants produced by automobile com 000100002100000400002 -threatening, polluted air .

000100001500000200007 If the polluter does not pay, it is the peo 000100001500000200005 But it is the polluter who should pay.

000100001000000300004 sions of heavy polluting chemicals have been pushed 000100000800000200002 goods to less polluting means of transport.

000100001100000300002 supply a less polluting product should be rewarded 000100000200000100004 year from air pollution, according to the WHO . 000100000800000100003 caused by air pollution, largely due to vehicle tr 000100002100000400001 tely mean less pollution, since even today 's cars 000100002000000200001 esponse to air pollution, when traffic is not banne 000100000600000200005 onment against pollution . 000100002000000100005 ributed to air pollution . 000100001600000100003 shown that air pollution affects people 's health . 000100002100000300003 nsumers, less pollution and less CO2 emissions - th 000100002900000200004 a worsening of pollution and safety risks, along wi 000100001100000100002 roblems of air pollution caused by road traffic . 
000100001600000100004 tality and air pollution caused by road traffic . 000100001200000100003 ncrease in air pollution due to our traffic using tw 000100001100000600002 oped to combat pollution effectively : I am referrin 000100000600000500001 duction in the pollution generated by vehicles today 000100002100000200002 enied that air pollution in our cities, including L 000100001200000300002 ncrease in air pollution in urban areas .

000100001800000100005 pers that town pollution is on the increase and that 000100000100000200003 ssue, because pollution knows no borders .

000100001500000200010 he cost of the pollution of the natural world deserv 000100001100000200001 to improve air quality, establishing two deadlines 000100000400000400002 ovement in air quality, in public health and also $t$ 000100000100000500003 impact on air quality. 000100000200000100002 ons, and fuel quality . 000100000600000200006 ould invest in quality . 000100001000000100006 vital for air quality . $000100001100000300001 \mathrm{w}$ to improving quality . 000100001500000100006 improve their quality. 000100001500000200012 to improve air quality . 000100001600000100005 set for petrol quality . 000100001900000200003 to better air quality . 000100002200000300007 of the highest quality . 000100002300000100002 rned about air quality . 000100002300000200003 ovement of air quality . 000100002300000300002 vements in air quality . 000100002900000200001 to improve air quality and to promote new technologi 000100001600000100007 ieving the air quality desired .

000100000900000200002 such as better quality fuel, traffic management, $\mathrm{t}$ 000100002200000200004 to use better quality fuel .

$000100001200000200001 \mathrm{n}$ offer better quality fuels when the health of thei 000100000100000500003 hown that fuel quality has a direct impact on air qu 000100001400000300002 mple, the air quality in Dublin, the capital city 000100000100000200003 environmental quality in Europe, and it is a Europ 000100002800000100002 ogramme on air quality in Europe .

000100000300000200002 improving air quality in European centres of popula 000100002300000100005 ovement of air quality in terms of their vehicles ' 000100002800000100005 ent in the air quality in the towns of Europe . 000100002800000200005 o that the air quality in the towns of Europe is imp $000100002000000100005 \quad$ Air quality is essential to public health 000100002600000100002 e specific air quality objectives, in line with the 000100002300000200001 ovement in the quality of fuel .

000100002100000100003 values of the quality of fuels and continuing to ca $000100001100000200001 \mathrm{~s}$ by which the quality of fuels and the limit values 000100001100000200002 improving the quality of fuels will have immediate 000100000100000200003 ornerstone for quality of life and environmental qua 000100001800000100006 civilization, quality of life and health of our peo 000100000300000300003 improving the quality of life of our fellow citizen 
000100001200000300001 dence over the quality of the air we breathe, espec 000100001200000100003 to improve the quality of the air we breathe . $000100000100000200006 \mathrm{f}$ Europe : the quality of their life is at stake, w 000100001500000200009 bsidizing poor quality oil . 000100001300000200005 improving fuel quality so that pollutants are totall 000100001600000200001 the new petrol quality standards and emission limits 000100000200000100006 goals for fuel quality than we did last spring, whe 000100000900000300001 vement in fuel quality would have immediate effects $000100000600000400001 \mathrm{t}$ above all in quality - think of vocational trainin 000100001400000200001 of health and safety.

000100002900000200004 pollution and safety risks, along with economic di $000100001900000200001 \mathrm{t}$ to stimulate technical development towards more ad 000100002600000300001 realistic and technically feasible space of time, 000200000500000700005 as good as the Americans for once?

000200001300000500001 eaten refinery closures because of the Auto-Oil prog 000200001800000300003 to justify the closures which they had - unfortunate 000200000200000400002 aps twice this cost, or about ECU 10 a year . 000200000500000800004 e petrol would cost 18 pfennigs a litre . 000200001400000400001 ted there is a cost factor built into this : costs $\mathrm{t}$ 000200000200000400001 that the added cost for a normal petrol-driven car $\mathrm{w}$ 000200000500000800007 es - about the cost of catalytic converters ?

000200001300000400006 icate that the cost of desulphurizing fuels and othe 000200001500000200010 except at the cost of the pollution of the natural $000200000500000800008 \mathrm{~s}$ - today they cost ten times less than the DM 5000 000200000400000300002 As regards the cost to the general consumer, the or 000200001100000500001 ls at no extra cost to the motor industry, particul 000200000200000400002 car owners the cost will work out at perhaps twice $t$ 000200000500000800009 s to money and costs, because I have learnt from ex 000200002700000300006 our production costs, but rather a sensible means o 000200001600000100010 mean increased costs, but the first thing to do is 000200000400000300001 us that those costs are in fact $17 \%$ cheaper for pe $000200001300000400004 \mathrm{~d}$ involve high costs for the oil industry with littl 000200001500000200003 meet these new costs itself. 000200000500000800001 ike to turn to costs now . 000200002100000300004 culated annual costs of ESC 1000 per motor vehicle 000200001500000200008 petitive, the costs of investment should not get pa 000200000200000200007 ted that their costs of making fuel cleaner were, $\mathrm{f}$ 000200001700000100007 about the true costs of road traffic will have to be 000200001400000400001 e consumer and costs that will affect our industrial 000200001400000400001 lt into this : costs that will be passed on directly 000200000400000200002 cates that the costs they are suggesting are not qui 000200000200000400001 If we look at costs to the motorist, then I trust 000200001600000200001 exaggerate the costs which would be involved in the $000200002000000100002 \mathrm{Mr}$ President, economic arguments have long prevaile 000200001600000100009 uld ignore the economic aspects .

$000200002900000200004 \mathrm{~s}$, along with economic difficulties for the manufac 
000200001900000300007 so easy to use economic means of control and to prev 000200001900000300004 e right to use economic means of control to improve $000200000600000200006 \quad$ From an economic point of view, it should be $000200001100000400001 \mathrm{~d}$ lead to some economic problems which, we believe 000200002100000100004 sures from the economic sectors involved?

000200000200000100009 nce considered economical, but which have now prove 000200000100000900001 islation helps employment, because European manufac $000200000600000400001 \mathrm{r}$ product : in employment, no longer in terms of qu $000200002200000300002 \mathrm{t}$ serve to aid employment .

000200002900000100002 dustry and for employment .

$000200001800000300001 \mathrm{t}$ the enemy of employment : the evolution of the car 000200002900000200001 titiveness and employment in the European vehicle an 000200001800000100010 thus reviving employment in this sector.

000200002200000300006 The effects on employment of this are unfathomable . 000200000500000300001 ty, providing flexibility for goods, services and 000200000500000300002 Of course, flexibility includes the free movemen 000200000100000900003 and preserving jobs, and whole new industries are e 000200000300000300003 and create new jobs .

000200000300000300001 make securing jobs and creating new ones a priority $000200000100000900004 \mathrm{~d} 15,000$ new jobs over the last 10 years - it did 000200002300000100004 at the vehicle manufacturers .

000200002900000200004 ulties for the manufacturers .

000200001800000100008 Of course the manufacturers are somewhat hesitant, 00020000040000010000811 require car manufacturers to make cleaner engines 000200000100000700002 ow independent manufacturers to produce spare parts 000200000100000900001 cause European manufacturers will gain some competit $000200000600000400001 \mathrm{~s}$ of small and medium-sized businesses alongside the 000200000400000100003 berdeen in the north of Scotland and Athens in Greec $000200000600000200005 \mathrm{~g}$ an intrinsic social commitment : the protection an 000200000600000400001 nally, in the social field.

000200000500000600007 he devotees of social policy in this House, but one 000200001200000300004 located in the south of the Union .

000200002000000200002 also exists in southern Europe .

000200000700000200003 eople from the southern Member States along with the 000200000300000200003 a time of mass unemployment all over Europe .

Debate 3 (September 15, 1998):

\section{Cat ID1 ID2 ID3}

000100000300000300001 suffering from asthma caused by car fumes if the tar 000100000400000400006 he sake of our children, because they need a health 000100000300000200001 o bring up our children and go about our daily lives 000100000300000300001 fewer people - children and older people - suffering 
000100000900000100002 eeping our air clean .

000100001100000200001 al benefits of clean air are to be achieved then str 000100000700000400004 , in future, clean diesel will cause less pollutio 000100000400000300006 o that we have clean engines and clean exhaust emiss 000100000400000200004 is to produce clean exhaust emissions, it has to $\mathrm{r}$ 000100000400000300006 an engines and clean exhaust emissions .

000100000600000400001 nsider whether clean fuel is available in sufficient 000100000600000300002 incentives for clean fuels .

000100001200000100004 ntroduction of clean fuels has been under discussion 000100000200000200003 really become cleaner, and so that industry would 000100000300000400001 companies made cleaner, more efficient engines and $000100000100000200008 \mathrm{~s}$ to make cars cleaner .

000100000300000400009 re efficient, cleaner and burn less fuel . 000100000300000200002 Athens will be cleaner and healthier places to live 000100000200000300003 gent calls for cleaner exhaust emissions, but it is 000100000200000600003 age the use of cleaner fuels .

$000100000300000400010 \mathrm{y}$ will produce cleaner fuels; indeed some of them a 000100000800000100006 ation aimed at cleaner fuels and cleaner vehicles ca 000100000200000600002 ket that these cleaner fuels are actually being awai 000100000300000400011 lready putting cleaner fuels on the market now that 000100000200000300003 industry needs cleaner fuels to be able to keep up w $000100000200000600001 \mathrm{y}$ on, because cleaner fuels will be coming onto the $000100000200000300002 \mathrm{e}$ on producing cleaner industrial technology . 000100000300000400001 panies to make cleaner petrol and diesel, whilst at $000100000200000400002 \mathrm{n}$ to invest in cleaner technologies .

000100000800000100006 aner fuels and cleaner vehicles cannot be underestim 000100000300000300002 mage caused to crops by pollution . 000100000400000400006 need a healthy environment . 000100001300000100002 health and the environment . 000100001300000100005 wards a better environment . 000100001300000300002 nterest of the environment . 000100000300000300003 protecting the environment and public health . 000100001000000100006 account of the environment and recognising the need 000100001200000500001 tion where the environment is concerned .

000100001000000300003 y coupled with environment policy, or rather enviro 000100001000000100005 licy is really environment policy .

000100000900000200005 ar of European environment policy; at some point in 000100000100000500003 en the helm in environment policy; it has combined $000100001000000300003 \mathrm{cy}$, or rather environment policy which determines i 000100000800000100005 threat to the environment will be worldwide, as a 000100000800000200005 together with environmental and consumer organisati $000100001100000200001 \mathrm{al}$, human and environmental benefits of clean air a 000100000200000400003 more stringent environmental demands could not be bl 000100000700000100003 by pushing its environmental demands to the limit wh $000100001100000400003 \mathrm{y}$ with the new environmental specifications . $000100000100000200005 \mathrm{r}$ to guarantee environmentally acceptable mobility . 
$000100000100000100003 \mathrm{t}$ a course for environmentally friendly mobility . 000100001300000400002 safer and more environmentally friendly motor cars . 000100000300000300003 ent and public health .

000100001300000100002 mpact on human health and the environment . 000100001000000100006 protect human health from possible damage can an in 000100000800000100004 ations for the health of humans, plants and animals 000100000300000200001 e and work and healthier places to bring up our chil 000100000300000200002 be cleaner and healthier places to live . 000100000400000400006 se they need a healthy environment . 000100001100000200001 erall social, human and environmental benefits of c 000100001300000100002 ajor impact on human health and the environment . 000100001000000100006 and to protect human health from possible damage can 000100000200000500003 stained out of human illness have to be taken into a 000100001000000100006 foundations of human life and to protect human healt $000100000200000500003 \mathrm{~d}$ out of human illness have to be taken into account 000100000600000400007 produces more pollution, we must remain particular 000100000300000300002 ed to crops by pollution . $0001000007000004000080 \%$ of all car pollution . 000100001200000100006 o reducing air pollution . $000100000800000200003 \mathrm{~m}$, namely air pollution from traffic and transport $000100000800000100003 \quad$ Air pollution is a particularly intractab 000100001100000100002 guarantee that pollution is defeated once and for al $000100001100000200001 \mathrm{r}$ reducing air pollution must be an imperative . 000100000700000400004 ill cause less pollution than unleaded petrol . 000100000700000400007 problem of car pollution until we have dealt with th 000100000700000300005 wer to the air pollution which has become the major 000100000500000200004 ovement in air quality .

000100000100000300002 improving air quality : we have succeeded in introd 00010000010000060000111 improve air quality and a success for our institu $000100000100000300001 \mathrm{f}$ improved air quality and employment in Europe ; se 000100001300000100004 tions and fuel quality by the years 2000 and 2005 . 000100000200000300001 tions for fuel quality for the year 2005 as well . 000100000200000200003 conditions for quality for the year 2005 too, so th 000100000600000400002 ce of superior quality fuel from the year 2005, or $000100001300000200001 \quad$ Higher quality fuels automatically lead to 1 000100000500000100003 rds better air quality in Europe .

000100000600000100002 tives, on the quality of fuels and the reduction of 000100000200000200001 itions for the quality of fuels only for the year 20 000100000800000100007 ssions and the quality of petrol and diesel fuels fo 000100001100000400001 to improve the quality of petrol and diesel fuels in 000100000200000600004 hope that the quality of the air will start to impr 000100000100000400008 ss because air quality will be improved, but also b 000100000100000400005 to improve air quality will have a direct and unprec $000100000800000200004 \mathrm{~h}$ is geared to sustainable development .

000100000800000200005 sations, to a sustainable technology which can resp 000100001300000200001 lead to lower toxic emissions and encourage the dev 
000200000300000400002 ssed about the cost, it is not great .

$000200000700000400013 \mathrm{~g}$ aware of its cost .

000200000300000400004 Europe it will cost only Ecu 5 to Ecu 8 more every y 000200000200000500002 a very narrow cost-effectiveness analysis, but Par 000200000200000500003 e to show that costs sustained out of human illness 000200000200000500002 brought other economic arguments to the discussion 000200001300000100005 e to introduce economic incentives to speed progress 000200000100000400004 ide-effects on employment .

000200000100000300001 ir quality and employment in Europe ; secondly from 000200000100000400005 the number of jobs created in the motor vehicle ind $000200000100000400008 \mathrm{t}$ also because jobs will be safeguarded and the sect 000200000100000400006 , up to $6 \%$ of jobs will disappear .

000200000700000400003 ss made by car manufacturers to comply with European 000200000100000400002 that small and medium-sized businesses can also be $i$ 000200000400000400003 have prevented medium-sized businesses from carrying 000200000100000400003 sing small and medium-sized businesses in this secto $000200000400000400005 \mathrm{I}$ am glad that medium-sized businesses will, in man 000200001100000200001 If the overall social, human and environmental bene 
Table 24: Multinomial logit regression estimates, first reading, 6.4. , 1996/163.

\begin{tabular}{lcc}
\hline & No Vote & Yes Vote \\
\hline Left-Right Dimension & $-3.18^{*}$ & $-5.42 * * *$ \\
Sovereignty-Integration Dimension & $(1.38)$ & $(1.30)$ \\
& $-1.45 * * *$ & -.10 \\
Constant & $(.44)$ & $(.33)$ \\
& 1.50 & $(.73)$ \\
Number of cases & $(.78)$ & \\
Log pseudo-likelihood & 412 & \\
Pseudo R & -208.88 &
\end{tabular}

Note: Table entries are multinomial logit estimates. The omitted (baseline) choice for each column is "Abstention." Robust standard errors appear in parentheses. Statistical significance is indicated as follows: $* * *<0.001$ level; $* *<0.01 ; *<0.05$

Table 25: Multinomial logit regression estimates, first reading, 6.4. , 1996/164a.

\begin{tabular}{lcc}
\hline & No Vote & Yes Vote \\
\hline Left-Right Dimension & $9.30^{* *}$ & $-1.78^{* * *}$ \\
Sovereignty-Integration Dimension & $(3.04)$ & $(.54)$ \\
& $-3.79 * * *$ & $.95^{*}$ \\
Constant & $(.79)$ & $2.25^{* * *}$ \\
& $-5.19^{* * *}$ & $(.21)$ \\
Number of cases & $(1.88)$ & \\
Log pseudo-likelihood & 411 & \\
Pseudo R & -140.40 & \\
\hline
\end{tabular}

Note: Table entries are multinomial logit estimates. The omitted (baseline) choice for each column is "Abstention." Robust standard errors appear in parentheses. Statistical significance is indicated as follows: $* * *<0.001$ level; $* *<0.01 ; *<0.05$ 


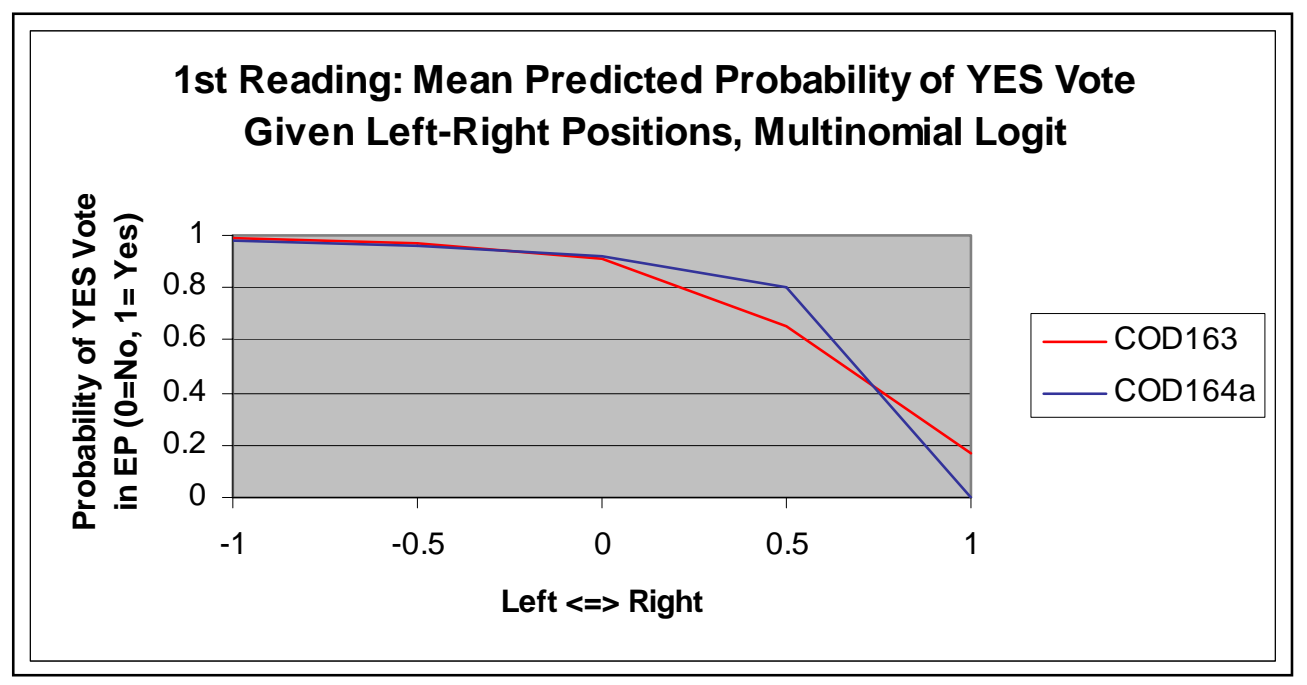

Figure 48: Probabilities 6.4.C

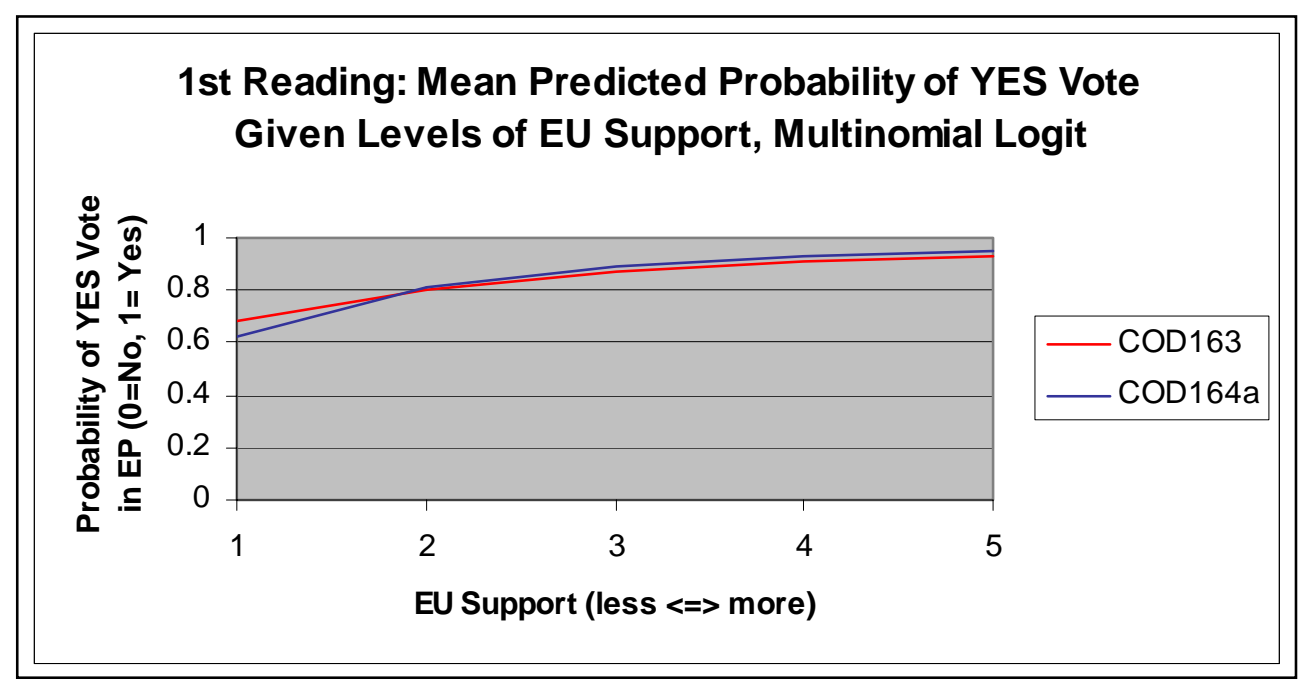

Figure 49: Probabilities 6.4. D 


\section{APPENDIX G}

\section{CHAPTER 6.5 .}

Table 26: Frequencies-of-use, content analysis, 6.5.

\begin{tabular}{|c|c|c|c|c|}
\hline & $\begin{array}{c}\text { \# of input } \\
\text { words }\end{array}$ & $\begin{array}{c}\text { \# of references to } \\
\text { Workability. }\end{array}$ & $\begin{array}{c}\text { \# of references to } \\
\text { License to Pollute. }\end{array}$ & $\begin{array}{c}\text { \# references to } \\
\text { Harmonization. }\end{array}$ \\
\hline Debate & 14,619 & 112 & 180 & 21 \\
First & $(10,000)$ & $(77)$ & $(123)$ & $(14)$ \\
Reading & 35 speakers & 31 speakers & 34 speakers & 11 speakers \\
\hline Debate & 9,574 & 92 & 71 & 9 \\
Second & $(10,000)$ & $(96)$ & $(74)$ & $(9)$ \\
Reading & 20 speakers & 18 speakers & 16 speakers & 4 speakers \\
\hline Debate & 3,968 & 17 & 14 & 9 \\
Third & $(10,000)$ & $(43)$ & $(35)$ & $(23)$ \\
Reading & 8 speakers & 5 speakers & 6 speakers & 4 speakers \\
\hline
\end{tabular}


Table 27: Binomial logit regression estimates, first reading vote, 6.5 .

Floor Vote, First Reading

Left-Right Dimension

Sovereignty-Integration Dimension

$4.11 * * *$

Government Status

$1.18^{* * * *}$

Liberal Market Economy

1.17

(.77)

Partial Coordinated Market Economy

Sectoral Coordinated Market Economy

Constant

1.07 *

(.47)

485

Number of cases

$-131.78$

Log pseudo-likelihood

0.59

$* * *=$ significant at 0.001 level; $* *=$ significant at 0.01 level $; *=$ significant at 0.05 level Dependent Variable: Vote: $1=$ for, $0=$ against, abstain $=0$

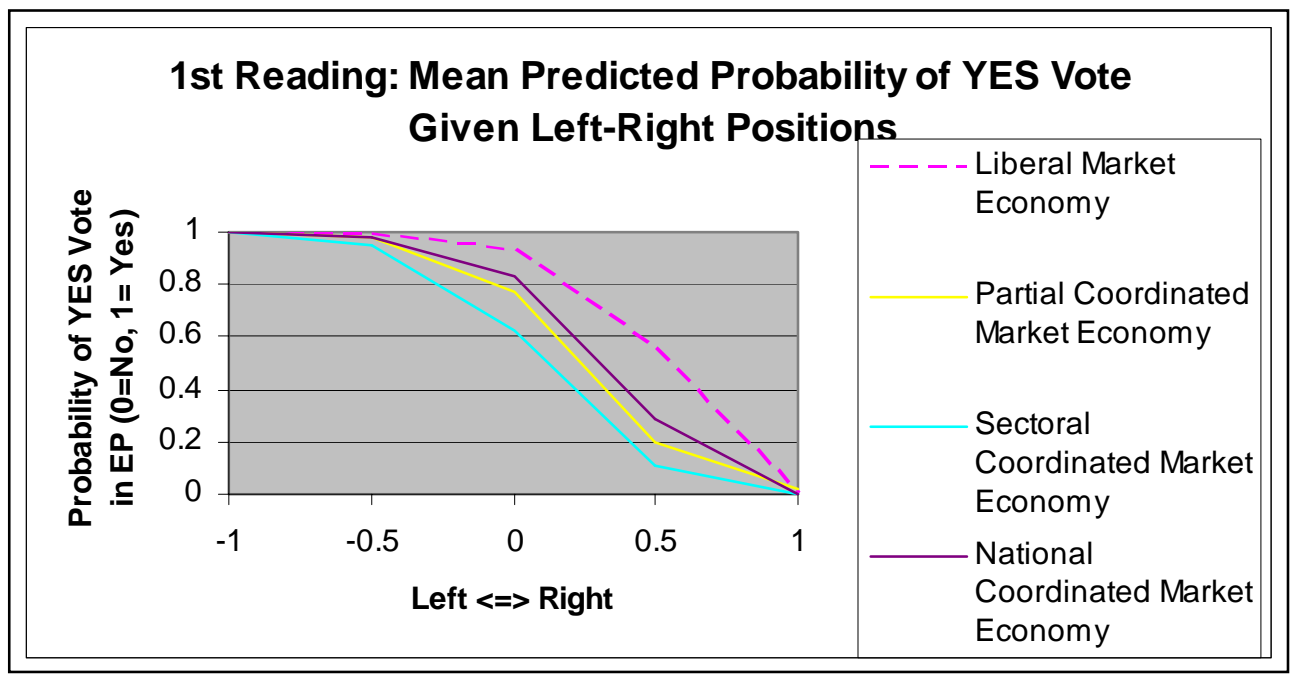

Figure 50: Probabilities 6.5. A 


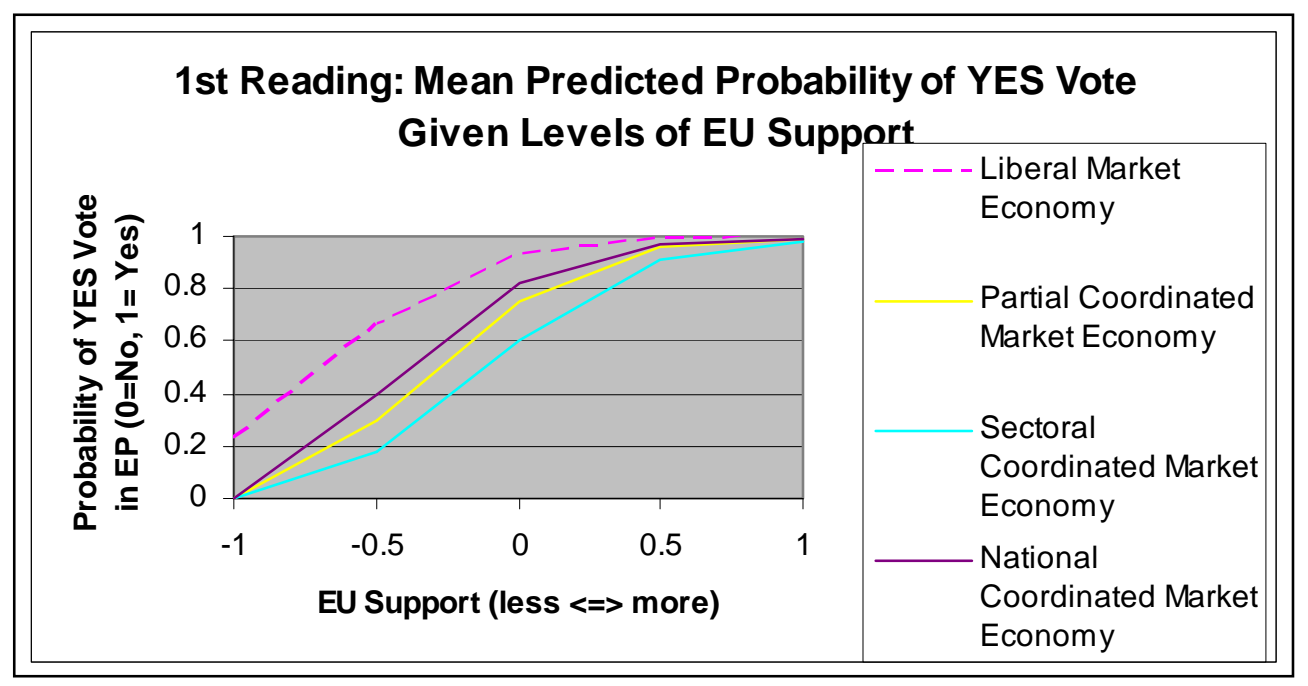

Figure 51: Probabilities 6.5. B

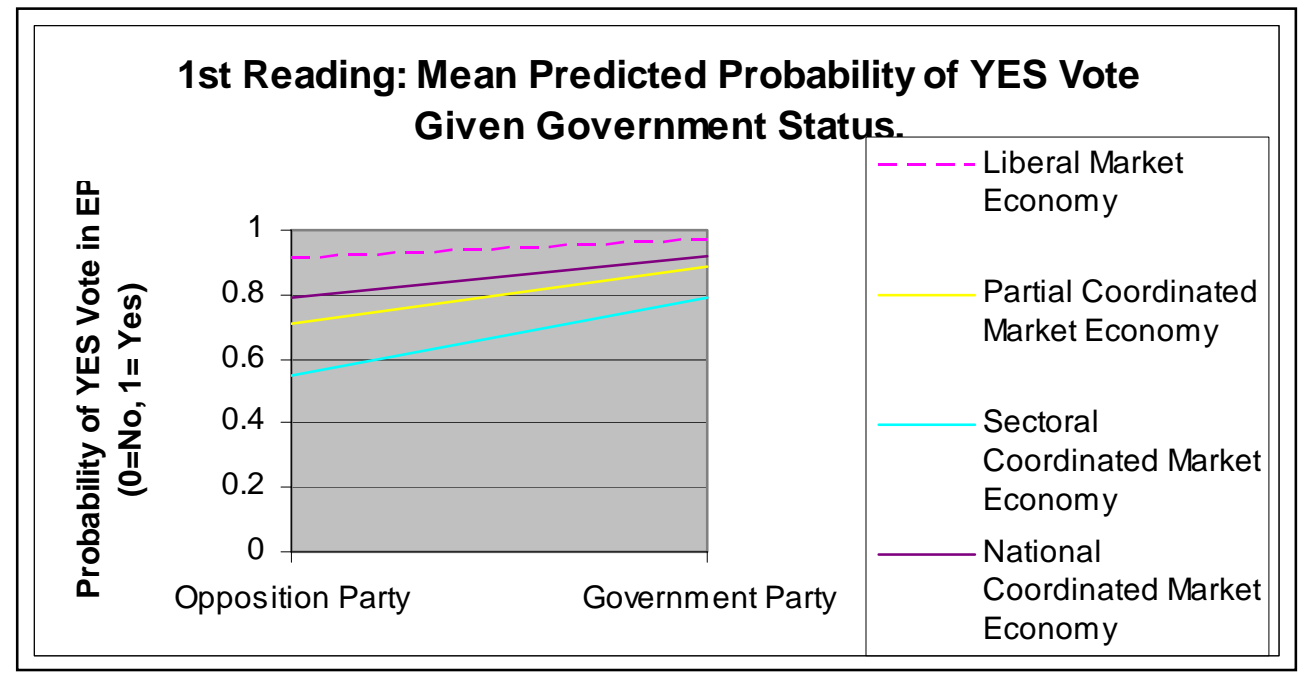

Figure 52: Probabilities 6.5. C 

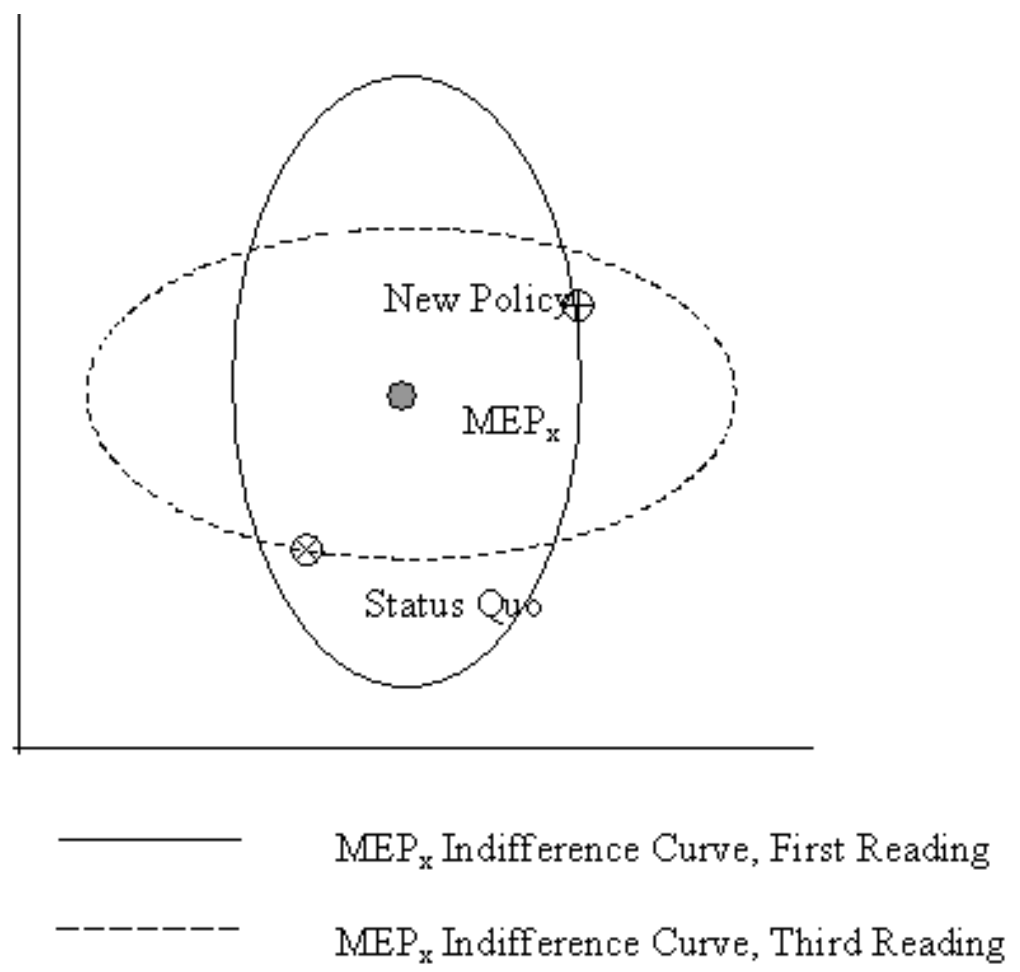

Figure 53: Policy Space 6.5. 


\section{TEXTPACK Analysis}

\section{Focal Point 1: Workability.}

achievable, business, companies, competition, distortions, efficient, gain, implementable, impractical, incalculable, moderate, patchwork, pragmatic, profit, proportional, realistic, reasonable, sensible, unworkable, well-balanced, America- (and relevant endings), cost- (and relevant endings), econom- (and relevant endings), industr-, (and relevant endings), practical(and relevant endings), relocat- (and relevant endings), workab- (and relevant endings), direct proportion, in proportion, scientific knowledge, small- and medium-sized small businesses, small companies, United States

\section{Focal Point 2: License to Pollute.}

agricult-, AZF, Aznalcoyar, biodiversity, dangerous, dumping, ecosystem, environment, environmentally-friendly, Erika, fauna, flora, forest, GMOs, health, biological diversity, ecolog(and relevant endings), environmental objectives, environmental protection, environmental responsibilities, Exxon Valdez, genetic- (and relevant endings), green fundamentalists, habitat(and relevant endings), human lives, licence to pollute, loopholes, maritime disaster, Natura 2000, nuclear accidents, oil, pesticides, precautionary, Prestige, Priolo, public funds, public health, public purse, radiation, radioactive, Seveso, species, sustainab- (and relevant endings), tax- (and relevant endings), Tricolor, vague

\section{Focal Point 3: Harmonization.}

Lisbon, harmonis- (and relevant endings), European model, internal market, level playing field, viability of Europe, people of Europe, uniform European framework, European standards, the whole of the European Union, European society, citizens of the European Union, European citizens, European principle, European model

\section{Keywords-in-context}

Cat $=$ focal point category: Cat $0001=$ workability, Cat $0002=$ license to pollute, Cat $0003=$ harmonization .

ID1: Speaker ID

ID2: Paragraph ID

ID3: Line ID 
EP Debate, first reading (May 13, 2003):

Cat ID1 ID2 ID3

000100001300000300002 time when the United States is putting pressure on 000100000500000300002 hether this is achievable at the moment .

000100001600000100004 easier for the business community to comply with thi 000100003500000200001 with regard to business interests, weakening the in 000100003000000300004 the event that companies become insolvent .

000100002500000300002 the insurance companies cannot take on this respons 000100002000000200004 ility of small companies is not jeopardised .

000100002000000100010 that insurance companies need a certai

000100000400000300005 at managers of companies that put the environment at 000100000200000500005 distortion of competition.

000100001400000100003 distortion in competition.

000100003300000200003 distortion of competition in the internal market, 000100000200000100003 bility and the cost and pollution is prevented, not 000100003500000100003 hese disasters cost human lives and lead to serious 000100001100000100004 y have time to cost it properly .

$000100002900000100006 \mathrm{r}$ to carry the cost of cleaning up the site .

000100003500000200002 uters bear the cost of environmental damage, giving 000100001200000200004 lities and the cost of insurance premiums reward tho 000100002000000200003 portioning the cost of restoring ecological damage $t$ 000100002000000100002 portioning the cost of restoring the damage . 00010000230000030000411 pick up the cost of that?

000100002200000300004 What will it cost when two wild hamsters are remov 000100000400000400007 at assigns the costs fairly and at the same time act 000100000400000400006 elves or incur costs in advance, which may be consi 000100002300000100004 ctual clear-up costs of a site .

$000100003300000200001 \mathrm{r}$ will pay the costs of remedying future environment 000100001500000300002 who bears the costs of remedying the environmental 000100001600000300005 including the costs relating to environmental damag 000100001600000300005 but if all the costs were to be charged on, includi 000100003200000200004 means that the costs will be split in cases where th 000100001400000200004 ur anger is in direct proportion to the extent of th 000100002000000100003 and to prevent distortions of the market . 000100001200000200002 are engaged in economic activities producing goods o 000100000600000200004 ts the various economic activities which are covered 000100001500000400001 ry for all the economic activities which could resul 000100000600000300001 ability of the economic activity in question .

000100000200000700001 eping with the economic and social objectives of the 000100003000000100004 ear message to economic operators that polluting doe 000100000500000200001 interests and economic sectors involved in this sub 000100000500000300003 urable for the economic sectors or whether it will $\mathrm{r}$ 000100000100000500001 is part of our economy . 000100001400000100002 e agricultural economy . 
000100003200000100005 social market economy .

000100000200000600006 dustry and the economy as a whole to turn green . 000100000200000500006 impact on the economy that we hope for .

000100003100000200006 e, workable, efficient and reasonable, and theref 000100002000000100007 ne qua non for efficient environmental protection . 000100000100000400004 - workable and implementable , one that will ultimat 000100003400000100003 unworkable and impractical solution to what is alrea 000100001400000300001 bility must be in proportion to the acknowledged fau 000100000500000300003 it will remain incalculable for them .

000100001600000200006 located in an industrial area .

000100001400000100002 ing either the industrial or the agricultural econom 000100002200000300004 emoved when an industrial park is built; who can pa 000100000500000100006 ion of certain industrial sectors, the extent of th 000100002200000200004 tors - the oil industry, the nuclear industry - is 000100001700000200004 consumer goods industry .

000100002400000200001 sibilities for industry .

000100002800000100003 ts of European industry .

000100002800000400002 alise European industry .

000100000100000400003 fically favor industry and does not specifically fa 000100002500000100002 ssure from the industry and from governmental organi 000100003300000300002 e interests of industry and of environmental players 000100000200000600006 rope, we need industry and the economy as a whole $t$ 000100003400000300004 erests of both industry and the environment . 000100002400000100008 If industry has an environmental permit 000100001700000100004 grettable that industry has managed to insert a seri 000100001100000100004 the insurance industry has said that it can make it $000100001700000300003 \mathrm{ch}$ are to give industry incentives to take preventiv $000100002400000100007 \mathrm{t}$ the whole of industry is rallying round Mr Manders 000100001100000200003 ing burdens on industry or on agricultural producers 000100000400000200005 sed by the oil industry or the nuclear industry or $\mathrm{w}$ 000100000400000200005 or the nuclear industry or why it should not apply t 000100002900000100003 mber States of industry polluting an area and then $\mathrm{m}$ 000100002400000100004 is not getting industry to pay, however, but the $n$ 000100000700000300001 pressure from industry to too great an extent . 000100002200000200004 , the nuclear industry - is sufficiently well cover 000100000300000300002 sued a clear, moderate and practicable opinion . $000100000200000100003 \quad$ The practical application of the polluter 000100001900000300001 pollution is a practical problem, remedial actions $000100000900000200002 \quad$ In practical terms, a farmer might be $f$ 000100001100000300011 o do something practical to protect it and to put al 000100001900000300001 ctions must be practical too . 000100000600000300002 principle then practically all related activities wo $000100001000000100004 \mathrm{~ns}$, making it practically impossible to demand that 000100002800000300005 a reference to proportional liability, not joint an 000100000100000300006 e workable and realistic .

000100003100000100004 , workable and reasonable, and it provides for upda 
000100003100000200006 efficient and reasonable , and therefore I am prepa 000100003400000300004 Thanks to the reasonable approach advocated by the 000100000200000100003 which is only reasonable because, of course, we n $000100001200000300002 \mathrm{n}$, which is a reasonable compromise to reach, so w 000100003200000200002 sed on current scientific knowledge .

000100000600000300001 e existence of scientific knowledge which, at the $t$ 000100000300000500004 ound here is a sensible one .

000100002000000200004 e viability of small companies is not jeopardised . 000100002200000400002 be relevant to small- and medium-sized enterprises i 000100003400000100003 ve produced an unworkable and impractical solution $\mathrm{t}$ 000100003100000100004 presenting is well-balanced, workable and reasonab 000100002800000100003 lation must be well-balanced and take into considera 000100000500000200001 he result is a well-balanced report and a well-balan $000100000500000200001 \mathrm{~d}$ report and a well-balanced result which takes acco 000100003100000200006 gally secure, workable, efficient and reasonable, 000100001400000100002 objective and workable, so as to protect the envir 000100001100000200003 legislation is workable and does not impose cripplin 000100000100000400004 alking about - workable and implementable, one that 000100000100000300006 rules that are workable and realistic .

000100003100000100004 ell-balanced, workable and reasonable, and it prov $000100002200000100005 \mathrm{n}$ to achieve a workable compromise .

000100002200000100004 e to be a very workable compromise that should win a $000100000700000300004 \mathrm{~s}$ directive is workable in the European Union . 000100000100000400004 nto a piece of workable legislation that will result $000100003200000100002 \mathrm{w}$, produced a workable proposal .

000200003500000100003 the example of AZF in Toulouse in 2002 or the Erika 000200002400000200003 estige and the Erika, as well as nuclear accidents 000200002100000200006 estige and the Erika .

000200003500000100003 in 2002 or the Erika and Prestige oil tankers, thes 000200000400000300001 not the names Erika and Prestige synonymous with ab 000200000100000300003 Valdez and the Erika and then the Prestige, but the 000200000100000300003 rst we had the Exxon Valdez and the Erika and then $t$ 000200002300000400001 he question of GMOs, not because we are against GMO 000200001300000300002 y must include GMOs, particularly at a time when th 000200000800000300004 which includes GMOs, they fall within the scope of 000200000800000300001 ple is that of GMOs . 000200001300000200002 ydrocarbons or GMOs . 000200003500000200002 mage caused by GMOs . 000200002100000200002 activities and GMOs?

$000200000800000300004 \quad$ GMOs are certainly covered by this pr 000200000800000300006 in the case of GMOs are clearly resolved in a way th 000200002300000400001 we are against GMOs but because we think this legisl 000200000600000300002 in the case of GMOs or of pesticides which are, amo $000200002200000300001 \mathrm{f}$ bringing the GMOs that are permitted back under th 000200000800000300002 ate release of GMOs was being discussed, the Commis 000200001700000300001 restricted to Natura 2000 areas, but also applies 
000200001300000200001 be limited to Natura 2000 areas and would exclude $n$ 0002000015000001000031 tanker, the Prestige, and, last but not least, 000200000100000300003 a and then the Prestige, but the report also has po 000200003500000300001 caused by the Prestige, causing amazement and ange 000200001400000200003 affair of the Prestige, when we observe the consta 000200000600000200008 victims of the Prestige accident .

000200002400000200003 involving the Prestige and the Erika, as well as n 000200002100000200006 sters like the Prestige and the Erika .

000200002500000100003 including the Prestige disaster, we must insist on 000200000800000200005 following the Prestige disaster.

000200003300000100002 concerning the Prestige oil tanker, which was shipw 000200003500000100003 the Erika and Prestige oil tankers, these disaster 000200000400000300001 ames Erika and Prestige synonymous with absolutely e 000200001500000100003 caused by the Priolo chemical plant, are all incid $000200001500000100003 \quad$ Seveso, the disasters, with which w 000200001600000300002 elating to the Tricolor disaster two months ago, an 000200002600000300001 ue of reducing biodiversity, I think it important $t$ 000200000200000200002 For example, biodiversity, as defined in the draf 000200000600000200002 In the case of biodiversity, for example, a propor 000200001300000100002 with regard to biodiversity, which is already gover 000200001400000200004 damage done to biodiversity .

000200002800000200003 definitions of biodiversity and biodiversity damage 000200000200000200003 and damage to biodiversity caused by genetically mo 000200001700000200002 that damage to biodiversity caused by the use of lic 000200002800000200003 odiversity and biodiversity damage .

000200003000000200004 The loss of biodiversity in the European Union is 000200002300000200004 definition of biodiversity is a very weak and very 000200003000000200003 e of damage to biodiversity must be clarified but th 000200002100000200003 ect and remedy biodiversity with a directive which e 000200000600000200002 to only $20 \%$ of biodiversity would be protected, and 000200000300000200004 mage caused to biological diversity, that is, for 000200000300000400001 definition of biological diversity .

000200002800000200002 e particularly dangerous, in that they would make $\mathrm{i}$ 000200003000000300004 rators in more dangerous activities, in order to pr 000200001700000200004 to the list of dangerous activities in this way mean 000200001500000300001 of some of the dangerous exemptions which allow wide $000200001500000400002 \mathrm{~s}$ deemed to be dangerous or not .

000200000100000500005 environmental dumping and we will avoid a situation 000200001400000200003 idents of fuel dumping at sea, we might think that 000200003000000300001 damage to the ecological and chemical makeup of wat 000200000300000200006 liability for ecological damage, even though we ar 000200000300000200004 what is termed ecological damage .

$000200002000000200003 \mathrm{t}$ of restoring ecological damage to the operator, $\mathrm{p}$ 000200002000000300001 effective and ecological disasters are to be preven 000200000200000600004 entlemen, the ecosystem and the flow of matter and 000200000400000100002 at deal of our environment, often too much . 
000200000400000100003 protecting the environment, such as the uniform pro 000200001100000200005 danger to the environment, then someone has to pay 000200000800000100003 caused to the environment, which is often cross-bo 000200000100000400003 lly favor the environment. 000200000100000400004 ly protect the environment . 000200000100000500005 or protect the environment . 000200000400000300005 oration of the environment . 000200000800000300006 lic and to the environment . 000200001200000100005 impact on the environment. 000200001500000200002 es against the environment . 000200002800000300006 ght affect the environment . $000200002900000200002 \mathrm{~s}$ to the Irish environment . 000200003300000100006 elating to the environment . 000200003400000300004 dustry and the environment . 000200000400000200003 they treat our environment and be more careful . 000200003100000200001 riches of the environment and even more important $t$ 000200003000000300003 amaging to the environment and international instrum 000200000500000100005 protecting the environment and the obligation to rep 000200000100000400004 pproach to the environment and will ultimately prote 000200003300000100004 linked to the environment around them .

$000200000400000300005 \mathrm{~s}$ that put the environment at risk have insurance or 000200000400000300003 eless with the environment because certain polluters 000200003400000300001 protecting the environment because it is inherently 000200001100000300010 ge done to our environment by human activity . 000200000400000400002 restoring the environment by the back door either . 000200001700000100002 rtance of this environment directive . 000200000900000200004 for the rural environment in general . 000200000600000200001 inition of the environment is too restricted . 000200000700000100002 we know, the environment is 'out' . 000200001900000100007 be helping the environment itself . 000200001900000100007 threat to our environment may not only be helping $\mathrm{m}$ 000200001300000200003 e state of the environment where the damage occurs, 000200002100000200002 we protect the environment while excluding nuclear a 000200001400000100002 to protect the environment without harming either th 000200003000000200002 weakening the environmental objectives .

000200000200000700001 arantee better environmental protection , in keeping 000200002000000100007 for efficient environmental protection .

000200003500000100002 uring improved environmental protection and combatin 000200000300000300003 wards improved environmental protection and therefor 000200002800000400002 nal furthering environmental protection but does not $000200002600000100005 \mathrm{y}$ to undermine environmental protection in the EU . 000200002000000300001 ates that, if environmental protection is to be eff 000200002600000400004 base from the environmental protection provisions $t$ 000200000100000500004 legislation on environmental protection throughout $\mathrm{E}$ 000200001000000100004 uld meet their environmental responsibilities . 000200001600000300005 ergy and other environmentally-friendly forms of ene 
000200001800000200003 he large-scale genetic modification of plants . 000200001800000200005 by the use of genetically modified crops .

000200002400000200003 tion caused by genetically modified food.

000200002700000100004 example, with genetically modified organisms, nucl 000200000200000200003 sity caused by genetically modified organisms . 000200000400000200005 the release of genetically modified organisms . 000200002600000300002 countryside by genetically modified organisms . 000200001000000300001 the spread of genetically modified organisms or eve 000200001800000300003 ark to use the genetically modified plants without $\mathrm{m}$ 000200001700000200002 se of licensed genetically modified seed is not cove 000200001800000200004 Plants are genetically modified so that they bec 000200000500000300001 including our green fundamentalists, would like to 000200002200000300003 definition of habitat.

000200000100000600004 tioned sites, habitat and species protected under $\mathrm{C}$ 000200002200000300005 e way in which habitat is defined .

000200001100000300006 eguard special habitats and species .

000200000200000200002 restricted to habitats and species covered by the $\mathrm{H}$ 000200002600000300001 o that all the habitats and species protected by Com 000200000300000400003 e the rules on habitats and species that are already 000200001700000300001 o property and health, liability is not only restri 000200001500000100003 stating future health implications of the environmen $000200003300000100004 \quad$ People's health is inseparably linked to the e 000200003500000100003 disasters cost human lives and lead to serious, lon 000200001500000300001 into a sort of licence to pollute, with the serious $000200002300000300009 \mathrm{~d}$ be seen as a licence to pollute.

000200001600000300003 ed and for the loopholes to be closed .

000200001000000300001 transport, by nuclear accidents, by the damage cau $000200002400000200003 \mathrm{a}$, as well as nuclear accidents and pollution cause $000200001700000200004 \mathrm{~d}$ drilling for oil and gas, are also excluded, as 000200002200000200004 sectors - the oil industry, the nuclear industry 000200000400000200005 caused by the oil industry or the nuclear industry 000200000200000200004 Thirdly, oil pollution and nuclear damage are 000200000800000200003 mage caused by oil pollution and to the damage cause 000200003000000300002 acceptable for oil pollution in maritime transport a 000200001500000100003 sinking of the oil tanker, the Prestige, and, las $000200003300000100002 \mathrm{~g}$ the Prestige oil tanker, which was shipwrecked on 000200003500000100003 a and Prestige oil tankers, these disasters cost hu 000200003300000100003 of some of the oil transporting vessels that sail al 000200001800000300002 umber of these pesticides .

000200001800000300001 portion of the pesticides on the market in the rest 000200000600000300002 of GMOs or of pesticides which are, amongst other 000200000400000300005 rance or other precautionary financial measures in $p$ $000200000200000200003 \mathrm{~d}$ also include radiation, damage to air quality and 000200002900000200002 a sick joke if radiation is not included, as Sellaf 000200002900000200001 le of covering radiation pollution should be include 000200003000000300002 transport and radioactive pollution caused by nucle 
0002000011000003000061 habitats and species .

000200000200000200002 o habitats and species covered by the Habitats and B 000200002600000300001 e habitats and species protected by Community legisl 000200000100000600004 , habitat and species protected under Community leg $000200000300000400003 \mathrm{n}$ habitats and species that are already protected by 000200000200000700003 of a model of sustainability and responsibility in 000200001200000100007 out of general tax revenues, with the problems whic 000200002900000100006 most of which tax-free - should walk away and leave 000200001500000300002 ible, not the taxpayer, who bears the costs of rem 000200000200000400002 burden on the taxpayer. 000200002000000200002 shifted to the taxpayer.

000200000200000100003 ay so that the taxpayer does not bear the liability $000200000800000200001 \mathrm{c}$, unless the taxpayer is called on to make good th $000200001400000300003 \quad$ The taxpayer should not have to support $\mathrm{f}$ 000200002900000100006 and leave the taxpayer to carry the cost of cleanin 000200001200000200003 ir capacity as taxpayers .

000200003000000300004 der to prevent taxpayers having to pay for damage in 000200000400000300002 e community of taxpayers should have to pay for the 000200001300000100002 irective is so vague, particularly with regard to b 000200002300000200002 e have left it vague.

000200002300000200004 weak and very vague description .

$000300001500000100002 \mathrm{~g}$ point by the European citizens .

000300003200000100005 strengthen the European model of an environmental an 000300003200000100005 strengthen the European model of an environmental an 000300003200000100005 ys principle a European principle that can be assert 000300000900000300002 iple useful to European society in general .

000300000500000200002 with specific European standards and the same rules 000300001000000300003 on, which the citizens of the European Union expect 000300000800000100003 o see European harmonisation in the area of damage c 000300000100000500004 ill be issuing harmonised draft legislation on envir 000300003300000200002 This to be a harmonised framework across the Europ 000300003300000200003 etition in the internal market, it is important tha 000300003300000200004 elating to the internal market, that is to say Arti 000300002600000400004 visions to the internal market .

000300000100000500005 to promote the internal market nor protect the envir $000300000100000500001 \mathrm{nt}$ to create a level playing field, because I belie 000300000100000500005 we will get a level playing field, we will avoid e 000300000100000600005 ere would be a level playing field and a comparable 000300001600000300006 er to create a level playing field for this issue as 000300001600000100003 pleased that a level playing field is being created 000300000500000200002 same rules for the whole of the European Union; one 000300000500000200002 well-defined, uniform European framework which prov 000300000200000600006 to protect the viability of Europe, we need industr 
EP Debate, second reading (December 15, 2003):

Cat ID1 ID2 ID3

000100000800000200002 act that their American rivals have enjoyed an arran 000100001500000200004 ssure from the United States, and it should simply 000100001500000100006 ven behind the United States in terms of legislation 000100001600000100002 onment and for business .

000100000200000200004 ourse of their business have to accept responsibilit 000100001800000300003 ing to go into business here .

000100001900000100003 good health of companies, although I believe that i 000100001300000200003 ters are often companies, and we must ensure their 000100000800000200002 ty of European companies , particularly in view of $t$ $000100000900000200002 \mathrm{~s}$ and costs on companies, possibly even driving the 000100002000000200001 tition between companies .

000100001900000300003 e need to give companies a period for adaptation and 000100001900000100003 of the effort companies can and must make in order 000100001300000300003 the fact that companies comply with the legislation 000100000100000500009 daries for our companies either, so as far as this 000100001600000100011 errible to see companies in 20 years ' time facing $p$ $000100001300000400003 \mathrm{~d}$ during which companies must be held responsible fo 000100001300000400003 represent for companies seems to me to be excessive 000100001300000300002 uld allow some companies to escape their duty to pay 000100001300000200004 ocation of our companies towards other markets, and 000100001400000100003 nsequences for companies which are not to blame, $\mathrm{Pa}$ 000100002000000200001 to trade or to competition between companies . 000100001700000100004 distortions of competition in the market . 000100000600000700004 station would cost USD 10 billion, and an accident 000100000300000200001 blic funds and cost many people their jobs and livel 000100001400000200003 nsurance, the cost must not be passed on to the tax 000100000600000100003 luter bear the cost of repairing the damage caused $t$ 000100001400000100003 erator for the cost of restoring ecological damage . $000100000500000100003 \mathrm{r}$ must pay the cost of restoring the damage which he 000100000500000200002 ce so that the cost of the damage is never passed on 000100001700000300002 e issue of how costs are to be shared between severa 000100001700000100003 ood, with the costs being borne primarily by the pe 000100002000000500003 ty and related costs must, therefore, only be appo 000100000900000200002 bligations and costs on companies, possibly even dr 000100002000000500001 the burden of costs where the damage has been cause 000100001700000100004 e incidence of distortions of competition in the mar 000100002000000200001 so as to avoid distortions to trade or to competitio 000100000600000100002 imed at making economic activities compatible with $\mathrm{p}$ 000100001200000100002 been caused by economic activities to the natural he 000100001100000300002 ere deliberate economic activity aimed quite laudabl 000100000600000700006 e liability of economic actors .

000100000600000200002 that it offers economic actors several ways out, in 
$000100000600000100003 \mathrm{~d}$ to encourage economic actors to minimise the risks 000100001700000100003 sible European economic and environmental policy mus 000100001900000100003 aintaining the economic good health of companies, a 000100001800000300002 on which, for economic reasons and reasons of fairn 000100001800000100002 djusted market economy, and consequently, a strict 000100001800000300003 have a viable economy, and that we find people who 000100000100000500007 , as does our economy, because we will then have $\mathrm{m}$ 000100001700000100002 onsible market economy, which makes it clear that $\mathrm{t}$ 000100000100000300007 nowledge-based economy . 000100000100000500009 onment and our economy . 000100001300000200003 val within our economy . 000100000100000300005 ts neither the economy nor the environment . 000100000100000400004 either for the economy or for the environment . 000100000100000300005 onment and the economy would benefit if we could cre 000100001100000300002 at profit and gain can cause exponentially spreadin $000100002000000200001 \mathrm{n}$ will have on industrial activity, we deem it nece 000100001900000200001 protection and industrial development .

000100000200000200001 ropean Union's industrial sites are contaminated, a 000100001600000200002 the insurance industries are not yet able to offer 000100001100000200004 of the nuclear industry .

000100000300000200003 nuclear power industry or genetically modified orga 000100000200000500004 the insurance industry too, must have time to devi 000100001500000300011 of power, and industry will be grateful to him . 000100000500000300004 is direction, industry will never be persuaded to a 000100000500000500001 exceptionally moderate and realistic and I do not $\mathrm{u}$ 000100001700000300003 e sensible and moderate approach that it has taken . 000100000600000400003 e described as moderate in so far as they stipulate 000100001600000300004 We need to be moderate in what we try to achieve to $000100001400000200001 \quad$ This moderate position on the part of the 000100000100000300005 creating this patchwork of environmental legislatio $000100000400000200001 \mathrm{w}$ me to take a practical example . 000100000900000200002 in danger, in practical terms, of imposing heavy, $000100000200000500006 \quad$ In practical terms, that means that our $000100001800000200001 \mathrm{n}$, that it is practically workable, that it is fai 000100001100000300002 te laudably at profit and gain can cause exponential 000100002000000500001 several, and proportional liability, according to 000100000600000400001 e learnt to be realistic after several years as a Me $000100000500000500001 \mathrm{y}$ moderate and realistic and I do not understand how 000100002000000500003 oned on fair, reasonable bases, with the requireme 000100001400000200004 directive, at reasonable intervals, and to define 000100000900000200002 riving them to relocate to other countries where the 000100001300000200004 to promote the relocation of our companies towards o 000100001800000200003 o the state of scientific knowledge, about the excl $000100000800000100005 \mathrm{n}$ the basis of scientific knowledge - and the permit 000100001700000300003 Market for the sensible and moderate approach that $\mathrm{i}$ 000100000900000300002 whether it is sensible to produce a definition whic 
000100000900000200002 beyond what is sensible would be in danger, in prac 000100001600000200003 nate burden on small businesses .

000100001600000200004 ble for making small businesses go under because we 000100001600000200001 also about the workability of the compulsory financi 000100001800000200001 is practically workable, that it is fair and that $\mathrm{i}$ 000200001900000200004 ts such as the Aznalcoyar accident would once again $000200001900000100002 \mathrm{nt}$ such as the Aznalcoyar accident - which took plac 000200000600000600005 mentioned the Erika and Prestige tragedies . 000200000300000200001 wo ships, the Erika and the Prestige, are synonymo 000200000700000100002 ified plants ( GMOs ).

$000200000700000100003 \mathrm{~d}$ labelling of GMOs, it has been clear that there $\mathrm{i}$ 000200000700000100003 correct use of GMOs .

000200000700000200001 als concerning GMOs by Mr Lannoye and others . 000200001200000200002 No 9 to exempt GMOs in advance or to lessen the liab 000200000300000200001 Erika and the Prestige, are synonymous with catast 000200000600000600005 the Erika and Prestige tragedies .

000200000500000300001 y can cause to biodiversity, the ground and water? $000200001500000100006 \quad$ Where biodiversity is concerned, we are la $000200001700000200002 \mathrm{t}$ actually are dangerous .

000200001200000200001 nsidered to be dangerous according to the state of $\mathrm{k}$ $000200000600000700006 \mathrm{pt}$ that such a dangerous activity is exempt from suc 000200000300000300004 those who use dangerous substances should not have 000200001400000100003 t of restoring ecological damage .

000200000200000300004 assess purely ecological damage and to calculate wh 000200001800000100002 adherent of an ecologically-adjusted market economy 000200000600000100003 caused to the environment, but also to act pre-emp 000200000300000100002 regard for the environment, for an undamaged enviro 000200000300000200003 uences for the environment, such as the nuclear pow 000200000100000500008 ficial for the environment, which does not have any 000200000100000300005 conomy nor the environment .

000200000100000400004 omy or for the environment . 000200000200000200001 tection of the environment . 000200000600000100002 protecting the environment . 000200001500000100005 tuation of the environment . 000200001600000100005 an destroy the environment . 000200000200000500004 is done to the environment alone, but businesses , $000200001600000100002 \mathrm{~d}$ both for the environment and for business . 000200000100000500009 efits both the environment and our economy . 000200000300000100003 caring for the environment and preventing damage to 000200000100000300005 that both the environment and the economy would ben 000200000900000200001 impact on the environment and the production system 000200001600000100002 protecting our environment and this is an important 000200000500000100004 health and the environment and we must not water it 000200001700000200003 ge done to the environment by wind power, biomass , 000200001700000100003 damage to the environment can be prevented, and th 000200000200000200007 protecting the environment in Europe . 
000200000200000700002 tection of the environment in the European Union, b 000200000200000200004 damage to the environment in the course of their bu $000200000300000100002 \mathrm{r}$ an undamaged environment is one of the most valuab 000200000200000400003 hat damage the environment must accept liability for 000200000300000100004 damage to the environment or bear responsibility fo 000200000100000500007 think that the environment stands to benefit from th 000200001900000200001 al certainty, environmental protection and industri 000200001300000200002 importance of environmental protection and the fact 000200001700000100002 has social and environmental responsibilities and he 000200000200000300001 with flora and fauna .

000200000200000300001 erference with flora and fauna .

000200000300000200003 er industry or genetically modified organisms .

000200000500000400002 nothing about genetically modified organisms and th $000200000600000600002 \mathrm{~s}$ and users of genetically modified organisms in the 000200000700000100002 rom the use of genetically modified plants (GMOs ) 000200000200000300003 cies and their habitats , too .

000200000500000100004 pes for public health and the environment and we mus 000200001900000100003 economic good health of companies, although I beli 000200000500000300001 fertilisers, pesticides and weedkillers when we al 000200000300000200001 ately burdened public funds and cost many people the 000200000500000100004 huge hopes for public health and the environment and 000200000300000300005 by way of the public purse, who is asked to pay up 000200000200000300003 e to protected species and their habitats, too .

000200000100000100003 ly complex and taxing matter, which is both legally 000200000300000300005 always be the taxpayer, by way of the public purse 000200001400000200003 ssed on to the taxpayer.

000200000500000200002 ssed on to the taxpayer and the polluter can cover $t$ 000200001600000200005 en made of the taxpayer having to bear the burden, 000200001600000200005 e Member State taxpayers who eventually would have t 000200000800000100003 ore us far too vague, but I nonetheless believe tha 000200001200000200004 sfied with the vague wording of the current text . 000300001700000100002 pporter of the European model of the environmentally 000300001700000100002 pporter of the European model of the environmentally 000300000100000300007 was agreed in Lisbon that Europe should become the $000300000100000500007 \mathrm{n}$ have minimum harmonisation .

$000300000100000500009 \mathrm{k}$ that minimum harmonisation is an excellent startin 000300001300000200004 ible degree of harmonisation within the European Uni 000300000400000300002 , however, be harmonised too far, because we have 000300000100000500009 Within the internal market that we want to optim 000300000100000300005 could create a level playing field instead of creati 000300000100000300006 This level playing field is of huge import 
EP Debate, third reading (March 30, 2004):

Cat ID1 ID2 ID3

000100000800000200002 er States that companies ' operating processes and a 000100000700000100004 ry restorative costs .

000100000100000100007 nsure that the costs of repairing environmental dama 000100000100000300004 ying field for economic activities, which we are af 000100000700000100003 ecure social, economic and environmental developmen 000100000100000100010 that connects economic and environmental legislatio 000100000100000200002 ularly in more economically difficult times, will $\mathrm{f}$ 000100000700000100004 onsible market economy, and so I very much welcome 000100000100000200002 will find the economy more important than environme 000100000100000200002 eate a kind of patchwork quilt in Europe and that th 000100000800000200001 rne out in the practical and pragmatic response that 000100000600000200003 From a practical point of view, therefore, 000100000800000200001 practical and pragmatic response that we have had, 000100000500000100003 of issues in a pragmatic way and to ' take it in sin 000100000600000200004 be completely realistic : there is no real progress 000100000500000100002 ieve this is a reasonable compromise . 000100000800000200001 hink we have a workable proposal . 000200000500000300003 mention of the Prestige .

000200000300000400002 e wreck of the Prestige make it necessary that we ag 000200000200000300003 benefiting the environment, so my group very defini 000200000100000300004 to benefit the environment .

000200000700000100004 damage to the environment and, where they have cau 000200000200000500004 tection of the environment in the European Union in 000200000100000200002 important than environmental protection .

000200000200000300001 great day for environmental protection in the Europ 000200000200000300002 ed species and habitats - what is termed purely envi 000200000200000300003 with liability loopholes whose closure was long over 000200000300000400002 who buy crude oil, for calamities such as the wrec 000200000600000200005 faced with an oil slick which entirely wrecks the a $000200000200000300002 \mathrm{e}$ to protected species and habitats - what is termed 000200000700000100003 velopment on a sustainable basis .

000300000700000100004 mitment to the European model of the environmentally 000300000700000100004 mitment to the European model of the environmentally 000300000100000200005 be too little harmonisation, and during the proced 000300000100000200003 e 95 , maximum harmonisation, has not been adopted 000300000100000200005 upport maximum harmonisation, something which I dee 000300000300000300001 or a system of harmonised mandatory financial securi 000300000400000200005 wanted a more harmonised system, and we could have 000300000400000200003 we now have a harmonised system of liability to pre 000300000100000300004 create in the internal market, by some Member Stat $000300000100000300004 \mathrm{r}$ to upset the level playing field for economic acti 
Table 28: Multinomial logit regression estimates, first reading vote 6.5 .

\begin{tabular}{lcc}
\hline & No Vote & Yes Vote \\
\hline Left-Right Dimension & $5.13^{* * *}$ & $-2.77^{* * *}$ \\
& $(1.53)$ & $(.55)$ \\
Sovereignty-Integration Dimension & $-2.46^{*}$ & $2.96^{* * *}$ \\
& $(1.00)$ & $(.69)$ \\
Government Status & .82 & $1.67 *$ \\
Liberal Market Economy & $. .66)$ & $(.68)$ \\
& -1.19 & .55 \\
Partial Coordinated Market Economy & $(1.31)$ & $(1.17)$ \\
Sectoral Coordinated Market Economy & -.93 & -.90 \\
& $(.94)$ & $(.79)$ \\
Constant & .27 & -.76 \\
& $(.94)$ & $(.85)$ \\
Number of cases & .39 & $2.36^{* * *}$ \\
Log pseudo-likelihood & $(1.00)$ & $(.70)$ \\
Pseudo R & 485 & \\
& -178.76 & \\
\hline
\end{tabular}

Note: Table entries are multinomial logit estimates. The omitted (baseline) choice for each column is "Abstention." Robust standard errors appear in parentheses. Statistical significance is indicated as follows: $* * * 0.001$ level; $* *<0.01 ; *<0.05$ 


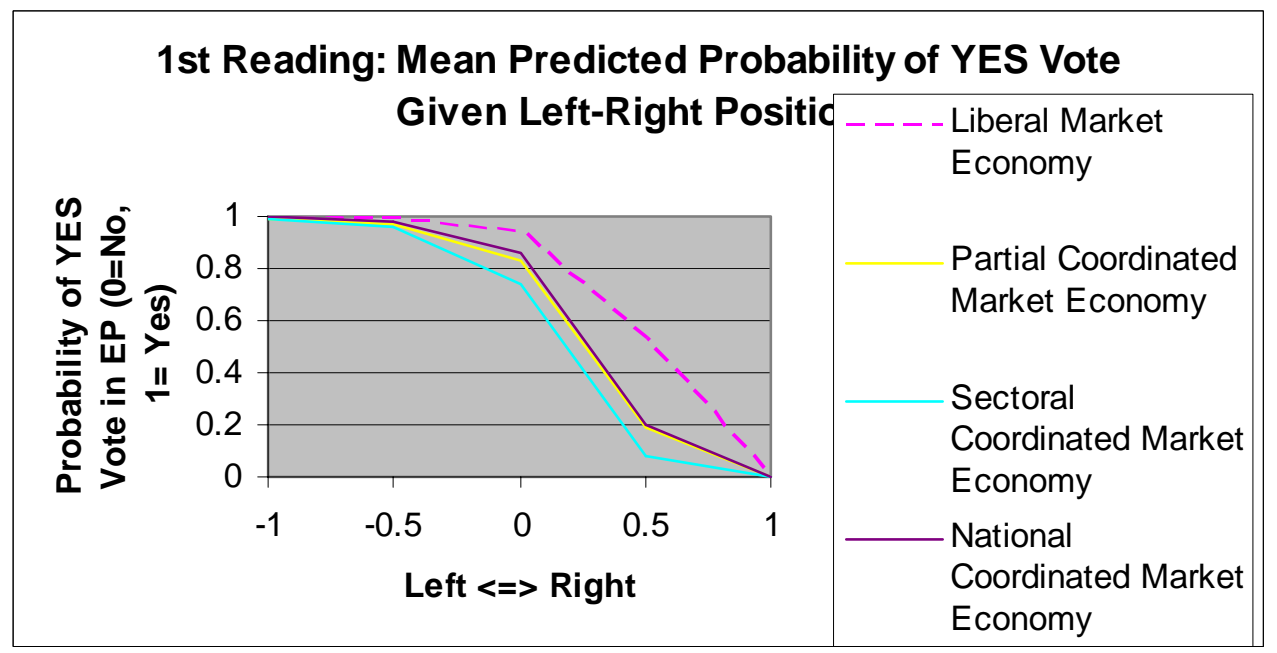

Figure 54: Probabilities 6.5. D

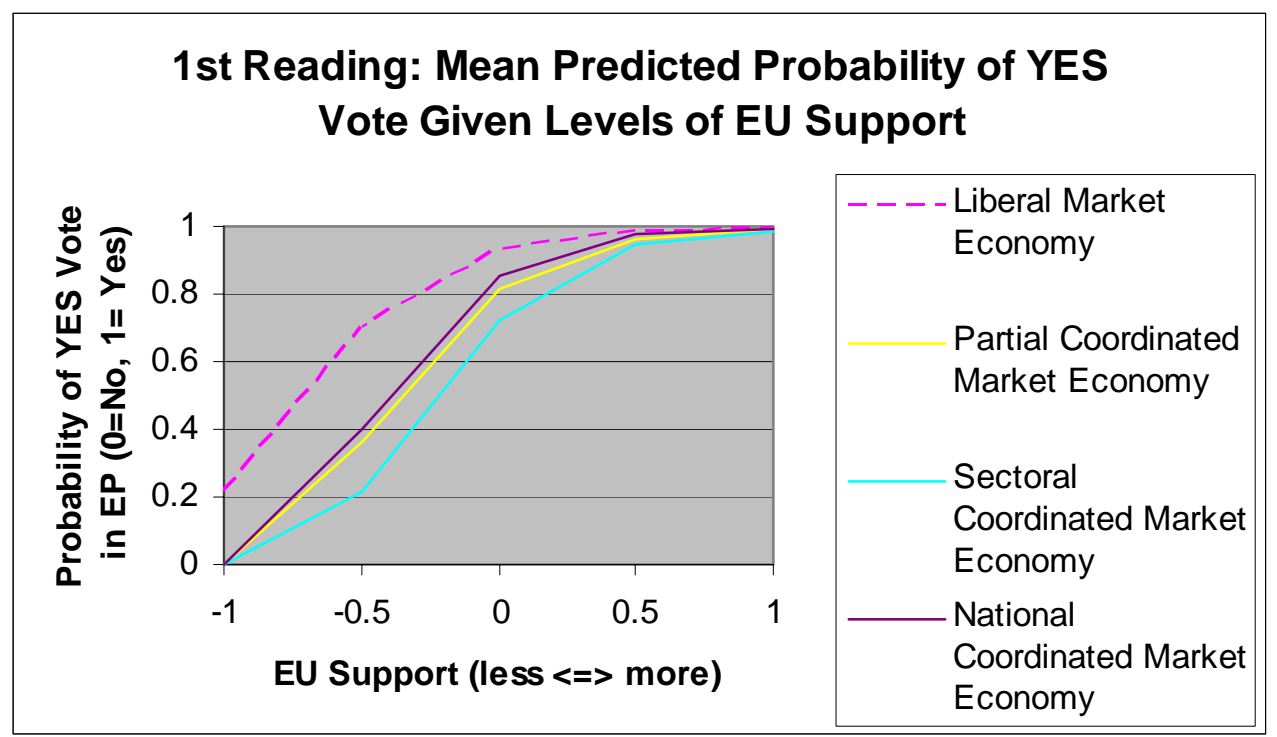

Figure 55: Probabilities 6.5. E 


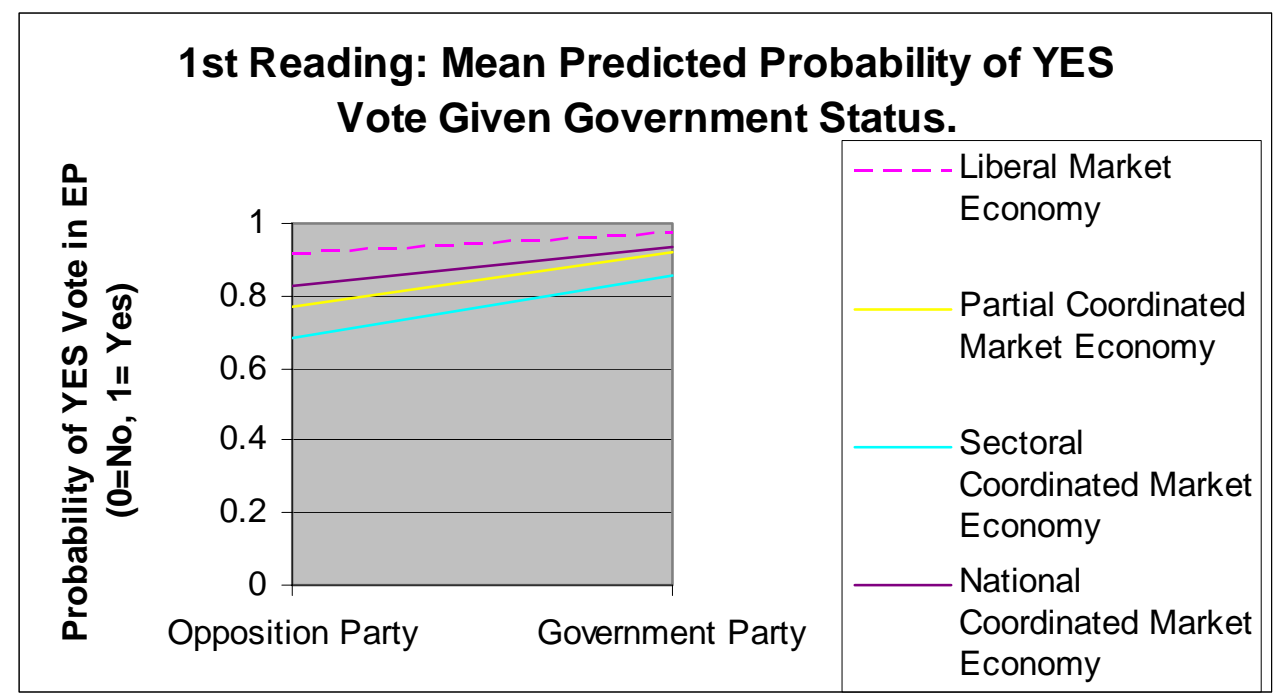

Figure 56: Probabilities 6.5. F 


\section{APPENDIX H}

\section{CHAPTER 6.6.}

Table 29: Frequencies-of-use, content analysis, 6.6.

\begin{tabular}{|c|c|c|c|}
\hline & \# of input words & $\begin{array}{l}\text { \# of references } \\
\text { to liberalization }\end{array}$ & $\begin{array}{c}\text { \# of references to } \\
\text { EU competitiveness }\end{array}$ \\
\hline $\begin{array}{c}1^{\text {st }} \text { Reading Debate } \\
\text { (adjusted by \# of input words) }\end{array}$ & $\begin{array}{c}7,397 \\
(10,000) \\
21 \text { speakers }\end{array}$ & $\begin{array}{c}100 \\
(135) \\
18 \text { speakers }\end{array}$ & $\begin{array}{c}84 \\
(114) \\
19 \text { speakers }\end{array}$ \\
\hline $\begin{array}{c}2^{\text {nd }} \text { Reading Debate } \\
\text { (adjusted by \# of input words) }\end{array}$ & $\begin{array}{c}10,755 \\
(10,000) \\
28 \text { speakers }\end{array}$ & $\begin{array}{c}304 \\
(283) \\
28 \text { speakers }\end{array}$ & $\begin{array}{c}83 \\
(77) \\
25 \text { speakers }\end{array}$ \\
\hline $\begin{array}{c}3^{\text {rd }} \text { Reading Debate } \\
\text { (adjusted by \# of input words) }\end{array}$ & $\begin{array}{c}13,708 \\
(10,000) \\
34 \text { speakers }\end{array}$ & $\begin{array}{c}400 \\
(292) \\
34 \text { speakers }\end{array}$ & $\begin{array}{c}94 \\
(69) \\
31 \text { speakers }\end{array}$ \\
\hline
\end{tabular}

Table 30: Extreme Terminology content analysis, 6.6.

\begin{tabular}{|c|c|c|}
\hline & \# of input words & \# of extreme terms \\
\hline $\begin{array}{c}1^{\text {st }} \text { Reading Debate } \\
\text { (adjusted by \# of input words) }\end{array}$ & 7,397 & 2 \\
\hline $2^{\text {nd }}$ Reading Debate & & $(3)$ \\
(adjusted by \# of input words) & 10,755 & 23 \\
\hline $3^{\text {rd }}$ Reading Debate & 13,708 & $(21)$ \\
& & 28 \\
\end{tabular}


Table 31: Binomial logit regression estimates, first reading vote, 6.6 .

Floor Vote, First Reading

Left-Right Dimension

Sovereignty-Integration Dimension

Government Status

Liberal Market Economy

Partial Coordinated Market Economy

Sectoral Coordinated Market Economy

Constant

Number of cases

Log pseudo-likelihood

Pseudo $\mathrm{R}^{2}$
$1.91 * * *$

$2.31 * * *$

(.30)

$-.43$

$(.25)$

$-1.82 * * *$

$(.45)$

$-.03$

(.36)

$1.00 * *$

$(.38)$

.14

(.32)

536

$-260.68$

0.30

$* * *=$ significant at 0.001 level; $* *=$ significant at 0.01 level; $*=$ significant at 0.05 level

Dependent Variable: Vote: $1=$ for, $0=$ against, abstain $=0$

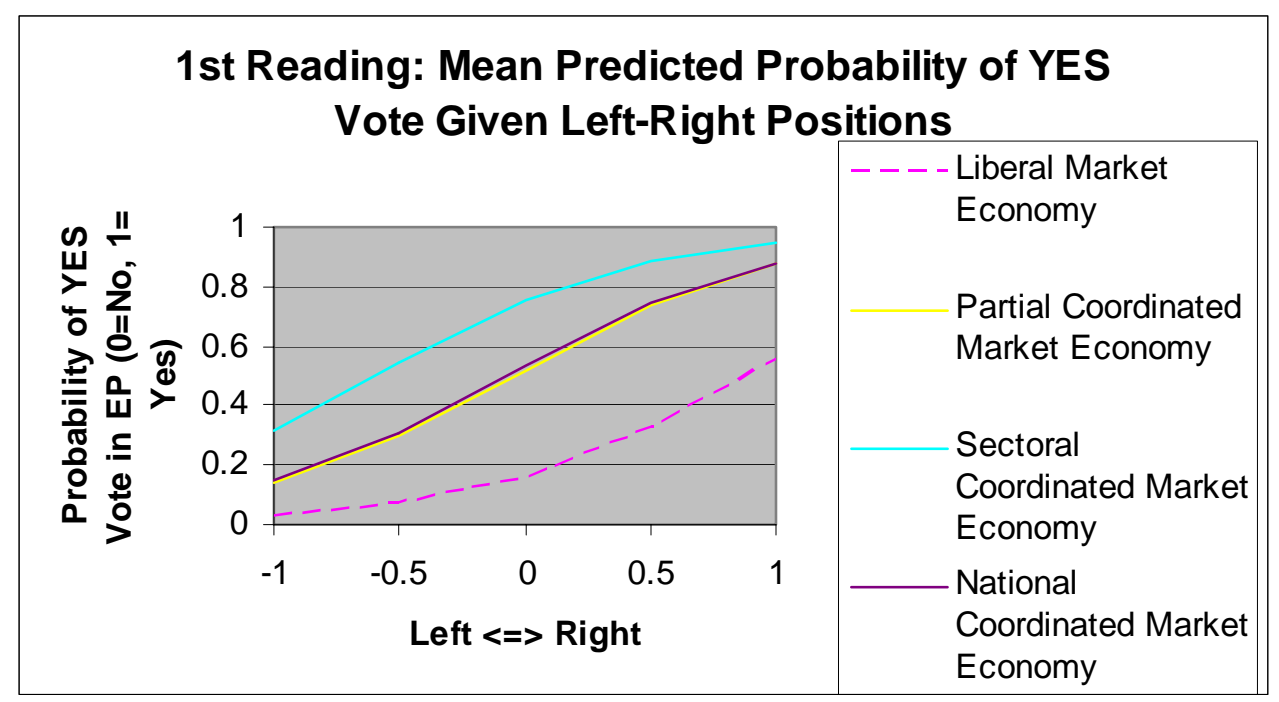

Figure 57: Probabilities 6.6. A 


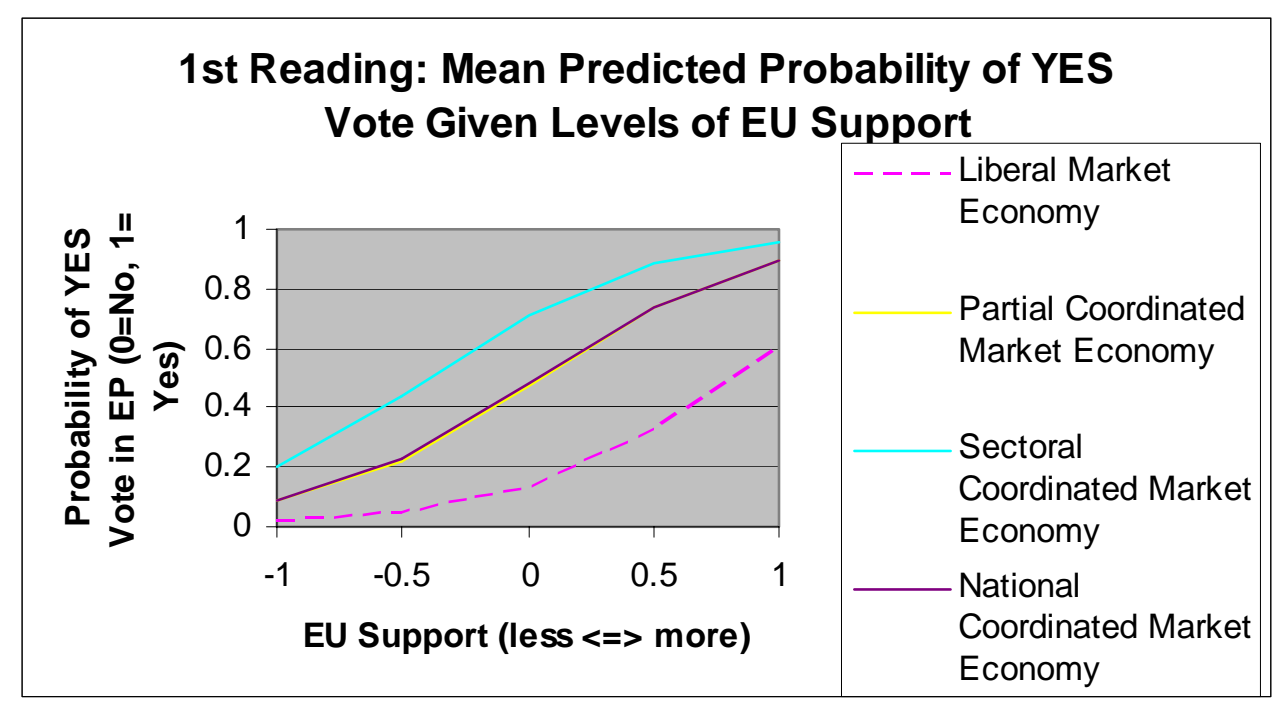

Figure 58: Probabilities 6.6. B

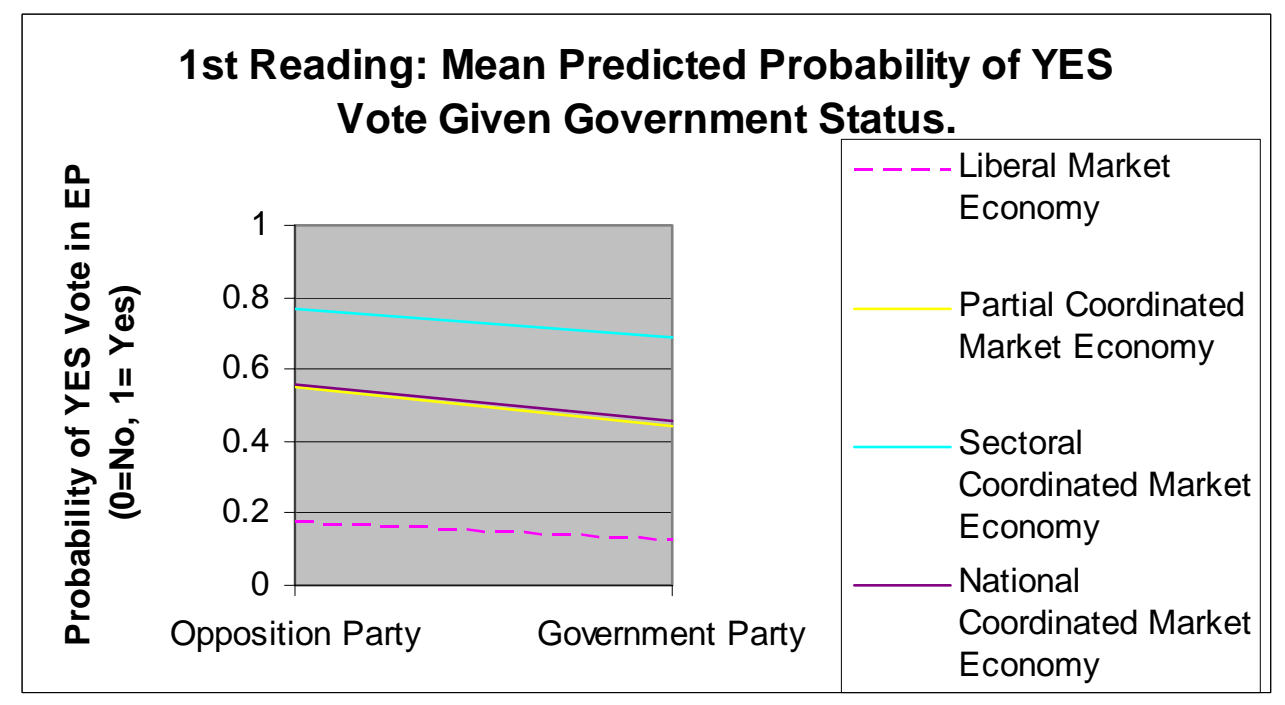

Figure 59: Probabilities 6.6. C 
Table 32: Binomial logit regression estimates, third reading vote, 6.6 .

Floor Vote, Third Reading

Left-Right Dimension

$6.45 * * *$

(.68)

Sovereignty-Integration Dimension

.70

$(.38)$

Government Status

.60

$(.35)$

Liberal Market Economy

$-1.63 *$

Partial Coordinated Market Economy

$-.40$

Sectoral Coordinated Market Economy

$-1.45^{* *}$

Constant

.24

(.43)

Number of cases

422

Log pseudo-likelihood

$-132.66$

Pseudo $\mathrm{R}^{2}$

0.54

$* * *=$ significant at 0.001 level; $* *=$ significant at 0.01 level; $*=$ significant at 0.05 level

Dependent Variable: Vote: $1=$ for, $0=$ against, abstain $=0$ 


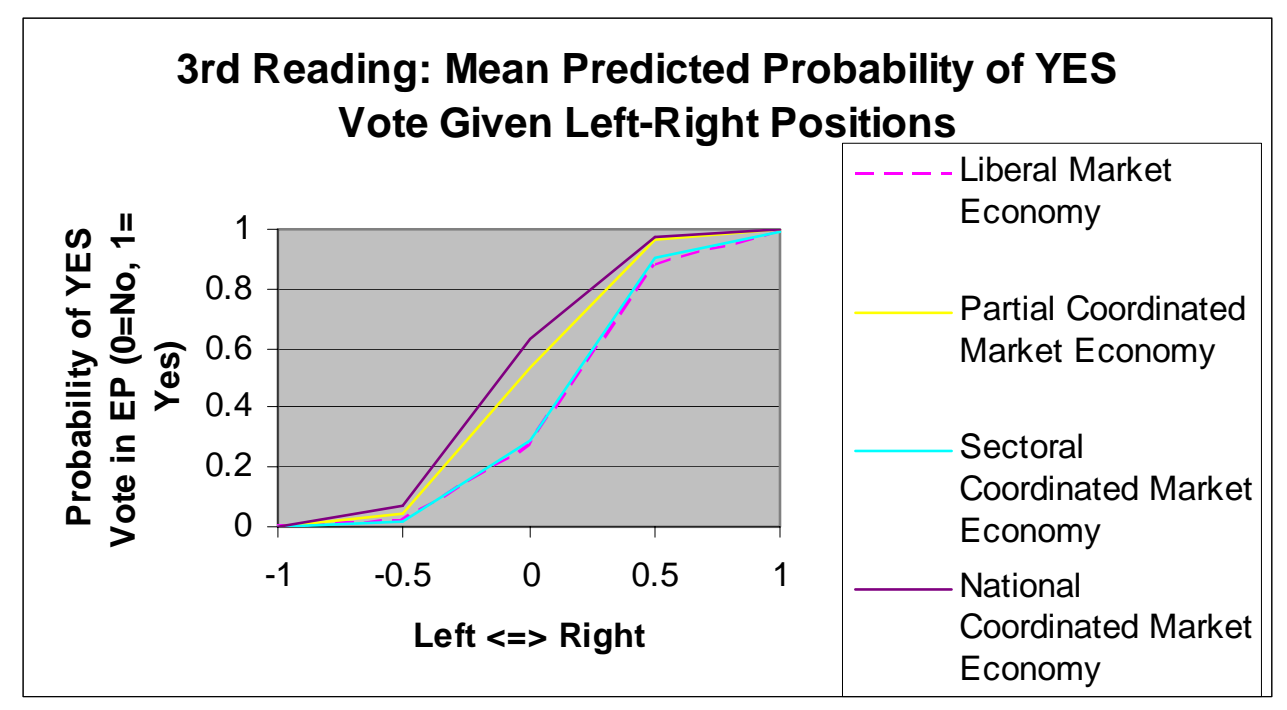

Figure 60: Probabilities 6.6. D

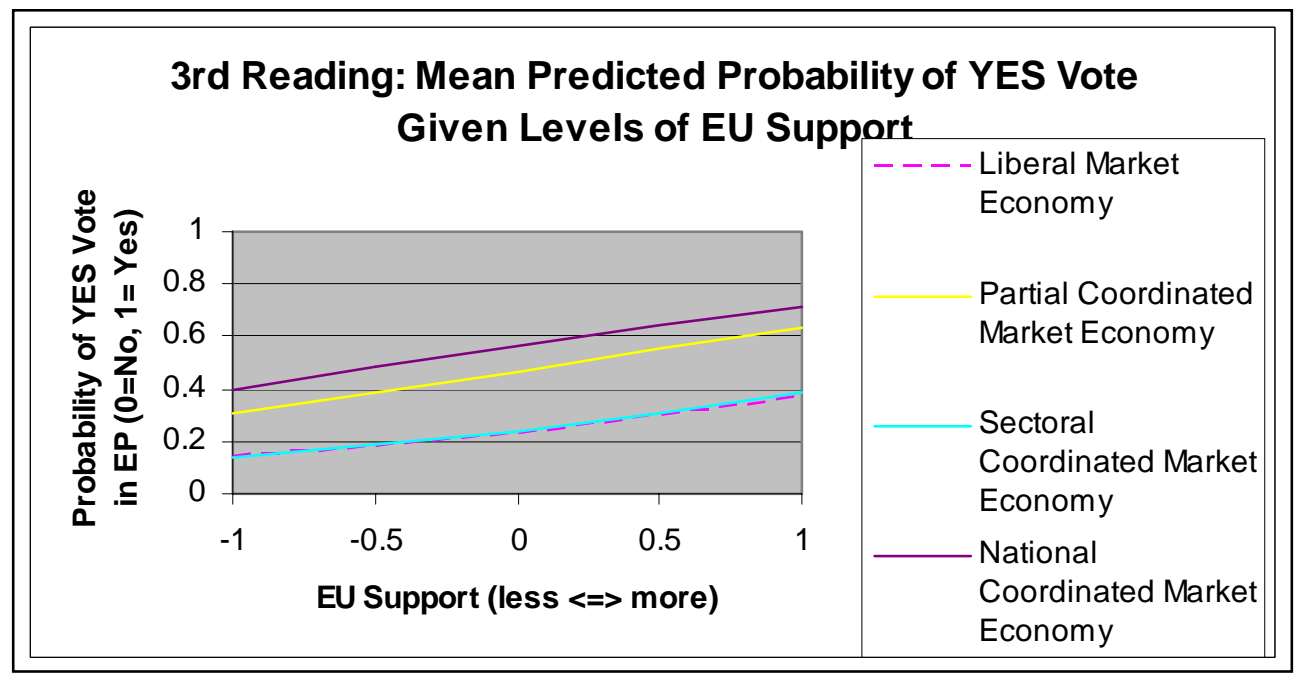

Figure 61: Probabilities 6.6. E 


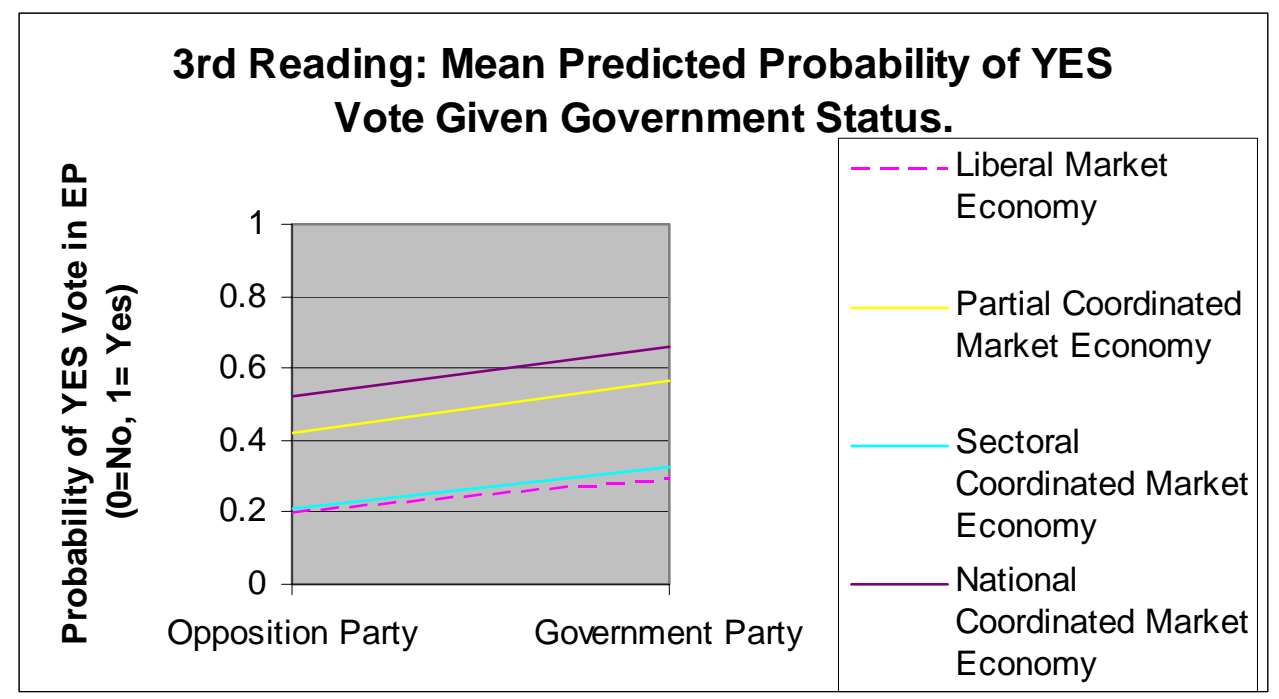

Figure 62: Probabilities 6.6. F 


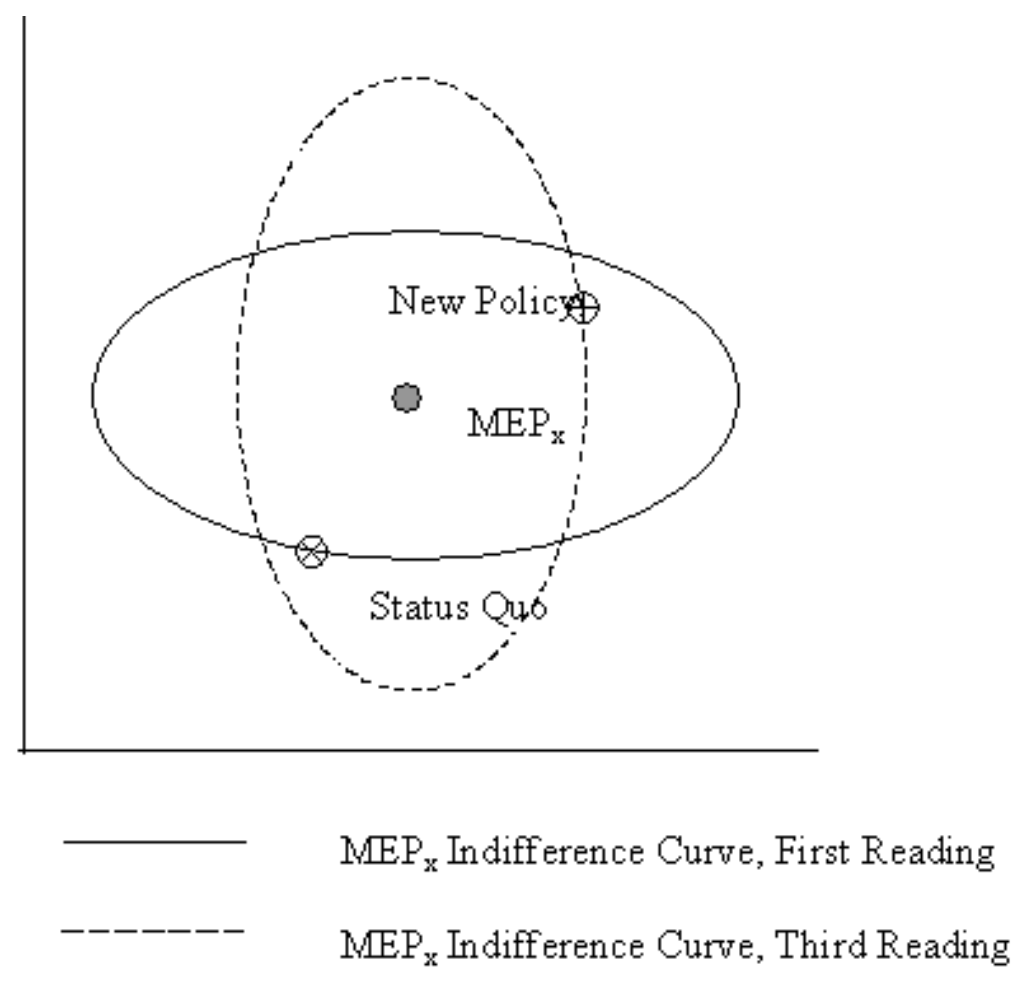

Figure 63: Policy Space 6.6. 


\section{TEXTPACK Analysis}

\section{Focal Point 1: Liberalization.}

abuse, accidents, African, anti-social, Argentinians, cheap, collective agreements, collective bargaining, collisions, competent pilots, competent port workers, cowboy ports, crooks, cutting, dangerous, detriment, developing countries, developing world, developingworld, disasters, dockers, ecological, economising, employ- (and relevant endings), environment- (and relevant endings), Erika, exploit- (and relevant endings), Filipinos, flags (of convenience), globali- (and relevant endings), health, illegal contractors, illegal support, inexperienced, insecurity, job- (and relevant endings), jungle, Karin Cat, labour, liberal, liberalis(and relevant endings), Malays- (and relevant endings), paid, pay, pernicious, Philippinos, pirate, poor, poorly organised, ports of convenience, Prestige, privatisation, qualifi- (and relevant endings), quality, race for profit, ruthless, safety, salar- (and relevant endings), security, slavery, social, solidarity, strik- (and relevant endings), subsidiarity, taxpayers', trade union, train- (and relevant endings), Tricolor, unemploy- (and relevant endings), unionist, unions, unsafe, unskilled, untrained, wage, well-trained, workers, working condition, working conditions, working environments, ultra-Liberal

\section{Focal Point 2: EU Competitiveness.}

business, cheaper services, compete, competition, competitive, economy, effective- (and relevant endings), efficien- (and relevant endings, e.g. bureaucracy), entrepreneur- (and relevant endings, e.g. bureaucracy), Eurosclerosis, financial, growth, harmonisation, internal market, investment, level playing field, levelling, Lisbon, modern, modernise, monopol- (and relevant endings, e.g. bureaucracy), open up, opening up, openness, regulation, single market

\section{Extreme Vocabulary:}

abuse, accidents, African, Argentinians, collisions, cowboy ports, crooks, developing countries, developing world, developing-world, disasters, Erika, exploit- (and relevant endings), Filipinos, illegal contractors, illegal support, Karin Cat, Malays- (and relevant endings), pernicious, Philippinos, pirate, Prestige, race for profit, ruthless, slavery, Tricolor, ultra-Liberal 


\section{Keywords-in-context}

Cat $=$ focal point category: Cat $0001=$ liberalization, Cat $0002=$ EU competitiveness.

ID1: Speaker ID

ID2: Paragraph ID

ID3: Line ID

EP Debate, first reading (November 13, 2001):

\section{Cat ID1 ID2 ID3}

000100000300000300003 the recurrent accidents off the German Baltic coast 000100002000000200002 mendment 52 is dangerous .

000100001000000200001 es not lead to dangerous or inappropriate radicalism 000100001100000200003 eek to exclude dockers from the directive .

000100001100000300001 conditions for employees in this sector, which is $\mathrm{t}$ 000100001100000100004 nvironment and employment .

000100002000000400008 ur to European employment and sustainable developmen 000100001100000200002 ental safety, employment and working conditions .

000100001100000300001 of working and employment conditions for employees i 000100002100000100006 th sustainable employment without the unnecessary pe 000100001100000100005 people and the environment, and have unrivalled kno 000100000900000100005 espect for the environment, are appropriate and vit 000100000500000300001 impacts on the environment, it results in an excess 000100001100000300001 respecting the environment .

000100001100000100004 s safety, the environment and employment . 000100000400000300003 aspects, the environment and public services, as 000100001800000100004 ential from an environmental point of view to have s $000100000900000200002 \mathrm{~s}$ of safety or environmental protection, it would $\mathrm{t}$ $000100000600000200001 \mathrm{~s}$ for safety, environmental protection and social s 000100000500000400001 for safety and environmental reasons .

000100001100000200002 terioration of environmental safety, employment and 000100001700000100003 ts relating to environmental safety, professional s 000100000300000100002 ciple the most environmentally-friendly mode of tran 000100001400000200006 the fact that flags of convenience are a common phe 000100000700000200004 hes legal from illegal support . 000100000300000300007 ad a difficult job, but his shadow does not always 000100002100000200002 conditions and job security .

000100001900000100005 is also about jobs, attractive business propositio 000100001000000200003 Thirdly, the jobs of the port workers affected mus 000100000800000400004 the growth and jobs which it creates . 000100002100000100002 expansion and labour relations in ports . 000100001100000100004 ffects of this liberalisation, in particular with $\mathrm{r}$ 000100000800000200003 titiveness and liberalisation and apply them to tele 
000100000600000100003 fact mean only liberalisation and privatisation, bu 000100000800000400001 ual message of liberalisation and transparency . 000100001900000300001 jeopardised by liberalisation at any cost .

000100001000000200001 philosophy of liberalisation must include making th 000100001000000100002 the process of liberalisation of access to the marke $000100000800000200001 \mathrm{~s}$ based on the liberalisation of port services, whi 000100001900000200002 have long-term liberalisation of the market in port 000100000200000300002 And this liberalisation proposed by the Commis 000100001800000100005 therefore see liberalisation within those areas pro 000100001900000200003 should not yet liberalise the pilot services . 000100001900000100003 and white when liberalising and creating free and fa 000100000200000300003 dance with the liberalising approach established at 000100000800000300005 facts are that liberalising port services will have 000100002000000400007 osis' hits the poor hardest .

000100001400000100003 competition or privatisation, as such, but quality 000100000600000100003 ralisation and privatisation, but also European har 000100001400000100002 ompetition and privatisation of various services . 000100001400000100003 as such, but quality, greater efficiency and good $000100001500000100003 \mathrm{~s}$ of price and quality .

000100001400000300003 I want to see quality and efficiency brought about 000100001900000200004 gh standard of quality and safety on sea routes . $000100000900000100005 \mathrm{n}$ of workers, quality of service and, of course , 000100000100000100002 on on improved quality of services in ports . 000100001500000200008 ot benefit the quality of the service which ports of 000100001900000300002 ents for which quality rather than competition must $000100001000000300001 \mathrm{n}$ many cases, quality services are already provided 000100001100000200002 environmental safety, employment and working condi 000100000600000200001 quirements for safety, environmental protection and 000100001700000100003 environmental safety, professional standards and c 000100001100000100004 tant issues as safety, the environment and employme 000100000900000100005 The calls for safety, the protection of workers, 000100000200000400002 the grounds of safety, training or anything else, 000100002100000200002 the expense of safety, working conditions and job s 000100000800000300003 age relates to safety .

000100001100000200004 still ensuring safety .

000100000500000400001 e scrapped for safety and environmental reasons . 000100001700000200002 vices in which safety and professionalism are of par 000100002000000300005 Therefore, safety aspects cannot be used as an e 000100000300000300002 duty, serving safety at sea and the safety of man a 000100001900000300004 but as far as safety at sea is concerned, there ar $000100000300000300005 \quad$ So, safety at sea with pilot services mus 000100001100000200002 to inadequate safety levels and the deterioration o 000100001100000100005 they know the safety needs of people and the enviro 000100000300000300002 at sea and the safety of man and nature, and the Me 000100001900000300005 compromise the safety of shipping lanes in the long 000100001900000200004 of quality and safety on sea routes . 
000100000900000200002 on grounds of safety or environmental protection, $000100001400000200004 \mathrm{n}$, but from a safety perspective .

000100002100000200002 itions and job security .

000100001700000100003 , that certain social clauses remain untouched, tha 000100001100000200001 te to allowing social dumping .

000100001100000300001 e economic and social effectiveness while respecting 000100000400000300003 ditions in the social field, and give due considera 000100001000000200003 well as their social protection .

000100000600000200001 protection and social standards but also the economi 000100001700000200002 e principle of subsidiarity, certain services in wh 000100001000000200004 e principle of subsidiarity must be taken into accou 000100002100000100005 ition involves taxpayers' money, and there is unnec 000100002100000100005 out the use of taxpayers' money .

$000100001100000100005 \mathrm{n}$ particular, trade unions ( we can always call the $000100000200000400002 \mathrm{ds}$ of safety, training or anything else, to justif 000100001100000100005 icular, trade unions ( we can always call them 'lob 000100000900000100005 protection of workers, quality of service and, of 000100001000000200003 bs of the port workers affected must be guaranteed, 000100002100000100006 vides the port workers with sustainable employment w 000100001100000200002 employment and working conditions .

000100001100000200002 employment and working conditions .

000100002100000200002 se of safety, working conditions and job security . 000100002100000200002 se of safety, working conditions and job security . 000100001100000100003 the living and working conditions of port staff but 000100001100000100003 the living and working conditions of port staff but 000200000200000300003 blished at the Lisbon Council and which has already 000200000900000200001 the volume of business of ports .

$000200001900000100005 \mathrm{~s}$, attractive business propositions and public prof 000200000800000200002 about better, cheaper services and improving the co 000200000800000300005 iding better, cheaper services to those who use the 000200001900000200002 rvices creates competition, and transparency is , $i$ 000200002100000100002 is wrong with competition, expansion and labour re $000200001700000100003 \mathrm{ng}$ elements of competition, provided, as some of $\mathrm{t}$ 000200001900000100003 free and fair competition, simply in order to adhe 000200001600000300003 re to increase competition, your entire sustainable 000200000100000600004 conditions for competition . 000200000300000300005 sts exerted by competition . 000200000500000400003 ny way benefit competition . $000200001100000100002 \mathrm{rt}$ services to competition .

000200000500000300002 In terms of competition among ports, we would th 000200000500000100003 eration of the competition among ports instead of in 000200002100000200001 at transparent competition among ports is far more $\mathrm{u}$ 000200001400000100002 of exposure to competition and privatisation of vari 000200001700000200001 e opened up to competition are concerned, there are 000200000400000200002 must increase competition at ports .

000200001600000300001 With regard to competition between ports, I feel th 
000200001200000100004 aracterised by competition between ports, not withi 000200001600000100003 with a text on competition between ports .

000200000300000200004 I think, that competition between ports has to be o 000200000100000500001 tions for fair competition between ports in the EU, 000200000100000600001 conditions for competition between ports is crucial $000200001600000300001 \mathrm{t}$ to decreeing competition between ports without clo 000200001600000400001 ther than just competition between products .

000200000300000100007 ement for fair competition between seaports .

000200001600000200002 would maintain competition for mooring service provi $000200000400000400001 \mathrm{n}$ of ports and competition in and among ports in a c 000200000100000300001 regulations on competition in individual ports and $\mathrm{i}$ 000200000500000300003 the opening of competition in ports, which has been $000200001600000100003 \mathrm{~s}$ the issue of competition in ports and we are now b 000200002100000200001 han organising competition in the ports .

$000200002100000100005 \quad$ This competition involves taxpayers' money 000200000500000200002 other, where competition is mainly generated from 000200001900000300002 ty rather than competition must come first . 000200001400000100003 really market competition or privatisation, as suc $000200000500000200005 \mathrm{~s}$ to distorted competition which does not really ben 000200000300000200002 enterprises in competition with each other, and so $000200000500000400001 \mathrm{r}$ attention to competition within ports, as is form 000200001900000100005 establish fair competition within ports and between 000200001900000300005 be subject to competition would, under certain cir 000200002000000400009 Europe towards competitive ports . $000200000800000200002 \mathrm{f}$ the European economy . 000200002000000100002 he dynamics of economy . 000200002000000100002 e the European economy is having a coughing fit we $\mathrm{m}$ $000200001100000300001 \mathrm{mic}$ and social effectiveness while respecting the en 000200001400000100003 lity, greater efficiency and good, cleverly design 000200002000000200008 hould economic efficiency be accepted as a criterion 000200001400000300003 ee quality and efficiency brought about through port 000200001200000100004 ing to improve efficiency in a cargo handling market 000200000100000600005 ncrease in the efficiency of ports .

000200000400000100004 to enhance the efficiency of ports .

000200001800000100005 ports must be efficient, and we must therefore see 000200002000000200008 operations are efficient and when they are not . 000200000200000200003 ion is to have efficient maritime and port services 000200001900000200001 ich works more efficiently . 000200001500000200001 are important financial channels that run from auth 000200001500000400002 parency of the financial flows with regard to infras $000200000700000200004 \mathrm{~d}$ by a clear, financial framework which distinguish 000200000700000300002 e far-reaching financial implications for the releva 000200000100000500003 ransparency in financial relations between ports and 000200000200000600002 parency in the financial relations between public au 000200000600000300001 parency of the financial relationship between ports 000200000300000100007 ransparency in financial relationships and in State 
000200000600000300001 with regard to financial settlement for investments 000200000300000100006 The present financial structures could be describ 000200000800000400004 ness, and the growth and jobs which it creates . $000200001100000300001 \mathrm{~d}$ work towards harmonisation at the top end of worki 000200000600000100003 also European harmonisation with due regard being g 000200001500000200002 sight into the investment flows has arisen .

$000200001500000200003 \mathrm{n}$ addition, a level playing field is needed for all 000200001500000100003 in the past, modern port users are uncommitted : $t$ 000200002000000100002 to allow port monopolies to remain as they are or $\mathrm{w}$ $000200002000000300005 \mathrm{n}$ excuse for a monopoly .

$000200001100000100002 \mathrm{n}$ is indeed to open up all port services to competit 000200001700000100003 helped to make opening up the port services market a $000200000300000100003 \quad$ The openness of seaports, though, bears 000200000200000200003 is a positive regulation and is very important if $t$ 000200000200000300003 for Community regulation of these services in accor 000200000100000500001 proposal for a regulation to create them . 000200000800000200004 he wall of the single market .

EP Debate, second reading (March 10, 2003):

\section{Cat ID1 ID2 ID3}

000100000300000500004 estige and the Erika, pilots have to answer for the 000100000800000400003 Further to the Erika and Prestige accidents, it is 000100002000000100003 involving the Erika and the Prestige and finds expr 000100001200000400009 hilippinos and Malaysians, for example, respect so 000100001200000400009 s, comprising Philippinos and Malaysians, for exam 000100000500000600001 caused by the Prestige, I met with professionals $\mathrm{f}$ $000100000400000200004 \quad$ The Prestige accident, an accident that $000100001500000200001 \quad$ The Prestige accident has already been me 000100000800000400003 the Erika and Prestige accidents, it is not possib 000100002000000100003 Erika and the Prestige and finds expression in the 000100000300000500004 appened to the Prestige and the Erika, pilots have 000100000500000600003 sinking of the Prestige and the decision taken today 000100000800000400003 a and Prestige accidents, it is not possible to cla 000100000800000400004 If accidents happen, the European Union 000100001500000200002 to see serious accidents like this in the future whe 000100000400000100006 convenience, cheap flags, for ships . $000100001500000100005 \mathrm{w}$ in favour of cheap prices . 000100002000000100004 ntained in the collective agreements . 000100001200000300004 ocial issues, collective agreements and harmonised 000100000700000500001 law and under collective bargaining agreements . 000100002800000200001 egislation and collective bargaining agreements in $\mathrm{f}$ 000100001500000300005 e market, and cowboy ports will develop, just as w 
000100002000000100004 ing salaries, cutting jobs, increasing work rates 000100001400000100004 was dirty and dangerous and poorly paid then . 000100002300000300003 ort of oil and dangerous goods, has been secondary 000100000500000100005 costs, to the detriment of all other factors .

000100002000000200002 ould be to the detriment of everyone .

000100002600000200004 rsist, to the detriment of maritime transport's com 000100001400000200006 paid crew from developing countries to take over loa 000100002100000100011 environmental disasters at sea .

$000100002700000100003 \mathrm{n}$ the maritime disasters experienced by Europe in re 000100002000000100003 to ecological disasters involving the Erika and the 000100002000000100003 his has led to ecological disasters involving the Er $000100001700000300002 \mathrm{ng}$ and ways of economising on professional qualifica 000100000500000300009 it possible to employ workers from outside the port 000100000500000300009 kers currently employed .

$000100000700000300002 \mathrm{rb}$ all workers employed in any capacity in ports and 000100000500000100008 against those employed in this sector was demonstra 000100001100000300001 wman - is that employers have rights too, even if $\mathrm{n}$ 000100001100000200006 en if the port employers wanted to, it will not be 000100002400000200004 Both port employers' and workers' organisations 000100000600000200001 e see what the employers' associations - and others 000100001100000300002 I think, the employer's right .

$000100001100000300002 \quad$ The employer's right to know whom he will 000100002800000200001 me gained from employing contracted workers in the s 000100000500000300001 issues such as employment, safety and the environme 000100000400000200003 cial rules and employment .

000100002400000200001 conditions of employment and health and safety and 000100002800000200001 will endanger employment as well as the social cond 000100000500000300010 se working and employment conditions and worse envir 000100002800000200001 ty for gaining employment in ports, it breaches pri 000100002800000200001 e stability of employment in the sector ; on the sta 000100002000000100003 ression in the employment of seamen at salaries ten 000100002300000300003 of view of the environment, congestion and safety . 000100000400000300001 ty or with the environment, that a port is certainl 000100000500000300001 safety and the environment . 000100002300000300002 nship with the environment . 000100000400000200003 safety and the environment to be taken into account 000100002100000100011 problems with environmental disasters at sea . 000100001700000300005 social rules, environmental protection and safety . 000100002700000200005 ontributing to environmental protection and to safet 000100001700000200001 cial rules and environmental protection are rigorous 000100002400000200001 and safety and environmental protection standards . 000100000500000100007 the safety and environmental requirements and have $\mathrm{i}$ 000100000500000300010 ions and worse environmental safety standards . 000100002400000200002 to extend the exploitation of seamen from the seago 000100000400000100006 nience, cheap flags, for ships .

$000100000400000100006 \mathrm{t}$ as there are flags of convenience, cheap flags, 
000100001800000100007 ty at work and health, social matters and jobs to b 000100002400000200001 employment and health and safety and environmental p 000100001400000100005 rom outside by illegal contractors .

000100000500000300010 will result in insecurity, worse working and employ $000100002300000100004 \mathrm{r}$ on doing his job, which is to defend the position 000100000200000100002 mbowski, on a job well done.

000100002000000100004 ries, cutting jobs, increasing work rates and doin 000100000300000200001 fear for their jobs, out of fear of social dumping 000100000200000300001 ill create new jobs .

000100000500000200003 rade and their jobs are being destroyed, we cannot 000100002300000400002 the number of jobs in ports .

000100000300000400003 ations for the jobs they do .

000100001800000100007 al matters and jobs to blind liberalisation dogma . 000100001500000100002 espect of port labour, precisely because port labou 000100001400000100005 id, unskilled labour being hired in from outside by 000100001400000200004 aim is to cut labour costs even further .

000100000700000500001 to absorb the labour force contracted to ports on $\mathrm{s}$ 000100001400000200005 e cost of port labour forms only a negligible part o 000100001500000100002 y because port labour has so much to do with safety 000100000700000400001 legislation on labour or on the operation of ports , 000100000600000200001 international labour organisation-conventions 137 000100000500000300006 e text remains liberal . 000100001800000100007 ainst a cold, liberal Europe that subordinates safe 000100000500000100005 e faced with a liberal directive which, as usual, 000100000800000200004 xample of this liberal vision .

000100000500000300001 ffects of this liberalisation, especially as regard $000100000600000100002 \mathrm{~g}$ up markets, liberalisation, port services - thes 000100000800000400002 vious cases of liberalisation, which proved unpopul 000100000200000300003 hamper further liberalisation and, by extension, $\mathrm{f}$ 000100002300000400004 the idea that liberalisation and lack of safety go 000100001800000100007 jobs to blind liberalisation dogma .

$000100000500000300002 \mathrm{r}$ Hatzidakis, liberalisation is not an aim in itsel 000100000200000200001 y restrict the liberalisation of port services . 000100000200000300001 nefit from the liberalisation of port services in th 000100000200000300004 spousal of the liberalisation of services, not as a $000100000200000200001 \mathrm{~d}$ up to oppose liberalisation or at least make comme 000100002300000400005 claim that its liberalisation reduces safety .

000100001200000400003 we should not liberalise everything now that we hav 000100001200000200003 ing a haste to liberalise port services which we fee 000100001100000400003 ber States may liberalise their pilotage services if 000100002700000300001 ferable not to liberalise this service, which is al $000100001200000400003 \mathrm{w}$ that we have liberalised one sector . 000100000200000200002 , in favour of liberalising air transport, in favou $000100000200000100002 \mathrm{~d}$ road towards liberalising port services, and I th 000100000200000200002 , and against liberalising port services .

000100000200000200002 , in favour of liberalising telecommunications, and 
$000100000200000200002 \mathrm{e}$ in favour of liberalising the railways , in favour 000100001400000100005 against poorly paid, unskilled labour being hired i 000100001400000200006 extremely low paid crew from developing countries t 000100001400000100004 ous and poorly paid then .

000100001100000500002 viders have to pay when buying themselves out of a c 000100001400000100005 selves against poorly paid, unskilled labour being 000100001400000100004 dangerous and poorly paid then .

000100001100000200006 e to work with poorly trained, unqualified workers $000100000400000100006 \mathrm{~s}$ the risks of ports of convenience, ports where al 000100002100000100007 rective brings ports of convenience closer .

000100001700000300005 : professional qualification, contractual and socia $000100001700000300002 \mathrm{n}$ professional qualification or safety .

000100001700000200001 , professional qualifications, contractual and soci $000100002200000200001 \mathrm{~ms}$ of workers' qualifications, social conditions, $000100001100000200005 \mathrm{~d}$ professional qualifications .

$000100000300000400003 \mathrm{rs}$, and their qualifications for the jobs they do . 000100000500000300008 afety, to the qualifications required of staff and $000100001100000400004 \mathrm{~d}$ professional qualifications that this entails . 000100002500000200004 rmore are duly qualified and have sufficient knowled $000100000900000100004 \mathrm{~s}$ that we have qualified and motivated people workin 000100000800000300001 y fulfilled by qualified professionals might, in fu 000100000500000300009 he work of the qualified workers currently employed 000100000900000200006 of safety and quality .

000100001300000200001 bout is better quality and more services, but a mon 000100000400000200004 e training and quality of ships' crews, which we ar 000100002000000100002 ompetition and race for profits that you wish to int 000100002800000200001 asing maritime safety, by allowing agencies from ou 000100001700000200001 provided that safety, professional qualifications $000100001800000100007 \mathrm{t}$ subordinates safety, safety at work and health, 0001000022000002000011 conditions, safety, the economic development of 000100000500000300008 These refer to safety, to the qualifications requir 000100001700000300002 alification or safety . 000100001700000300005 protection and safety . 000100002300000300003 congestion and safety . 000100002300000400005 sation reduces safety . 000100002700000300001 atures of port safety . 000100001500000100002 uch to do with safety and because this is an area wh 000100002400000200001 and health and safety and environmental protection s 000100000500000100007 iliar with the safety and environmental requirements 000100002100000100011 re : a lack of safety and problems with environmenta 000100000900000200006 a guarantee of safety and quality . $000100000500000300001 \mathrm{~s}$ employment, safety and the environment . 000100000400000200003 spects such as safety and the environment to be take 000100001800000100007 nates safety, safety at work and health, social ma 000100000500000600002 that maritime safety begins at ports . 000100000200000400002 approaches and safety factors have to be taken into 
000100002300000400004 on and lack of safety go hand in hand .

000100002700000200005 tection and to safety in Community ports, I therefo 000100001500000100005 the fact that safety in the ports will go out of th 000100000800000300005 cceptable when safety is at stake .

000100002500000200004 to ensure that safety is not jeopardised .

000100002300000400005 sport in which safety is vital and nobody can claim 000100000500000600001 nce to discuss safety issues .

000100000800000100004 ervice and the safety of operations are part and par 000100002400000100005 e occupational safety of other dock workers .

000100000900000200001 undermine the safety of our ports, unsettle the so 000100000300000500004 answer for the safety of ships .

000100001100000200006 threat to the safety of the ports .

000100000300000500003 etition, that safety often gets left behind .

000100000400000200005 nisation about safety on ships and in ports - in fac

000100000400000300001 ake risks with safety or with the environment, that 000100000100000600004 dance with the safety requirements in force in that 000100000500000300010 environmental safety standards . 000100000500000500001 le maintaining safety standards . 000100000800000200005 nores the high safety standards currently in place . $000100002000000100004 \mathrm{~ms}$ of lowering salaries , cutting jobs , increasing 000100001200000300006 uce prices and salaries .

000100002000000100003 than European salaries.

000100000700000500001 ed to ports on salaries around three times higher th $000100002000000100003 \mathrm{t}$ of seamen at salaries ten times lower than Europea 000100002000000200003 conditions of salary and social protection, modell 000100002700000100003 ds of maritime security .

000100000300000400003 ction, social security matters, and their qualific 000100000900000200004 of modern-day slavery - than to the survival of the $000100002000000100004 \mathrm{~h}$ the forms of social and wage protection contained 000100000900000200003 only result in social breakdown and more unemploymen $000100001800000100008 \mathrm{u}$ pulled their social charter out from under their $\mathrm{f}$ 000100002100000100008 tive organises social competition between the Europe 000100002200000200001 alifications, social conditions, safety, the econ 000100001200000300005 elling-down of social conditions . 000100002500000200003 t for European social conditions .

000100001200000300003 ally different social conditions in different countr 000100002800000200001 as well as the social conditions of port workers, $\mathrm{s}$ 000100000400000300001 here you allow social dumping, but that a port is $\mathrm{i}$ 000100000500000300007 to permitting social dumping, despite the various 000100000300000200001 out of fear of social dumping, taking to the street 000100001200000400005 or significant social dumping . 000100001900000200003 prevention of social dumping. 000100001500000300001 tition through social dumping ? 000100002100000100008 will result in social dumping and also, in time, $t$ 000100001700000300002 oting forms of social dumping and ways of economisin 000100001500000100002 an area where social dumping has occurred. 
000100001300000100008 ns' fear about social dumping is nonsense . 000100001500000200003 isk is that of social dumping on account of self-han $000100002400000200005 \mathrm{y}$ economic and social dumping that will increase . 000100000900000200001 the umpteenth social graveyard, but it will also u 000100000700000300001 threat to the social harmony that has marked relati 000100001200000300004 directives on social issues, collective agreements 000100001200000400004 test amount of social malpractice probably takes pla $000100001800000100007 \mathrm{k}$ and health, social matters and jobs to blind libe $000100000700000300001 \mathrm{~ns}$ between the social partners in all Portuguese por 000100000900000200001 , unsettle the social peace that we have, cripple $t$ 000100002000000200003 of salary and social protection, modelled upon the 000100000300000400003 ' benefit - on social protection, social security m 000100002100000200002 favour of the social protection of dock workers, a 000100000400000200001 requirements - social requirements too - on anyone w $000100000600000100004 \mathrm{r}$ of affecting social rights .

000100001700000300005 ontractual and social rules, environmental protecti $000100000400000200003 \mathrm{t}$, as well as social rules and employment .

000100001700000200001 ontractual and social rules and environmental protec 000100000400000100006 where all the social rules go overboard, just as $\mathrm{t}$ 0001000003000004000031 protection, social security matters, and their q 000100001200000400008 ompliance with social standards?

000100001200000400009 mple, respect social standards?

000100001200000400007 that national social standards will be complied wit $000100001100000200005 \mathrm{r}$ position and social standing is extremely well pro 000100001800000300005 aintaining the social system in Europe .

000100000900000100003 ss my complete solidarity with the workers who have $000100001400000300002 \quad$ Strikes against this unreasonableness 000100000100000700001 nd a number of strikes in European ports, were abou $000100001800000300001 \mathrm{ck}$ workers are striking, Mr Jarzembowski . 000100000100000700005 The unions are striking, and I have no idea why . 000100001800000300002 , of course, striking because if you permit self-h 000100000100000700002 scussions with trade unionists .

$000100000400000100006 \quad$ The trade unions are also right to point 000100001400000200008 y clear to the trade unions at the first reading in $000100001000000100003 \mathrm{t}$ managers and trade unions to make this directive $\mathrm{i}$ $000100000200000400004 \mathrm{n}$ proper staff training, which is why I think that $000100001100000200005 \mathrm{ht}$ up to their training and professional qualificati 000100000400000200004 tention on the training and quality of ships' crews 000100000900000200003 kdown and more unemployment as a priority . 000100002100000100006 dock workers' unions, and I was impressed by their 000100000400000100006 The trade unions are also right to point out to $000100000100000700005 \quad$ The unions are striking, and I have no $\mathrm{i}$ $000100001400000200008 \mathrm{r}$ to the trade unions at the first reading in Novemb 000100000500000100007 sultation with unions or others involved, despite $t$ 000100001000000100003 gers and trade unions to make this directive into so 000100001400000100005 poorly paid, unskilled labour being hired in from 
000100002000000100004 of social and wage protection contained in the coll 000100000300000400003 touch - to the workers ' benefit - on social protect $000100001600000200001 \mathrm{t}$ only against workers ' expectations but also again 000100002100000200002 ection of dock workers, and I hope that some social 000100000700000400001 equipment and workers, and possibly on docks for w 000100001400000200006 red local dock workers, but this is difficult to mo $000100002800000200001 \mathrm{~s}$ representing workers, it contradicts declared obj 000100000300000200001 ave seen their workers, out of fear for their jobs 000100002800000200001 itions of port workers, since it does not enshrine 000100001100000200004 ts of the dock workers, then it is this directive . 000100000300000400005 better for the workers . 000100000900000200004 own best port workers . 000100001400000200002 over the dock workers . 000100002400000100005 of other dock workers . 000100000900000200006 e Flemish port workers : working for your own people 000100001200000400010 he port's dock workers?

000100000100001000004 e places where workers and entrepreneurs can coexist 000100001500000100005 What the dock workers are afraid of, and this is a 000100001800000100004 that the dock workers are angry, very angry, and 000100001200000400012 o why the dock workers are demonstrating their disco $000100001800000300001 \mathrm{u}$ why the dock workers are striking, Mr Jarzembowsk 000100000300000200001 hise with port workers as they draw attention to the $000100000100001000002 \mathrm{~s}$, and of the workers both on the ships and on land 000100002000000200002 of having dock workers compete with one another on $t$ 000100000500000300009 the qualified workers currently employed .

000100001100000200003 here were dock workers demonstrating outside the Par 000100000700000300002 to absorb all workers employed in any capacity in $p$ 000100000900000100004 ecognised dock workers ensures that we have qualifie 000100000500000300009 ible to employ workers from outside the port to do $t$ 000100000500000500001 yees like dock workers fulfil a very important econo 000100001800000100009 with the dock workers in Antwerp, for example . 000100000800000300001 non-specialist workers in a completely fragmented wa 000100000700000500001 thereby using workers in more favourable conditions 000100002300000400003 the number of workers in ports while making them mo 000100001400000100003 people are the workers in the ports .

000100002800000200001 ing contracted workers in the sector and on the righ 000100000900000100004 highly skilled workers in the world. 000100002500000200002 tection of the workers involved. 000100000800000300002 The dock workers made their discontent clear $\mathrm{t}$ 000100000600000100003 he position of workers may be affected .

000100000200000300001 nd to the port workers protesting today - that , in 000100001300000200002 ns of the dock workers themselves .

000100001200000300006 The dock workers understand well that we are n $000100002800000100002 \mathrm{f}$ thousands of workers who, throughout Europe, hav 000100001100000200006 , unqualified workers who could be a threat to the 000100002000000300001 rd to the dock workers who demonstrated before what 
000100000900000100003 arity with the workers who have come to Strasbourg t 000100002100000100003 es of the dock workers who have got in .

000100002100000100008 on of the dock workers' charter as we know it in Bel 000100000200000400004 hink that port workers' current demands on the quest 000100000200000400003 you like, of workers' demands and the question of 000100000500000100008 ormidable dock workers' demonstration .

$000100000900000200001 \mathrm{~m}$ and the dock workers' monopoly will not only resul 000100002400000200004 employers' and workers' organisations unanimously ag $000100002200000200001 \mathrm{~ns}$ in terms of workers' qualifications, social cond 000100001100000300001 talking about workers' rights, Mr Bouwman - is tha 000100002100000100006 from the dock workers' unions, and I was impressed $000100000600000200001 \mathrm{~h}$ concerns the working conditions for such port acti $000100000600000200001 \mathrm{~h}$ concerns the working conditions for such port acti 000100001300000200002 expense of the working conditions of the dock worker 000100001300000200002 expense of the working conditions of the dock worker 000200000200000300005 pean Union can compete with each other .

$000200002000000200002 \mathrm{~g}$ dock workers compete with one another on the basis $000200001200000300001 \mathrm{e}$ in favour of competition, it must have an equitab $000200002400000200002 \mathrm{r}$ the guise of competition, ship owners are now try 000200000100000300004 conditions for competition, such declarations of in $000200000300000500003 \mathrm{~d}$ face so much competition, that safety often gets 000200000800000200002 establish fair competition, which seems to amount $t$ 000200000300000600003 of inter-port competition . 000200000800000200002 profitable to competition. 000200001500000300004 distortion of competition . 000200001700000300003 is transparent competition . $000200002400000200003 \mathrm{t}$ it increases competition . $000200000100000400001 \mathrm{~s}$ that distort competition; and finally, that it s 000200000100000800001 here is fierce competition among ports, and that th 000200000100000200002 clear rules on competition among ports and within ea $000200000100000800003 \mathrm{~d}$ between fair competition and entrepreneurial freed 000200002000000100002 resident, the competition and race for profits that 000200002600000300003 nts that limit competition and to support those whic $000200000500000100002 \mathrm{rt}$ services to competition at the first reading . $000200001400000200007 \mathrm{ng}$ flouted and competition being distorted in years 000200000300000600002 ues to be with competition between one port and anot 000200001400000100006 ules governing competition between ports , particula 000200000100000300003 conditions for competition between ports . 000200000600000400002 lation, about competition between ports . 000200001400000200001 to restricting competition between ports but rather 000200002100000100008 ganises social competition between the European port 000200002500000100002 opardises free competition between the different Com 000200002200000200001 distort mutual competition between the ports . 000200001900000100003 tions for fair competition both between and in ports $000200001200000300006 \mathrm{t}$ implementing competition but a terrible mechanism $000200000300000600001 \mathrm{f}$ attention to competition in ports . 
000200001100000100002 nteeing honest competition in ports .

000200001200000200001 the problem of competition in ports is certainly not $000200000600000400002 \mathrm{t}$ directive on competition in ports is completely in $000200000300000500001 \mathrm{keen}$ - to see competition introduced.

$000200001400000200002 \quad$ This competition is trampling all over the 000200001800000300002 of the sacred competition rules, and that is the $r$ $000200002700000100002 \mathrm{ng}$ respect for competition rules and for economic fr 000200001500000300001 e aiming for, competition through social dumping ? 000200001200000300005 other words, competition will not be fair but will 000200002400000200004 sly agree that competition will not increase with th 000200001200000400010 we ensure fair competition with the port's dock work 000200002700000300002 opening up to competition would be slightly more ac $000200000900000100005 \mathrm{r}$ ports fast, competitive and in particular safe ha 000200002200000300005 ur of the same competitive conditions existing in al $000200002600000300001 \mathrm{ent}$, safe and competitive shipping industry and for $000200000200000300003 \mathrm{n}$ the European economy .

000200000700000300001 perability and effectiveness of national ports where 000200000800000200003 Although the efficiency and reliability of public 000200001900000100003 heir levels of efficiency throughout the Union must 000200002600000300001 trade, for an efficient, safe and competitive ship 000200002300000400003 king them more efficient .

000200000400000300001 tal link in an efficient and sustainable European tr 000200000100001000004 seaports to be efficient and to perform well, and $t$ 000200002600000100002 industry needs efficient maritime transport . 000200002600000100004 just such more efficient maritime transport . $000200001300000100012 \mathrm{k}$ smoothly and efficiently and that they can therefo 000200000100000800003 ompetition and entrepreneurial freedom, and so I ca 000200000100001000002 , of the port entrepreneurs, and of the workers bo 000200000100001000004 re workers and entrepreneurs can coexist amicably . 000200000100000500002 to know which financial arrangements regarding port 000200000100000300004 details of the financial links that exist between th 000200000400000100004 on transparent financial relationships between the $p$ 000200000200000300004 ns to economic growth .

000200000200000300003 oster economic growth; but they should not hamper $\mathrm{f}$ 000200000200000300003 sion, further growth in the European economy .

000200000100000800002 erated harbour monopoly, nor indeed to the shipping 000200001300000200001 rvices, but a monopoly must not be allowed to devel 000200000900000200001 dock workers' monopoly will not only result in the 000200002300000300001 ve attempts to open up a European area of transport 000200002300000300002 ts proposal to open up the market, attempts to stim $000200000500000100002 \mathrm{~s}$ directive on opening up all port services to compe 000200000600000100002 , rapporteur, opening up markets, liberalisation , $000200000800000200002 \mathrm{~s}$ to amount to opening up markets judged to be suffi $000200002700000300002 \quad$ An opening up to competition would be sl 000200001700000200001 I believe that opening up to the market could be pos 000200000100000800001 there must be openness and a fair balance between $t$ 
000200000600000400002 rrangement, a regulation, about competition betwee 000200002500000200003 ve, but their regulation must remain in the hands o 000200000100000700006 ed to European regulation of ports, then let them $\mathrm{s}$ $000200000100000100002 \mathrm{f}$ the European regulation of sea ports .

000200000100000400002 resident, the regulation on state aid that the Comm $000200000100001000002 \mathrm{t}$ demands is a regulation that holds in a balance th

EP Debate, third reading (November 18, 2003):

\section{Cat ID1 ID2 ID3}

000100000900000200004 inians and one African engaged in self-handling will 000100000900000200004 e Malays, two Argentinians and one African engaged 000100000900000200004 t called, two Filipinos, three Malays, two Argent 000100000500000400005 h freight ship Karin Cat in February . 000100000900000200004 ipinos, three Malays, two Argentinians and one Afr 000100001100000600004 caused by the Prestige, that security began in the 000100001100000600002 inquiry on the Prestige .

000100000900000100002 debate on the Prestige by explaining to us that the $000100001800000200010 \quad$ The Tricolor off the Flemish coast was a 0001000005000009000021 disputes and abuse, particularly in the North Sea $000100003000000200002 \mathrm{r}$ all sorts of abuse by the crooks involved in marit 000100000500000700002 and scope for abuse remained, but the parties invo 000100000500000100002 more scope for abuse than many other businesses . 000100003000000300002 se the risk of accidents and pollution .

000100000500000400005 event shipping accidents as a result of faults durin 000100000500000300002 ys be the most anti-social, the most environmentall 000100001100000200005 e to call upon cheap labour, which would be dangero 000100000700000300002 tained through cheap labour .

000100001900000200002 nal basis that collective agreements be adhered to $\mathrm{h}$ 000100001800000200011 e than 60 near collisions .

000100001800000200012 e must be more competent pilots on board, therefore 000100002200000300002 eave it to the competent port workers to ensure that $000100003000000200002 \mathrm{f}$ abuse by the crooks involved in maritime transport 000100001700000300002 hing more than cutting costs in the economic sphere 000100000500000400001 ing unfair and dangerous competition per group of po 000100001100000200005 which would be dangerous for the ports and their env 000100001100000200004 ystem would be dangerous to people because it would 000100001100000100003 costs, to the detriment of security, employment an 000100000500000200006 eople from the developing world who are not admitted 000100000500000200001 istration in a developing-world country . 000100000500000200002 hire crews at developing-world salaries . $000100001800000100003 \mathrm{~d}$ bad news for dockers, because there are no minimu $000100003000000200003 \mathrm{nt}$ salaries of dockers, nor even to respect labour 
000100002500000100004 protection of dockers, on safety in ports . $000100001800000200006 \mathrm{~h}$ for ordinary dockers .

000100002400000200002 tion for Dutch dockers . 000100002500000400001 especially the dockers .

000100003400000200001 horities, the dockers and the Belgian politicians? 000100003400000100003 yers, nor the dockers are looking to change this sy 000100002800000400001 an prevent the dockers from being left holding the $\mathrm{b}$ 000100001500000100006 for ports and dockers in Europe .

000100001100000400001 security : the dockers who fulfil a very important e 000100002500000300006 for all those dockers who have demonstrated against 000100002800000400004 ss the Belgian dockers with the following request : $000100003000000300003 \mathrm{~s}$ - seamen and dockers - into competition with each 000100001700000100005 economic, the ecological and the social .

000100002500000300001 for social and ecological etiquette that apply to al 000100003100000200003 heir own or to employ people under bad conditions . 000100000700000300001 untrained and employed on a casual basis .

000100002200000300001 re in any case employed on modern ships and that the 000100002200000300002 ly many people employed on modern ships that we shou $000100001100000400007 \mathrm{n}$ Strasbourg, employee representatives again met th 000100001300000100006 employers and employees .

000100000700000300002 unlikely that employees' social protection and the 000100003400000100003 ties, nor the employers, nor the dockers are looki 000100003400000100005 ialogue offers employers a guarantee that their requ 000100001000000400001 dock workers, employers and dock installations have 000100001300000100006 burdens across employers and employees .

000100000700000300001 wners directly employing their own equipment and the $000100003400000100005 \mathrm{o}$ - as regards employment, social services, safety 000100003300000200004 ia relating to employment, the social aspects, pro 000100000400000400003 ans growth and employment .

000100001100000100003 of security, employment and the quality of service 000100001100000700001 of security, employment and the sustainable develo 000100000800000300002 veness, their employment and their provision of ser 000100001700000200002 o achieve full employment by 2012 , but keep going $\mathrm{i}$ 000100003000000200005 sult in secure employment in port areas being axed a 000100001500000100007 arm quality of employment in the ports that do have 000100001500000100009 arm quality of employment in the well-organised port 000100000200000200003 Protecting employment rights, where there is an 000100001100000400003 ts, and where employment too is concerned . 000100000100000700002 tection of the environment, and the fact that the $\mathrm{c}$ $000100001000000300002 \mathrm{n}$ the areas of environment, public services and , 1 000100000300000400001 safety and the environment, then you have to reject 000100001100000200005 orts and their environment . 000100001600000100005 at sea and the environment . 000100001800000200013 lives and the environment. 000100002000000100004 ers and of our environment . 000100003400000200008 on of work and environment . 
000100001700000100007 damage to the environment and does nothing to impro 000100003000000200005 ntails for the environment and safety .

000100003200000100006 , security and environment rules .

$000100000900000100002 \mathrm{t}$ the maritime environment was an area of uncontroll

000100000600000100003 etition on the environment when new terminals are bu

$000100000600000100006 \mathrm{rd}$ to social, environmental and other requirements

000100003300000200004 ifications and environmental considerations .

000100002100000300001 , and that the environmental contribution of that $\mathrm{tr}$

000100000500000500001 mber of recent environmental measures of the Europea

000100000500000100005 al dumping and environmental pollution as ways of wi 000100001200000100004 al dumping and environmental pollution in ports .

000100000500000100004 the extent of environmental protection .

$000100000500000200006 \mathrm{y}$, safety and environmental protection ; ports that $000100002600000300002 \mathrm{r}$ maritime and environmental safety that this entail 000100000700000300003 ifications and environmental security, and would al $000100000700000300001 \mathrm{~d}$, social and environmental security could, in the 0001000007000002000021 , social and environmental security must in fact $\mathrm{r}$ 000100001600000200001 offers a more environmentally friendly alternative 000100000500000300002 ial, the most environmentally-unfriendly, the most 000100002500000300005 unsafe working environments in our ports .

000100003000000200005 ly paid, over exploited, inexperienced, with all 000100000900000300003 en it comes to flags and crews reduced to slavery an 000100000500000200001 phenomenon of flags of convenience, whereby ships 000100001900000400001 sailing under flags of convenience. 000100002200000100007 sailing under flags of convenience . 000100001800000200003 oting negative globalisation and social disintegrati 000100000700000200001 mpetitive in a globalised economy, we did not want 000100002700000100003 ocial rights, health, safety and wellbeing of work 000100000700000300001 , who would be inexperienced, untrained and employe 000100003000000200005 er exploited, inexperienced, with all the threats 000100002100000300001 , the enormous insecurity, which is much greater th 000100000800000100003 ey will have a job in a few months' time .

000100000700000300003 cost linked to job losses .

000100000100000500002 one a splendid job of it .

000100002500000200001 al approach to job protection and safety .

000100000800000300001 competition, job quality and the provision of serv $000100001500000200007 \mathrm{~s}$ case, where job quality is concerned .

000100002600000200002 oblems for the job stability of port service workers 000100002200000100005 ill lose their jobs, simply because seafarers on sh $000100000400000400004 \quad$ More jobs, that is the best social policy 000100002900000400001 it to British jobs, the future of investment in ou 000100000500000200006 only temporary jobs, which are dirty and unsafe and 000100003000000200005 with insecure jobs, who are badly paid, over expl 000100000200000300001 anies mean new jobs .

000100002200000100006 arge number of jobs .

000100001700000200001 , if the same jobs are done by people who already $\mathrm{h}$ 
000100001700000200001 , that reduces jobs rather than encouraging the crea 000100001700000100010 ument that new jobs will be created is crazy . 000100000500000200003 international jungle.

000100000500000200004 to date, that jungle in the European ports has been 000100001100000300002 the law of the jungle into the whole sector .

000100000900000200002 ing the social jungle of the maritime sphere into ou $000100000900000100002 \mathrm{om}$, a kind of jungle that needed to be subjected to 000100000500000400001 rules for port labour, these must be geared to elim 000100001100000200005 all upon cheap labour, which would be dangerous for $000100000500000100004 \mathrm{~s}$ of reward of labour, working conditions, safety 000100000700000300002 through cheap labour.

000100000500000400005 qualified port labour across Europe, and which woul 000100000500000600002 egistered port labour against unfair competition at 000100000600000300001 or working and labour conditions, and safety . 000100001900000300002 and underpaid labour for loading and unloading ship 0001000003000002000041 security and labour law .

000100000400000500001 ure that Dutch labour law is observed in the ports . 000100003100000200005 the social and labour law regulations governing port 000100003000000200003 ven to respect labour legislation .

000100000600000100007 ope in current labour relations at most ports . 000100002200000300004 poorly trained labour that may jeopardise port secur $000100001100000100003 \mathrm{k}$ that it is a liberal directive that has one sole $\mathrm{p}$ 000100002600000100003 ts emphasis on liberalisation, its position on the 000100001500000100008 ention of this liberalisation . 000100001500000200006 bad example of liberalisation . 000100002700000100003 ill-considered liberalisation . 000100001700000200004 ou want to let liberalisation advance . 000100000800000100005 dockworkers, liberalisation in this context means 000100001200000200004 This push for liberalisation is currently presentin 000100001700000300002 se, for you, liberalisation means nothing more tha 000100001900000200003 Furthermore, liberalisation now also extends to in $000100000800000300001 \quad$ The liberalisation of particularly energy 000100002400000100003 's aim was the liberalisation of port services, but 000100000700000200001 ve : the total liberalisation of port services . 000100002200000100003 o want a total liberalisation of port services and $t$ 000100000800000100002 's vote on the liberalisation of port services will 000100002300000100002 rective on the liberalisation of the port services $\mathrm{m}$ 000100003100000100004 eralisation or liberalisation of the regulations , b 000100003100000100004 ither economic liberalisation or liberalisation of $\mathrm{t}$ 000100002800000100006 get hurt in a liberalisation process have been file 000100002200000300001 ampaigning for liberalisation say that not so many $p$ 000100002300000200001 hat this crazy liberalisation will be approved by th 000100002800000100004 lise or not to liberalise, that is not the question 000100002800000100005 tant is how we liberalise and whether we do it human $000100002800000100004 \quad$ To liberalise or not to liberalise, tha 000100002100000200001 o regulate and liberalise ports . 
000100002100000300002 , which is to liberalise the various transport sect 000100003000000200005 who are badly paid, over exploited, inexperienced 000100000500000200006 lower level of pay, safety and environmental protec 000100003000000200004 , work for low pay and subject them to whatever work $000100002700000100005 \mathrm{t}$ the EU under pay conditions that are not pushed do 000100000500000200002 result, they pay lower taxes, need not comply wit 000100003000000200003 ship owners to pay their personnel the current salar 000100002500000300005 esponsible for pernicious competition via social dum 000100002500000100004 ation system, pernicious competition will inevitabl 000100000800000300002 ind could have pernicious consequences for our ports 000100000900000300003 ne knows, are pirate countries, no less than the $s$ 000100000600000300001 with regard to poor working and labour conditions, 000100003400000200007 strict, where poorly organised, poor-quality dock $000100002200000300004 \mathrm{ng}$ the door to poorly trained labour that may jeopar 000100002600000400001 , we will have ports of convenience, in which every 000100002200000100007 We do not want ports of convenience, just as we do $000100000600000300002 \mathrm{~s}$ turning into ports of convenience. $000100001200000200002 \mathrm{ing}$ faced with ports of convenience . 000100003100000100002 ning so-called ports of convenience . 000100000700000400001 he creation of ports of convenience and self-handlin 000100001900000400001 together with ports of convenience consonant with o $000100000500000200005 \mathrm{rt}$ companies, ports of convenience would have taken 000100001100000200004 : insufficient qualifications, ignorance of the loc 000100003300000200004 , professional qualifications and environmental cons $000100000700000300003 \mathrm{f}$ professional qualifications and environmental secu 000100000300000300001 ame vocational qualifications as other service provi 000100001100000200003 to staff being qualified .

000100000500000400005 registered and qualified port labour across Europe , 000100001100000200002 ace of current qualified staff .

$000100001100000400001 \mathrm{r}$ upon all the qualified staff who until now have co 000100000300000400002 tead to enable qualified workers to operate under go $000100003400000100007 \mathrm{~d}$ of excellent quality .

000100000800000300001 petition, job quality and the provision of services 000100001500000200007 se, where job quality is concerned .

000100001500000100007 which can harm quality of employment in the ports th 000100001500000100009 his could harm quality of employment in the well-org 000100001100000100003 oyment and the quality of services .

000100000400000400005 tle say in the quality of the work .

$000100003400000100005 \mathrm{~s}$, safety and quality - will be included in a socia 000100003000000400003 tition and the race for profit

000100001800000200005 tween ports is ruthless .

000100001800000200013 ake savings on safety, and to play with lives and $t$ 000100000100000700002 unds of public safety, continue to restrict pilotag $000100002300000100004 \mathrm{f}$ port traffic safety, pilotage, towing or mooring 000100002600000300001 sons of public safety, recognise the mandatory natu 000100003400000200008 al framework, safety, training, organisation of w 
$000100000300000200002 \mathrm{t}$ committed to safety . 000100000600000100006 ents, such as safety . 000100000600000300001 nditions, and safety . 000100002500000200001 protection and safety . 000100003000000200005 nvironment and safety . 000100000500000200006 level of pay, safety and environmental protection ; 000100003400000100005 ial services, safety and quality - will be included 000100001700000400004 than promoting safety and social standards and there $000100000300000400001 \mathrm{~ns}$ in terms of safety and the environment, then you $000100000500000100004 \mathrm{~g}$ conditions, safety and the extent of environmenta 000100000100000700002 es in terms of safety and the protection of the envi $000100002700000100003 \mathrm{hts}$, health, safety and wellbeing of workers to th 000100001600000100005 ve in terms of safety at sea and the environment . 000100002500000300004 e an essential safety function . 000100002900000300006 voted down on safety grounds alone . $000100002500000100004 \mathrm{f}$ dockers, on safety in ports . 000100001700000100006 e jeopardising safety in ports? $000100002600000400001 \mathrm{~d}$ for maritime safety itself. 000100003100000200004 ports and the safety of those who work in them must 000100002600000300002 environmental safety that this entails, and this $i$ 000100002900000400001 and above all safety to reject this proposal . 000100000500000200002 veloping-world salaries . 000100003000000200003 el the current salaries of dockers, nor even to res 000100000700000300003 environmental security, and would also entail a so 000100001100000100003 e detriment of security, employment and the quality 000100001100000700001 e interests of security, employment and the sustain $000100001200000100004 \mathrm{~d}$ to a lack of security, social dumping and environ 000100001100000600001 es on maritime security . 000100002200000300004 eopardise port security . 000100001100000200004 prejudicial to security : insufficient qualification 000100001100000400001 ibuted to port security : the dockers who fulfil a $\mathrm{v}$ 000100001100000400001 by preserving security; and nautical services such 000100001100000600003 ur of maritime security and, Commissioner, you hav 000100001100000600006 rning maritime security and, on the other hand, ef 000100003200000100006 otect social, security and environment rules . 000100000300000200004 erms of social security and labour law . 000100001100000400002 ve of maritime security and sustainable development 000100001100000200003 references to security and to staff being qualified 000100001900000400002 dermining port security at a time when major investm 000100001100000600004 restige, that security began in the ports .

000100000700000300001 environmental security could, in the same way, be $000100000700000300002 \mathrm{nts}$ of optimum security count for very much faced wi 000100002200000400001 we talk about security in EU ports, there are two 000100002300000100003 epared to risk security in airports by establishing 000100000700000200002 environmental security must in fact remain the obje $000100002200000400001 \mathrm{~d}$, namely the security of people who work in the po 
000100002200000400001 ports and the security of the goods handled. 000100000100000500001 for the social security regulations to apply are not 000100000900000100003 the case where security was concerned is , unfortuna 000100000900000300003 ews reduced to slavery and that it be ensured that a 000100000600000100006 with regard to social, environmental and other requ 000100003200000100006 fully protect social, security and environment rul 000100001700000100005 ogical and the social .

000100001400000200002 and effective social Europe.

000100002700000100002 e we created a social Europe as well as an economic 000100001400000100003 re pitting the social Europe of the nineteenth centu 000100003400000100005 included in a social agreement.

000100002500000300001 down rules for social and ecological etiquette that 000100000700000300001 is concerned, social and environmental security cou 000100000700000200002 Technical, social and environmental security mus 000100000900000200001 es and also of social and geographic origins .

000100003100000200005 orkers and the social and labour law regulations gov 000100003300000200004 ployment, the social aspects, professional qualifi 000100000900000300001 sorting to the social break-up of an entire professi 000100000900000400002 er, a form of social break-up that you are proposin 000100000300000400002 ate under good social conditions; if you want socia 000100000900000400001 the fiscal and social conditions in all our own coun 000100000100000500002 osition on the social conditions of port workers, a $000100001100000400003 \mathrm{t}$ have serious social consequences in the ports, an 000100000700000300003 also entail a social cost linked to job losses . 000100003400000200006 proceeding via social dialogue .

000100003400000100004 s achieved via social dialogue and, if necessary, $000100003400000100005 \quad$ This social dialogue offers employers a gu 000100003400000100004 is adapted via social dialogue to the situation of $\mathrm{t}$ 000100001800000200003 balisation and social disintegration .

000100002500000300005 ompetition via social dumping, and unsafe working e 000100001100000200003 ts to allowing social dumping, even if it is now ac 000100000900000300001 tition through social dumping, that is to say by re 000100002700000100005 pushed down by social dumping .

$000100003100000200001 \mathrm{~ns}$ may lead to social dumping .

000100003100000200002 and to resist social dumping.

$000100000300000400002 \mathrm{u}$ want to deny social dumping a foothold in our port 000100000500000100005 those who see social dumping and environmental poll 000100001200000100004 of security, social dumping and environmental poll 000100002400000100004 as the risk of social dumping arising . 000100002400000100009 nd the risk of social dumping is slight .

000100001700000100008 engthening the social element when you allow self-ha 000100003400000200008 e field of the social framework, safety, training 000100000300000400002 ; if you want social harmony to be maintained in ou 000100000900000200002 ntroducing the social jungle of the maritime sphere 000100001000000300002 ut not least, social legislation .

000100001100000200002 ffect upon the social legislation of the Member Stat 
000100001300000100007 in the area of social maladministration . 000100000800000100005 employment and social misery .

000100001200000200003 oncerned about social peace in our ports, which is 000100000800000200002 ns of years of social peace in the Flemish ports in 000100000400000400004 at is the best social policy, in general . 000100000300000300001 e standards of social protection and possess the sam 000100000700000300002 hat employees' social protection and the constraints 000100002500000100004 tions, on the social protection of dockers, on saf 000100002700000100003 bordination of social rights, health, safety and w 000100000900000200003 iance with the social rules of both the recipient co 000100000900000200004 spect the same social rules that apply in the countr $000100000300000200004 \mathrm{~ns}$ in terms of social security and labour law . 000100000100000500001 ion or for the social security regulations to apply $000100003400000100005 \mathrm{~s}$ employment, social services, safety and quality 000100000900000100003 he case in the social sphere .

000100001800000200002 thers with our social standards .

000100001700000400004 ing safety and social standards and thereby putting 000100001800000100003 are no minimum social standards that are enforceable 000100001200000200001 of a breach in social tradition in our ports . 000100002600000200002 a breakdown in solidarity between the established wo 000100002200000200001 et rid of this solidarity by means of a bad piece of 000100003200000100006 that refers to subsidiarity , to what the Member Sta 000100000100000400002 to follow the subsidiarity principle and leave this 000100000800000100006 damn about the subsidiarity principle with which the 000100002500000100003 - this form of subsidiarity - makes the whole author 000100003000000100002 arge number of trade union organisations . 000100000400000500001 providers and trade unions, I have received writte 000100000500000200005 tles fought by trade unions and without local port $\mathrm{c}$ 000100000500000700002 as far as the trade unions wanted, and scope for a 000100003400000200008 ork, safety, training, organisation of work and e $000100001100000200004 \mathrm{~d}$ insufficient training .

$000100002200000500002 \quad$ What training opportunities do they have ? 000100000800000200002 the name of an ultra-Liberal ideology, which is at 000100001900000400001 quence will be unemployed port workers, together wi 000100002200000500001 here would the unemployed port workers go ?

000100000800000100005 hing more than unemployment and social misery . 000100000400000500001 ders and trade unions, I have received written pled 000100000500000200005 ought by trade unions and without local port compani 0001000032000003000031 the workers' unions in my country, Italy - CGL , $000100000500000700002 \mathrm{r}$ as the trade unions wanted, and scope for abuse $\mathrm{r}$ 000100000500000300002 dly, the most unsafe, and consequently, the port $000100001800000100002 \mathrm{t}$ not if it is unsafe.

000100000500000200006 are dirty and unsafe and, above all, attract unsk 000100002500000300005 dumping, and unsafe working environments in our po 000100000500000200006 all, attract unskilled labourers ; ports where muc 000100000700000300001 nexperienced, untrained and employed on a casual ba 
000100001900000300001 and collective wage agreements . 000100001900000500003 tervening in, wage and working conditions . 000100002200000100008 he working and wage conditions were not in order . 000100001900000300002 ather than use well-trained port workers who, throu 000100003100000200005 governing port workers

000100000100000500002 itions of port workers, and have done a splendid jo 000100000200000300001 it serves the workers, because in this way new com 000100001200000200003 ent among port workers, but also among those who ar $000100000100000100002 \mathrm{nd}$ of the port workers, but also of fair competitio 000100001000000400001 ons among dock workers, employers and dock installa 000100001900000300001 seamen or port workers, just as entrepreneurs and s 000100002600000200003 facilities and workers, since the seamen might not 000100001900000400001 nemployed port workers, together with ports of conv 000100003000000200004 wners can make workers, who are taken on without gu 000100001700000400003 ed by the port workers, whose 21000 signatures mak $000100002600000200002 \mathrm{f}$ port service workers, will hamper the coordinatio 000100000300000100005 , citizens and workers .

000100002200000100003 account of our workers . 000100002200000300001 ean fewer port workers . 000100002000000100004 he sake of the workers and of our environment . $000100001700000400001 \mathrm{ng}$ to the port workers and the pilots, you have, $\mathrm{i}$ $000100003100000200005 \mathrm{t}$ is defending workers and the social and labour law 000100002200000500006 ver, the port workers are to be given help, we can 000100000900000300001 ot simply dock workers but also dock work companies 000100003000000300003 ecause it puts workers from different professions 000100002200000500001 nemployed port workers go ?

$000100001400000300001 \mathrm{~d}$ from certain workers in European ports, the moder 000100000100000100004 ors, and port workers mean that the European Union 000100002200000100008 amples of port workers refusing to handle goods from 000100001900000500001500 or so port workers that is on the agenda .

000100002900000300005 upport of port workers themselves .

000100002200000300002 competent port workers to ensure that cargoes are ha 000100000300000400002 able qualified workers to operate under good social $000100002700000100003 \mathrm{~d}$ wellbeing of workers to the laws of an ill-conside 000100001900000300002 1-trained port workers who, through agreements, ha 000100001100000200002 ially taken-on workers will, as you pointed out , b 000100001900000500004 ther groups of workers will be up for consideration 000100002200000100004 European port workers will face an uncertain future 000100002200000100005 promise, port workers will lose their jobs, simply 000100003000000200005 the number of workers with insecure jobs, who are 000100000900000300001 at is how dock workers - and not simply dock workers 000100000400000200001 from the dock workers' demonstrations here in Bruss 000100000800000100002 f Flemish dock workers' families are anxiously waiti 000100002400000200006 providers and workers' organisations - we can conti 000100003200000300003 mple, all the workers' unions in my country, Italy 000100002500000100004 tive impact on working conditions, on the social pr 
000100002500000100004 tive impact on working conditions, on the social pr 000100000500000100004 rd of labour, working conditions, safety and the e 000100000500000100004 rd of labour, working conditions, safety and the e 000100001900000500003 in, wage and working conditions.

000100001900000500003 in, wage and working conditions .

000100003100000200002 good rules and working conditions in shipping and to 000100003100000200002 good rules and working conditions in shipping and to 000100003000000200004 em to whatever working conditions they want .

000100003000000200004 em to whatever working conditions they want .

$000100002500000300005 \mathrm{~g}$, and unsafe working environments in our ports . 000200001700000200002 es against the Lisbon agenda if we want to achieve $\mathrm{f}$ 000200000100001000003 EU's ports to compete, being as they are crucially 000200000100000200001 er which ports compete with each other, and would $t$ 000200000500000200003 of EU citizens compete with each other through the $i$ 000200000100000800003 distortions of competition, and it has already indi 000200000800000300001 sely impact on competition, job quality and the pro 000200000200000100002 e opened up to competition, railway services to be 000200000700000200003 from unbridled competition, the freedom given to ea $000200001300000100004 \mathrm{~g}$ studies into competition, we have actually attain 000200001500000100007 romotes unfair competition, which can harm quality 000200000200000100002 e opened up to competition .

000200000900000400001 alk about fair competition . 000200002200000400004 reserving free competition . 000200002800000300001 distortion of competition . 000200003000000400001 munications to competition . 000200000600000100003 ined to tackle competition among ports , particularl 000200000100000200001 distortions of competition among ports and uncontrol $000200001200000100003 \quad$ Unfair competition among ports should theref 000200000500000800002 her study into competition and a text which juggles 000200000200000100002 e opened up to competition and air transport to be o 000200001600000100008 lled, healthy competition and increasing their tran $000200002300000100003 \mathrm{~g}$ private free competition and more than one service 000200000200000100003 se services to competition and that the exception wa 000200000600000100003 cularly unfair competition and the implications of $t$ 000200003000000400003 damage such as competition and the race for profit 000200000500000600002 against unfair competition at Member State level, $t$ $000200000200000200002 \mathrm{n}$ board ship, competition between ports, where bas 000200002600000400001 nsequences for competition between ports and for mar 000200002000000100004 convinced that competition between ports demands the 000200001800000200005 lear, because competition between ports is ruthless 000200002900000200003 Rather than competition between the ports it focu 000200000300000200002 be subject to competition but committed to safety . $000200000100000100002 \mathrm{t}$ also of fair competition conditions in and between 000200000100000800001 conditions of competition in and between ports . 000200002800000300002 distortion of competition in itself can also lead $t$ 000200000600000100004 a directive on competition in ports and the opening 
000200000500000600002 e level, this competition is only set to increase . 000200001700000400004 hereby putting competition on a single footing, is 000200000600000100003 of this unfair competition on the environment when $\mathrm{n}$ $000200002500000300001 \mathrm{rt}$ services to competition on the internal market, 000200000500000400001 and dangerous competition per group of ports that $\mathrm{s}$ 000200001500000100009 and the unfair competition resulting from this could $000200003000000400001 \mathrm{rt}$ services to competition stems from the same retro $000200000900000300001 \mathrm{w}$ to engage in competition through social dumping, 000200002500000300005 for pernicious competition via social dumping, and $000200002500000100004 \mathrm{~m}$, pernicious competition will inevitably follow, 000200003000000300003 dockers - into competition with each other - in orde 000200002900000200003 on to increase competition within a supermarket rath 000200001300000100004 ually attained competition within ports .

000200002900000200003 it focused on competition within the ports - a litt 000200001400000200003 ts, which are competitive and able to provide an al 000200000500000100005 s of winning a competitive battle .

000200001200000100006 vices from the competitive battle .

$000200000500000300001 \quad$ In a competitive battle of this kind, por 000200000700000200001 ge of becoming competitive in a globalised economy, $000200000700000200001 \mathrm{n}$ a globalised economy, we did not want this to be 000200002400000200001 e able to take effective measures to prevent problem $000200003400000300002 \mathrm{t}$ already have effective regulations and a safe syst $000200001400000200002 \mathrm{t}$ a modern and effective social Europe .

000200000400000200003 MEPs fully and effectively. 000200001300000100009 pose much more effectively . 000200001100000600006 e other hand, effectively destroying these with the 000200001600000100008 and levels of efficiency, which will increase the $000200001600000100007 \mathrm{o}$ increase the efficiency and competitiveness of por 000200000700000200001 for increased efficiency in order to face the chall 000200000100001000004 ese ports more efficient, and so I ask you to accep 000200002100000400001 , determined, efficient and intelligent Member of P 000200000400000400002 acquired more entrepreneurial room, which they nee 000200001900000300001 kers, just as entrepreneurs and shipowners will be $000200002700000100002 \mathrm{n}$ economic and financial Europe .

000200000700000300002 the search for financial profitability obtained thro 000200000100000800002 ber States the financial relations between themselve 000200000300000200001 ted the ports' financial relations to be made transp 000200000300000100003 ing impressive growth, and doing so without this di 000200000400000400003 ore room means growth and employment .

000200001500000200005 hort, genuine harmonisation on a key issue such as 000200002500000300001 etition on the internal market, we must firstly and 000200002900000400001 the future of investment in our ports and above all 000200002400000200005 creation of a level playing field with regard to st 000200000700000300003 ould involve a levelling down of the services provid 000200001400000200002 We want a modern and effective social Europe . 000200002200000300001 se employed on modern ships and that the Port Direct 
000200002200000300002 le employed on modern ships that we should leave it 000200000200000300001 it breaks the monopoly and there is greater choice 000200000500000900001 cts concerning monopoly ports with a small hinterlan 000200000200000100003 e of action to open up all these services to competi 000200002500000300001 if we want to open up port services to competition 000200003200000100004 ve measures to open up the market in port services $\mathrm{w}$ 000200000600000100004 ports and the opening up of markets to new service 000200003000000400001 ade mindset as opening up rail transport, air traff $000200001600000100003 \mathrm{~s}$ step towards opening up the market in port service 000200000200000100003 he vanguard of opening up these services, came alon 000200002800000300002 so lead to lax regulation .

000200002900000200003 a little like single market legislation to increase 
Table 33: Multinomial logit regression estimates, first reading vote, 6.6 .

\begin{tabular}{lcc}
\hline & No Vote & Yes Vote \\
\hline Left-Right Dimension & $1.61^{* *}$ & $3.33^{* * *}$ \\
& $(.61)$ & $(.63)$ \\
Sovereignty-Integration Dimension & $3.55^{* * *}$ & $5.61 * * *$ \\
& $(1.11)$ & $(1.16)$ \\
Government Status & .70 & .21 \\
Liberal Market Economy & $.70)$ & $(.72)$ \\
& .46 & -1.34 \\
Partial Coordinated Market Economy & $(1.25)$ & $(1.31)$ \\
Sectoral Coordinated Market Economy & -1.35 & -1.30 \\
& $(.81)$ & $(.85)$ \\
Constant & -1.66 & -.57 \\
& $(.86)$ & $(.89)$ \\
Number of cases & $4.60^{* * *}$ & $4.77^{* * *}$ \\
Log pseudo-likelihood & $(1.14)$ & $(1.16)$ \\
Pseudo R & 536 & \\
& -322.96 & \\
\hline
\end{tabular}

Note: Table entries are multinomial logit estimates. The omitted (baseline) choice for each column is "Abstention." Robust standard errors appear in parentheses. Statistical significance is indicated as follows: $* * * 0.001$ level; $* *<0.01 ; *<0.05$ 


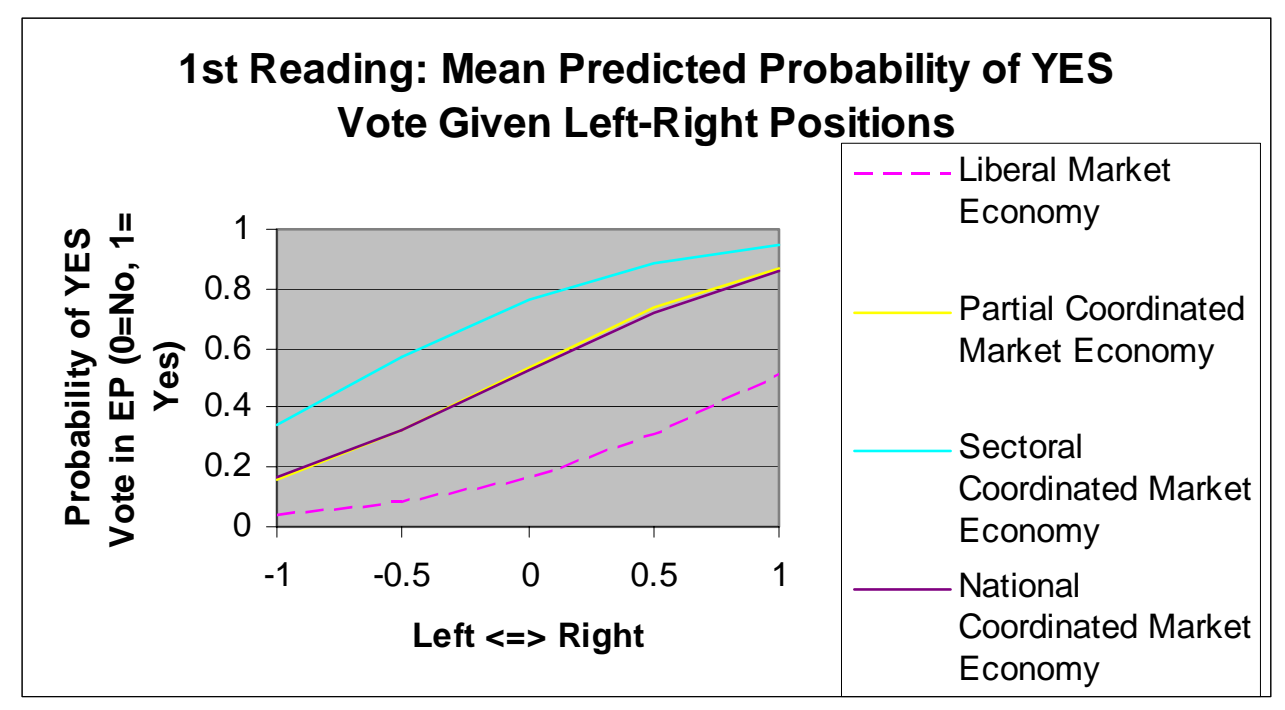

Figure 64: Probabilities 6.6. G

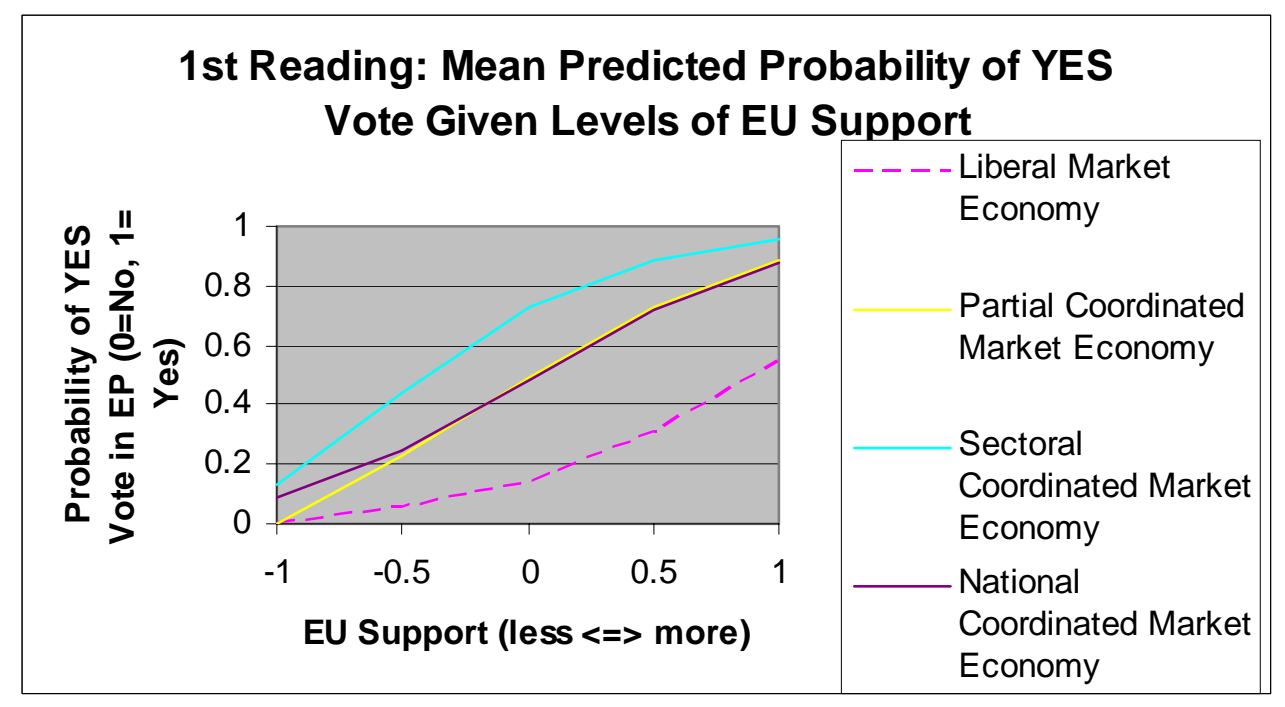

Figure 65: Probabilities 6.6. H 


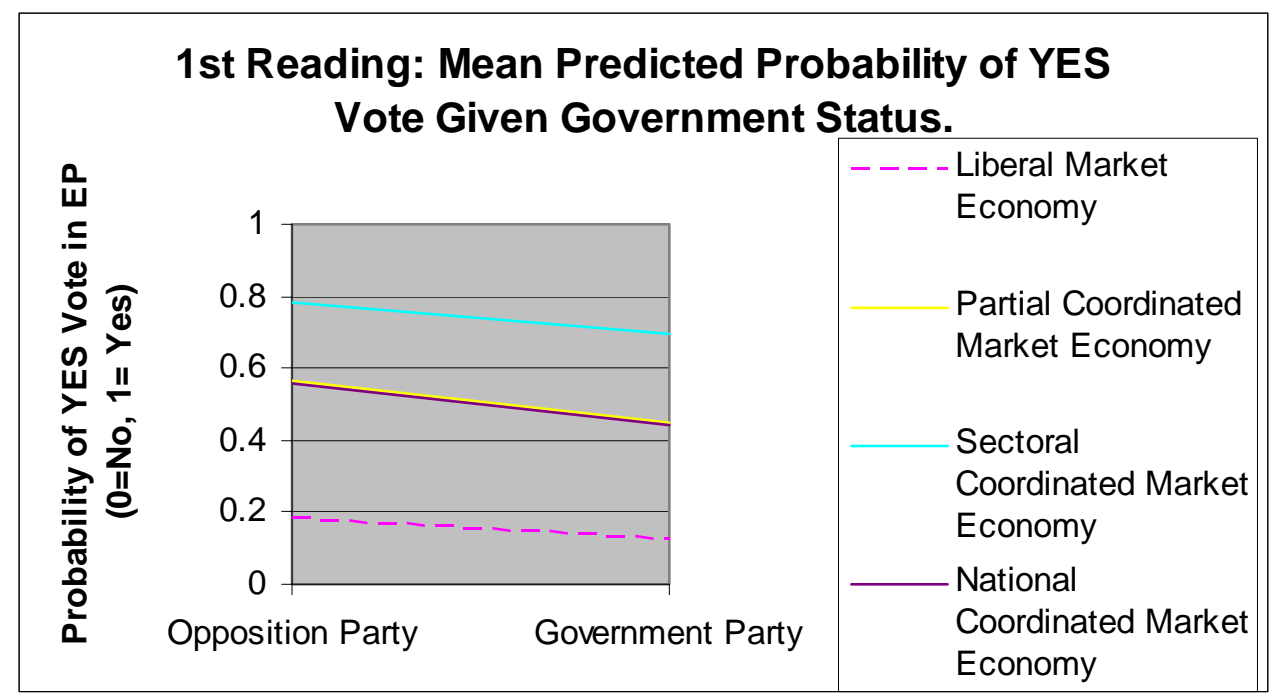

Figure 66: Probabilities 6.6. I 


\section{APPENDIX I}

\section{CHAPTER 6.7.}

Table 34: Frequencies-of-use, content analysis, 6.7.

\begin{tabular}{|c|c|c|c|}
\hline & \# of input words & $\begin{array}{l}\text { \# of references to } \\
\text { family definition }\end{array}$ & $\begin{array}{l}\text { \# of references to } \\
\text { practical value }\end{array}$ \\
\hline $\begin{array}{c}1^{\text {st }} \text { Reading Debate } \\
\text { (adjusted by \# of input words) }\end{array}$ & $\begin{array}{c}7,401 \\
(10,000)\end{array}$ & $\begin{array}{c}70 \\
(95) \\
\text { (by } 17 \text { of } 18 \\
\text { speakers) }\end{array}$ & $\begin{array}{c}54 \\
(73) \\
\text { (by } 15 \text { of } 18 \\
\text { speakers) }\end{array}$ \\
\hline $\begin{array}{c}2^{\text {nd }} \text { Reading Debate } \\
\text { (adjusted by \# of input words) }\end{array}$ & $\begin{array}{c}3,452 \\
(10,000)\end{array}$ & $\begin{array}{c}18 \\
(52) \\
\text { (by } 8 \text { of } 8 \\
\text { speakers) }\end{array}$ & $\begin{array}{c}30 \\
(87) \\
\text { (by } 7 \text { of } 8 \\
\text { speakers) }\end{array}$ \\
\hline
\end{tabular}


Table 35: Binomial logit regression estimates, first reading vote, 6.7.

Floor Vote, First Reading

Left-Right Dimension

$-4.72 * * *$

(.40)

Sovereignty-Integration Dimension

$2.93 * * *$

$(.42)$

Government Status

$-1.69 * * *$

$(.42)$

$1.88 *$

National Same-Sex Marriage Legislation

$(.74)$

Constant

Number of cases

514

Log pseudo-likelihood

$-159.84$

Pseudo $\mathrm{R}^{2}$

0.55

$* * *=$ significant at 0.001 level; $* *=$ significant at 0.01 level; $*=$ significant at 0.05 level Dependent Variable: Vote: $1=$ for, $0=$ against, abstain $=0$ 


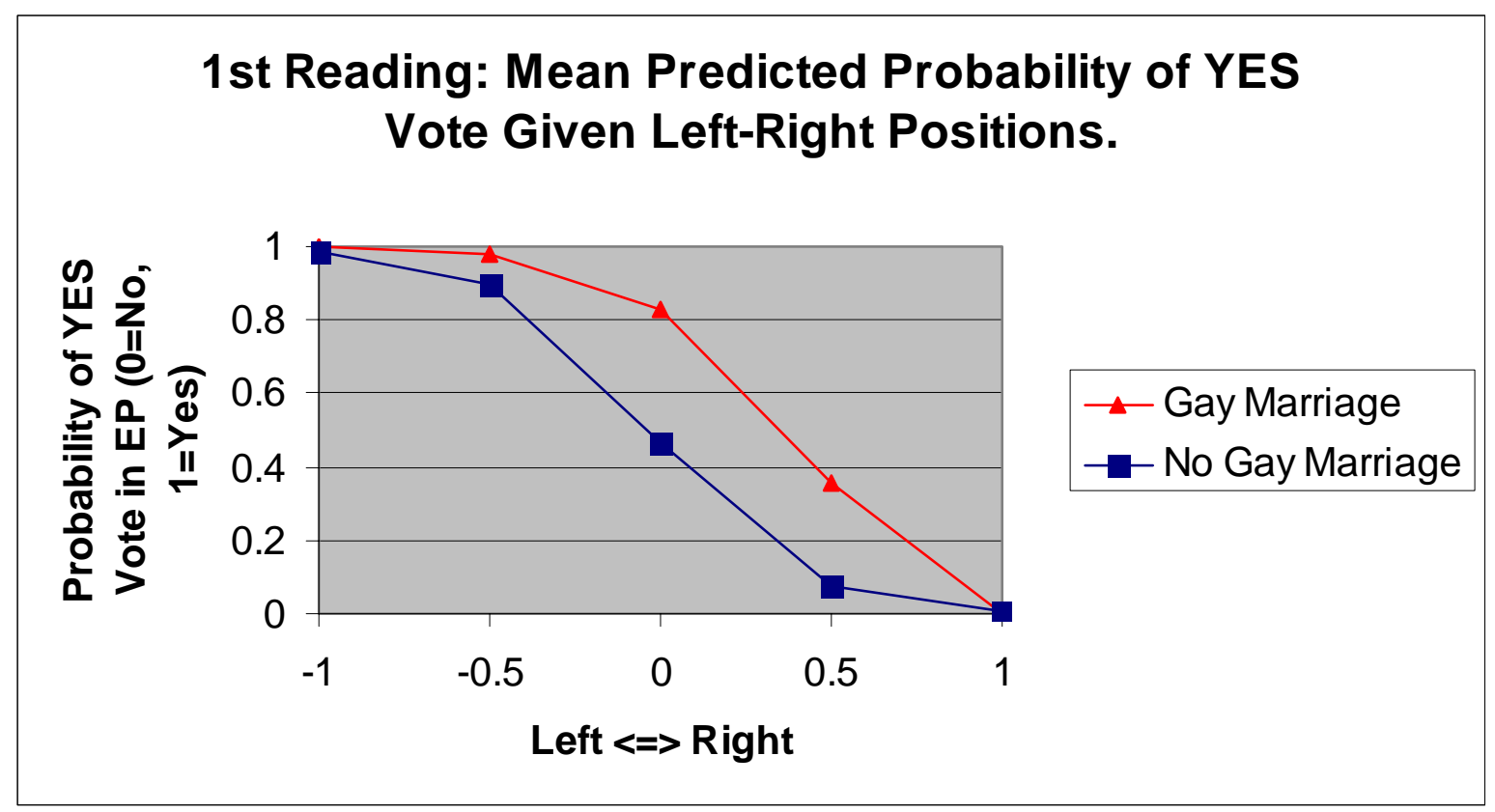

Figure 67: Probabilities 6.7. A

\section{1st Reading: Mean Predicted Probability of YES Vote Given Levels of EU Support.}

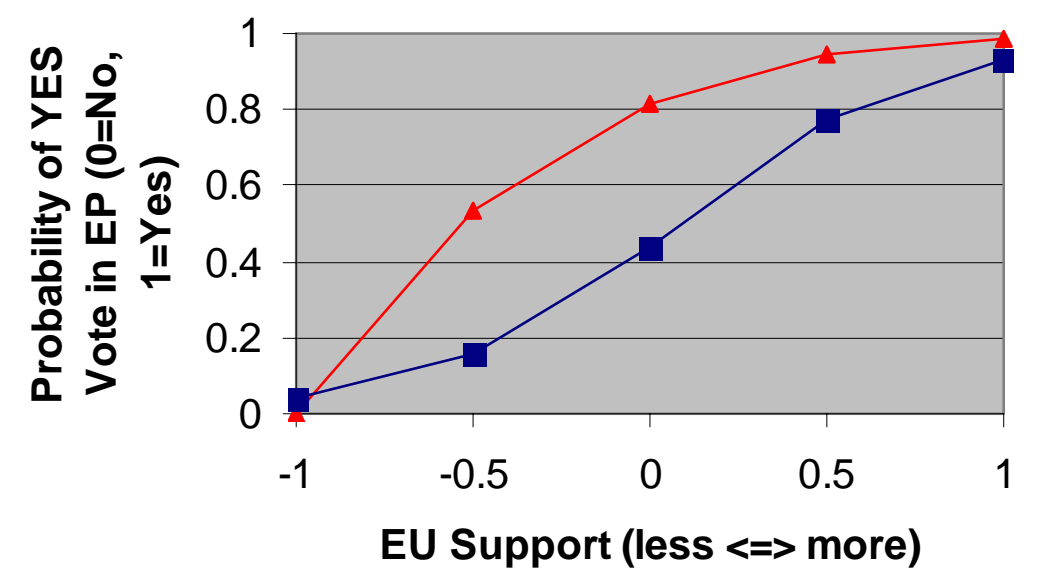

Figure 68: Probabilities 6.7. B 


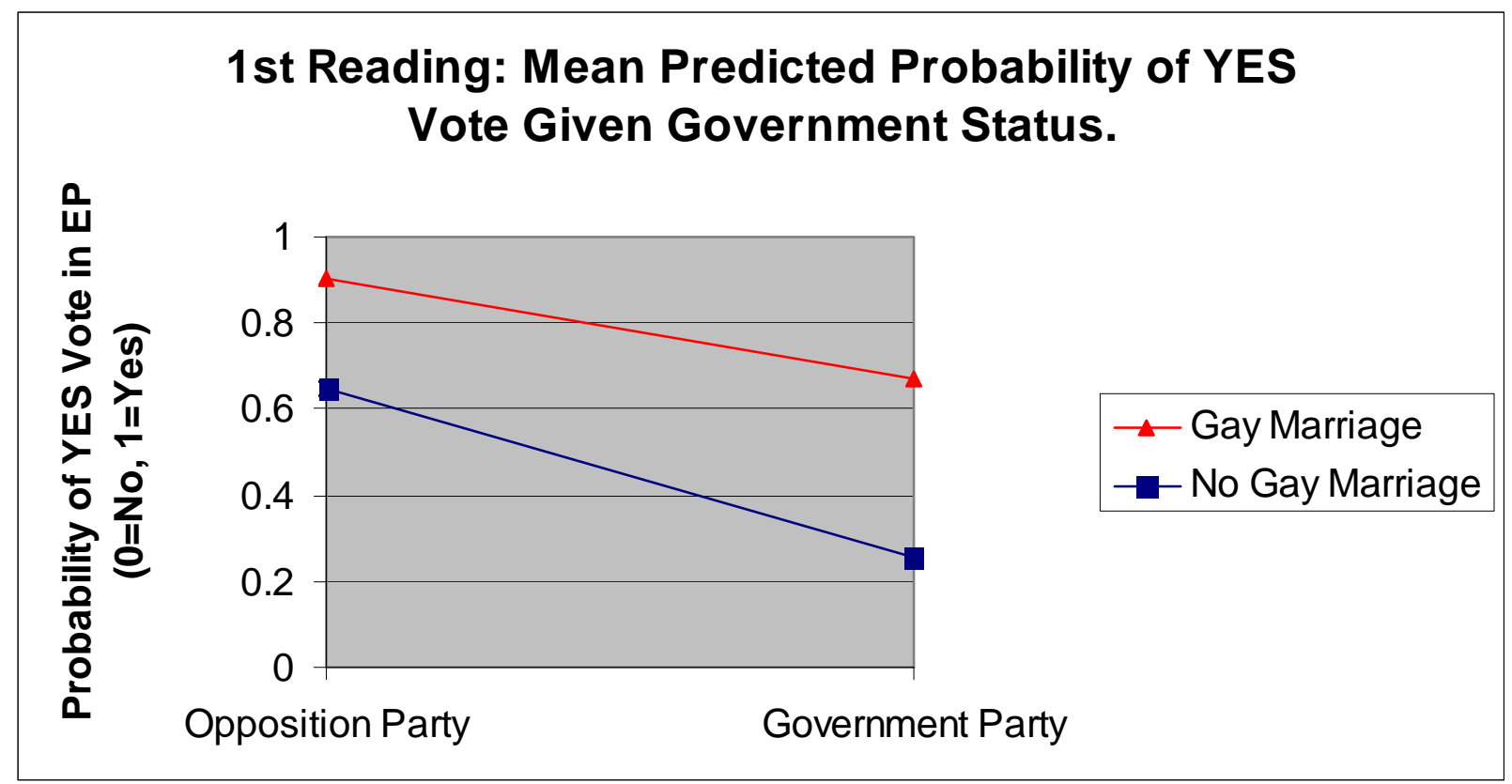

Figure 69: Probabilities 6.7. C 
Table 36: Binomial logit regression estimates, second reading vote, 6.7. Amend. 4.

Floor Vote, Second Reading, Am. 4

Left-Right Dimension

$-8.48 * * *$

$(1.28)$

Sovereignty-Integration Dimension $-2.62 * * *$

Government Status

(.36)

$-1.46^{*}$

National Same-Sex Marriage Legislation

(.68)

$-1.37 * *$

Constant

$-3.38 * * *$

(.47)

Number of cases

476

Log pseudo-likelihood

$-59.10$

Pseudo $\mathrm{R}^{2}$

0.72

$* * *=$ significant at 0.001 level; $* *=$ significant at 0.01 level; $*=$ significant at 0.05 level Dependent Variable: Vote: $1=$ for, $0=$ against, abstain $=0$ 


\section{Second Reading, Am. 4: Mean Predicted Probability of YES Vote Given Left-Right Positions.}

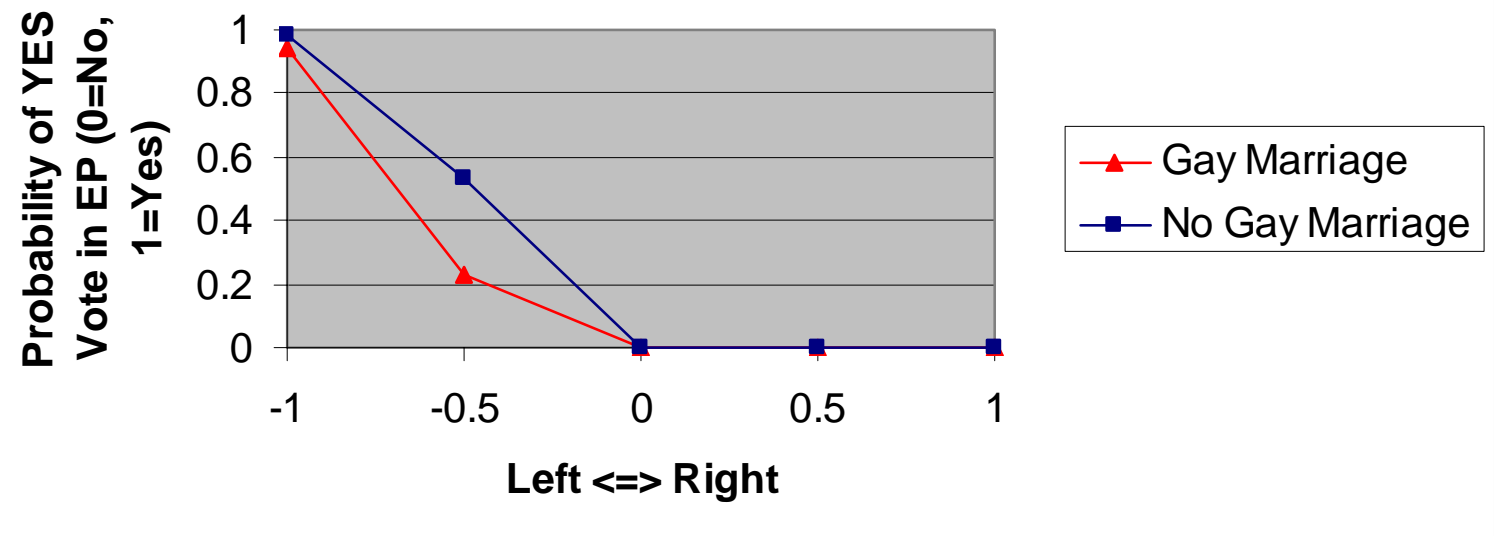

Figure 70: Probabilities 6.7. D

\section{Second Reading, Am. 4: Mean Predicted Probability of YES Vote Given Levels of EU Support.}

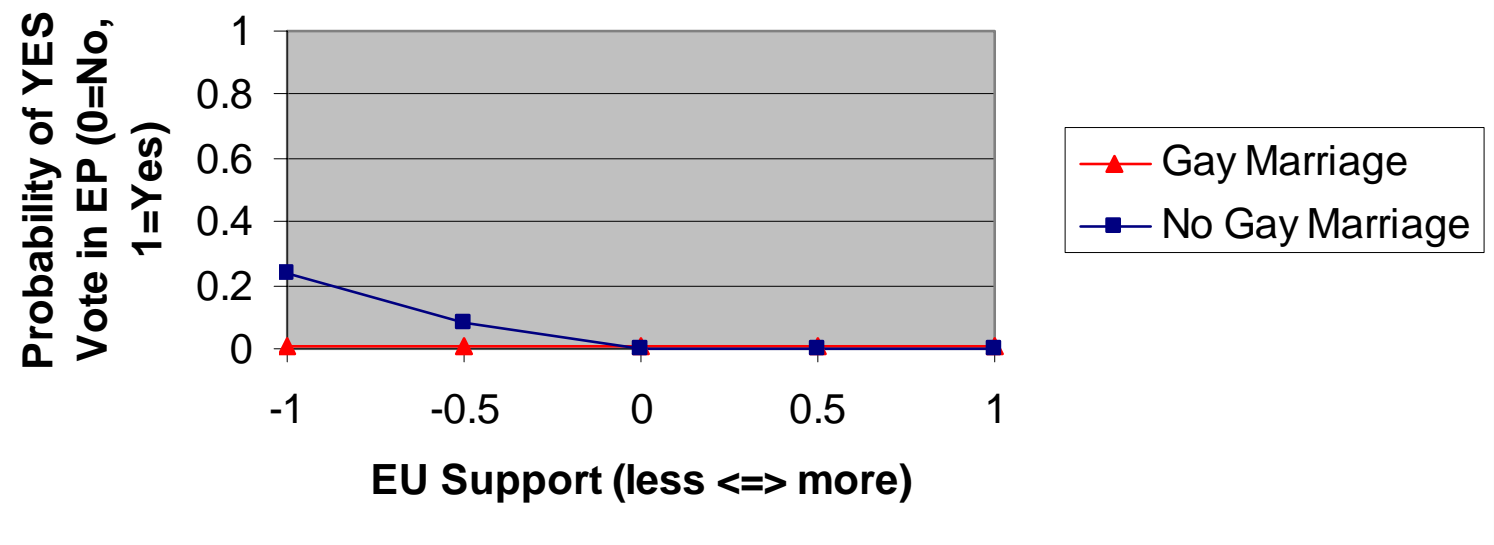

Figure 71: Probabilities 6.7. E 


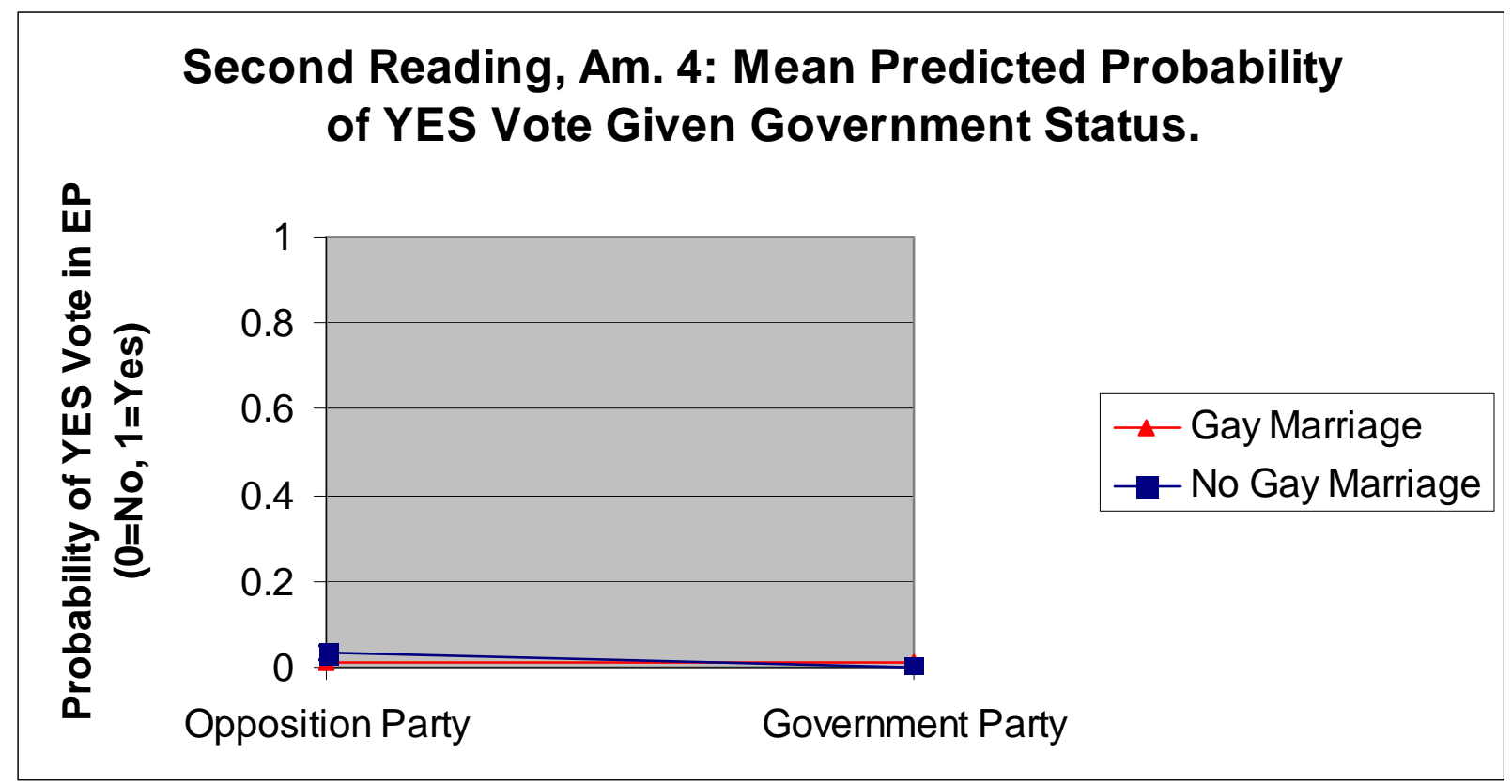

Figure 72: Probabilities 6.7. F 


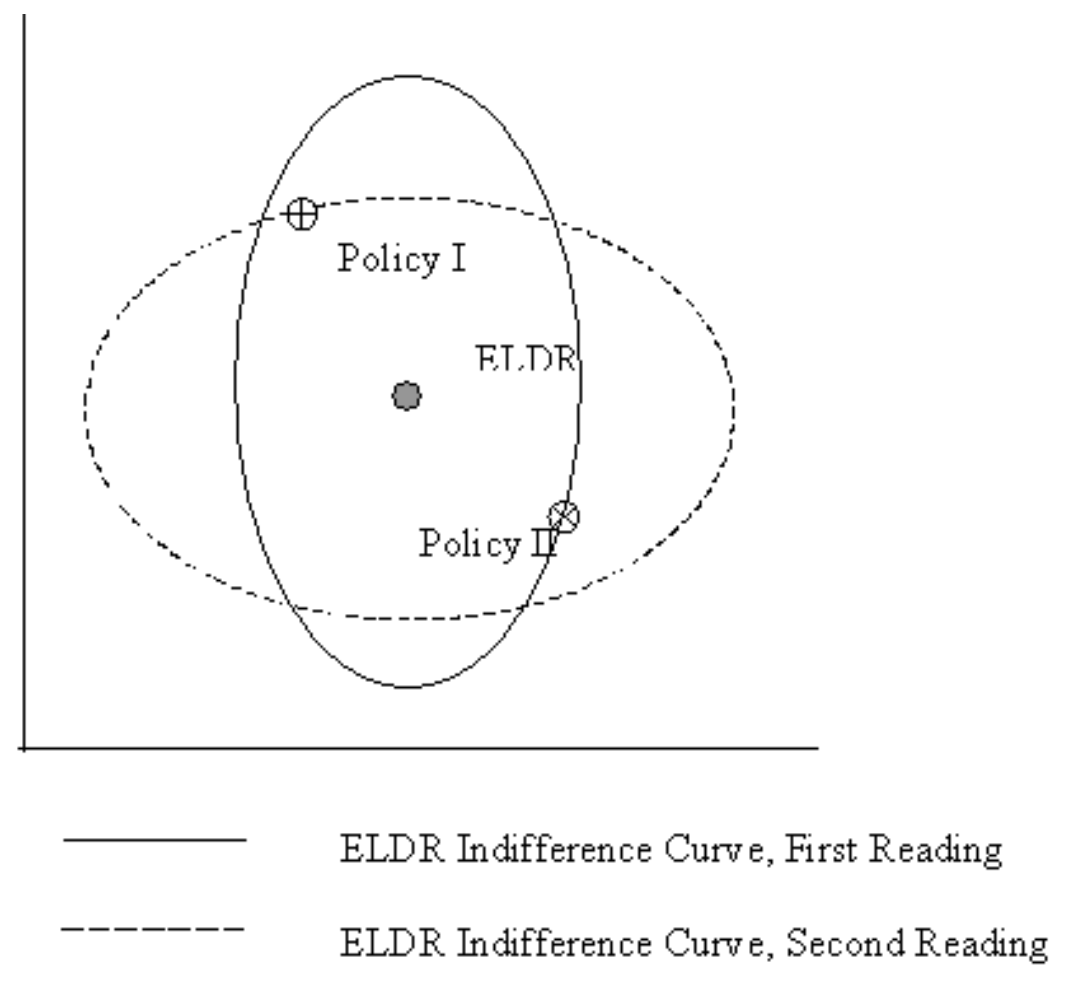

Figure 73: Policy Space 6.7. A 


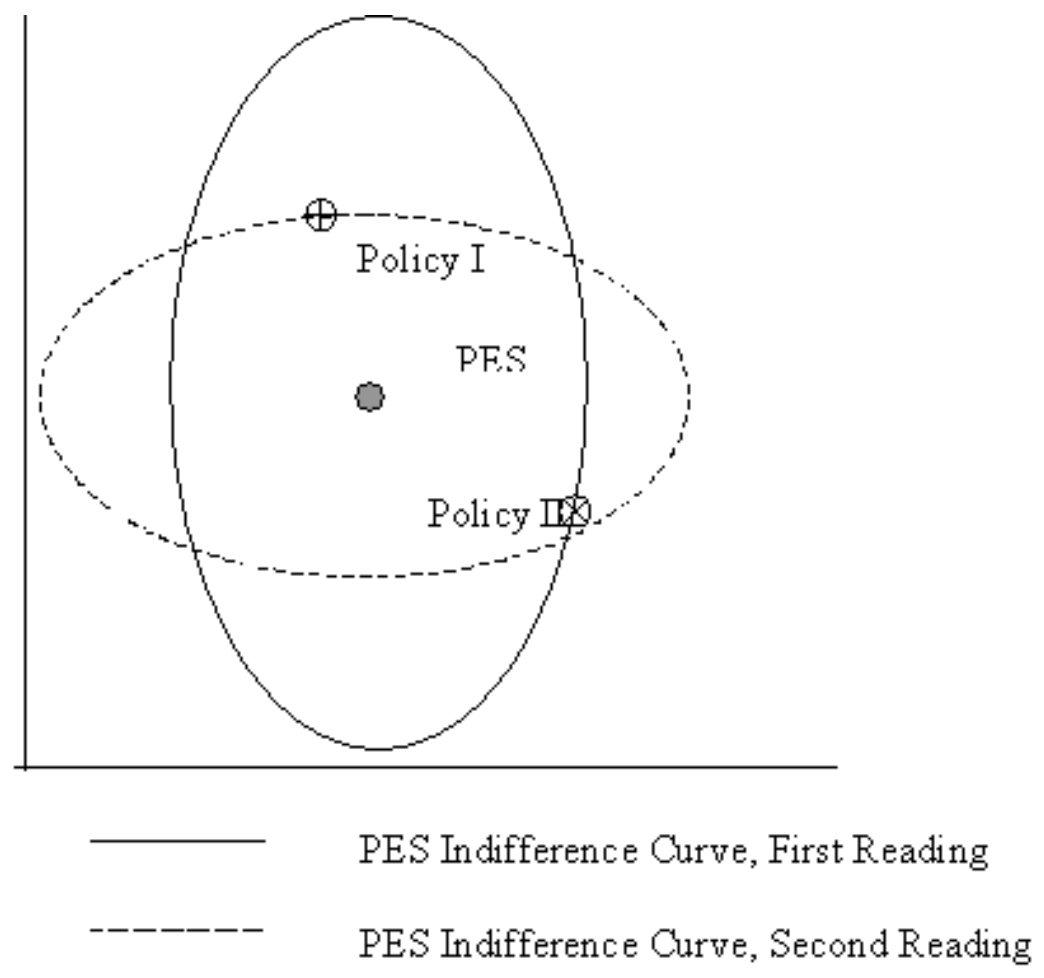

Figure 74: Policy Space 6.7. B 
First Reading: Mean Predicted Probability of YES Vote Given Levels of EU Support.

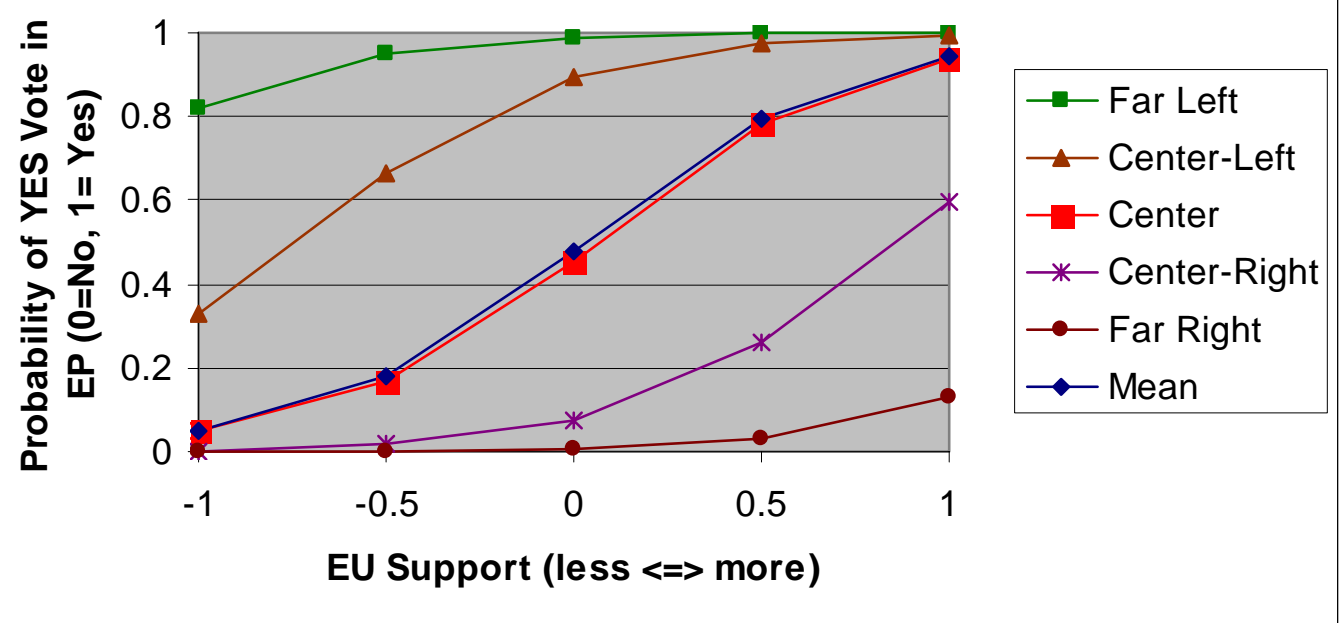

Figure 75: Probabilities 6.7. G

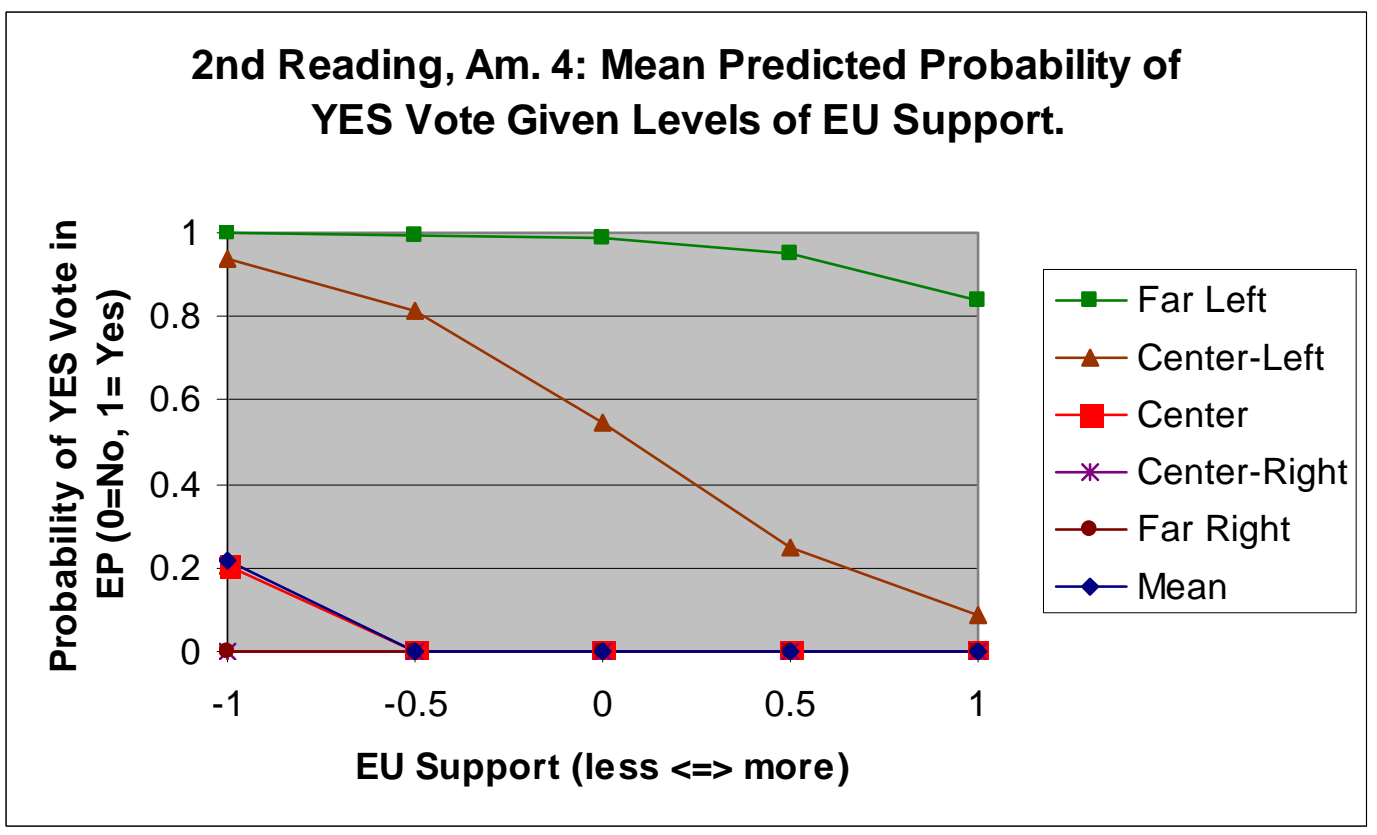

Figure 76: Probabilities 6.7. H 


\section{TEXTPACK Analysis}

\section{Focal Point 1: Practical value (of legislation)}

administrative, barriers, burden, bureaucr- (and relevant endings, e.g. bureaucracy), clari(and relevant endings, e.g. clarify), combines, common market, competitive, content to EU citizenship, core of EC law, employment, enlargement, European identity, facilitat- (and relevant endings, e.g. facilitate), family member, free market for people, historic, hurdles, labour force, Lisbon, milestone, mobility, obstacles, one legal instrument, red tape, multiplicity of regulation, replace, restrictions, simplif- (and relevant endings, e.g. simplify), single act, single legal instrument, single text, step forward, streamline

\section{Focal Point 2: Family definition}

civil liberties, cohabit, definition of 'family', discrimination, equal rights, equal treatment family, gender, heterosexual, homosexual, immigration, marriage, mutual recognition, mutually recognised, non-discriminatory, same-sex, sex, sexual, social rights, two men, two women, unmarried

\section{Keywords-in-context}

Cat $=$ focal point category: Cat $0001=$ practical value, Cat $0002=$ family definition

ID1: Speaker ID

ID2: Paragraph ID

ID3: Line ID

EP Debate, first reading (February 11, 2003):

\section{Cat ID1 ID2 ID3}

000100000500000200001 the idea of a European identity by means of the cre 000100001800000300001 or a system of European identity cards or by arrangi 000100001100000100002 ts political, administrative, judicial, social an 000100000200000300001 rictions of an administrative nature, either for en 000100000400000100003 the remaining barriers and surmount the bureaucrati 000100001500000100003 administrative burden should be reduced to that whic 000100001200000300002 om unnecessary bureaucracy and excessive red tape . $000100000400000100003 \mathrm{~d}$ surmount the bureaucratic and political hurdles an 000100000100000400002 he excessively bureaucratic sections as far as is po 
000100001400000100003 ow needs to be clarified is which restrictions are t $000100000100000400002 \mathrm{r}$ merit is its clarity and, in this regard, I feel 000100000100000400001 ive is that it combines all the previous provisions 000100001200000600007 for people, a common market for EU citizens and the 000100001200000200003 much more of a common market for people than it is a 000100001200000300003 Union the most competitive economy in the world by 2 000100000600000100003 s to give more content to EU citizenship and to incr 000100001700000100002 ovement is the core of EC law .

000100001400000200001 ble to take up employment that could provide them wi $000100001700000100005 \quad$ Following enlargement, it will be still more i 000100001200000400003 our efforts to facilitate freedom of movement for le 000100001700000200003 sed rules that facilitate the freedom of movement of 000100001200000500002 at this report facilitates .

000100001300000100004 was all about facilitating illegal immigration and 000100001500000100002 rucial for the facilitation of the free movement of 000100001100000300005 oad concept of family member, on which I think it w $000100001100000300003 \mathrm{~d}$ partner as a family member . 000100000300000300003 definition of family members . 000100001400000100004 zens and their family members . $000100001700000200003 \mathrm{t}$ of different family members . 000100001400000100002 zens and their family members to move freely and res 000100000100000500004 In the case of family members who are third-country 000100000700000200001 xpectations of family members who wish to live outsi 000100001200000600007 they wish : a free market for people, a common mar 000100000400000100003 and political hurdles and obstacles that block the 000100000600000400004 obility of the labour force and, of course, the pr 000100000600000400004 ncrease in the mobility of the labour force and, of 000100000600000200001 of the present multiplicity of regulations, directi 000100001200000200002 ct to too many obstacles, and Mrs Buitenweg has jus 000100001100000100002 faces too many obstacles, with initiatives having $\mathrm{t}$ 000100001100000200001 deal with the obstacles still hampering EU citizens 000100000400000100003 al hurdles and obstacles that block the way to freed 000100000300000100002 fied technical obstacles that persist even in united 000100000600000200003 the practical obstacles to people's freedom of move 000100001200000300002 and excessive red tape.

000100000900000200006 inate a lot of red tape and uncontrollable rules . 000100000100000500001 he proposal to replace the residence card, as the $\mathrm{C}$ 000100001400000100003 ified is which restrictions are to be permissible fo 000100000200000400001 moving all the restrictions in terms of administrati 000100000200000300001 tablishment of restrictions of an administrative nat $000100000800000200002 \mathrm{~s}$ is now being simplified.

000100000700000100002 moreover, to simplify and streamline a veritable s 000100000100000400002 have helped to simplify the excessively bureaucratic 000100001700000200001 must begin by simplifying the rules .

000100001400000100003 replaced by a single act, conditions and formaliti 000100001100000200002 combining in a single legal instrument the right to 
000100000100000400001 e subject in a single text .

000100000500000300004 o be a genuine step forward .

000100001600000200008 This is a big step forward an

$000100000200000400001 \mathrm{t}$ an effective step forward by removing all the rest 000100000700000100002 o simplify and streamline a veritable spider's web o 000200000700000200001 ne increase in civil liberties, eliminating discrim 000200000100000800002 guarantees of civil liberties.

000200001600000200004 and prefer to cohabit but without losing all their 000200000700000200001 ion or form of cohabitation .

$000200001000000100003 \mathrm{r}$ to eliminate discrimination against same-sex coupl 000200000700000200001 , eliminating discrimination on the basis of gender 000200001000000200002 treatment, no discrimination on the basis of the fa 000200001500000400007 citizens, not equal rights for some . 000200001500000400007 and affording equal rights to all of our citizens, 000200000100000200003 e principle of equal treatment of third citizens who 000200001500000200001 efinition of ' family ' and the importance given to 000200001100000300003 inition of the family, an excessively broad definit 000200000100000700001 Chamber : the family, its composition and the defi 000200000600000400002 inition of the family . 000200001300000400001 cognition as a family . 000200001700000200004 concept of the family . 000200001400000100006 we define the family? $000200001400000200004 \mathrm{~s}$ I see it, a family exists when someone takes on $\mathrm{t}$ 000200000100000200003 of a Community family has been established since the 000200001500000400001 definition of family if he were to move with me to 000200000600000400001 inition of the family incorporated into the proposal 000200001400000100010 inition of the family is urgently needed; after all 000200000800000400006 at they have a family life .

000200001500000300004 ight of modern family life and the diversity of dura $000200001200000600003 \mathrm{ll}$ citizens to family life and we, as a Parliament 000200000800000400004 ant to disrupt family life because there is a certai 000200000800000400007 , not disrupt family life because there is a signat 000200001000000200001 mpose a single family model throughout Europe - that 000200001000000200002 mpose a single family model unduly but ensure that, 000200000400000200005 inition of the family on all the other states .

000200000600000400004 inition of the family ought not therefore to distrac 000200000100000500004 existence of a family relationship, purely in order 000200001100000300006 ple requesting family reunification .

000200001700000200005 re traditional family structures must have the same 000200001300000200001 definition of family that EU citizens can take with 000200000100000300001 tizen of whose family they are members .

000200000600000400003 , to preserve family unity .

000200000600000400004 reservation of family unity .

000200001500000200002 definition of family will not be welcomed by all, 000200000700000200002 or to build a family without being forced to marry 000200000300000100004 the grounds of gender . 
000200001400000100008 es of whatever gender ?

$000200000700000200001 \mathrm{n}$ the basis of gender identity, sexual orientation 000200000300000200001 a text that is gender neutral and takes account of $\mathrm{t}$ 000200001000000200002 be same-sex or heterosexual couples .

000200000700000100003 ers of illegal immigration .

000200001300000100004 tating illegal immigration and terrorism .

000200001300000400001 is not just an immigration question, it is also a q $000200001200000600006 \mathrm{ht}$ want to use marriage as an avenue to gain illegal 000200001400000200005 have signed a marriage certificate.

000200001300000400002 I believe the mutual recognition argument has stron 000200001500000400006 a principle of mutual recognition here .

000200001600000200001 the system of mutual recognition in this area, and 000200001600000200007 e principle of mutual recognition in this area .

000200001300000200003 o champion the mutual recognition principle in crimi

000200001600000200002 lationship are mutually recognised by the Member Sta 000200001000000100003 nation against same-sex couples .

000200001600000200004 talking about same-sex couples; a growing number o 000200001000000200004 urope, but if same-sex marriages are recognised in 000200001000000200004 be introducing same-sex marriages throughout Europe $000200001000000200002 \mathrm{r}$ form, to be same-sex or heterosexual couples . 000200000700000200002 lone or with a same-sex partner or to build a family 000200001500000400001 tand here in a same-sex relationship of 20 years , y 000200001600000200003 rrespective of sex .

000200000300000300001 ners of either sex the same rights as a spouse . 000200000700000200001 der identity, sexual orientation or form of cohabit 000200001300000300004 and the tax or social rights that go with that - for $000200001600000100008 \quad$ Even two men or two women who were ma 000200001600000100008 ven two men or two women who were ma 000200001400000100008 amily' include unmarried couples of whatever gender 000200000100000700004 in relation to unmarried couples too, the rapporteu 000200001600000100005 ry but who are unmarried or in a registered partners 000200001100000300003 finition of an unmarried partner as a family member

EP Debate, second reading (March 8, 2004):

\section{Cat ID1 ID2 ID3}

000100000400000100003 erstone of the Lisbon process and a precondition for $000100000600000400002 \mathrm{e}$ is to reduce administrative formalities to the bar 000100000600000200002 are still many barriers to exercising this fundament 000100000400000100006 most important barriers to mobility is constituted b 000100000500000200002 not to be a 'burden on the state ' , in the langu $000100000100000100004 \quad$ For bureaucratic reasons, we have only r 000100000100000300008 interpret and clarify it . 
000100000500000100004 gives greater clarity to citizens, the approach se 000100000600000300003 e closeness of enlargement .

000100000700000100006 re expected to facilitate entry and residence for pa $000100000400000200004 \quad$ It will facilitate mobility by doing away wit 000100000700000100006 use to admit a family member, they must give a just 000100000100000100002 nion and their family members to move and reside fre 000100000100000400004 endents deemed family members within the meaning of 000100000100000400005 therefore, as family members within the meaning of 000100000300000100009 of creating a free market for people so that they c $000100000100000300002 \mathrm{t}$ as an almost historic step, which is , at any rat 000100000100000500007 certainly be a milestone in creating European citize $000100000400000100006 \mathrm{nt}$ barriers to mobility is constituted by the limite 000100000400000100005 ding increased mobility is not limited to the partic 000100000200000100003 is now indeed one legal instrument to assess what $t$ 000100000400000200003 directive will replace nine existing directives and 000100000300000100006 something of a simplification, because it is a lot 000100000100000500002 irective fully simplifies all the current formalitie $000100000400000200002 \mathrm{t}$ considerably simplifies matters .

000100000600000200003 ble, so as to simplify the exercise of the right to 000100000300000100005 a question of simplifying formalities .

000100000500000300004 his might be a step forward, but it still does not 000100000100000400001 inely historic step forward has been taken . 000100000500000100004 that this is a step forward in terms of codification $000100000700000200001 \mathrm{ew}$, the major step forward that has been taken is $\mathrm{t}$ 000200000600000400002 the concept of family, I would like to emphasise th 000200000200000200001 ns of extended family, family and partnership, des 000200000500000200007 efinition of a family, that things are changing and 000200000100000400003 the rights of family, there are some very interest 000200000200000200001 ended family, family and partnership, descriptions $000200000600000400003 \mathrm{t}$ to live as a family from the sphere of Union compe 000200000300000200001 cept of what a family is then we are undermining the 000200000700000100006 use to admit a family member, they must give a just 000200000100000100002 nion and their family members to move and reside fre 000200000100000400004 endents deemed family members within the meaning of 000200000100000400005 therefore, as family members within the meaning of 000200000200000300001 the concept of family should also be defined effecti 000200000600000400002 nitions of the family status . 0002000001000003000061 marriage for homosexual partners exists . 000200000100000300005 equivalent to marriage, such partners should be co 000200000100000300006 es where civil marriage for homosexual partners exis 000200000200000200005 ship entails a marriage relationship or otherwise . $000200000100000300006 \mathrm{~s}$ between same sex and different sex partners are on 000200000100000300006 and different sex partners are only possible in the 000200000100000400002 the rights of unmarried couples are recognised even 000200000100000300005 ants rights to unmarried partners that are equivalent 
Table 37: Multinomial logit regression estimates, first reading vote, 6.7 .

\begin{tabular}{|c|c|c|}
\hline & No Vote & Yes Vote \\
\hline Left-Right Dimension & $\begin{array}{c}10.25^{* * *} \\
(2.01)\end{array}$ & $\begin{array}{c}-1.31 * * \\
(.50)\end{array}$ \\
\hline Sovereignty-Integration Dimension & $\begin{array}{c}-4.33 * * \\
(1.37)\end{array}$ & $\begin{array}{c}1.91 * * * \\
(.49)\end{array}$ \\
\hline Government Status & $\begin{array}{l}-.85 \\
(.53)\end{array}$ & $\begin{array}{c}-2.19 * * * \\
(.40)\end{array}$ \\
\hline National Same-Sex Marriage Legislation & $\begin{array}{c}-1.86^{*} \\
(.82)\end{array}$ & $\begin{array}{c}.43 \\
(.72)\end{array}$ \\
\hline Constant & $\begin{array}{l}-.30 \\
(.82)\end{array}$ & $\begin{array}{c}2.24 * * * \\
(.30)\end{array}$ \\
\hline $\begin{array}{l}\text { Number of cases } \\
\text { Log pseudo-likelihood } \\
\text { Pseudo } \mathrm{R}^{2}\end{array}$ & $\begin{array}{c}514 \\
-192.34 \\
0.5963\end{array}$ & \\
\hline
\end{tabular}

Note: Table entries are multinomial logit estimates. The omitted (baseline) choice for each column is "Abstention." Robust standard errors appear in parentheses. Statistical significance is indicated as follows: $* * *<0.001$ level; $* *<0.01 ; *<0.05$ 


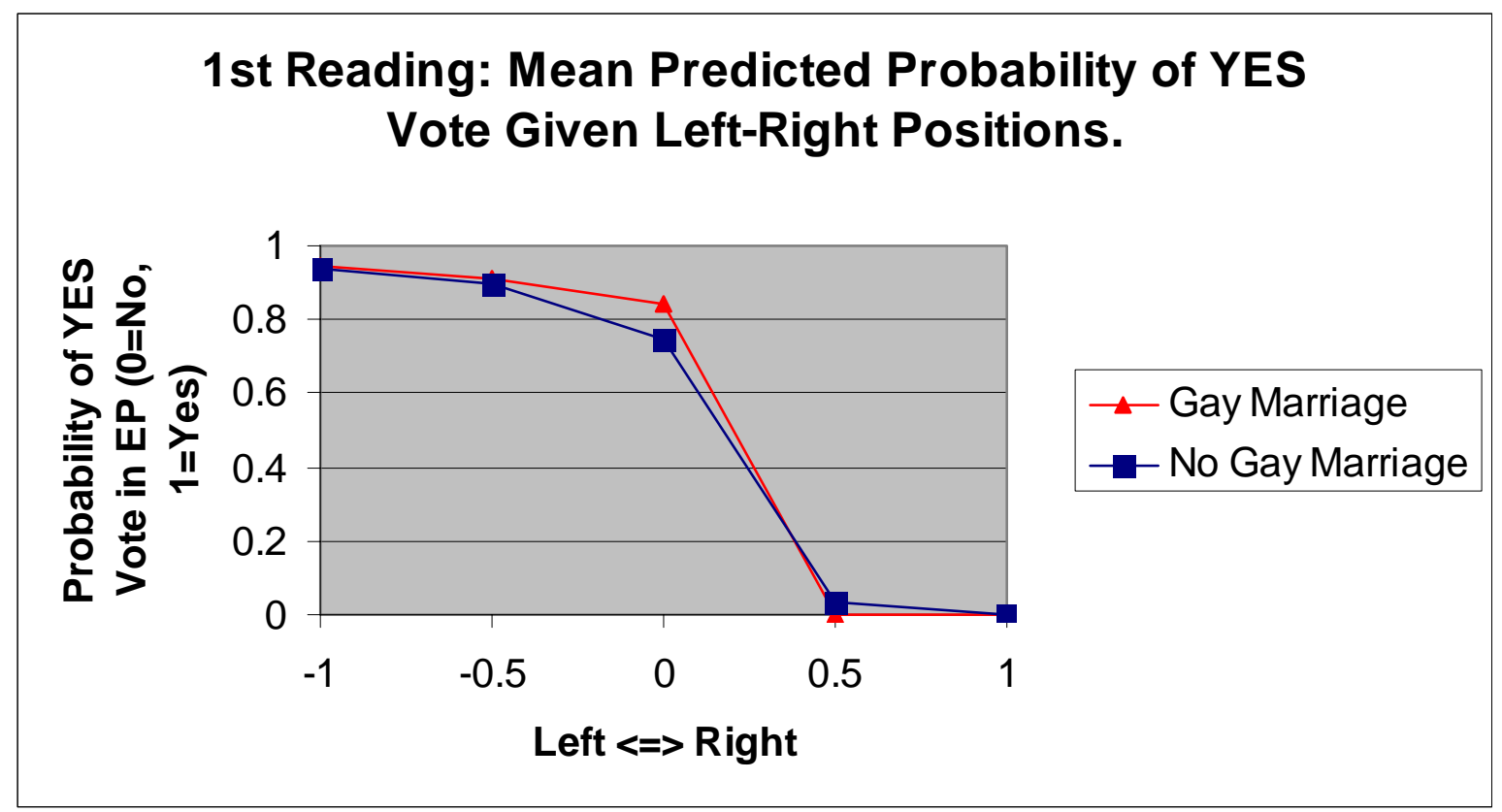

Figure 77: Probabilities 6.7. I

\section{1st Reading: Mean Predicted Probability of YES Vote Given Levels of EU Support.}

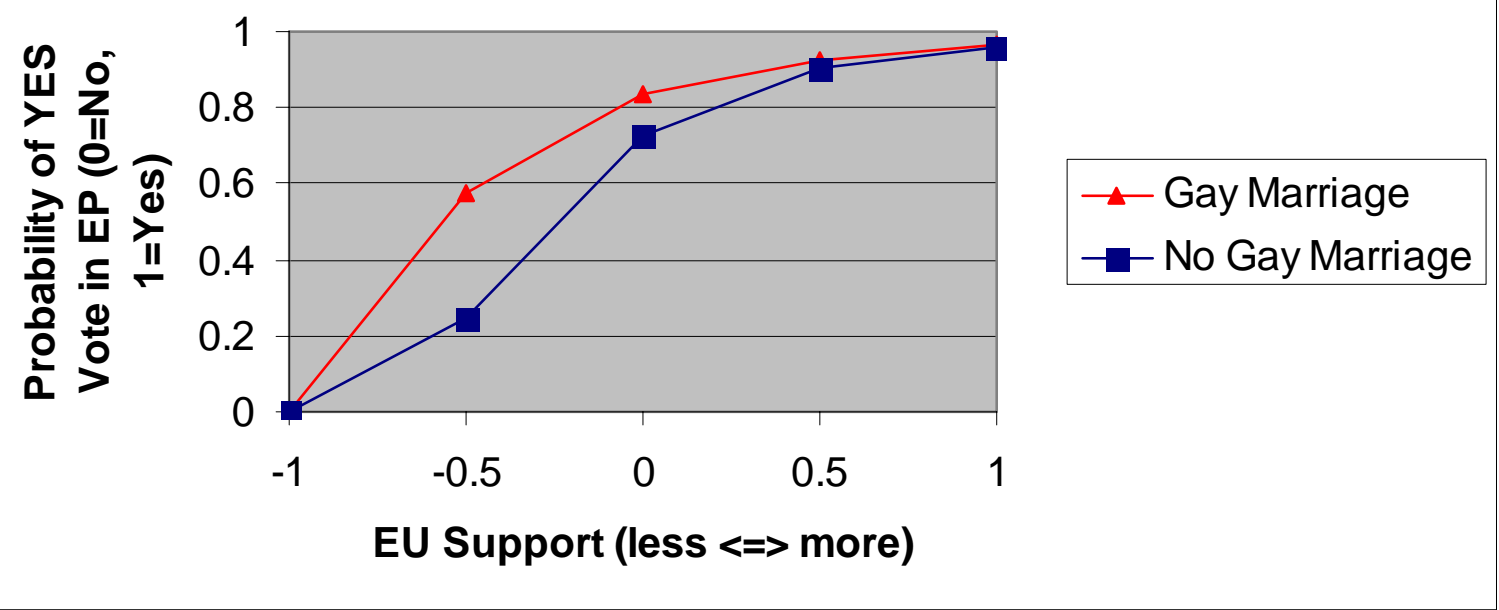

Figure 78: Probabilities 6.7. J 


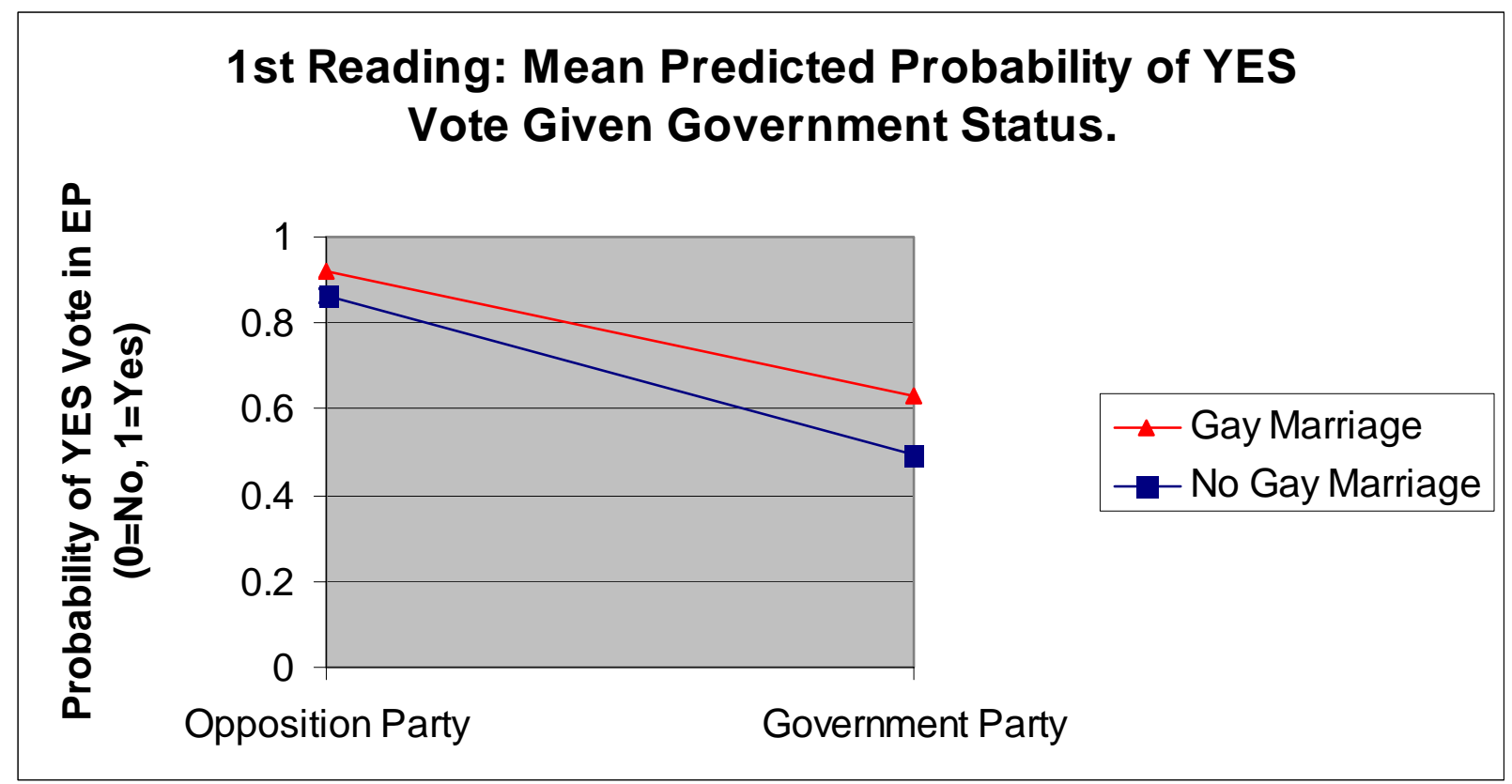

Figure 79: Probabilities 6.7. K 


\section{APPENDIX J}

\section{CHAPTER 7}

Table 38: Hypotheses Review.

\begin{tabular}{|l|l|l|}
\hline & \multicolumn{1}{|c|}{ Policy preferences } & \multicolumn{1}{c|}{ Outcomes } \\
\hline $\begin{array}{l}\text { Exogenous } \\
\text { preference model }\end{array}$ & $\begin{array}{l}\text { Exogenous (H1a) } \\
\text { Disconfirmed (in Chapter 4) }\end{array}$ & $\begin{array}{l}\text { Predetermined (H1b) } \\
\text { Disconfirmed (in Chapter 5) }\end{array}$ \\
\hline Garbage can model & $\begin{array}{l}\text { Endogenous (H2a }=\mathrm{H} 3 \mathrm{a}) \\
\text { Confirmed (in Chapter 4) }\end{array}$ & $\begin{array}{l}\text { Random (H2b) } \\
\text { Disconfirmed (in Chapter 6) }\end{array}$ \\
\hline Focal point model & $\begin{array}{l}\text { Endogenous (H2a = H3a) } \\
\text { Confirmed (in Chapter 4) }\end{array}$ & $\begin{array}{l}\text { Neither random nor predetermined; } \\
\text { predictable on basis of prevailing } \\
\text { focal points (H3b) } \\
\text { Confirmed (in Chapter 6) }\end{array}$ \\
\hline
\end{tabular}




\section{BIBLIOGRAPHY}

Aldrich, John H., and David W. Rohde. 1997-98. "The Transition to Republican Rule in the House: Implications for Theories of Congressional Politics." Political Science Quarterly 112: 541-567.

Aldrich, John H., and David W. Rohde. 1998. "Measuring Conditional Party

Government." Paper presented at the Annual Meeting of the Midwest Political Science Association.

Aldrich, John H., and David W. Rohde. 2000. "The Consequences of Party Organization in the House: The Role of the Majority and Minority Parties in Conditional Party Government." In Polarized Politics: Congress and the President in a Partisan Era, ed. Jon Bond and Richard Fleisher. Washington: Congressional Quarterly Press, pp. 31-72.

Aldrich, John H. and David W. Rohde. 2001. "The Logic of Conditional Party Government: Revisiting the Electoral Connection." In Congress Reconsidered, $7^{\text {th }}$ edition, ed. Lawrence C. Dodd and Bruce I. Oppenheimer. Washington, D.C.: Congressional Quarterly Press, pp. 269-292.

Arrow, K.J. 1963. Social Choice and Individual Values. New Haven, CT: Yale University Press. $1^{\text {st }}$ Edition published by Wiley, 1952.

Aspinwall, Mark. 2002. "Preferring Europe: Ideology and National Preferences on European Integration." European Union Politics 3 (1): 81-111.

Attinà, Fulvio. 1990. "The Voting Behaviour of the European Parliament Members and the Problem of Europarties.” European Journal of Political Research 18 (2): 557-79.

Austen-Smith, David and William H. Riker. 1987. "Asymmetric Information and the Coherence of Legislation.” American Political Science Review 81(3): 897-918.

Baumgartner, Frank R., Bryan D. Jones, and Michael C. MacLeod. 2000. "The Evolution of Legislative Jurisdiction.” The Journal of Politics 62 (2): 321-49. 
Benedetto, Giacomo. 2005. "Rapporteurs as legislative entrepreneurs: the dynamics of the codecision procedure in Europe's Parliament.” Journal of European Public Policy 12 (1): $67-88$.

Bennedsen, Morten, and Kasper Nielsen. 2004. "The Impact of a Break-Through Rule on European Firms." European Journal of Law and Economics 17 (3): 259-83.

Berglöf, Erik, and Mike Burkart. 2003. "European Takeover Regulation.” Economic Policy 36 (1): 173-213.

Black, D. (1958) The Theory of Committees and Elections. New York: Cambridge University Press.

Blondel, Jean. 1968. "Party Systems and Patterns of Government in Western Democracies." Canadian Journal of Political Science 1: 180-203.

Bowler, Shaun, and David M. Farrell. 1995. "The Organizing of the European Parliament: Committees, Specialization and Co-ordination." British Journal of Political Science 25 (2): 219-43.

Brzinski, J. Bay. 1995. "Political Group Cohesion in the European Parliament, 1989-1994.” In The State of the European Union, Vol.3: Building a European Polity?, ed. Carolyn Rhodes and Sonia Mazey. Boulder: Lynne Rienner, pp. 135-158.

Carrubba, Clifford J., Matthew Gabel, Lacey Murrah, Ryan Clough, Elizabeth Montgomery, and Rebecca Schambach. 2005. "Off the Record: Unrecorded Legislative Votes, Selection Bias, and Roll-Call Vote Analysis." Working Paper, Emory University.

Cohen, Michael D., James G. March, and Johan P. Olsen. 1972. "A Garbage Can Model of Organizational Choice.” Administrative Science Quarterly 17 (1): 1-25.

Cooper, Joseph. 1977. “Congress in Organizational Perspective.” In Congress Reconsidered, ed. Lawrence C. Dodd and Bruce I. Oppenheimer. Washington, DC: Congressional Quarterly Press.

Corbett, Richard, Francis Jacobs, and Michael Shackleton. 2005. The European Parliament, $6^{\text {th }}$ Edition. London: John Harper Publishing.

Cox, G. and M. McCubbins. 1993. Legislative Leviathan: Party Government in the House. Berkeley: University of California Press.

Downs, A. 1957. An Economic Theory of Democracy. New York, Harper \& Row. 
Druckman, James N. and Arthur Lupia. 2000. "Preference Formation." Annual Review of Political Science 3: 1-24.

Duverger, M. 1951. Political Parties: Their Organization and Activity in the Modern State. London: Methuen.

Enelow, J. and M. Hinich. 1984. The Spatial Theory of Voting: An Introduction. New York: Cambridge University Press.

Farrell, Henry and Adrienne Heritier (2003b) "Formal and Informal Institutions Under Codecision: Continuous Constitution-Building in Europe", Governance, 16(4): 577-600.

Finer, S.E. 1987. "Left and Right.” In The Blackwell Encyclopedia of Political Institutions, ed. Vernon Bogdanor. Oxford: Blackwell.

Gabel, Matthew J., and Simon Hix. 2002. "Defining the EU Political Space: An Empirical Study of the European Elections Manifestos, 1979-1999." Comparative Political Studies 35 (8): 934-64.

Garrett, Geoffrey, and Barry R. Weingast. 1993. "Ideas, Interests, and Institutions: Constructing the European Community's Internal Market." In Ideas and Foreign Policy Beliefs, Institutions, and Political Change, ed. Judith Goldstein and Robert O. Keohane. Ithaca: Cornell University Press, pp. 173-206.

Gilligan, Thomas W. and Keith Krehbiel. 1987. "Collective Decision-Making and Standing Committees: An Informational Rationale for Restrictive Amendment Procedures.” Journal of Law, Economics, and Organization 3: 145-93.

Gilligan, Thomas W. and Keith Krehbiel. 1989. "Asymmetric Information and Legislative Rules with a Heterogeneous Committee.” American Journal of Political Science 33: 459-90.

Gilligan, Thomas W. and Keith Krehbiel. 1990. "Organization of Informative Committees by a Rational Legislature.” American Journal of Political Science 34(2): 531-64.

Hall, Peter A. Forthcoming. "Preference Formation as a Political Process: The Case of European Monetary Union.” In Preferences over Time, ed. Ira Katznelson and Barry Weingast. New York: Russell Sage Foundation.

Hall, Richard L. 1996. Participation in Congress. New Haven: Yale University Press.

Hausemer, Pierre. 2005. "Representation and Committee Assignments in the European Parliament." Paper prepared for the Annual Meeting of the Midwest Political Science Association, Chicago, April 7-10 2005. 
Hinich, M. and M. Munger. 1994. Ideology and the Theory of Political Choice. Ann Arbor: University of Michigan Press.

Hinich, Melvin J., and Michael C. Munger. 1997. Analytical Politics. New York: Cambridge University Press.

Hix, Simon. 1999a. The Political System of the European Union. New York: Palgrave.

Hix, Simon. 1999b. "Dimensions and Alignments in European Union Politics: Cognitive Constraints and Partisan Responses.” European Journal of Political Research 35 (1): 69106.

Hix, Simon. 2001. "Legislative Behavior and Party Competition in the European Parliament: An Application of Nominate to the EU." Journal of Common Market Studies 39 (4): 66388.

Hix, Simon. 2002. "Parliamentary Behavior with Two Principals Preferences: Parties, and Voting in the European Parliament." American Journal of Political Science 46 (3): 68898.

Hix, Simon, and Christopher Lord. 1997. Political Parties in the European Union. New York: St. Martin's Press.

Hix, Simon, Amie Kreppel, and Abdul Noury. 2003. "The Party System in the European Parliament: Collusive or Competitive?” Journal of Common Market Studies 41(2): 309-31.

Hix, Simon, Abdul Noury, and Gerard Roland. Democracy in the European Parliament. forthcoming.

Hix, Simon, Abdul Noury, and Gerard Roland. 2005. "Power to the Parties: Cohesion and Competition in the European Parliament, 1979-2001." British Journal of Political Science 35(2): 209-34.

Hooghe. Liesbet, and Gary Marks. 1999. "The Making of a Polity: The Struggle over European Integration." In Continuity and Change in Contemporary Capitalism, ed. Herbert Kitschelt, Peter Lange, Gary Marks, John D. Stephens. New York: Cambridge University Press, pp. 70-97.

Hooghe, Liesbet, and Gary Marks. 2001. Multi-level Governance and European Integration. Boulder: Rowman \& Littlefield.

Hooghe, Liesbet, Gary Marks, and Carole J. Wilson. 2002. "Does Left/Right Structure Party Positions on European Integration?” Comparative Political Studies 35 (8): 965-89. 
Hotelling, H. 1929. "Stability in Competition.” Economic Journal 39: 41-57.

Hoyland, Bjorn. 2006. "Allocation of Codecision Reports in the $5^{\text {th }}$ European Parliament."

Hug, Simon. 2005. "Selection Effects in Roll-Call Votes." Paper prepared for presentation at the ECPR Joint Sessions of Workshops, Granada, Spain; 14-19 April, 2005.

Inglehart, Ronald, and Scott C. Flanagan. 1987. "Value Change in Industrial Societies." American Political Science Review 81 (4): 1289-1319.

Judge, David and David Earnshaw. 2003. The European Parliament. New York: Palgrave MacMillan.

Kaeding, Michael. 2004. "Rapporteurship Allocation in the European Parliament: Information of Distribution?" European Union Politics 5 (3):353-78.

Kaeding, Michael. 2005. "The World of Committee Reports.” Journal of Legislative Studies 11 (1): 82-104.

King, Gary, Michael Tomz, and Jason Wittenberg. 2000. "Making the Most of Statistical Analyses: Improving Interpretation and Presentation." American Journal of Political Science 44 (2): 341-55.

Kingdon, John. 1981. Congressmens' Voting Decisions, $2^{\text {nd }}$ ed. New York: Harper and Row.

Kingdon, John W. 1984. Agendas, Alternatives, and Public Policies. Boston: Little, Brown and Company.

Kitschelt, Herbert, Peter Lange, Gary Marks, and John D. Stephens, eds. 1999. Continuity and Change in Contemporary Capitalism. New York: Cambridge University Press.

Krehbiel, Keith. 1991. Information and Legislative Organization. Ann Arbor: Michigan University Press.

Kreppel, Amie. 2002. The European Parliament and Supranational Party System. Cambridge:

Cambridge University Press.

Kreppel, Amie. 2005. "Understanding the European Parliament from a Federalist Perspective: The Legislatures of the USA and EU Compared." Paper presented at the $9^{\text {th }}$ Biennial EUSA Meeting, Austin, March 31-April 2, 2005.

Kreppel, Amie and George Tsebelis. 1999. "Coalition Formation in the European Parliament." Comparative Political Studies 32(8):933-66.

Kreps, David M. and Robert B. Wilson. 1982. "Sequential Equilibria." Econometrica 50: 863894 
Laver. Michael and Norman Schofield. 1990. Multiparty Government: The Politics of Coalition in Europe. Oxford: University Press.

Lord, Christopher. 1998. "Party Groups, EP Committees and Consensus Democracy." In Transnational Parties in the European Union, ed. Bell, David Scott and Christopher Lord. Brookfield, VT : Ashgate.

Lowi, Theodore. 1979. The End of Liberalism: The Second Republic of the United States. $2^{\text {nd }}$ ed. New York: Norton.

Lupia, Arthur and Mathew D. McCubbins. 1994. "Who Controls? Information and the Structure of Legislative Decision Making." Legislative Studies Quarterly 19(3): 361-84.

Mackie, Gerry. 2003. Democracy Defended. New York: Cambridge University Press.

Mamadouh, Virginie, and Tapio Raunio. 2002. "Allocating Reports in the European Parliament: How parties influence committee work." European Parliament Research Group Working Paper (8).

Mamadouh, Virginie and Tapio Raunio. 2003. "The Committee System: Powers, Appointments, and Report Allocation.” Journal of Common Market Studies 41(2): 333-51.

Marks, Gary, and Marco Steenbergen. 2002. "Introduction: Understanding Political Contestation in the European Union." Comparative Political Studies 35 (8): 879-92.

Marks, Gary, and Carole J. Wilson. 2000. "The Past in the Present: A Cleavage Theory of Party Positions on European Integration.” British Journal of Political Science 30 (3): 433-59.

Marks, Gary, Carole J. Wilson, and Leonard Ray. 2001. "National Political Parties and European Integration.” American Journal of Political Science 46 (3): 585-94.

Matthews, Donald and James Stimson. 1975. Yeas and Nays: Normal Decision-Making in the U.S. House of Representatives. New York: Wiley

Mattson, Ingvar and Kaare Strøm. 1995. "Parliamentary Committees." In Parliaments and Majority Rule in Western Europe, ed. Herbert Döring. Frankfurt: Campus Verlag, pp. 249307.

McElroy, Gail. 2002. "Committees and Party Cohesion in the European Parliament." European Parliament Research Group Working Paper (8).

McElroy, Gail. 2003. In Pursuit of Party Discipline: Committees and Cohesion in the European Parliament. Unpublished doctoral dissertation, University of Rochester. 
McElroy, Gail and Kenneth Benoit. 2005. "Party Groups and Policy Positions in the European Parliament.” IIIS Discussion Paper No. 101, November 2005.

McElroy, Gail. 2006. "Committee Representation in the European Parliament." European Union Politics 7(1).

Meny, Yves. 1990. Government and Politics in Western Europe: Britain, France, Italy, and Germany. New York: Oxford University Press.

Metha, J., Starmer, C., and Sugden, R. 1994. "Focal Points in Pure Coordination Games: An Experimental Investigation." Theory and Decision 36: 163-85.

Neuhold, Christine. 2001. "The "Legislative Backbone" or Keeping the Institution Upright? The Role of European Parliament Committees in the EU Policy-Making Process." European Integration online Papers 5 (10) (available at: eiop.or.at/eiop/texte/2001010a.htm).

Noury, A.G., and G. Roland. 2002. "More power to the European Parliament?" Economic Policy 17 (35): 280-319.

Noury, A.G. 2002. "Ideology, Nationality, and Euro-Parliamentarians.” European Union Politics 3: 33-58.

Ordeshook, P. 1986. Game Theory and Political Theory. New York: Cambridge University Press.

Peterson, J. and E. Bomberg. 1999. Decision-Making in the European Union. London: McMillan.

Rasmussen, Anne and Michael Shackleton. 2005. "The scope for action of European Parliament negotiators in the legislative process: lessons of the past and for the future." Paper presented at the $9^{\text {th }}$ Biennial EUSA Meeting, Austin, March 31-April 2, 2005.

Raunio, Tapio. 1997. The European Perspective: Transnational Party Groups in the 19891994 European Parliament. Aldershot: Ashgate Publishing.

Riker, William H. 1982. Liberalism Against Populism. San Francisco: W.H. Freeman and Company.

Riker, William H. 1986. The Art of Manipulation. New Haven: Yale University Press.

Riker, William H. 1990. "Heresthetics and Rhetoric in the Spatial Model." In Advances in the Spatial Theory of Voting, ed. James M. Enelow and Melvin Hinich. New York: Cambridge University Press, pp. 46-65. 
Rhodes, Martin, and Bastiaan Van Apeldoorn. 1997. "Capitalism versus Capitalism in Western Europe." In Developments in West European Politics, ed. Martin Rhodes, Paul Heywood and Vincent Wright. New York: St. Martin's Press: 171-89.

Sabatier, Paul and David Whiteman. 1985. "Legislative Decision Making And Substantive Policy Information: Models of Information Flow." Legislative Studies Quarterly X(3): 395-421.

Schelling, T. C. 1960. The Strategy of Conflict. London: Oxford University Press.

Scott, D. J. 2001. The Salience of Integration: The Strategic Behavior of National Political Parties in the European Union. Unpublished doctoral dissertation, UNC Chapel Hill.

Shepsle, K. 1979. "Institutional Arrangements and Equilibrium in Multidimensional Voting Models.” American Journal of Political Science 23: 27-60.

Shepsle, K. 1991. Models of Multiparty Electoral Competition. Chur, Switzerland: Harwood Academic.

Shepsle, K. and M.S. Bonchek. 1997. Analyzing Politics: Rationality, Behavior, and Institutions. New York: Norton.

Shepsle K and B. Weingast. 1981. "Structure-induced equilibrium and legislative choice." Public Choice 37: 503-29

Smith, Steven. 1988. "An Essay on Sequence, Position, Goals, and Committee Power." Legislative Studies Quarterly 8: 151-77.

Smithies, A. 1941. “Optimum Location in Spatial Competition.” Journal of Political Economy 49: 423-39.

Snyder, James M., Jr. 1992. “Committee Power, Structure-Induced Equilibria, and Roll-Call Votes.” American Journal of Political Science 36 (1): 1-30.

Thomassen, Jacques, Abdul Noury, and Erik Voeten. 2004. "Political Competition in the European Parliament.” In European Integration and Political Conflict, ed. Gary Marks and Marco Steenbergen. New York: Cambridge University Press, pp. 141-64.

Voeten, Erik. 2005. "Legislator Preferences, Ideal Points, and the Spatial Model in the European Parliament." Working Paper 2005/12, Institute of Governmental Studies, University of California, Berkeley.

Wattenberg, Martin P. 1990. The Decline of American Political Parties, 1952-1988. Cambridge: Harvard University Press. 
Weingast, B. and W. Marshall. 1988. "The industrial organization of Congress." Journal of Political Economy 96: 132-63.

Westlake, Michael. 1994. A Modern Guide to the European Parliament. London: Pinter.

Whitaker, R. 1999. "Party Control in a Committee-based Legislature? The Case of the EP." Journal of Legislative Studies 7(4): 63-88.

Woll, Cornelia. 2005. "Learning to Act on World Trade: Preference Formation of Large Firms in the United States and the European Union." Max Planck Institute for the Study of Societies (MPIfG) Discussion Paper 05/1.

Zwier, Robert. 1979. "The Search for Information: Specialists and Nonspecialists in the U.S. House of Representatives.” Legislative Studies Quarterly IV(1): 31-42. 